\title{
EXPERIENTIAL DENSITY: INFILL STRATEGIES WITHIN TORONTO'S CENTRES - BRINGING HUMAN SCALE, CHARACTER, AND WALKABILITY
}

\author{
An Architectural Design Thesis \\ by \\ Dustin Lee Sauder, B.Arch.Sci, \\ Ryerson University, 2013
}

\author{
A thesis presented to Ryerson University \\ in partial fulfillment of the \\ requirements for the degree of \\ Master of Architecture \\ in the Program of \\ Master of Architecture \\ Toronto, Ontario, Canada, 2015 \\ (C) Dustin Sauder 2015
}





\section{AUTHOR'S DECLARATION FOR ELECTRONIC SUBMISSION OF A THESIS}

I hereby declare that I am the sole author of this thesis. This is a true copy of the dissertation, including any required final revisions, as accepted by my examiners.

I authorize Ryerson University to lend this thesis to other institutions or individuals for the purpose of scholarly research

I further authorize Ryerson University to reproduce this dissertation by photocopying or by other means, in total or in part, at the request of other institutions or individuals for the purpose of scholarly research.

I understand that my dissertation may be made electronically available to the public. 



\section{EXPERIENTIAL DENSITY: INFILL STRATEGIES WITHIN TORONTO'S CENTRES - \\ BRINGING HUMAN SCALE, CHARACTER, AND WALKABILITY \\ Dustin Sauder. B.Arch.Sci., Ryerson University. 2013 \\ Ryerson University, Masters of Architecture Program}

\section{ABSTRACT}

A variety of approaches are being used to accommodate Toronto's growing population. Most of these solutions rely on high-rise and mid-rise developments, emphasizing the quantity of density instead of the quality. However, this thesis focuses on blocks of slab towers, and explores how the perception of an environment and intensity of development can form an experiential density. Introducing new public and pedestrian orientated spaces to the neglected land between apartment towers to improve the experience of urban blocks also offers open space to increase the density in Toronto's designated growth areas. To achieve this new environment, urban blocks containing clusters of slab towers will be fragmented into walkable distances; scaled outdoor spaces will activate the neglected park; infill will increase density and define outdoor spaces; and transitional areas will mediate the public and private realm, all to bring life into the block and improve experience of urban density. 



\section{ACKNOWLEDGMENTS}

I would like to thank my supervisor, Leila Farah, for going out of her way to continuously support my work, and encouraging me to expand my research interests beyond the confines of thesis. Without her encouragement, I would not have won an Award of Merit in the Toronto Urban Design Awards Competition. I also thank Cheryl Atkinson for stepping in as my second reader with a fresh perspective that helped me through many roadblocks. Finally, I thank my parents for their continued reassurance and support throughout my education.

I would also like to honor the late lan McBurnie who began this process with me as a second reader. He inspired me to challenge the norms for urban design and architecture's ability to transform a dense environment. 

TABLE OF CONTENTS - EXPERIENTIAL DENSITY: INFILL STRATEGIES WITHIN TORONTO'S

CENTRES - BRINGING HUMAN SCALE, CHARACTER, AND WALKABILITY

1 Introduction

1.1 Introduction: Experiencing Density in the Urban Environment $3-4$

1.2 The Condition of Urban Growth 5-9

$2 \quad$ Forming the Urban Environment

2.1 Past Views on Approaching Density to Improve Experience $12-13$

2.2 Current Understanding of Experiential Density 14-16

3 Density and Experience in Toronto

3.1 Impact of Toronto's Perceived Growth 18-21

3.2 The Slab Tower in Toronto 22-23

$4 \quad$ A Study of Toronto's Urban Fabric Surrounding Residential Apartment Blocks

4.1 Identifying Residential Apartment Neighbourhoods 26-27

4.2 Characteristics of the Residential Apartment Block 28-39

4.3 Analysis of Urban Context at the Yonge and Eglinton Centre

4.3.2 A Study of Experience and Human Scale 49-53

$5 \quad$ Design Factors for Improving Experiential Density

5.1 Design Approaches with a Focus on Experience 56-59

5.2 Design focuses in Relation to Density and Experience 60-61 



\section{TABLE OF CONTENTS CONTINUED}

$6 \quad$ Strategies for Generating Experiential Density Around Slab Towers

$\begin{array}{lll}6.1 & \text { Fragment } & 65-66 \\ 6.2 & \text { Activate } & 67 \\ 6.3 & \text { Infill } & 68 \\ 6.4 & \text { Mediate } & 69-70\end{array}$

$7 \quad$ Implementing Experiential Density: Design Proposal

7.1 Site Selection and Analysis: Mt Pleasant and Eglinton $\quad 72-77$

7.2 Project Massing and Proposal 78-91

7.3 Applying Design Strategies to Increase Experiential Density in the Residential Apartment Site

$\begin{array}{lll}\text { 7.3.1 Fragment } & \text { 92-99 }\end{array}$

$\begin{array}{lll}\text { 7.3.2 Activate } & \text { 100-107 }\end{array}$

$\begin{array}{ll}7.3 .3 \text { Infill } & 108-119\end{array}$

$\begin{array}{lll}\text { 7.3.4 Mediate } & \text { 120-125 }\end{array}$

8.0 Experiential Sequence in the Residential Apartment Towers 136-134

9.0 Conclusion: Using Experiential Density as an Alternative Method 136-138 for Urban Growth

$\begin{array}{lr}\text { Appendix } & 140-145\end{array}$

$\begin{array}{lr}\text { Bibliography } & \text { 188-196 }\end{array}$

$\begin{array}{lr}\text { Glossary } & 197-198\end{array}$ 



\section{LIST OF TABLES}

Table 1 Growing Canadian Cities and Population Density,

(Statistics Canada, 2012).

Table 2 Additional Density Generated Through Infill, (Sauder, 2015). 



\section{LISTS OF MAPS}

Map 1 Historic view of Yonge-Eglinton Neighbourhood in 1947, (Information collected from City of Toronto Archive, drawn by Sauder).

Map 2 Present day (2014) view of Yonge-Eglinton Neighbourhood, (Information collected from City of Toronto Property Data Maps, drawn by Sauder).

Map 3 Yonge-Eglinton neighbourhood physical density 2014, (Information 42 collected from City of Toronto Archive, drawn by Sauder).

Map 4 Yonge-Eglinton Neighbourhood Land Use Intensity, (Information 43 collected from City of Toronto Archive, drawn by Sauder).

Map 5 Yonge-Eglinton Zoning Regulations, (Information collected from City of Toronto Zoning By-Law 569-2013, drawn by Sauder).

Map 6 Identifying the Mt Pleasant and Eglinton Block within Neighbourhood Context, (Sauder, 2014).

Map 7 Residential Apartment Block, (Sauder, 2014).

Map 8 Local Transit Routes, (Sauder, 2014).

Map 9 Planned LRT Stations, (Metrolinx, 2014). 



\section{LIST OF FIGURES}

Figure 1 Neglected Land Between Slab Towers, (Sauder, 2015).

Figure 2 Urban and Rural Population as Proportion of Total Population by Major Areas, 1950-2050, (United Nations, 2014).

Figure 3 Reflection of Toronto's Physical Density, (Sauder, 2014 as part of AR8106).

Figure 4 Toronto's Densification Strategies, (Data retrieved from Official Plan, 2010. Sauder, 2015).

Figure 5 Toronto's Residential Apartments, (City of Toronto, 2011).

Figure 6 Identifying Residential Apartment Neighbourhoods in Toronto, (Sauder, 2014).

Figure 7 Residential Apartment Neighbourhood Densities, (Sauder, 2014).

Figure 8 Residential Apartment Neighbourhood Building Typologies, (Sauder, 2014).

Figure 9 Residential Apartment Neighbourhood Boundary Lines, (Information Retrieved from Property Data Maps, 2012).

Figure 10 Residential Apartment Neighbourhood Open Spaces, (Sauder, 2014).

Figure 11 Residential Apartment Neighbourhood Slab Towers and Blank Facades, (Sauder, 2014).

Figure 12 Residential Apartment Zoning Setbacks, (Zoning Information from City of Toronto, 2014. Drawn by Sauder, 2014).

Figure 13 Commercial Residential Zoning Setbacks, (Zoning Information from City of Toronto, 2014. Drawn by Sauder, 2014). 



\section{LIST OF FIGURES CONTINUED}

Figure 15 East elevation along the Yonge Street corridor, (Sauder, 2014).

Figure 16 Typical residential elevation along the Hillsdale Street corridor, (Sauder, 2014).

Figure 17 Setbacks along a typical residential neighborhood, (Sauder, 2014).

Figure 18 Setbacks along a typical low-rise commercial area, (Sauder, 2014).

Figure 19 Privacy from the public realm in a typical residential context, (Sauder, 2014).

Figure 20 Privacy from the public realm in a mixed use context, (Sauder, 2014).

Figure 21 Elevation of Renzo Piano's Central Saint Giles in Relation to the Surrounding Context (Sauder, 2015).

Figure 22 Architectural and planning principles that effect key forms of density, (Sauder, 2014).

Figure 23 Fragmenting the Urban Block, (Sauder, 2015).

Figure 24 Pedestrian Street Precedent Study, (Sauder, 2015).

Figure 25 Activate - Placing Courtyards on the Urban Block, (Sauder, 2015).

Figure 26 Infill - Creating a Boundary Wall, (Sauder, 2015).

Figure 27 Mediate - Transitioning Between Two Spaces, (Sauder, 2015).

Figure 28 Creating Additional Privacy for Residential Units, (Sauder, 2015). 



\section{LIST OF FIGURES CONTINUED}

Figure 30 Massing Variations Exploring the Effect of an Increased Physical Density on the Mid-block Experience (Sauder, 2015)

Figure 31 Images of Built Model Depicting the Overall Massing Scheme, (Sauder, 2015).

Figure 32 Schematic Proposal for Eglinton and Mt. Peasant, (Sauder, 2015).

Figure 33 Images of Built Model Depicting the Physical Characteristics of the Proposal, (Sauder, 2015).

Figure 34 Site Plan, (Sauder, 2015).

Figure 35 Site Section AA, (Sauder, 2015).

Figure 36 Site Section BB, (Sauder, 2015).

Figure 37 Site Fragmentation - Reflecting the Scale of a Low-rise Residential Block, (Sauder, 2015).

Figure 38 South Elevation Illustrating Fragmentation of Block Facade, (Sauder, 2015).

Figure 39 North Elevation Illustrating Fragmentation of Block Facade, (Sauder, 2015).

Figure 40 South Longitudinal Site Section - Illustrating Courtyards Role in Fragmenting the Primary Pedestrian Pathway, (Sauder, 2015).

Figure 41 North Longitudinal Site Section - Illustrating Courtyards Role in Fragmenting the Primary Pedestrian Pathway (Sauder, 2015)

Figure 42 Primary Pedestrian Street Typical Section Showing Proportions that Relate to the Human Scale and Resulting Lighting Conditions, (Sauder, 2015). 



\section{LIST OF FIGURES CONTINUED}

Figure 43 Environment Created Through Design Factors to Influence a Pleasant Walking Experience, (Sauder, 2015).

Figure 44 Voids Along the Central Axis Are Used as a Critical Component in Defining Experienc, (Sauder, 2015).

Figure 45 Plan of the Primary Courtyard, (Sauder, 2015).

102

Figure 46 Primary Courtyard Surrounded by Public Amenities to Bring Traffic Through the Urban Block, (Sauder, 2015).

Figure 47 Forested Courtyard Plan, (Sauder, 2015).

Figure 48 Forested Courtyard Crating a Relaxing Environment with Tree Canopies, (Sauder, 2015).

Figure 49 Parked Courtyard Plan, (Sauder, 2015).

Figure 50 Parked Courtyard Opening to Form a Larger Activation, (Sauder, 2015).

Figure 51 Defining Boundaries of Infill, (Sauder, 2015).

108

Figure 52 Public Pool and Residences - Level 1, Bringing temporary density through public amenities, (Sauder, 2015).

Figure 53 Public Pool and Residences - Level 2, (Sauder, 2015).

Figure 54 Public Pool and Residences - Level 3, Elevated Units with Access to Outdoor Circulation, (Sauder, 2015).

Figure 55 Commercial/Offices, Live-work and Residences - Level 1, (Sauder, 2015).

Figure 56 Commercial/Offices, Live-work and Residences - Level 2, (Sauder, 2015). 



\section{LIST OF FIGURES CONTINUED}

Figure 57 Commercial/Offices, Live-work and Residences - Level 3, (Sauder, 2015).

Figure 58 Commercial/Offices, Live-work and Residences - Level 4, (Sauder, 2015).

Figure 59 Typical Infill Section Showing Unit Variation and Connection to the Outdoor Environment, (Sauder, 2015).

Figure 60 Typical Residential Unit Layout and Considered Design Factors, (Sauder, 2015).

Figure 61 Formation of Pathways Breaking Down the Oversized Block Which Increase Traffic And Activity (Aerial Photo Retrieved From Bing Maps, 2015, Image By Sauder, 2015).

Figure 62 Transitional Areas Between Pathways and Residential Units to Mediate Privacy, (Sauder, 2015).

Figure 63 Resulting Environment Between Infill and Slab Towers Created Through Mediation, (Sauder, 2015).

Figure 64 Section of Primary Activation and Mediation's Role in Maintaining Openness, (Sauder, 2015).

Figure 65 Section Showing Site Entrance and Underpass, (Sauder, 2015).

Figure 66 Exploded Axo Breaking Down Design Strategies: Fragment, Activate, Infill, Mediate, (Sauder, 2015).

Figure 67 Mt Pleasant Entrance to the Primary Pedestrian Street, (Sauder, 2015).

Figure 68 Perspective of Primary Courtyard Looking Towards Pool and Mt Pleasant Entrance, (Sauder, 2015). 



\section{LIST OF FIGURES CONTINUED}

Figure 69 Perspective of Primary Pedestrian Street Looking Through the Entire Site, (Sauder, 2015).

Figure 70 Perspective of Treed Courtyard with Filtered Light, (Sauder, 2015).

Figure 71 Perspective of Park Courtyard Extending Through Pavilion to Abut Secondary Pathway, (Sauder, 2015).

Figure 72 Experiential Section Showcasing Interior Environments, (Sauder, 2015)

Figure 73 Replacing the Slab Tower's Ground Floor Units with Mixed-use Programing to Generate a Podium and Further Engage the Pedestrian (Sauder, 2015). 



\section{LISTS OF APPENDICES}

A. Explanations of Quantifiable Densities $\quad 138-140$

B. Additional Statistics on Global Density 141-143

C. Design Exploration: Working Models 144-145

D. Design Iterations 146-161

E. Study: Exploring the Impact of Infill on a Low-rise Neighbourhood 162-167

F. $\quad$ Study: Applying Additional Density to Slab Towers 168-173

G. Precedent Studies 174-183 

1 INTRODUCTION 


\section{$1.1 \quad$ INTRODUCTION: EXPERIENCING DENSITY IN THE URBAN ENVIRONMENT}

Global populations are growing at an astounding rate, and for the first time in history, more people are living in urban areas than in rural communities (Rogers, 1998). While urban growth has now reached a plateau in many North American cities, Toronto stands out as an exception and continues to increase in population and density. To accommodate its rapid growth, the Official Plan (2010) has identified Toronto's Downtown (and Central Waterfront), Centres, Avenues, and Employment Districts as parts of the city where intensification should be prioritized. From these areas, a majority of growth occurs downtown because of access to transit, employment, and amenities. However, density has also begun to expand beyond the downtown and into the inner suburban centres where there is access to transit, services, and mixed-use communities. This thesis explores alternative strategies for accommodating density - without resorting to point towers or mid-rise developments along city avenues - by taking advantage of the unused space surrounding clusters of slab towers, and the oversized block structures found around the Yonge Eglinton Centre (Figure 1). Breaking down these large sites with low-rise and mixed-use infill will work towards improving the perception of the neighbouhood by dealing with issues of scale, lack of walkability, and the lifeless ground plane. At the same time, addressing these concerns will lead to a more lively public realm and pedestrian friendly environment, which will effectively improve the experiential density in addition to quantifiable densities*.

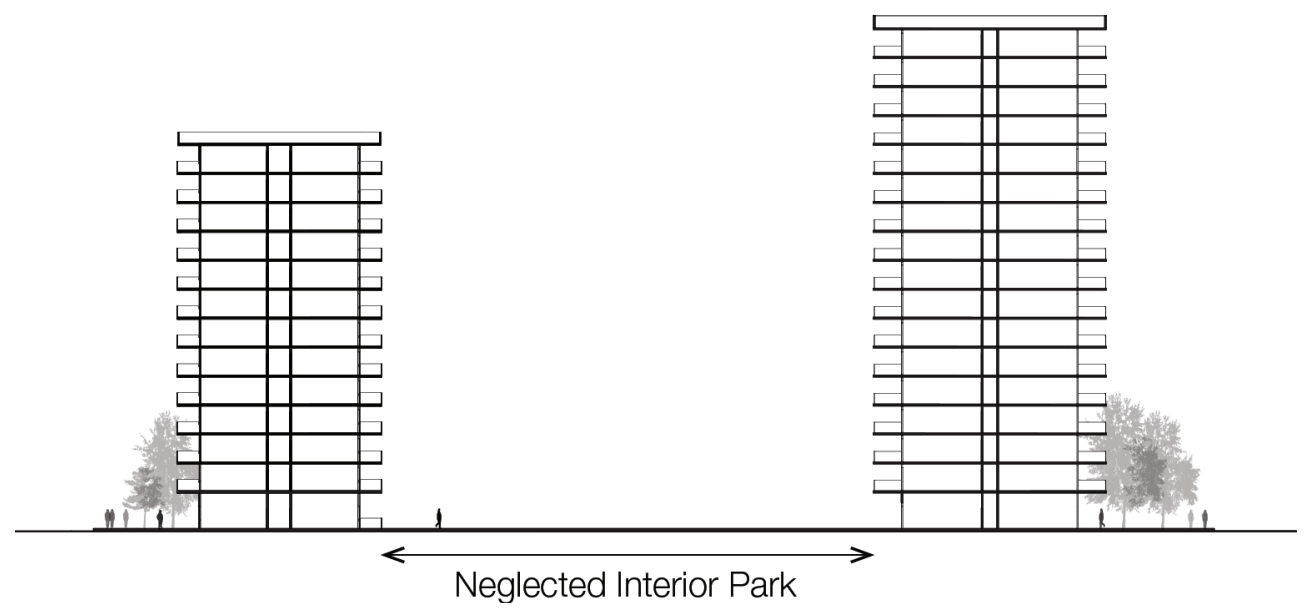

Figure 1 Neglected Land Between Slab Towers, (Sauder, 2015).

* See Appendix A for further discussion on specific types of density. 
Unlike its quantifiable counterparts, experiential density is based on the perception of space which comes from a personal interaction and is often associated to the quality of environment (Reffer to Appendix A for further discussion on experiential density). To generate a strong sense of experiential density, infill around clusters of residential apartment towers, lighting, scale, openness, and walkability have to be taken into account. Seen in the downtown, point towers have become a relatively successful form of infill which can often generate a comfortable experience despite its extremely high density. This is because the point tower infill is situated on much smaller properties compared to those in the centres. Also, an immediate context of mixed-use programing, density, and a finer grain of existing building complement high-rise interventions and maintain a lively ground plain. In contrast, the bigger blocks found around centres already have large scaled structures in the form of slab towers, but are missing the active public realm. Therefore, using the same point tower infill on Yonge and Eglinton would only be covering the neighbourhood with a second layer of large scale structures, and promote the negative sensations of crowding and lack of privacy. Meanwhile, the concerns over a lively street life coincide with properties from the outer suburbs and the Mayor's Tower Renewal Program - which is aiming to increase density on the even larger sites and bring missing services to the area (City of Toronto, 2011). However, towers in the Renewal Program are usually vehicular dependent and completely isolated from any amenities, while the clusters of slab towers around the Yonge and Eglinton Centre are within walking distance to the subway line and a mixed-use hub. These differences cause the centres to act as unique transitional areas between the downtown and outer suburbs where very different densities generate specific responses to the perception of an environment. This also suggests that infill needs to adapt to specific conditions of the centres' larger scale and look for alternative strategies that will enable these sites to accommodate the growing population while also improving the experience of the public realm. 


\subsection{THE CONDITION OF URBAN GROWTH}

Experiential density is applicable globally as the human and urban populations continue to increase at an alarming pace. Within just 64 years, the total number of people residing in cities has exploded and grown five times from just 746 million to 3.9 billion in 2014 (United Nations, 2014). This means that more than half of the global population is already living in urban centres. Increasing at this speed puts stress on architects, planners, and governments to develop transportation, infrastructure, services, housing, and amenities that will meet the needs of the expanding density (Bascaramurty, 2012). In the past, cities like Toronto, Chicago, and Paris have heavily relied on the residential apartment towers, while cities like Moscow, Barsilia, Mumbai, and Shanghai still actively depend on the slab tower's ability to house the masses (Urban, 2013). As illustrated in Figure 2, these cities and many others in the global south have a much higher percentage of change than their counterparts in the global north, which seem to have hit a plateau of consistent growth rate.

Average rate of change of the percentage urban by major areas, 1950-2050

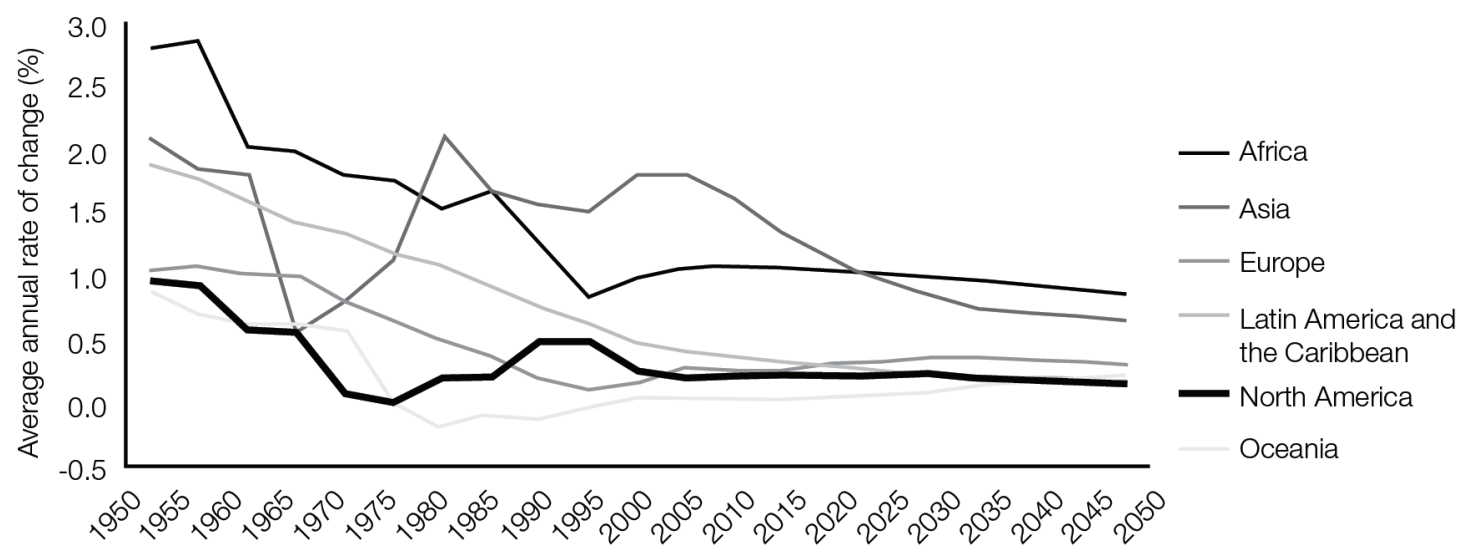

Figure 2 Urban and Rural Population as Proportion of Total Population by Major Areas, 1950-2050, (United Nations, 2014). 
Despite Figure 2's generalization of urban areas in the global north having hit a plateau, there are individual cities that carry on with a constant increase in population. Included in this trend are some Canadian cities. Census show that between the years 2006 and 2011 there was a 5.9 per cent overall population growth rate in urban centres (Statistics Canada, 2014). According to the United Nation prediction, the growth that Canadian cities have been experiencing will continue to be drawn out for the foreseeable future. While it is important to maintain these trends to "support economic growth and social development" (City Planning, 2010, page 2-1) within the city, it is also critical to plan for the extended population increase so it does not negatively impact the quality of life for the urban dweller. Authors like O'Toole and Chakrabarti suggest that steps need to be taken in these situations to control the specific methods of densification. While most Canadian cities have a document like Toronto's Official Plan to discourage developments that disregard the experience of the public realm, there are always opportunities for improvement or reinterpretation of past building typologies that justifies further investigation.

Looking more closely at the growth rate of Canadian cities also reveals interesting trends and exceptions that are present in the various urban centres. According to Statistics Canada (2012), there are 33 cities with populations over 100,000 across the country (see Table 1). Out of these 33 cities, most have relatively low population densities. Toronto, Montreal, Mississauga, Vancouver, Brampton, Richmond Hill, and Barrie are the only areas that actually have a density over 1,500 people per square kilometer. Since Toronto has the largest population and one of the highest densities from this list, it will be the primary focus for the study of experiential density. 


\begin{tabular}{|c|c|c|c|}
\hline City & Density & $\begin{array}{l}\text { Growth Rate since } \\
2011 \text { Census }\end{array}$ & Population \\
\hline Toronto, ON & $4,150 \mathrm{ppl} / \mathrm{km} \mathrm{sq}$ & $4.5 \%$ & $2,615,060$ \\
\hline Montreal, QB & 4,519 ppl / km sq & $1.8 \%$ & $1,649,519$ \\
\hline Calgary, AB & $1,329 \mathrm{ppl} / \mathrm{km} \mathrm{sq}$ & $10.9 \%$ & $1,096,833$ \\
\hline Ottawa & $316 \mathrm{ppl} / \mathrm{km} \mathrm{sq}$ & $8.8 \%$ & 883,391 \\
\hline Edmonton, $\mathrm{AB}$ & $1,186 \mathrm{ppl} / \mathrm{km} \mathrm{sq}$ & $11.2 \%$ & 812,201 \\
\hline Missisauga, ON & 2,443 ppl / km sq & $6.7 \%$ & 713,443 \\
\hline Winnipeg, MB & 1,430 ppl / km sq & $4.8 \%$ & 663,617 \\
\hline Vancouver, BC & 5,293 $\mathrm{ppl} / \mathrm{km} \mathrm{sq}$ & $4.4 \%$ & 603,502 \\
\hline Brampton, ON & $1,969 \mathrm{ppl} / \mathrm{km} \mathrm{sq}$ & $20.8 \%$ & 523,911 \\
\hline Quebec City, QB & $1,137 \mathrm{ppl} / \mathrm{km} \mathrm{sq}$ & $5.2 \%$ & 516,622 \\
\hline Surrey, BC & $1,481 \mathrm{ppl} / \mathrm{km} \mathrm{sq}$ & $8.6 \%$ & 468,251 \\
\hline Laval, QB & $1,625 \mathrm{ppl} / \mathrm{km} \mathrm{sq}$ & $8.9 \%$ & 401,553 \\
\hline Halifax, NS & $71 \mathrm{ppl} / \mathrm{km} \mathrm{sq}$ & $4.7 \%$ & 390,096 \\
\hline Markham, ON & 1,423 ppl / km sq & $15.3 \%$ & 301,709 \\
\hline Vaughan, ON & $1,056 \mathrm{ppl} / \mathrm{km} \mathrm{sq}$ & $20.7 \%$ & 288,301 \\
\hline Gatineau, QB & 775 ppl / km sq & $9.6 \%$ & 265,349 \\
\hline Saskatoon, SK & $1.063 \mathrm{ppl} / \mathrm{km} \mathrm{sq}$ & $9.8 \%$ & 222,189 \\
\hline Kitchener, ON & $161 \mathrm{ppl} / \mathrm{km} \mathrm{sq}$ & $7.1 \%$ & 219,153 \\
\hline Regina, SK & 1,331 ppl / km sq & $7.7 \%$ & 193,100 \\
\hline Richmond Hill, ON & $1.855 \mathrm{ppl} / \mathrm{km} \mathrm{sq}$ & $14.0 \%$ & 185,541 \\
\hline Oakville, ON & $1.322 \mathrm{ppl} / \mathrm{km} \mathrm{sq}$ & $10.2 \%$ & 182,520 \\
\hline Burlington, ON & $950 \mathrm{ppl} / \mathrm{km} \mathrm{sq}$ & $6.9 \%$ & 175,779 \\
\hline Oshawa, ON & $1,031 \mathrm{ppl} / \mathrm{km} \mathrm{sq}$ & $5.7 \%$ & 149,607 \\
\hline Levis, QB & 309 ppl / km sq & $6.7 \%$ & 138,769 \\
\hline Barrie, ON & 1,762 ppl / km sq & $5.7 \%$ & 135,711 \\
\hline Abbotsford, BC & $355 \mathrm{ppl} / \mathrm{km} \mathrm{sq}$ & $7.4 \%$ & 133,497 \\
\hline Cambridge, ON & $1,121 \mathrm{ppl} / \mathrm{km} \mathrm{sq}$ & $5.3 \%$ & 126,748 \\
\hline Kingston, ON & $273 \mathrm{ppl} / \mathrm{km} \mathrm{sq}$ & $5.3 \%$ & 123,363 \\
\hline Whitby, ON & $835 \mathrm{ppl} / \mathrm{km} \mathrm{sq}$ & $9.7 \%$ & 122,022 \\
\hline Guelph, ON & 1,398 ppl / km sq & $5.9 \%$ & 121,688 \\
\hline Kelowna, BC & $555 \mathrm{ppl} / \mathrm{km} \mathrm{sq}$ & $9.6 \%$ & 117,312 \\
\hline St. Johns, NFL & $239 \mathrm{ppl} / \mathrm{km} \mathrm{sq}$ & $5.5 \%$ & 106,646 \\
\hline Terrebonne, QB & $689 \mathrm{ppl} / \mathrm{km} \mathrm{sq}$ & $12.3 \%$ & 106,322 \\
\hline
\end{tabular}

Table 1 Growing Canadian Cities and Population Density, (Statistics Canada, 2012). 
Toronto's first major growth closely coincides with the rate of change in the global urban population to ten times its previous size. Originally much smaller than it is today, the "population grew from just over 56,000 in 1871 to nearly 522,000 only 50 years later" (Hodge \& Gordon, 2008, page 56) because of a steep increase in immigration. During this time, the immigrant population typically settled in crowded low-rise neighbourhoods on edges of the early city centre (Troper, 2000). Following this period, the city continued to expand into two different quantifiable areas of population and density. The first being the metropolitan region, known as the Greater Toronto Area (GTA), which also contains many of the other Canadian cities with densities over 1,500 people per square kilometer. With 5,583,064 people covering an area of 5,905.71 square kilometers, according to the 2011 census (Statistics Canada, 2014), the total population density for the GTA is 945.4 people per square kilometer or 9.4 persons per hectare. Initially this value seems quite low; however, it also includes suburban areas in the calculation. Meanwhile the core, or City of Toronto, has a significantly higher population density than the metropolitan region that reaches 4.150 persons per square kilometer. This concentration in the urban core has lead to a drastic increase in physical density, as illustrated in Figure 3, where a clear majority of built space is located in a few very concentrated parts of the city. To fit the inflated physical density in these select areas, developers resort to high-rise buildings to push the land-use intensity to its limit. "Since 2009, 4.7 million square feet of office space" (O'Toole, 2013) and countless residential condominiums have been constructed and continue to inflate the urban intensity. Teetering on the edge of overcrowding, these extreme densities are still attracting new people to the city. Following global trends illustrated earlier by the United Nations in Figure 2, and according to O'Toole (2013), it is a result of the Baby Boomer's children (also referred to as the Echo Boomers) moving closer to the all important transit, workplaces, and amenities. Given these statistics, the city needs to plan alternatives to fit the ever increasing growth, while still ensuring the quality and experience of the public realm is maintained. 


$$
\frac{b}{b}
$$


2 FORMING THE URBAN ENVIRONMENT 


\subsection{PAST VIEWS ON APPROACHING DENSITY TO IMPROVE EXPERIENCE}

Through various stages of urban growth there have been many architectural and planning responses that aim to accommodate density within the cities. Each of these responses has taken a different perspective on populated areas; some are encouraging experience, while others try to disperse density because of its negative perception. Originally, filth, disease, "inadequate housing, water supply and sewage disposal" (Hodge \& Gordon, 2008, page 33), which made life unsuitable for the working classes and threatened the quality of life for the rich, were the first factors to draw planners' and architects' attention to density during the industrial revolution (Oswalt, 2006). Their involvement soon lead to major shifts in thinking and multiple views on improving the poor experience of the Industrial City such as, the City Beautiful, Garden City, and City Efficient. Each movement had a different strategy for approaching density, but they all shared common outlooks that focused on spaciousness, aesthetic, and public outdoor space. In the late nineteenth century the City Beautiful appeared which primarily addressed aesthetics and inserting large new avenues through dense urban areas (Hodge \& Gordon, 2008). However, the movement received criticism for avoiding the "real problems", like inadequate housing and poor health, which lead to Ebenezer Howard's introduction of Garden Cities in 1898. He took a radically different approach by removing density from the urban centre and distributing it to smaller settlements in the greenbelt where "housing [was] located in spacious settings surrounding the centre [of the new development] and industry on the outer ring" (Berghauser Pont \& Haupt, 20010, page 47). Although this approach created a pleasant experience for those relocated to settlements, it decentralizes the city instead of focusing on improving the actual experience.

Shortly after the City Beautiful and Garden City movements, the Twentieth Century brought new planning principles that emphasized functionality in City Efficient, or City Scientific. This approach to experiential density in urban centres was influenced by the failing infrastructure and rising housing shortages (Urban, 2013). New ideals brought more attention to the infrastructure required to support growing cities, while proposals by Le Corbusier and other prominent architects started to reinterpret housing. Continuing the importance of cleanliness and open park space discussed in earlier movements he proposed...

"a 'Green City' with plenty of open space, light, sun and fresh air. Densities were high - up to 1,000 inhabitants per hectare, comparable to the density of Jordan 50 years earlier, which had often been characterized as being heavily overcrowded. The rational for such a high density was to minimize land-use and distance traveled." (Berghauser Pont \& Haupt, page 51, Citing Le Corbusie). 
In order to bring this level of density, while still improving the urban experience, "Le Corbusier envisioned the city as a huge park where 60-story office towers and 10-story apartment buildings were woven in zigzag form across landscaped space in his Contemporary City" (Hodge \& Gordon, 2008, page 75). Emphasizing the park and generating new open areas within the growing urban centres was Le Corbusier's attempt to prioritize the public realm by bringing more people to the ground plane.

Ideas from Le Corbusier's Tower in a Park were quickly adopted by many cities and architects globally as a defining feature of the modernism movement to improve the quality of life and experiential density. Canada was among the many countries to do so by using their post-war wealth to construct slab tower apartments for "working couples, middle-income professionals, small families, and empty-nesters as an almost Jetsons-esque vision of the future" (Steward, Thrope, McClelland, 2013). Marketing the new living conditions to the working class was also part of the social reform which "housed and fed the needy [and] went along with more or less coercive methods to categorize, regulate, and discipline the masses, to enforce moral rule and social hygiene" (Urban, 2013). Providing better living environments for these groups finally began addressing earlier concerns that were unsuccessfully resolved by previous movements and encouraged density instead of trying to work around it. The social reform was not the only ongoing evolution that enabled the slab towers to become a popular and defining moment in the modernist period. Construction itself was evolving and "two innovations were particularly consequential: steel frames and reinforced concrete" (Urban, 2013). These new methods of building along with technologies like the elevator (Kirkman, 2010) enabled a higher physical and population density with the lowest land-use intensity possible. Despite advancements made in bettering experiential density, the residential apartment tower is seen much differently today. Typically, the affordable prices (which actually tend to benefit new immigrants who seek slab towers as their first residents according to Stewart, Thrope, \&Mclelland (2012)), lack of services, and sometimes isolation tend to re-establish the negative association with density and experience around the residential apartment tower (City of Toronto, 2011). However, the slab towers still remain an important part of the history of physical density and land-use intensity within urban environments and accounts for large volumes of housing stocks. 


\subsection{CURRENT UNDERSTANDING OF EXPERIENTIAL DENSITY}

Following the Corbusian slab towers, there was a period where urban growth moved away from city centres in favor of the suburban periphery. At the time, larger properties, affordability, spaciousness, and open landscape seemed to provide a more desirable experience. However, the trend has reversed, as Richard Rogers (1998) explains the mass shift in population towards urban centres has made the present day cities more populated than ever before. Many theorists, including Drover (1974) and Kirkman (2010), argue the shift is because the suburbs have not taken the idea of density seriously or valued mixed-use neighborhoods, while the quality of services and amenities within the city are becoming more of an asset to dwellers. This suggests a fundamental change in cultural values which place more emphasis on the community than the individual home. Also, urban dwellers desire proximity to work, services, and amenities to shorten commuting and spend more time with their families (Chakrabarti, 2013). These perspectives are resulting in another large population movement back into the centre of the city. Therefore, new theories on approaching an urban lifestyle need to focus on maintaining and improving the desired experience, while also accommodating the increase in density.

A major concern with increasing density in urban centres is the limited amount of open land. As a result, property value is typically much higher in growing cities then suburban areas, which can make land for new services difficult to acquire. Raymond Unwin justifies the expense by explaining higher cost of land for infrastructure serves an exceptionally larger population than it would in the suburbs (Berghauser Pont \& Haupt, 2010) and also contributes to improving the quality of life in the city. Additionally, property costs also become a concern for individual home owners who have a difficult time finding an affordable place to live. The resulting demand for housing has attracted many developers, especially in Toronto, who profit from placing the highest possible land-use intensity on one site with a high-rise point tower. In turn, smaller units within the skyscrapers accommodate new services, businesses, and inhabitants that are returning to the city at a much more affordable cost (Scallan, 2012). The downside is people living in these new towers are often confined to very tight living conditions and inefficient levels of privacy that lead to the sensation of crowding (Bascaramrty, 2012).

Some people, like Bennet (2011), are against the high-rise construction typology for the poor environments they often create, but they accept the ambitions to accommodate more people within the city centre. Despite these feelings, the condominium seems to be the most popular approach for accommodating the increasing city population. It allows inhabitants to live close to work and in areas surrounded with amenities and services, all of which contribute to the expected experience of an urban lifestyle. However, it is becoming more difficult for planners and architects to combat the condo tower, as the desire to live in central areas and own property close to amenities is giving private developers 
“...more [power] in project negotiations with local authorities. They gave a greater say on the quantitative goals (number of dwellings to be developed) and qualitative ambitions (type of dwellings, amount of green space, parking options) of such projects. This gradual shift from government to governance has created a receptive environment for a project-based approach, an approach in which public and private partners sign agreements (under private law) before the spatial aspect as these agreements become legally binding through zoning plans (under public law)" (Berghauser Pont \& Haupt, 11)

This process makes the developers extremely powerful and allows them to control densification within North American cities. Kirkman (2008) also notices this problem and suggests their projects should have a more ethical approach by thinking "carefully and critically about the ends and means of our projects, and about matters of character, motivation, and consequence." In these situations, the developer is making all the critical decisions, but these two authors are urging the design community to become more influential. To accomplish this ideal condition, both architect and developer need to recognize the existing context and understand how their project will influence the experience and quality of an area. Resorting to a conventional point tower will always disconnect its residents from the community and overshadow the street level condition, while looking for new and innovative solution to bring additional density to an underutilized area, such as the unused parks enclosed by clusters of residential apartment towers, can help focus attention back on the pedestrian realm. The end result would be a more lively and active public realm, where the residents can still interact and experience the amenities that make urban living desirable.

The other key player in determining how density will be accommodated in today's urban environment is the city government and policy makers. Regulations and by-laws controlled by these authorities have the power to dramatically influence the perception of density by establishing by-laws, standards, and publishing documents like the official and secondary plans. Using such mediums, the governing bodies are able to make strict demands that will contribute to a more planned public realm, while still allowing developers to achieve their desired levels of land-use intensity (Poplak, 2012). An example of such can be found in Toronto's Official Plan (2010), which encourages public outdoor spaces in new construction to compensate for the lack of parks. Such documents can also encourage density to be more evenly distributed throughout a neighborhood at a human scale, instead of isolated within a few high-rise towers. Introducing a new low-rise density surrounding the existing slab and point towers could impact the typical opposition that is associated with the "proliferation of high-rise towers, [which create] a monotonous repetition of building forms..." (Drover, 1947, page 16), while also drawing the attention back to the public realm and ground plane. It is similar to European 'mat urbanism' described by Allen (2002), this approach would still be able to increase population density, by pressuring 
developers to take a different approach to physical density and land-use intensity. The overall effect of stricter governing guideline with alternative approaches to density will influence new development typologies that can make better use of the available land to improve the overall experience of the city. 
3 DENSITY AND EXPERIENCE IN TORONTO 


\subsection{DENSITY AND EXPERIENCE IN TORONTO}

\subsection{IMPACT OF TORONTO'S PERCEIVED GROWTH}

Implementing strategic plans to improve human perception and experience has already been undertaken in the City of Toronto. The formation of the Official Plan (2010), Secondary Plans, Tall Building Guidelines (2013), and the Avenues and Mid-Rise Building Study (2010) all attempt to address the population growth and increasing density in the city by ensuring it develops into a pleasurable environment. However, there is a limit to the documents effectiveness, as developers still fight for their own interests and profit. The result is a dramatic increase in building height and proximity to each other which causes inhabitants to experience overcrowding (Bascaramurty, 2012). Since this perception generates a negative experience, the Official Plan (2010) has tried to draw attention away from high-rise developments, by creating a more walkable condition on the ground plane. While this focus is more important in highly dense areas of Toronto, it also strains the limited amounts of available public space. This forces the city to turn back to the same developers who are contributing to the negative experience, and encourage them to focus some of their attention and resources on improving the public realm. This cycle ends up relying heavily on both the Official Plan, which outlines the primary goals, as well as Section 37 of the Planning Act. Section 37 allows developers to exceed the designated physical density in exchange for more public amenities in the immediate neighbourhood (Apostolides, 2013). Although there are certain drawbacks to this approach, it is generally effective at ensuring amenities, services, and public spaces are concentrated in the most densely built areas of the city and ensuring the urban growth follows the general guidelines laid out in the Official Plan to improve the experience.

Along with promoting an improved public realm and ground plane experience, Toronto's Official Plan plays a necessary role in determining how to accommodate future density. Already recognizing the city is expanding at an exceptionally fast pace, planners believe "...our choice is not whether we grow, but how well we grow. Making Toronto better should always come before making Toronto bigger, but we will get bigger" (City Planning, 2010, page 1-1). Aiming to advance the experiential conditions of the urban environment, the Official Plan (2010) focuses on strategically accommodating new density in areas that are supported by transit, public amenities, and jobs. Identifying parts of the city that have these and other resources, planners have selected four regions of growth: downtown (including central waterfront), centres, avenues, and employment districts as illustrated in Figure 4 (City of Toronto, 2010). Developers also acknowledge the benefits from services and amenities in the growth regions, which are shown by the 86 per cent of new construction projects that have occurred in identified areas (O'Toole, 2013). However, Toronto's downtown, centres, avenues, and employment districts all have their own unique characteristics that make some more conducive to an experiential density then others. 


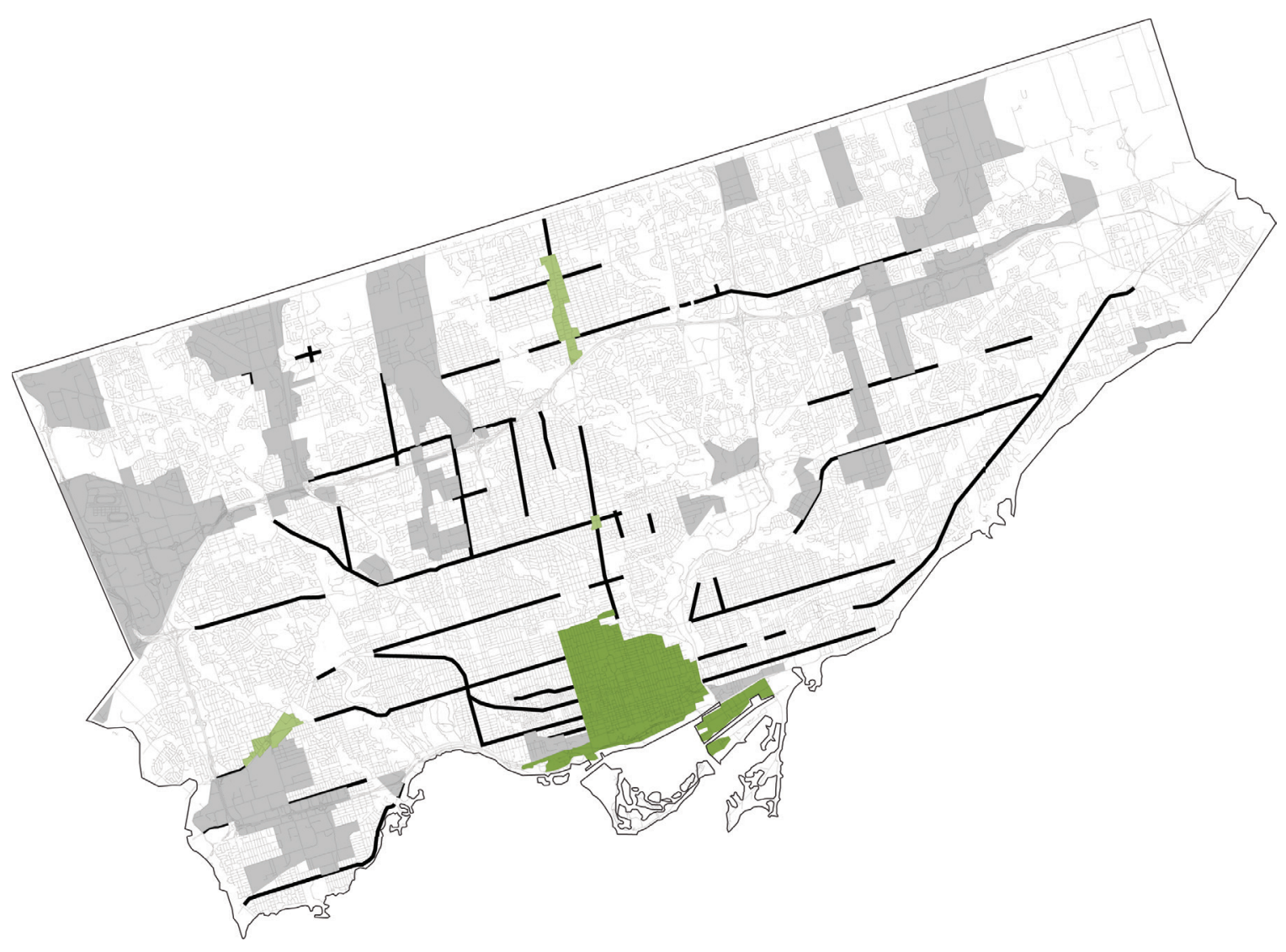

Downtown

Centers

- Avenues

Employment Districts

Figure 4 Toronto's Densification Strategies, (Data retrieved from Official Plan, 2010. Sauder, 2015). 
Already the highest physical density in the city (refer to Figure 3), Toronto's downtown core has a very distinctive atmosphere in comparison to the avenues and employment districts because of the abundance of high-rise towers. Downtown "is the main location for residential and office development, with 40 per cent of the residential units and 38 per cent of the non-residential GFA proposed in the City" (Your City, 2014). Rapid population growth in the downtown core is pushing the area to its capacity. The limited outdoor space, available land, and strained transit system have to deal with both residents and commuters that occupy this part of the city. Continued construction in the downtown will only result in a magnified perception of crowding and further removal of the human scale from the public realm as buildings become taller to make up for the lack of available land. While intensifying the area is possible, it will only continue to strain the existing amenities and remove any connection to the ground plane. Therefore, it would be worthwhile to investigate new development in other identified growth areas.

In addition to Toronto's downtown area, the high-rise developments are also common in centres. The centres, as identified in the Official Plan, tend to be located along the city's major avenues, but deviate from the typical developments found in Toronto's Avenue Plan. One of the intersections which is presently undergoing a period of substantial growth, is the Yonge and Eglinton centre. At this junction, it is expected "in the coming decade we'll see up to 30 new towers, about 23,000 new people, and a few new amenities..." (Poplak, 2012). The rapid growth will drastically alter the physical characteristics of the neighbourhood as well as the experiential density which currently portrays spaciousness because of the unused open spaces surrounding slab towers. Ignoring design strategies that could respond to the specific conditions found in this area will end up replicating the same experience and conditions found in the downtown.

In addition to the high-rise developments, which are the most common form of construction in Toronto's downtown and centres, the Avenues takes a different approach to accommodating density within the city. Along the avenues, which tend to be major traffic routes, the Planning Department encourages mid-rise developments which are no taller than the right of way (ROW). Following a long list of guidelines set out in the Avenues \& Mid-Rise Buildings Study (2010) the plan aims to generate a continuous street wall, with appropriate setbacks, along the avenue that responds to the human scale. Seemingly very comprehensive, this plan establishes a framework for the most common conditions along the avenues. Unfortunately, there has been criticism about this approach because of the cost of construction associated with development in these areas is equivalent to building in the downtown area (Apostolides, 2013). The Avenue Plan also neglects to address the Residential Apartment sites, or newly zoned Residential Commercial Apartment sites, which also frequently occur along the avenues. These sites are usually removed from the street and disconnected from the rest of the neighbourhood. However, the Avenues \& Mid-Rise Buildings Study (2010) does state that the Residential Apartment 
sites are also a viable location to accommodate the city's density along the avenues, but it does not comment on the strategies to create the desired quality or pedestrian atmosphere along the street.

Comparing Toronto's downtown, centres, and avenues, (which deal with much higher densities than the peripheral employment districts) illustrates a range of responses to density. However, each contributes to a different experience in the public realm. The already densely developed downtown removes the human scale from the pedestrian environment, while the avenue's emphasize the streetscape. Areas like Yonge and Eglinton, which falls under both the centres and avenue designation are at an impasse, where the high-rise typology is quickly beginning to overtake the area, but large areas of unused land are available for alternative development strategies that more closely reflect the values for an experiential urban environment with supporting public amenities. 


\subsection{THE SLAB TOWER IN TORONTO}

While Toronto's Official Plan identifies the downtown, centres, avenues, and employment districts as regions within the city that can support the continued growth, it neglects to address a very specific typology that can be found in each of these areas, the residential apartment tower (Mapped on Figure 5). Housing over 500,000 urban residents, the slab tower played an important role in the city's last major growth period (City of Toronto, 2011, 5). Mostly built between 1945 and 1984 (City of Toronto, 2011), the "boom represents the region's interpretation of the modernist, post-Corbusian housing movement that proliferated around the globe" (Steward, Thrope \& McClelland, 2013). Like many other residential apartments from the modernist period, these towers are characterized by heavy concrete construction and large open properties. Unfortunately, today the large open spaces surrounding the towers that were originally intended to act as a park, have either been converted into parking lots or remain neglected and unused. This has left many of the residential apartments isolated and disconnected from the surrounding public realm. More recently, the city has recognized the value of this real estate by issuing the Tower Renewal Project and new zoning by-laws that specifically address the unused land. The Tower Renewal Project (2011) focuses on improving the overall condition of the slab towers by creating stronger communities, increased social and cultural benefits, and improved economic activity. Although these strategies do not specify an increase in density, they promote an improved experience with a stronger sense of mixed-use community. This influenced the city to produce Zoning By-Law 569-2013-15 (City of Toronto, 2013), changing many of the previously zoned 'Residential Apartment' areas to 'Residential Apartment Commercial' (RAC) to encourage local economic development. Bylaw 569-2013-15 still caters to the idea of a tower in a park by promoting large setbacks, but it does not prohibit additional structures from the site like previous zoning. This means it is also possible to increase the density of the residential apartment tower blocks by infilling portions of the open park space with built volumes that will aim to improve the experience of the ground plane, and introduce a new public realm for the site. Applying this new outlook to residential apartment towers throughout the city, particularly in the four growth areas-downtown, centres, avenues, and working districts-will help to distribute the population and intensify as the city grows. 


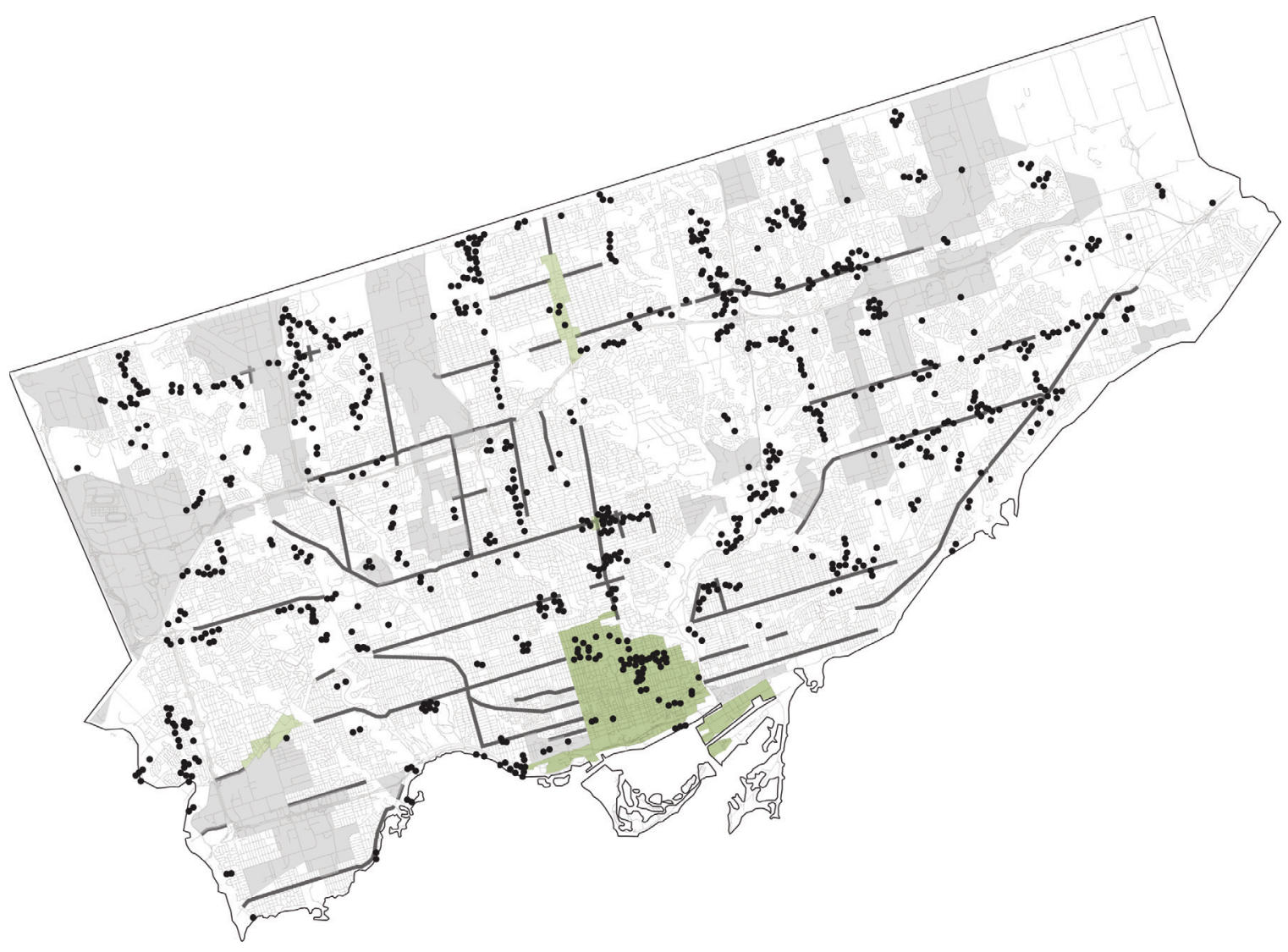

- Slab Towers

Downtown

Centers

- Avenues

Employment Districts

Figure 5 Toronto's Residential Apartments, (City of Toronto, 2011). 


\section{A STUDY OF TORONTO'S URBAN FABRIC SURROUNDING RESIDENTIAL APARTMENT BLOCKS}




\subsection{A STUDY OF TORONTO'S URBAN FABRIC SURROUNDING RESIDENTIAL APARTMENT BLOCKS}

\subsection{IDENTIFYING RESIDENTIAL APARTMENT NEIGHBOURHOODS}

Comparing the potential of Toronto's Tower Renewal Program (2011) with growth areas laid out in the Official Plan (2010) suggests certain strategies are most effective in a specific part of the city. Focusing on the outer regions of Toronto, the Tower Renewal (2011) approach addresses an almost blank slate condition, where groupings of existing towers are removed from low-rise structures and mixed-use communities that could improve the pedestrian experience. Also distributed throughout this part of Toronto are the employment districts and avenues, which are also very removed from high density areas of the city to focus on intensification. Meanwhile, the highly developed downtown already has its own relatively successful approach to development. Mixing the existing fine grain building fabric and diverse programing with new point towers dramatically increases the quantifiable densities, while still maintaining an active and lively street. Therefore, groupings of residential apartment towers in the downtown are exposed to a completely different experience than their isolated counterparts in Toronto's outer suburbs, with direct access to services and walkable streets. A third distinctive urban condition exists where slab towers are also abundantly common, the Yonge-Eglinton centre. Unique to this growth region, residential apartment towers combine many features of the diverse downtown and isolated suburbs. Like the peripheral regions of the city, the block structure is oversized leaving an unfriendly pedestrian environment, but transit and a nearby mixed-use area show promise in creating an experiential density within the Yonge-Eglinton centre. Additionally, the centre is the fastest growing area in the city, with the rate of change at 14.5 per cent compared to Toronto's overall growth rate of 4.5 per cent (Poplak, 2012). In addition to surpassing the overall rate of change, the Yonge-Eglinton centre is increasing faster than many of Canada's other largest cities shown in Table 1 (Brampton and Markham being the exceptions). Therefore, the Yonge-Eglinton centre and downtown will be studied to further understand the existing conditions of slab towers within the context of higher densities. In addition to their location, each of the urban blocks also meets additional selection criteria. This includes multiple residential apartment towers on a single urban block, additional building typologies, and a location on a major street with proximity to transit. Finally, each site needed to have a significant amount of grade level parking, and/or open park areas. A group of sites were selected that met this criteria, which include: Mt Pleasant and Eglinton, Mt Pleasant and Broadway, St James and Bleeker, and finally Church and Isabella (shown in Figure 6). 




- Slab Towers

Downtown

Centers

- Avenues

Employment Districts

Figure 6 Identifying Residential Apartment Neighbourhoods in Toronto, (Sauder, 2014). 


\subsection{CHARACTERISTICS OF THE RESIDENTIAL APARTMENT BLOCK}

The first step in understanding typical conditions of residential apartment blocks involves breaking down densities and quantifiable areas of the four selected blocks; Mt Pleasant and Eglinton, Mt Pleasant and Broadway, St James and Bleeker, and Church and Isabella. As shown in Figure 7, the total area of each block can be rounded to either 20,000 square meters for Mt Pleasant and Eglinton, and Church and Isabella or 30,000 square meters for Mt Pleasant and Broadway, and St James and Bleeker, with populations that reflect the differences in block size. However, the land-use intensity

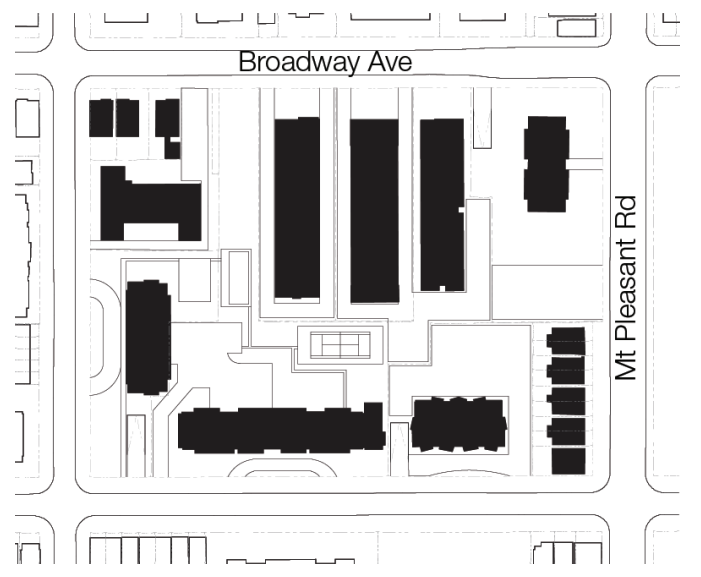

MT PLEASANT AND BROADWAY

Total Block Area: 30,628 m²

Land Use Area: 8,641 $\mathrm{m}^{2}$

Land Use Intensity Ratio: 28\%

Physical Density: 196,834 m³

Unit Density: 989 units

Estimated Population: 2,498 persons

Population Density: 0.081 people $/ \mathrm{m}^{2}$

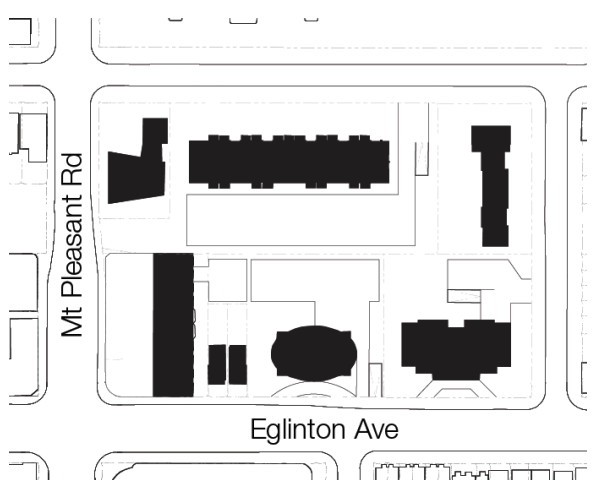

MT PLEASANT AND EGLINTON

Total Block Area: 19,272 m²

Land Use Area: 3,714 m²

Land Use Intensity Ratio: 19\%

Physical Density: 165,375 m³

Unit Density: 672 units

Estimated Population: 1,680 persons

Population Density: 0.087 people $/ \mathrm{m}^{2}$

Note: Population Density is calculated based on the average of 2.5 persons per household, according to the City of Toronto's 2011 Census: Marital Status, Families, Households and

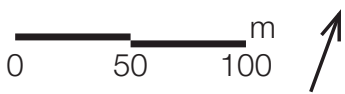
Dwelling Characteristics.

Figure 7 Residential Apartment Neighbourhood Densities, (Sauder, 2014). 
ratio does not have the same relationship with total area as the population density. Instead, the landuse intensity is influenced by the building typologies found on the block. Generally, more slab towers results in a lower land-use intensity ratio and more unused space. Meaning the potential to further increase density and improve the overall experience of the area is more dependent on the number of towers and available land, than the existing population density on the selected sites.

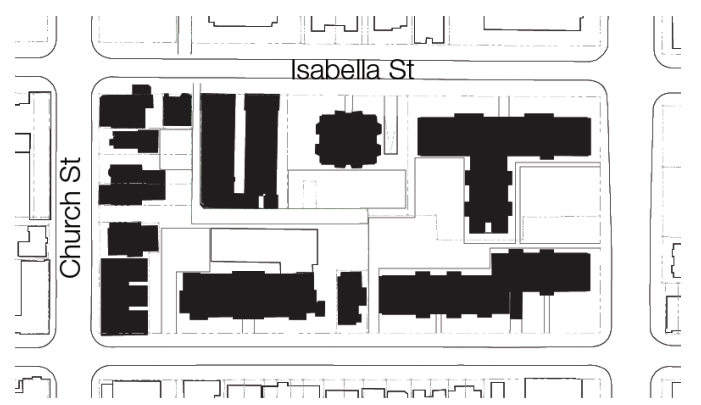

CHURCH AND ISABELLA

Total Block Area: 18,562 m²

Land Use Area: 7,356 m²

Land Use Intensity Ratio: 40\%

Physical Density: 198,757 $\mathrm{m}^{3}$

Unit Density: 844 units

Estimated Population: 2,110 persons

Population Density: 0.125 people/m²

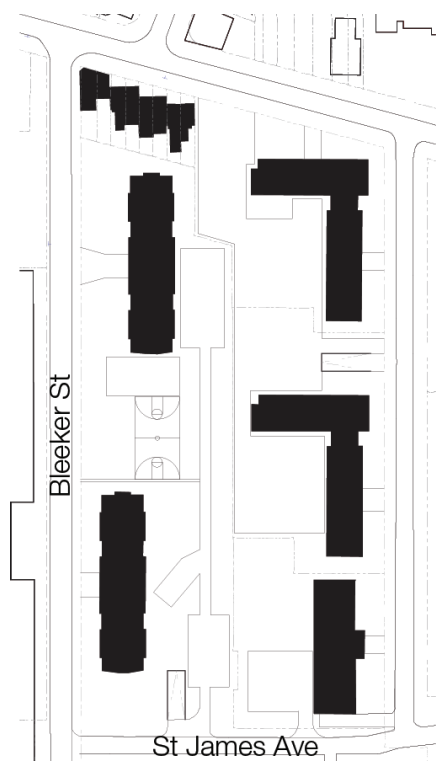

ST JAMES AND BLEEKER

Total Block Area: 29,729 m²

Land Use Area: 6,399 $\mathrm{m}^{2}$

Land Use Intensity Ratio: 22\%

Physical Density: 320,190 m³

Unit Density: 1,584 units

Estimated Population: 3,960 persons

Population Density: 0.135 people/m²

Note: Population Density is calculated based on the average of 2.5 persons per household, according to the City of Toronto's 2011 Census: Marital Status, Families, Households and Dwelling Characteristics.

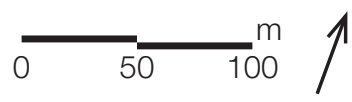

Figure 7 Residential Apartment Neighbourhood Densities, (Sauder, 2014). 
To further understand the impact of the residential apartment on the urban block, the second study looks at the number of different building typologies. While each site obviously contains numerous slab towers, as seen in Figure 8, low and mid-rise housing is also common and emphases the areas as a residential zone. With some exceptions, the mixed-use communities referred to in the Official Plan (2010) are rarely seen immediately adjacent to the clusters of residential apartments. This limits the pedestrian traffic moving through the urban blocks and continues to isolate the open land surrounding each tower. Additionally, the scale of the slab towers overshadows the adjacent low and mid-rise buildings, creating a negative interpretation of the high density areas.

$\wedge$ Non-Residential $\checkmark$ Residential

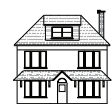

Detached Housing $\times 3$

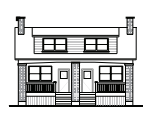

SEMI DETACHED HOUSING X5

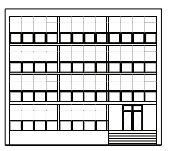

Mid-Rise Housing X4

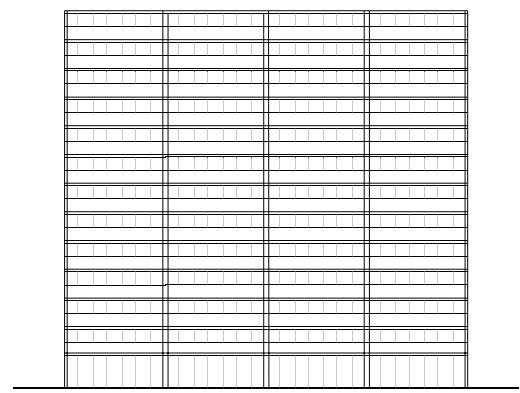

Slab Tower X4

MT PLEASANT AND BROADWAY

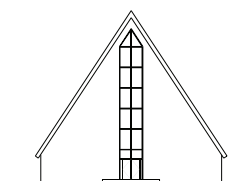

Church $x 1$

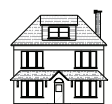

Detached Housing $\times 2$

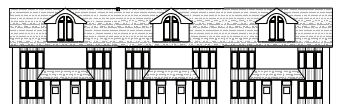

Town Homes $x 1$

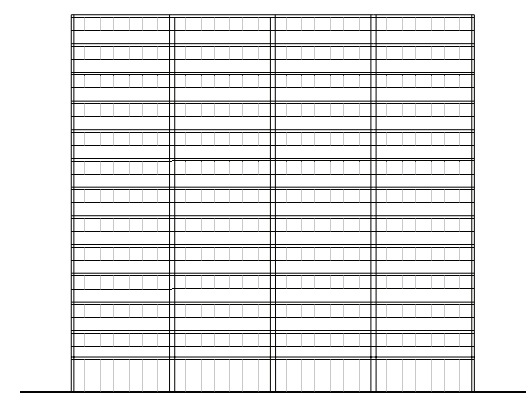

Slab Tower x4

MT PLEASANT AND EGLINTON

Figure 8 Residential Apartment Neighbourhood Building Typologies, (Sauder, 2014). 


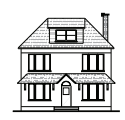

Detached Housing $\times 5$

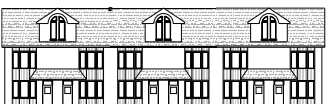

Town Homes X1

$$
\begin{aligned}
& \text { 표표묘 }
\end{aligned}
$$

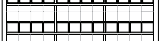

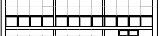

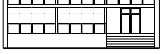

Mid-Rise Housing $\times 1$

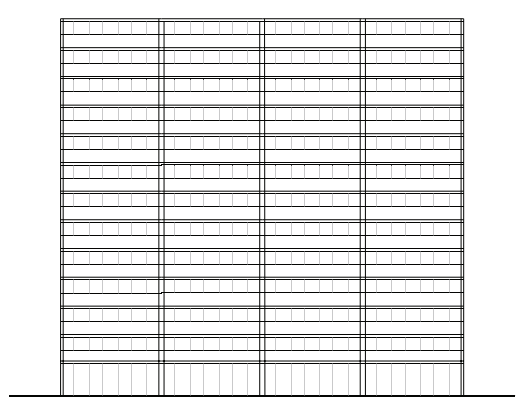

Slab Tower X4

CHURCH AND ISABELLA

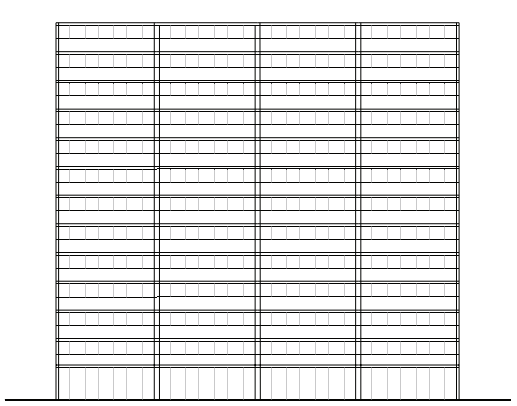

Slab Tower X5

ST JAMES AND BLEEKER

Figure 8 Residential Apartment Neighbourhood Building Typologies, (Sauder, 2014). 
The next phase investigated division lines between real estate on the selected blocks of residential apartment towers. As seen in Figure 9 all of the sites show little regularity or consistency in the way they are fragmented. The only exception to this is a common property line that runs through the centre of the block in the direction parallel to the longest street edge. This condition is found on all four blocks and suggests the central division line is the only strictly regulated boundary when the area was originally developed into the residential towers. Property lines divided in this fashion indicate the presence of hard and soft boundaries within the overall development. The common property line would represent the hard division through the site, while the perpendicular divisions act as a soft boundary condition that can be crossed depending on the relationship between property owners.

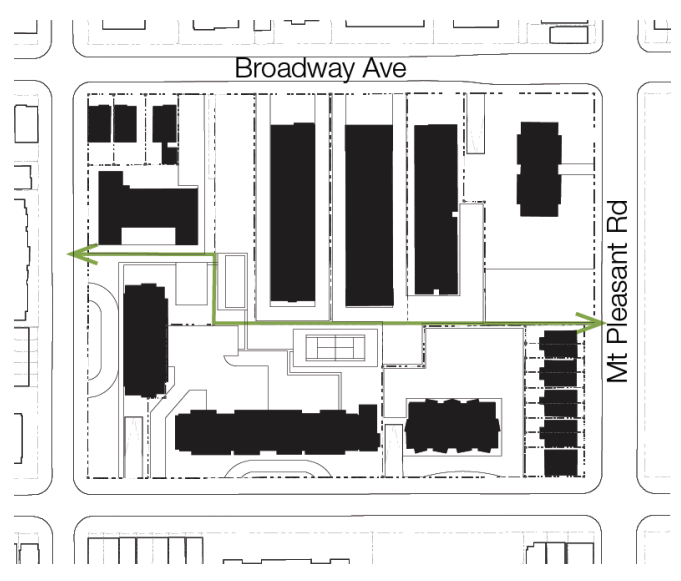

MT PLEASANT AND BROADWAY

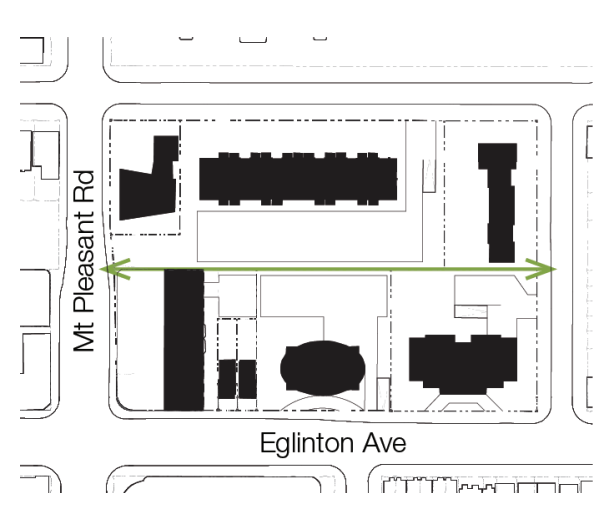

MT PLEASANT AND EGLINTON

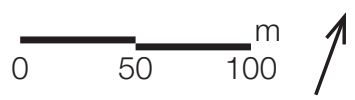

Figure 9 Residential Apartment Neighbourhood Boundary Lines, (Information Retrieved from Property Data Maps, 2012). 


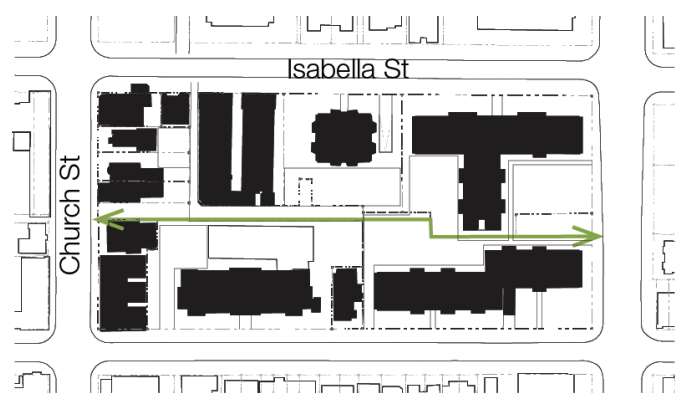

CHURCH AND ISABELLA

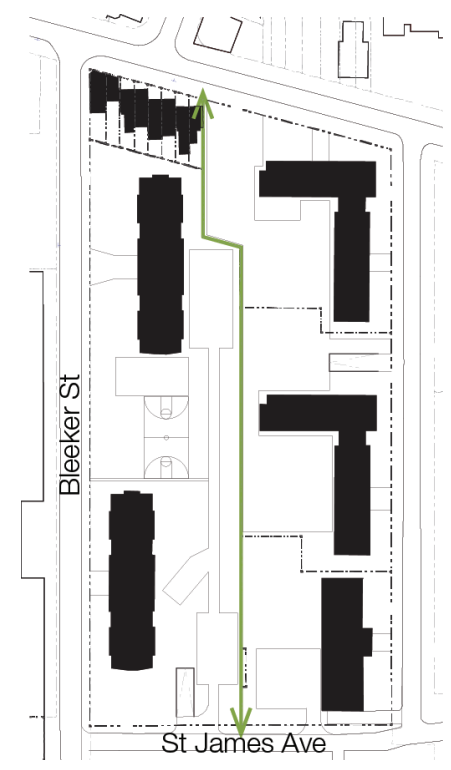

ST JAMES AND BLEEKER

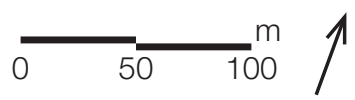

Figure 9 Residential Apartment Neighbourhood Boundary Lines, (Information Retrieved from Property Data Maps, 2012). 
Following the legal boundaries of the site, the next study looks at the open space contained by the residential apartment tower block. Figure 10 shows the sites without any formal property divisions and highlights the remaining open space with dashed lines. Findings from these diagrams indicate the largest areas of unused land are in the centre of the urban block and coincide with the common property line. Voids along the street are less common, but still a typical condition because of the large setbacks required between each tower. While the peripheral voids still act as a potential area for development, the consistent interior spaces are more readily available and a unique opportunity for increased density and land-use intensity.

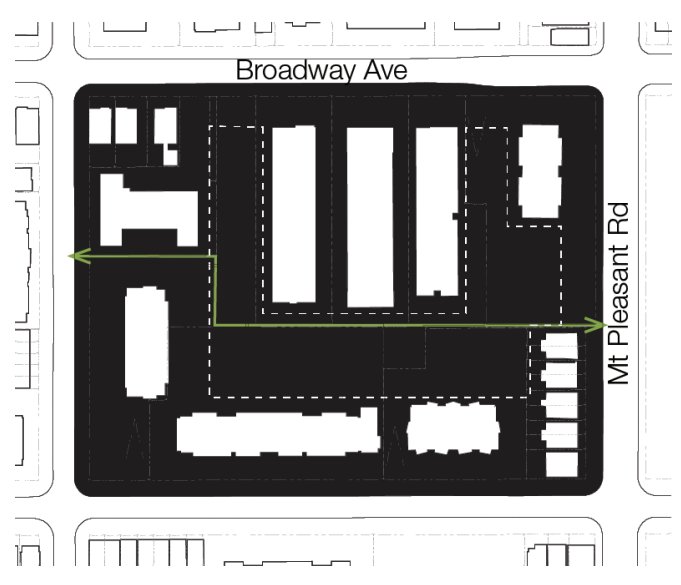

MT PLEASANT AND BROADWAY

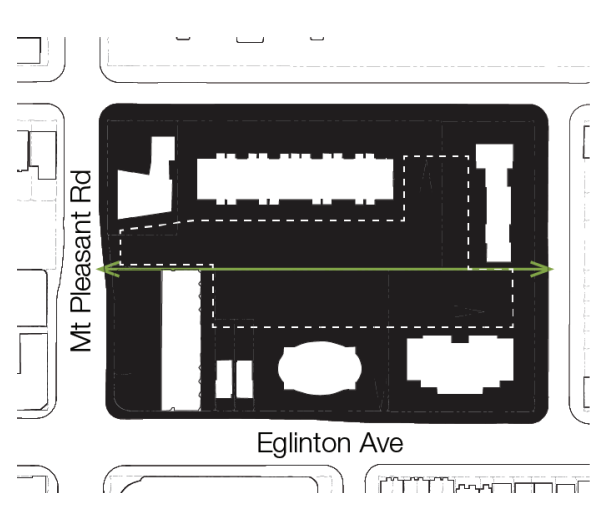

MT PLEASANT AND EGLINTON

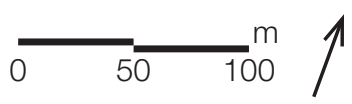

Figure 10 Residential Apartment Neighbourhood Open Spaces, (Sauder, 2014). 


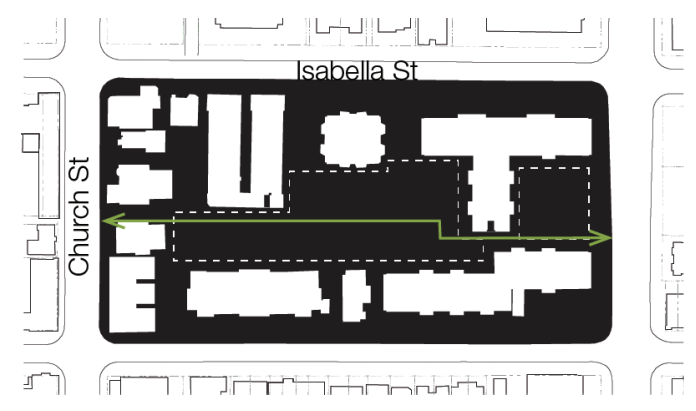

CHURCH AND ISABELLA

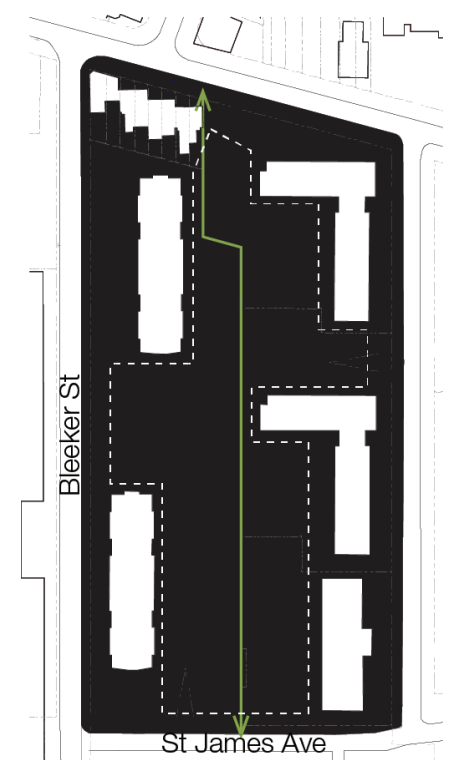

ST JAMES AND BLEEKER

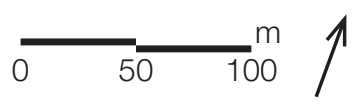

Figure 10 Residential Apartment Neighbourhood Open Spaces, (Sauder, 2014). 
The apartments themselves have a very distinct style. Made predominantly out of concrete and brick, a long facade runs parallel to the street with almost all of the building's balconies and windows. This same facade is usually replicated on the rear wall of the building, while the narrow sides are usually left blank. Figure 11 looks at these empty facades and maps areas where there are either no openings or a single small opening. In either case, it creates an unfriendly condition and causes the tower to turn its back on a large part of the site. However, this empty facade and the large side yards which are common around these towers would act as an ideal location to generate some form of infill to help create continuity along the street facade and further increase the density of the neighbourhood.

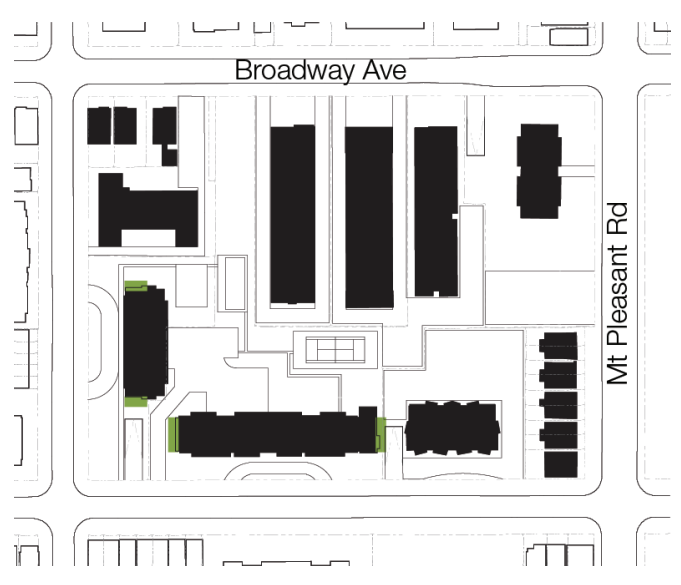

MT PLEASANT AND BROADWAY

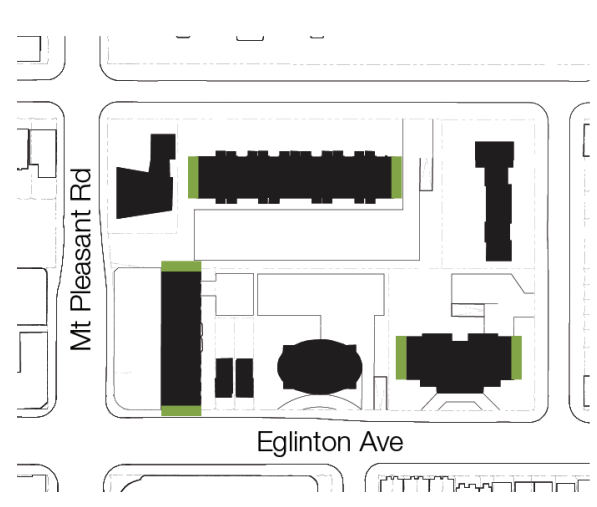

MT PLEASANT AND EGLINTON

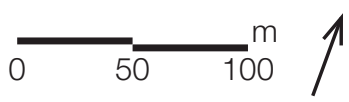

Figure 11 Residential Apartment Neighbourhood Slab Towers and Blank Facades, (Sauder, 2014). 


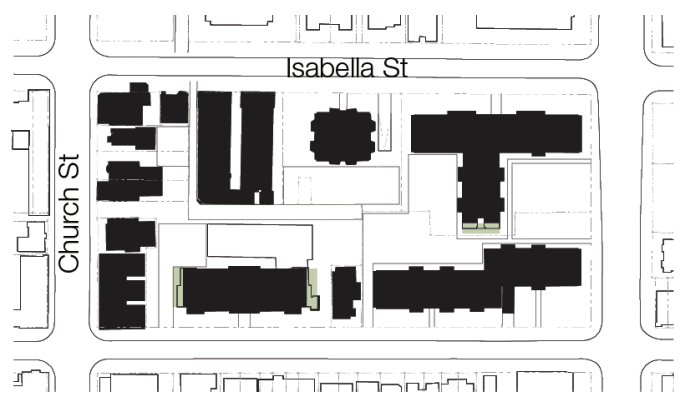

CHURCH AND ISABELLA

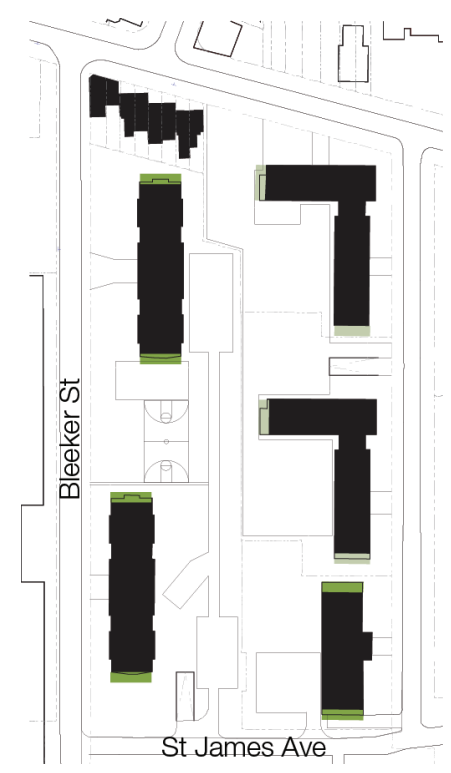

ST JAMES AND BLEEKER

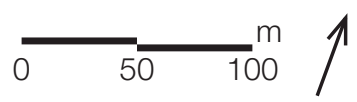

Figure 11 Residential Apartment Neighbourhood Slab Towers and Blank Facades, (Sauder, 2014). 
Large setbacks surrounding the residential apartment towers also play a significant role in forming side yards, open park space, and the overall experience around the towers. Original zoning for tower sites enforced the setbacks to allow light into adjacent buildings, and attempt to soften the overpowering scale of the slab towers. The recent change to Zoning By-Law 569-2013-15 maintain the original setbacks for these same reasons (seen in Figure 12), yet it allows for new mixed-use structures to be placed at grade. However, if slab tower setbacks are compared to a modern point tower, the zoning regulations are radically different. Figure $\mathbf{1 3}$ shows the setbacks of a point tower podium imposed on a typical slab tower, which are significantly smaller. This is because the podium condition will still allow light into the surrounding buildings, create a more pedestrian friendly scale, and bring more mixed-use developments to the site. Coinciding with the blank facades found on the slab tower's side walls, the side yard setbacks offer an additional area for future development that can focus on the experience of the public realm and increase physical density.

The study of typical residential apartment block conditions reveals many common features that could lead to potential strategies that would create additional density and improve the experience of the neighbourhood. First of which, is the common property line which is surrounded by a majority of the unbuilt land. This feature suggests new infill will be located in the centre of the block and follow a very clear division made by the property line. Additionally, the variances in building setbacks indicate a low-rise infill development, while a mixed-use community should be introduced to complement the existing residential typologies. However, further study of the urban environment is required in order to fully understand the perception of density and its effect on the public realm. 


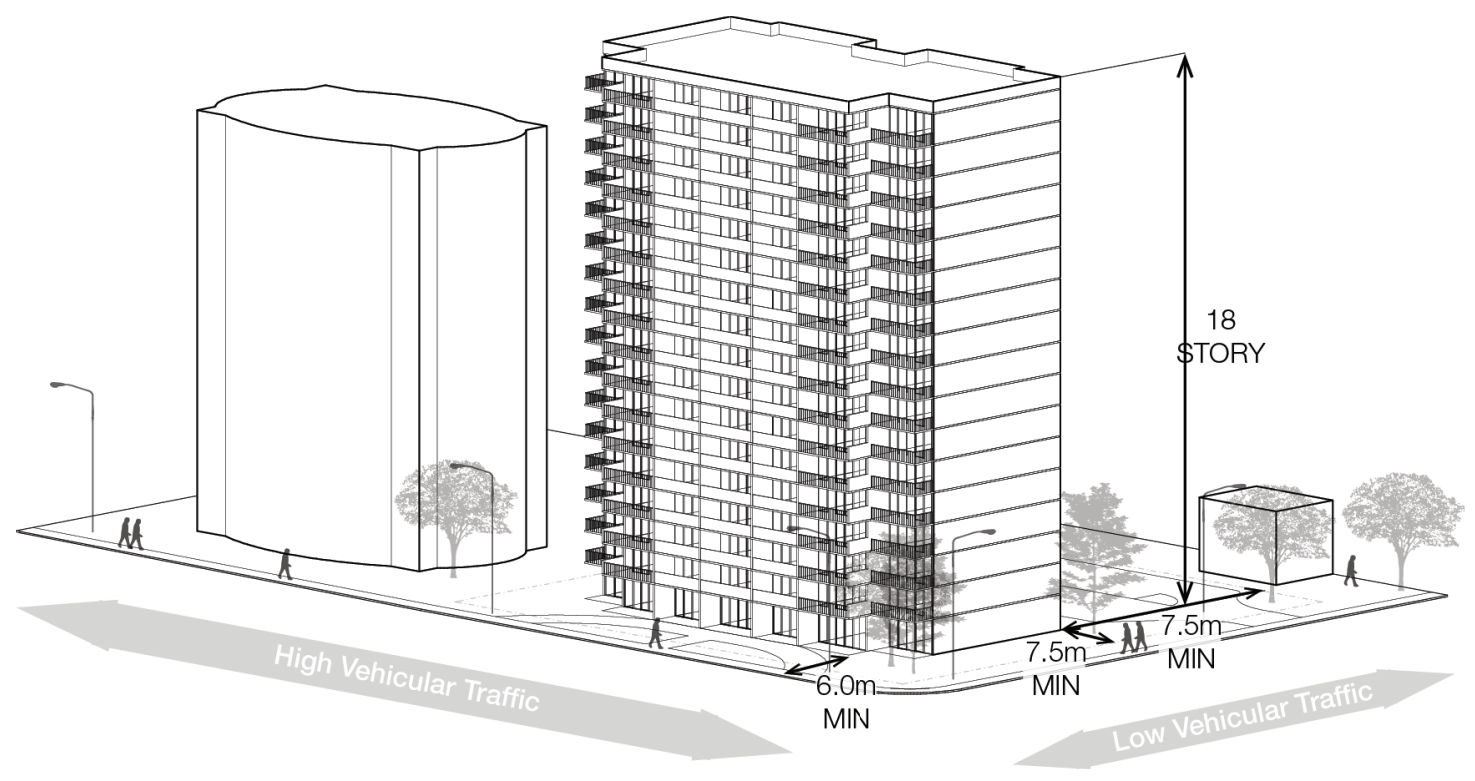

Figure 12 Residential Apartment Zoning Setbacks, (Zoning Information from City of Toronto, 2014. Drawn by Sauder, 2014).

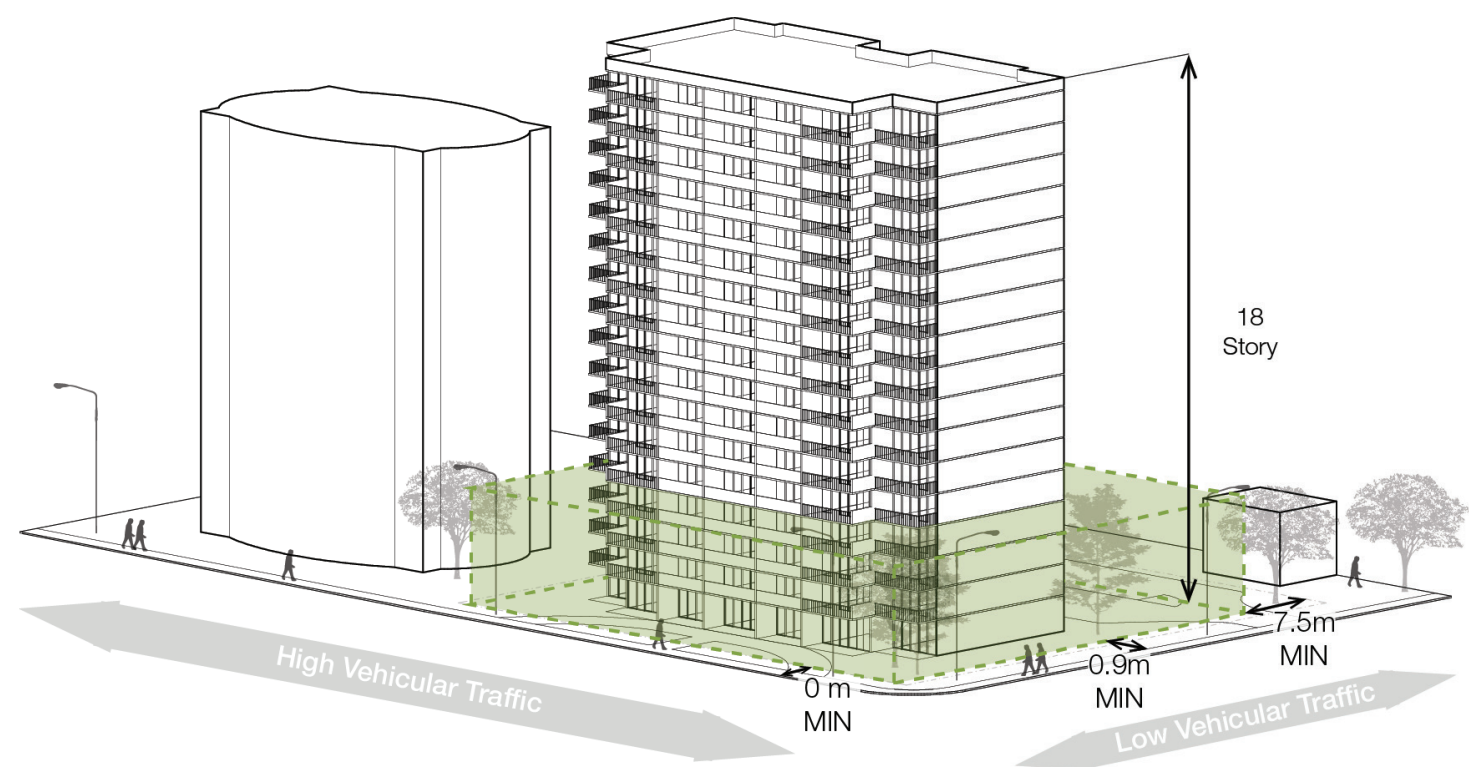

Figure 13 Commercial Residential Zoning Setbacks, (Zoning Information from City of Toronto, 2014. Drawn by Sauder, 2014). 


\subsection{ANALYSIS OF URBAN CONTEXT AT THE YONGE AND EGLINTON CENTRE}

\subsubsection{UNDERSTANDING THE NEIGHBOURHOOD}

The residential apartment blocks that made up the previous study are only a small part of the urban fabric in these neighbourhoods. Although they tend to hold the highest population densities in the immediate area, they account for a small part of the quality of environment in the overall built fabric. Therefore, a secondary study looking at the conditions of the broader neighbourhoods that surround the towers showcases how the built environment interacts with the residential apartment towers. Additionally, this study provides an understanding of existing characteristics, zoning regulations, building scales, block size, walkability and grade conditions that impact the quality of space and perceived density of the city.

While the former study looked at four different sites in the downtown and centre growth districts, the neighbourhood analysis will focus on one area in greater depth. Containing both the Mt PleasantBroadway and Mt Pleasant-Eglinton sites, the study looks at the Yonge-Eglinton intersection. In addition to being a centre, the area also falls under the avenue growth strategy and is currently undergoing a drastic change in density because of several new residential developments (Toronto Official Plan, 2010). Situated on one of the most recognized streets in the city, the Yonge-Eglinton intersection is also a significant transit point for the city. There is a major subway line that runs along Yonge Street and a connecting bus route which travels along Eglinton Avenue. Future plans for this area will also improve the current transit system with a new LRT line along Eglinton Avenue that will connect to the existing subway network. This will increase the number of commuters that pass through the area and bring more people into the neighbourhood, encouraging further development.

In addition to the importance of the transit node, Yonge-Eglinton has been experiencing rapid growth and population densification in recent years. Within the past five years, the neighbourhood has received 39,171 new inhabitants at a growth rate of $14.5 \%$, while the city's average growth rate for the same time period was only $4.5 \%$ (Poplak, 2012). The population increase indicates a large change in the area has taken place to accommodate such a high number of people in such a short period of time, which can also be experienced when walking through the neighbourhood. As one of Toronto's areas for densification, this expansion will continue. Thus, "in the coming decade we'll see up to 30 new towers, about 23,000 new people, and a few new amenities..." (Poplak, 2012) emerge in the neighbourhood. To understand just how much the Yonge-Eglinton area has changed in recent years,

Map 1 illustrates the neighbourhood in 1947, while Map 2 shows the present day neighbourhood. Within the time laps between the two maps, it is clear there has already been a significant amount of development, mostly along the main roadways, but also along the residential streets in favor of the mid-rise and high-rise towers over the single family home. 


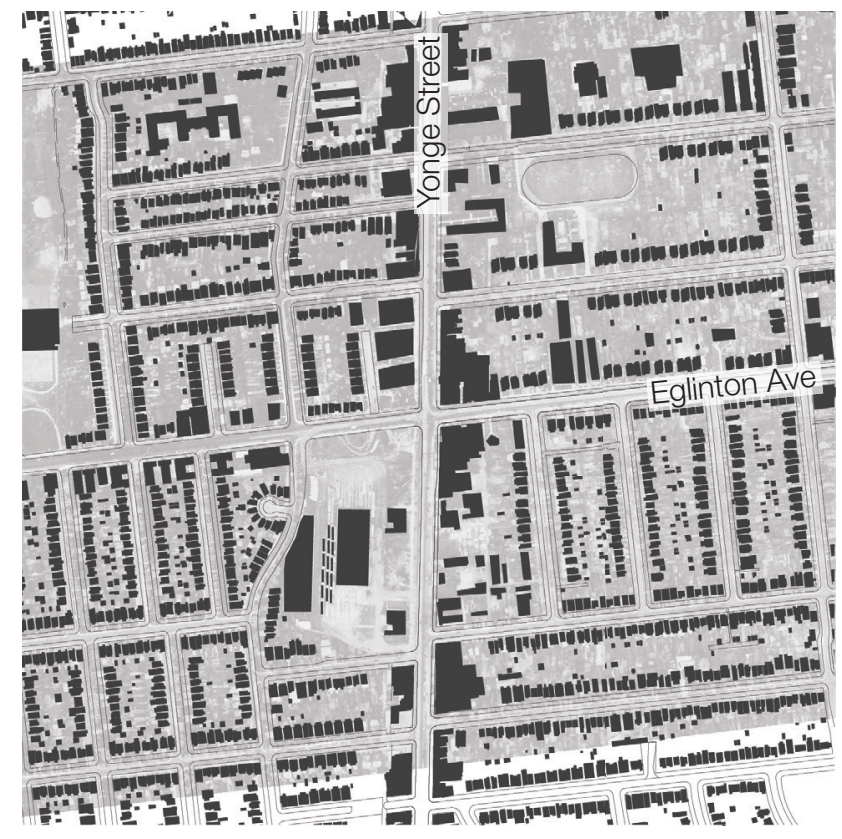

Map 1 Historic view of Yonge-Eglinton Neighbourhood in 1947, (Information collected from City of Toronto Archive, drawn by Sauder).
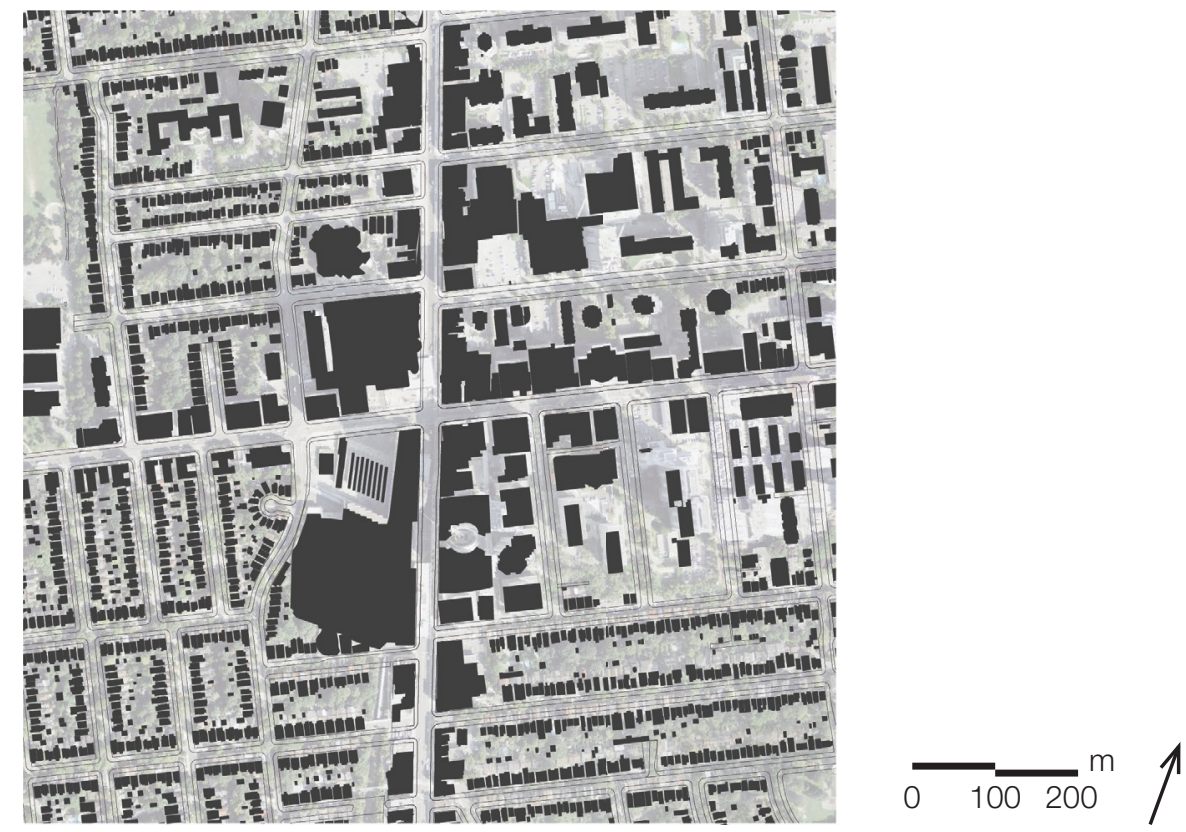

Map 2 Present day (2014) view of Yonge-Eglinton Neighbourhood, (Information collected from City of Toronto Property Data Maps, drawn by Sauder). 
As the two maps show the transformation over a period of time, the differences in physical density becomes very apparent. Map 3 continues to investigate the physical condition of the neighbourhood and implied volume of structures as it looks at building height and area. A majority of the density and volume occur along the two major streets, conforming to the city's Official Plan. Surprisingly, the development along Yonge Street is far less than initially anticipated. Except for the odd high-rise tower, Yonge Street is still occupied by many low-rise buildings that coincide with the scale of single family homes to the east. However, this will quickly change as new developments reach completion (Yonge-Eglinton Secondary Plan, 2010). Eglinton Avenue takes on a very different characteristic than Yonge Street and is already lined with tall buildings. The height along Eglinton Avenue and the NorthEast quadrant of the neighbouhood is primarily a result of residential apartment towers. Meaning the increased height is also accompanied with lower land-use intensity than the low-rise single family homes that occupy the rest of the neighbourhood. This concentrated physical density disconnects the human from the scale of the built environment and does not contribute to an improved urban experience.

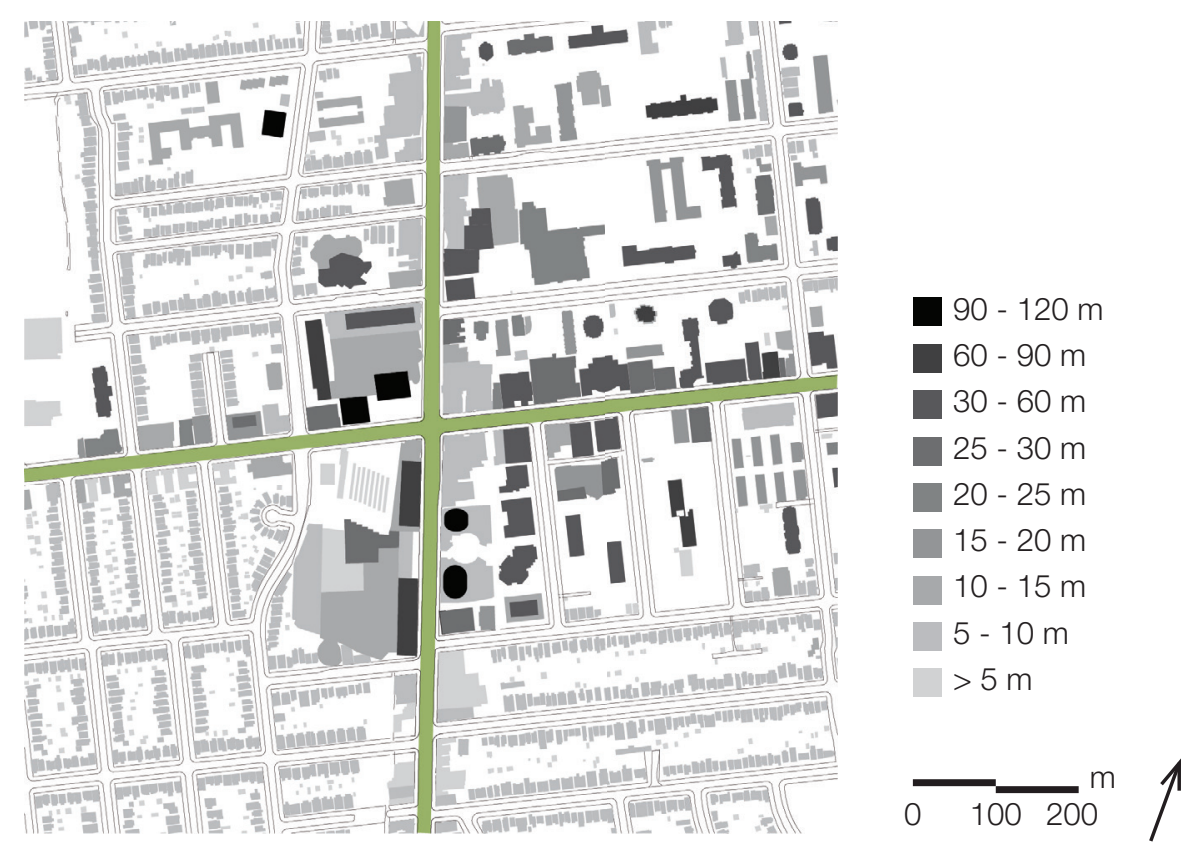

Map 3 Yonge-Eglinton neighbourhood physical density 2014, (Information collected from City of Toronto Archive, drawn by Sauder). 
Different from the physical density, Map 4 depicts land-use intensity and the amount of unbuilt land in the neighbourhood. Higher levels of development are found along Yonge and Eglinton which occupy each entire site to create a wall condition. This is likely due to the transit that runs along these streets and encourages traffic from daily commuters. However, moving away from the main roads, there is a very different form of land-use intensity. Here, two typologies form most of the physical environment, the single family home and the slab tower. Single family homes create a matt density-like feeling because of their narrow lots and setbacks. Contrary to this, the slab tower sites are more spacious and leave large portions of land open, following Le Corbusier's theories on the tower in the park. This would imply the neighbourhood's experiential density could be quite low in these areas because there remains a large portion of land left unbuilt. However, at ground level these open spaces are not as pleasant as expected. Instead of the beautiful open parks, they are all filled with parking lots to support tower residents.
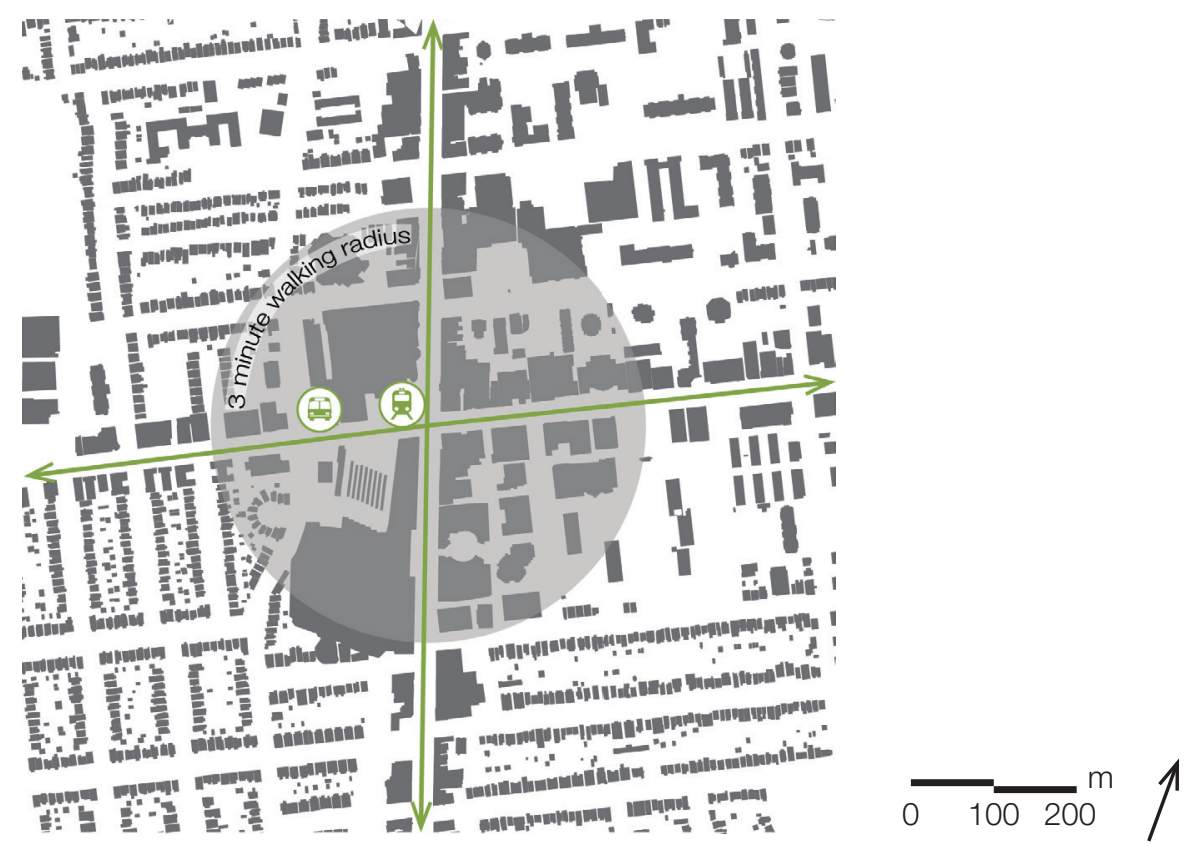

Map 4 Yonge-Eglinton Neighbourhood Land Use Intensity, (Information collected from City of Toronto Archive, drawn by Sauder). 
In addition to rapid growth and transit, the distribution of physical density and land-use intensity has also relied heavily on zoning regulations. As seen on Map 5, the Yonge-Eglinton neighbourhood can be broken down into Utility and Transportation, Residential, Commercial Residential, and Open Space designations. Commercial Residential, or mixed-use, sits along both Yonge Street and Eglinton Avenue where commercial tenants occupy the street level and residential units are located above. Mixed-use areas also coordinate with parts of the neighbourhood that are currently going through major redevelopment and introducing high-rise condominium towers. Also found along the major roadways is another zoning category titled 'City Ward' which is a designation that refers to the YongeEglinton Secondary Plan, or changes in regulations such as By-Law 569-2013-15 which introduces Commercial Residential Apartment zoning (City of Toronto, 2013). In these areas, the slab tower sites still remain untouched, while the Secondary Plan (2010) has encouraged a significant change in scale which has altered the experience and quality of the neighbourhood.

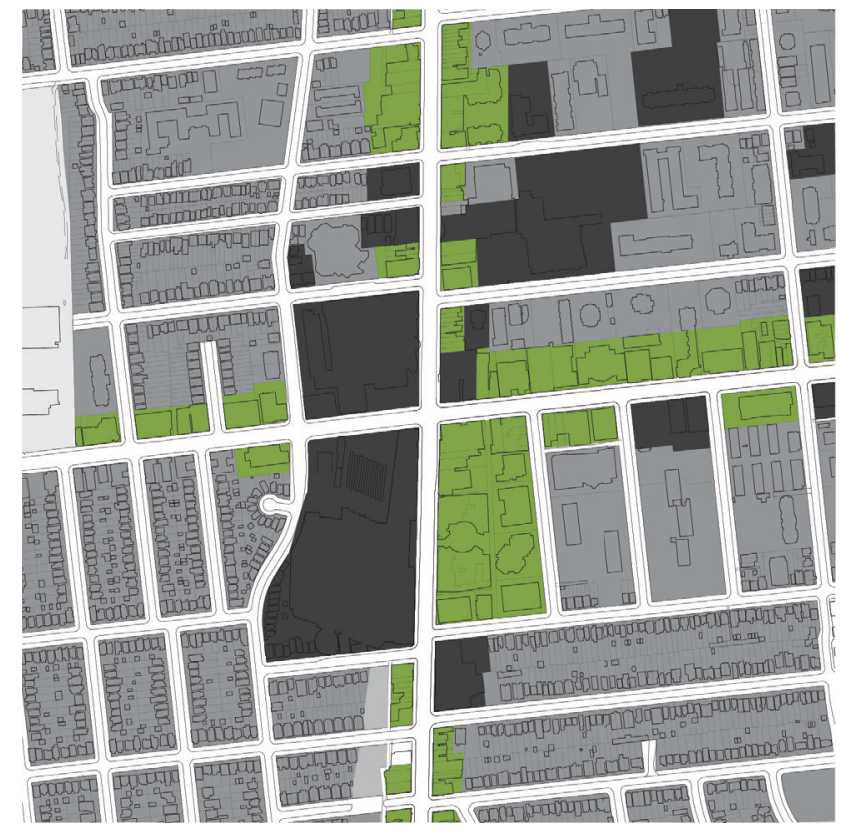

Residential

Residential Commercial

City Ward Open Space Utility and Transportation

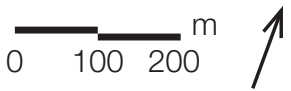

Map 5 Yonge-Eglinton Zoning Regulations, (Information collected from City of Toronto Zoning By-Law 569-2013, drawn by Sauder). 
Zoning changes and increasing density are also reflected in building elevations which tend to increase in mass and height as the population grows. Figures 14-16 compares the differences in physical form between the heavily developed mixed-use zoning and traditional low-rise residential areas to determine the effect it has on the pedestrian experience. Along Yonge Street (Figure 14-15), the buildings can be categorized under one of two scales, low-rise or high-rise. Reflecting the scale of Yonge Street's spacious right of way, the larger towers appear more appropriate for the major city road. Meanwhile, the low-rise commercial buildings also found along the same street appear dwarfed by the right of way, and disconnected from the adjacent high-rise towers. A lack of relationship between building scales needs to be improved by implementing transitional areas as suggested by Toronto's Tall Building Design Guidelines (2013) and illustrated in Figure 14-15. Not only will this help to mediate the differences in building height, it will help the street wall respond to the large right of way and create a more consistent walking environment. Moving further away from the primary intersection of Yonge-Eglinton, the low-rise building typology becomes increasingly common. Although this does not respond to the scale of right of way, the mixed-use programing casts fewer shadows on the sidewalk and has a stronger relationship to the human scale in comparison to the older slab towers which abruptly connect to the ground plane (Your City, 2014). The common lack of podiums in the neighbourhood also makes the condition worse, with nothing to transition the tower's height and enforce setbacks. Instead, one monolithic wall abruptly connects to the sidewalk where there is no longer low-rise retail. As the neighbourhood continues to develop, and more low-rise retail is replaced with point towers, the overall perception of the neighbourhood will become further removed from the pedestrian.

Unlike Yonge Street, there are more harmonious elevations found on the adjacent narrow residential roads in Figure 16. The elevation is composed of either single family or semi-detached, low-rise housing situated close together along the streets. The low-rise fabric brings abundant daylight into the street, leaving it feeling spacious and open. Also, the consistent building height and scale creates a comfortable perception that would typically be associated with low density. The only physical characteristic to suggest there may be a higher density then initially expected is the side setback, which is no greater than three meters. The differences between elevation in Hillsdale and Yonge Street make a clear statement about the overall effect the built form has on the experience of an environment. Promoting a variation of Allen's (2002) mat density will help maintain the quality found in the residential neighbourhood and enable the growing centre reach a density closer to that of a modern point tower. 
$-----\ldots--\ldots+-$
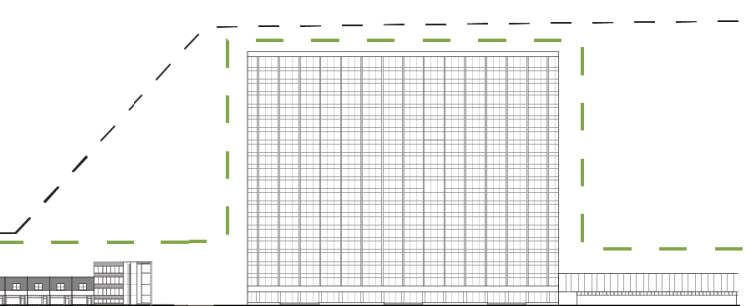

B
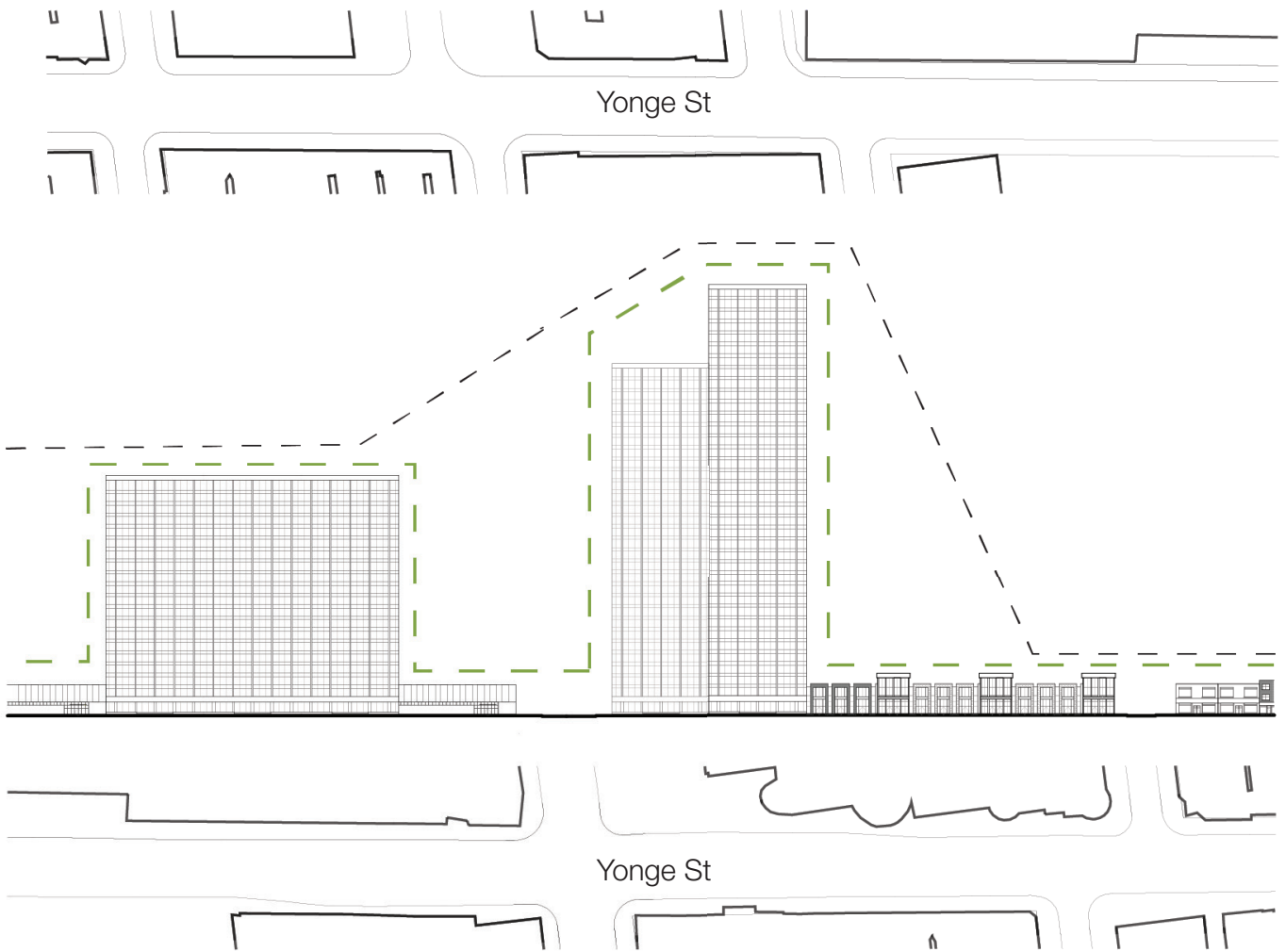

Yonge St
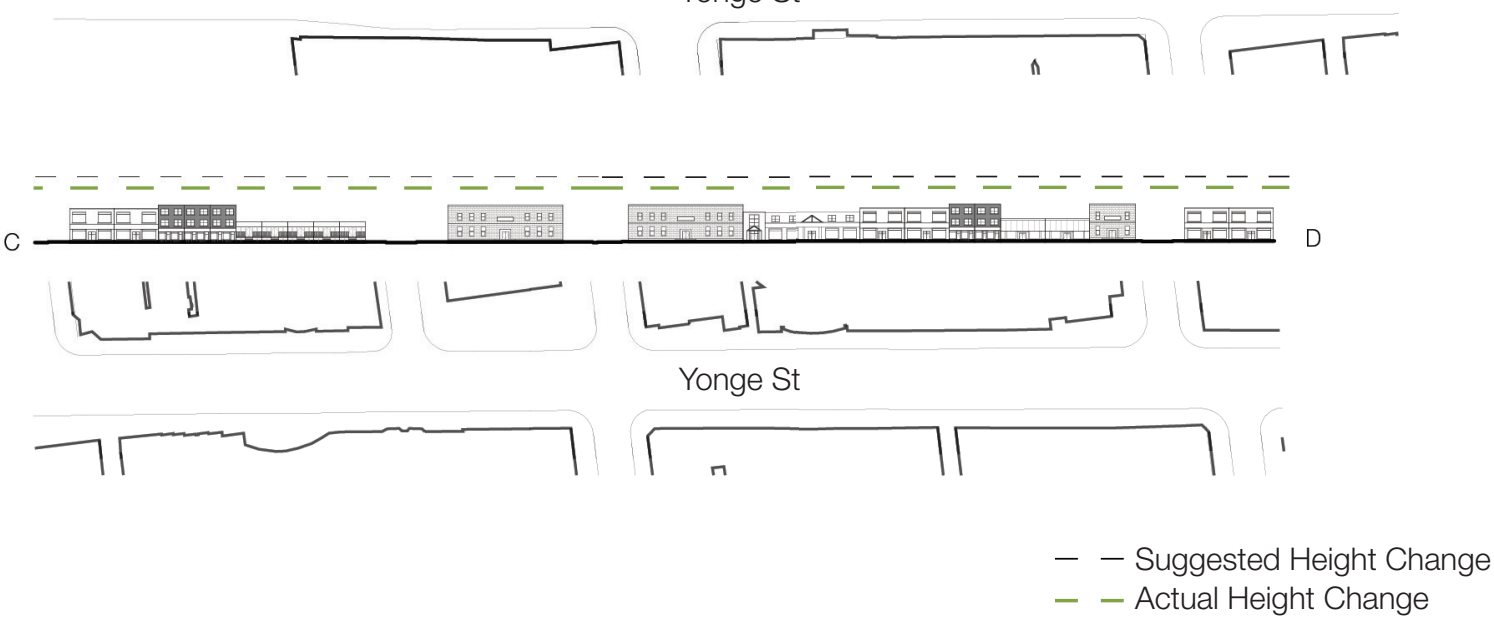

Figure 14 West elevation along the Yonge Street corridor, (Sauder, 2014).

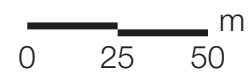



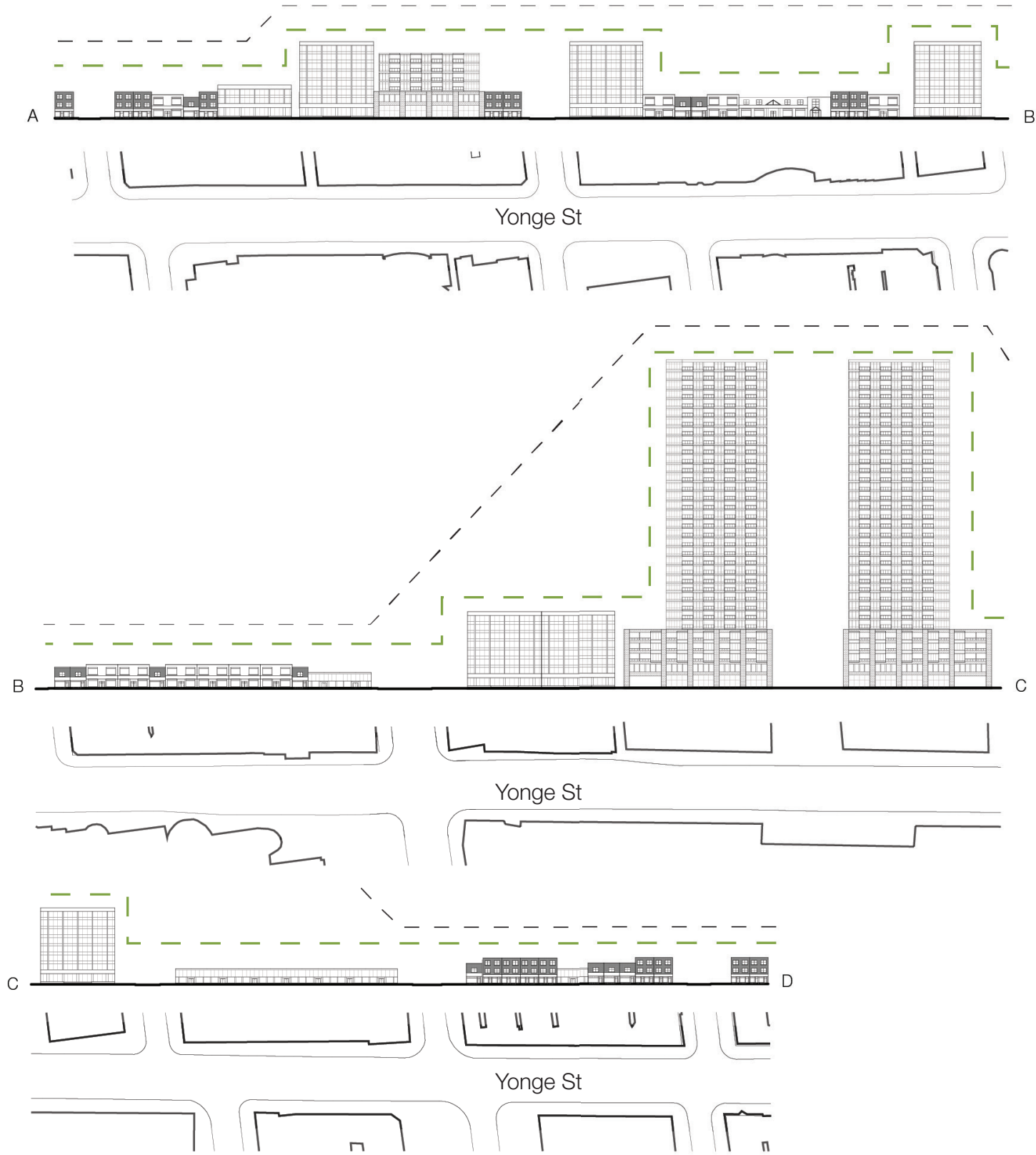

Figure 15 East elevation along the Yonge Street corridor, (Sauder, 2014).

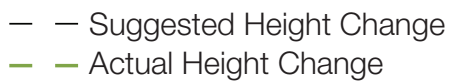

- - Actual Height Change

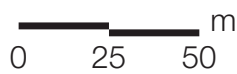




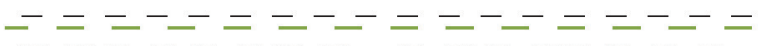

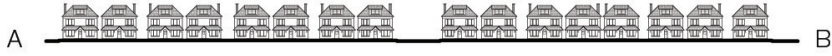

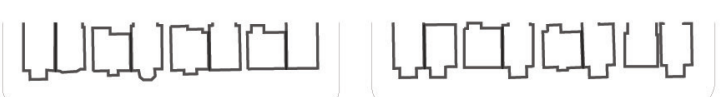 \\ Hillsdale Rd

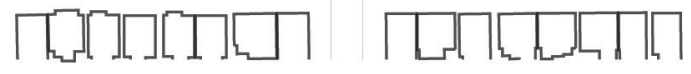

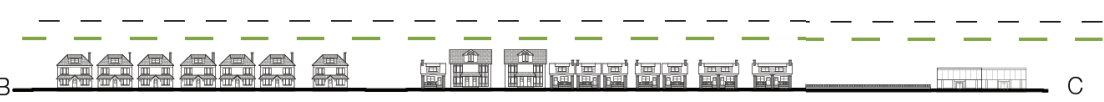

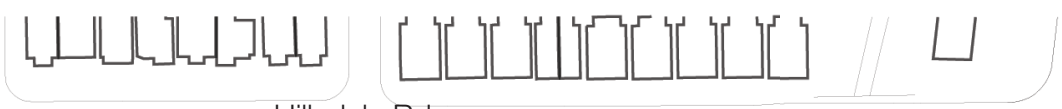

Hillsdale Rd

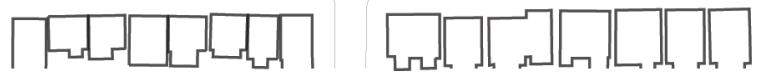

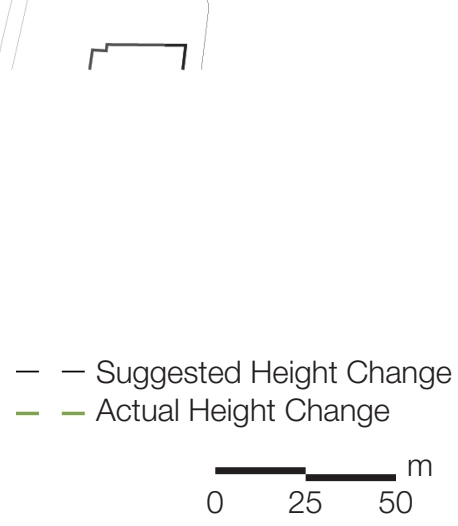

Figure 16 Typical residential elevation along the Hillsdale Road corridor, (Sauder, 2014). 


\subsubsection{A STUDY OF EXPERIENCE AND HUMAN SCALE}

Analyzing conditions of the Yonge and Eglinton centre from a neighbourhood scale create an overall understanding of experience within the urban fabric and challenges it faces. However, studying the area from the human perspective reveals there is still a lot to learn from the existing environment. Looking more closely at the individual structures that make up the pedestrian friendly and low-rise portion of the neighbourhood reveals that property setbacks are a critical component to the perception of an area. As illustrated in Figure 17, Toronto's zoning bylaws have influenced the spaciousness of typical residential streets by restricting the area a home can occupy. A front yard setback makes the public street appear much wider, while the relatively low height limits prevent shadows from being cast on the sidewalks and keeps buildings from looming over the pedestrian. The residential streets also use a typical building style, where variations in finishes and minor renovation are the only distinguishing feature of each home. In this manner, the city street is similar to typical suburban developments, where personal identity has been removed from the neighbourhood. Repetitious homes along the low-rise street also create a steady rhythm, but their small side yard setbacks of $1.8 \mathrm{~m}$, begins to impose a higher perception of density upon the otherwise spacious area.

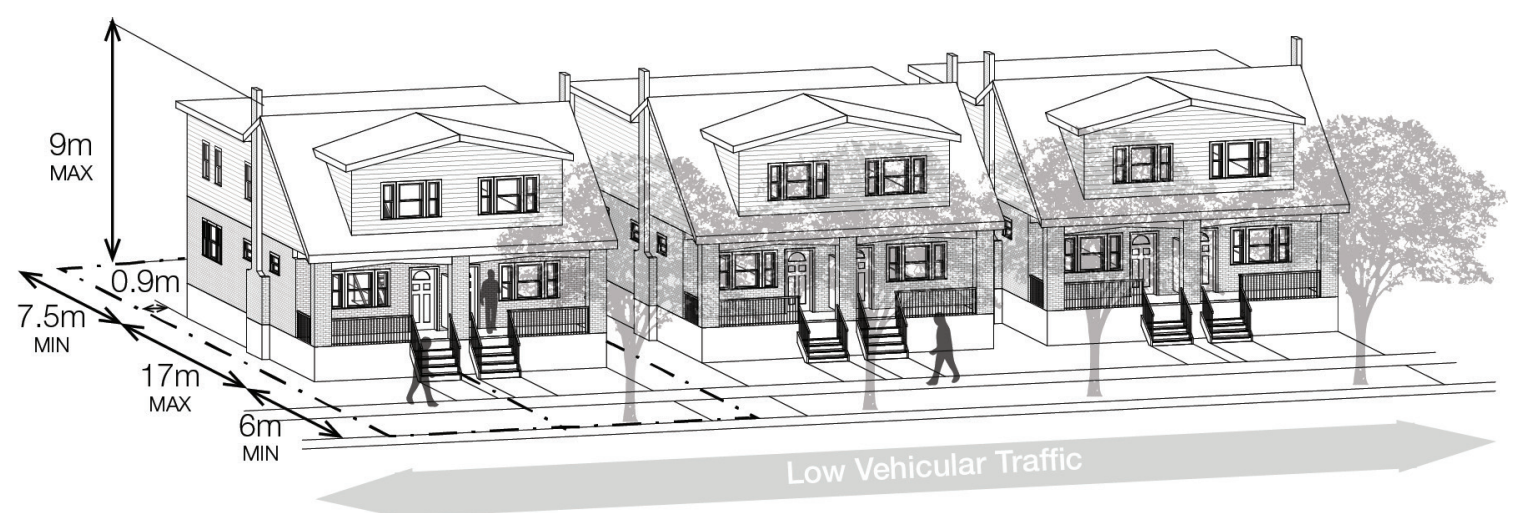

Figure 17 Setbacks along a typical residential neighborhood, (Sauder, 2014). 
The physical makeup of the mixed-use and commercial area is much different than the residential area. A variety of building typologies are found here, but the most common is the original two or three storey commercial store with residences above as seen in Figure 18. The low height of these structures is usually bellow the maximum restriction, leaving room for future developments to further densify the area without breaking any zoning regulations. Mixed-use buildings along the main avenues and streets also occupy the maximum land-use intensity possible, by building right up to the front and side edges of the property line. Only the rear is left with its minimum setback, and the mandatory three meter public allowance along the road is left unoccupied by the built form. The land-use intensity and proximity to adjacent structures would promote the idea of a high physical density, but the low building heights compensate for the compactness of the street.

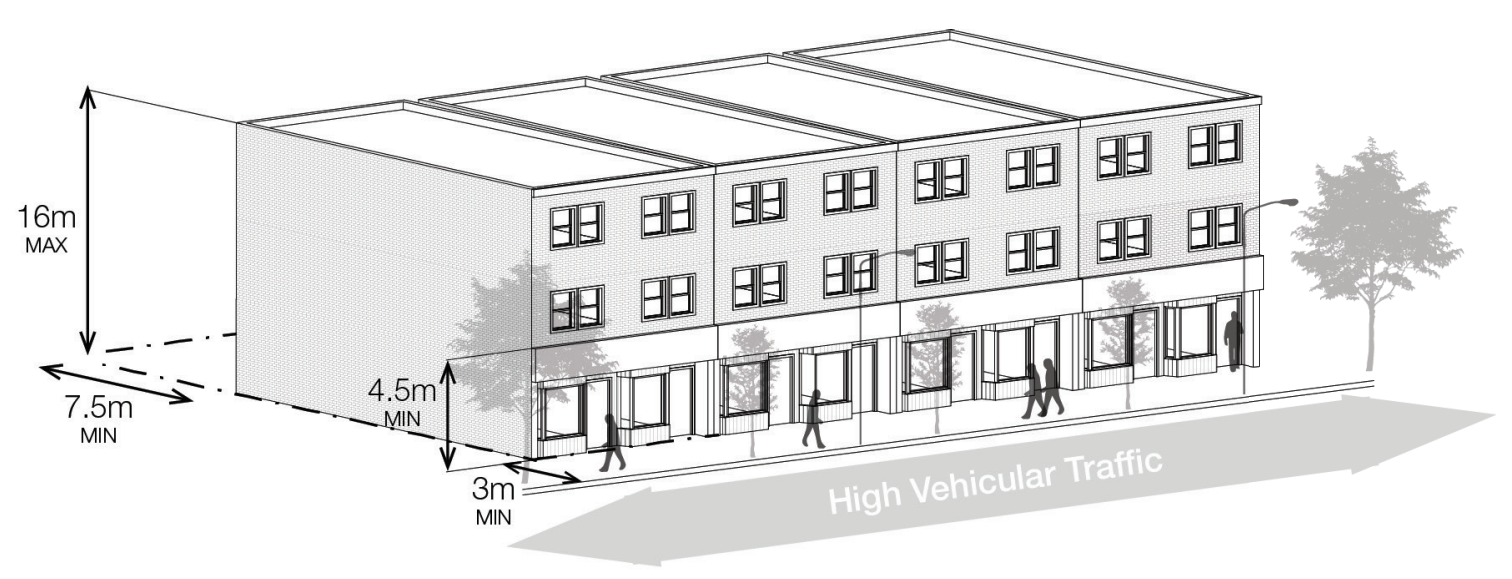

Figure 18 Setbacks along a typical low-rise commercial area, (Sauder, 2014). 
Characteristics and physical attributes of the individual building typologies also play an important role in defining the experience of a neighbourhood as they control lighting and privacy. As shown in Figure 19 , views from the street and sidewalk have been limited due to obstacles and shadows. The mature trees in front of every property provide the first layer of coverage and seclusion by restricting eyesight from the street into the home. Additionally, an elevated porch segregates the primary entrance from the public realm and acts as a buffer zone between the two spaces. Contrary to this, the many commercial establishments on the main streets have reduced or eliminated their buffer zone as a means of advertising and drawing people into the building (Figure 20). This major difference between the two neighbourhood zones is a result of the given program, but it also has a significant impact on the perception and sense of crowding. If the residences were as open to the streets as the commercial spaces, the inhabitants would begin to experience a lack of privacy, and the homes packed into small blocks could become uncomfortable.

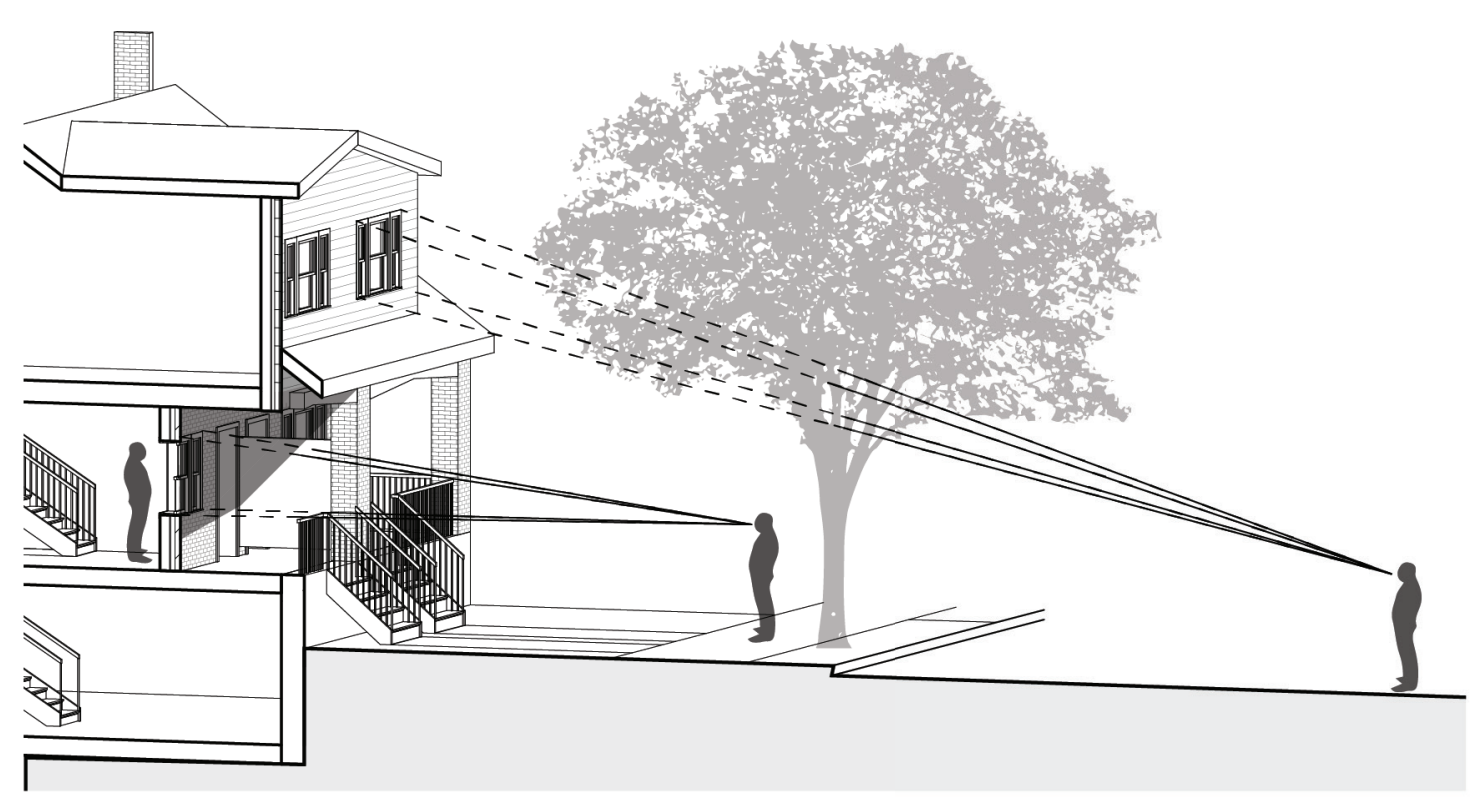

Figure 19 Privacy from the public realm in a typical residential context, (Sauder, 2014). 
Just as residential streets in the Yonge-Eglinton neighbourhood use architectural features to control privacy, so do the commercial and mixed-use areas seen in Figure 20. Unlike the residential areas however, the major roads have a very different perspective on privacy. Instead of blocking sight lines, the commercial space along Yonge Street attempts to open up the interior to the public realm. This is accomplished by eliminating the transitional zones and pushing the frontage of the building right up to the property line. Large windows and openings also flank the front facade to encourage pedestrians on the street to enter and purchase their products or services. Moving from the street level of the building, up to the residential units, the architectural responses change drastically. Windows are no longer large with fancy displays; instead the openings on the second and third floors are reduced in size. Downsizing the openings still provides light into the interior of the residence, and improves privacy from the busy street in a similar manner to the second floor of the residential street.

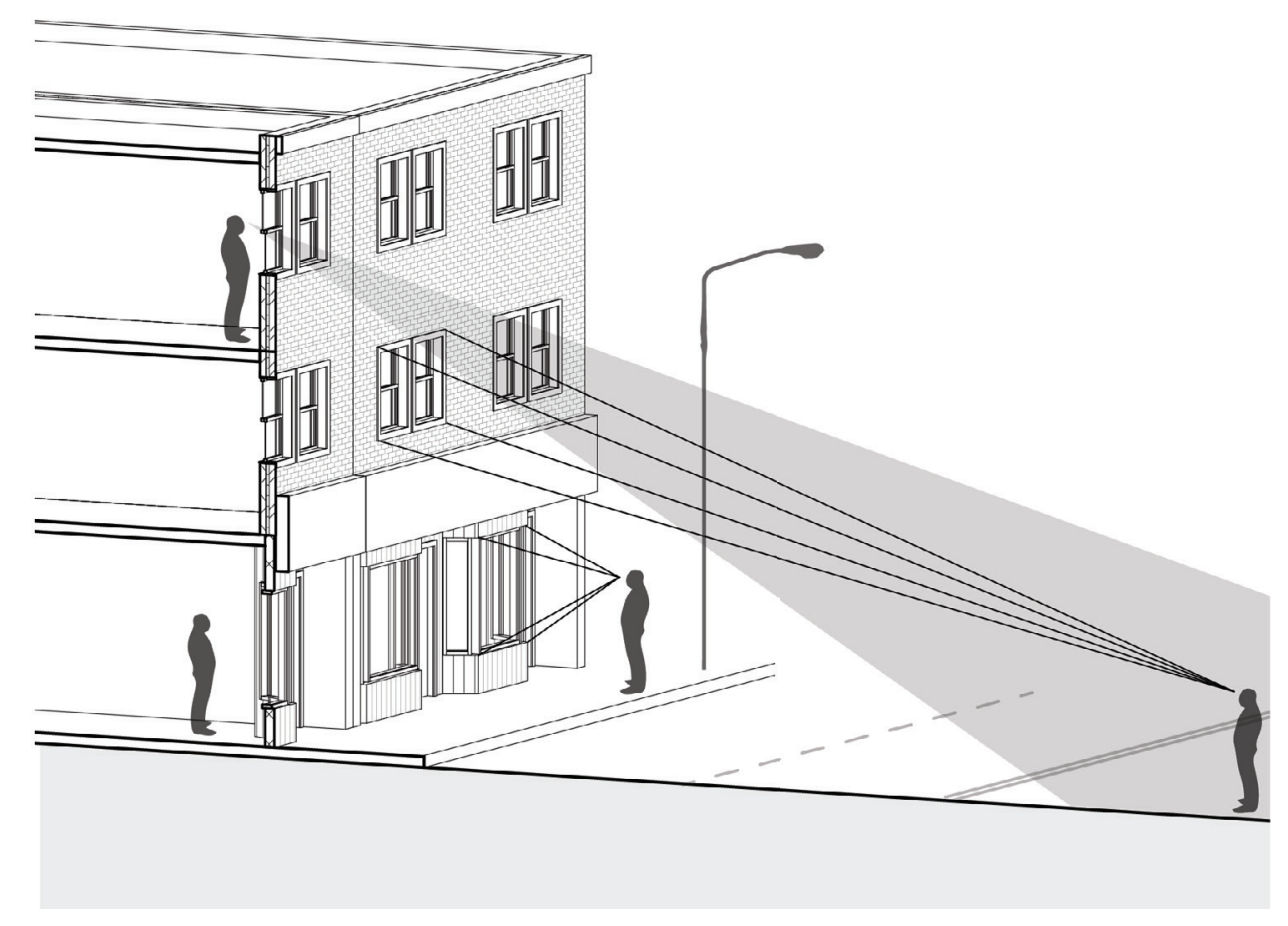

Figure 20 Privacy from the public realm in a mixed use context, (Sauder, 2014). 
Studying existing conditions of the Yonge-Eglinton centre reveals many interesting effects of scale and privacy on the pedestrian experience. The environment and function of an area also have a significant impact on the understanding of the built fabric and human interaction. Public oriented spaces tend to remove barriers that separate the interior environment from the street, while the more private residential areas attempt to enforce transitional areas and evoke privacy. However, both settings create walkable environment with setbacks for the pedestrian and low building heights which keep the streets feeling open. These conditions are far different from those surrounding the conventional slab tower, where large yards remove the building's entrance from the street and the scale overpowers the ground plane. 
5 DESIGN FACTORS FOR IMPROVING EXPERIENTIAL DENSITY 


\subsection{DESIGN FACTORS FOR IMPROVING EXPERIENTIAL DENSITY}

\subsection{DESIGN APPROACHES WITH A FOCUS ON EXPERIENCE}

Studying the Yonge-Eglinton centre has revealed how existing conditions impact the experience of the urban environment. However, there are other theories and approaches for increasing density that can also be reinterpreted to address the empty space within clusters of slab towers. The first of these approaches is discussed by Chakrabarti who believes "new surgical development remains critical to the rebirth of neighborhoods and the vitality of urban economies" (Chakrabarti, 2013). The City of Toronto also seems to have a similar perspective laid out in the Official Plan. "For the most part, future development will be built on infill and redevelopment sites and will need to fit in, respecting and improving the character of the surrounding area" (Toronto Official Plan, 2010, page 3-5). Both strategies seem to pressure new architectural interventions to densify the city with more people and activities, while maintaining the existing city fabric. This will require interventions to work with any remaining available land, such as the empty parks behind residential apartments, and create infill projects that respond to the direct conditions of the site. Of course it becomes difficult for larger developments which have more of an impact on the street and surrounding context because of their effect on lighting and wind conditions. Requiring the surgical interventions to increase physical density while also responding to the existing conditions of the urban context will require new developments to closely consider the effects of scale.

Scale arises in many different architectural projects that are working to increase urban density and improve the experience of each neighbourhood. This is particularly important in cities like Toronto where an abundance of high-rise towers are currently under construction and the population continues to grow. In response to this movement, the City of Toronto has released a statement to architects and developers noting that "tall buildings should respect the scale of the local context and display an appropriate transition in height and intensity especially when adjacent to areas of differing land-use, lower scale built form, and heritage properties" (Tall Building Guidelines, 2013, page 18). Following similar guidelines, Renzo Piano attempted to increase density of a London neighbourhood with a project called Central Saint Giles. Shown in Figure 21, the facade is broken down into smaller sections in an attempt to replicate the scale and rhythm of the surrounding buildings. However, the demand for an increased density in the London Plan forced Piano to make compromises in his design, which received criticism for being out of place in comparison to the surrounding low-rise townhouses (Building Design Online, 2010). Forcing the building to inflate in height and mass, undermined Piano's ambitions to break up the facade and have the development tie into the scale of the surrounding context. 


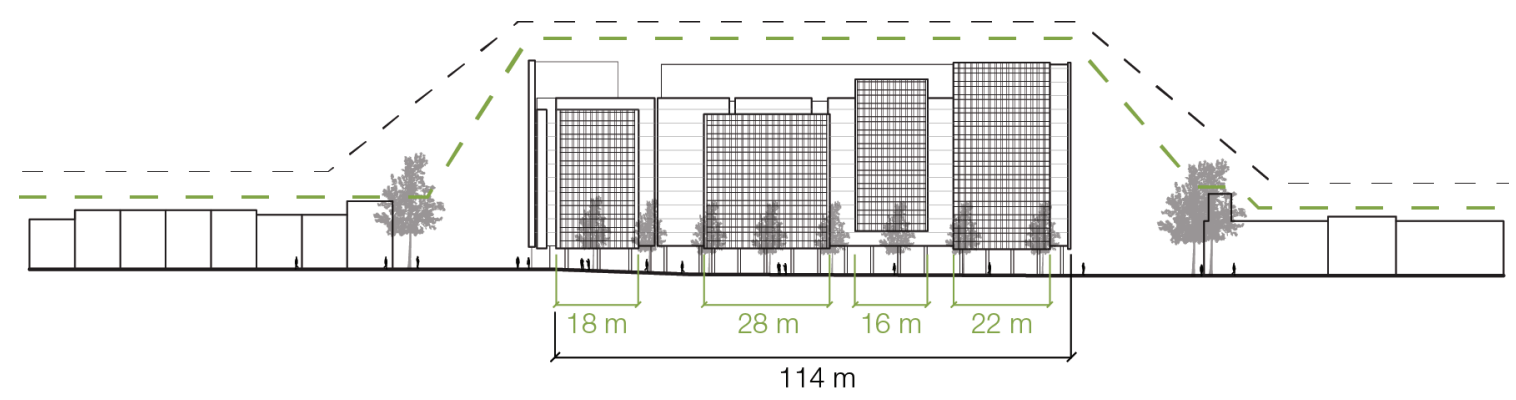

Figure 21 Elevation of Renzo Piano's Central Saint Giles in Relation to the Surrounding Context , London, United Kingdom (Sauder, 2015).

Closely connected to the effects of scale in a dense urban environment, natural daylight also has a significant impact on experience of interior spaces, the street life, and the surrounding buildings. "When poorly located and designed tall buildings can physically and visually overwhelm adjacent streets, parks and neighbourhoods, they can block sunlight, views of the sky and create uncomfortable wind conditions in adjacent streets, parks and open spaces and cause traffic congestion" (Toronto Official Plan, 2010, page 3-8). Infill projects between residential apartment blocks will have to be particularly cautious of this condition because of the multiple towers that sit on one site and block a large portion of natural daylight. This overshadowing, which is primarily a result of location, scale, and massing is often addressed through setbacks and height restrictions (Haupt and Berghauser Pont, 2010). Despite these regulations there are still many conditions where high-rise towers cast shadows on neighbouring low-rise areas. Considerations on the effects of daylight are present in every project, but it is particularly important in high density areas due to its impact on spacial experience. This is discussed by most projects featured in High Density Housing Architecture (2009) that use daylight in the interior to make the small spaces feel bigger and benefit the health of the inhabitants. So in addition to the massing of the development and surrounding context, elements such as orientation, openings, and reflections are all critical in creating spaces that are pleasant for inhabitants and removing the sensation of crowding. 
Site selection, scale, and lighting all play a significant role in forming an experiential density which can promote an enjoyable environment, or make it seem overpopulated. Density itself is not a bad thing, nor do people mind living in dense environments, instead overcrowding is what people are generally concerned about (Bascaramurty, 2012). But how does architecture respond to overcrowding? A sociological study discussed in Densityarchitecture: A Study on High Density Residential Architectures (2013) believes crowding is only a sensation resulting from negative experiences and a lack of privacy. To remedy this, designers should look into ways that allow users to have control over their space and interact with the public realm. In Toronto, a typical response to privacy involves segregation and regulations controlling the level of separation which takes the form of: setbacks, openings, gates, or even long homogenous hallways in a high-rise tower. Despite the importance of privacy in forming the experience of a space, architects also need to ensure there continues to be a level of social interaction to prevent complete isolation (Bascaramurty, 2012). A possible solution could involve giving residents control over filters that segregate themselves from the street, or by providing a space that can act as a barrier and transition between the public and private areas. This would help maintain a level of spaciousness and control that would help prevent residents of densely populated areas from perceiving the space as overcrowded.

In addition to these architectural notions - infill, scale, lighting, and privacy - there are also important planning strategies that influence the design of future developments within a dense urban environment. The first strategy develops infrastructure needed to sustain expanding neighbourhoods. "Sustainably requires us to think holistically, and this is as true of a city's infrastructure - the 'urban glue' that holds the city together - as it is of its architect" (Chakrabarti, 2013, page13). In each project, architects are able to cater to the public realm which will eventually have an overall impact on the greater urban environment. Using infrastructure and public amenities in a design can stimulate social interaction in the street or generate a stronger social mix throughout the neighbourhood. Rogers believes that "when buildings contribute to the public realm, they encourage people to meet and converse. They engage the passer-by. They stimulate rather than repress people's natural human potential" (Rogers, 1998, page 74). Social interaction between people can occur in various places controlled by the architect, such as small gardens or yards, outdoor seating areas, ground level storefronts, courtyards and many other physical spaces. These small scaled pieces of infrastructure and amenities are especially evident in urban areas where parks are more sparse and things like "plazas, pedestrian corridors, courtyards are going to be the kind of open spaces that you see" (Bascaramurty, 2012). Influencing these areas can improve the general experience of the public realm while also deterring from the sensation of overcrowding in dense environments. 
Density's influence on the urban environment also encourages mixed-use communities, which directly extends from the development or new public space. Mixed-use communities have been discussed by Calthoroe and Lerup, Chakrabarti, Duran, Haupt and Berghauser Pont, Kirkman, O'Toole, and Scallan, some in depth and others very briefly, but it always has an important role in forming a healthy densified area. This is particularly important to the Echo Boomers discussed by O'Toole (2013) who claim the growth in population is a result of walkable cities and areas where urbanites can live close to their work and social gatherings. Cities like this have "thriving neighborhoods with a strong sense of community; it mixes living and working and has a messy vitality; it has an incredible park, as well as other smaller green spaces, and an extraordinary range of culture and civic amenities close at hand; it has an excellent public transportation system; car ownership is very low; and it is natural to walk or take the subway, which is faster than driving" (Chakrabarti, 2013, page 11). More and more of these types of communities are developing along major avenues and streets, particularly around transit stations. Hence, it is expected that the same areas will continue to densify and the amenities that come with a mixed-use community will support this growth. 


\subsection{RELATIONSHIPS BETWEEN EXPERIENCE AND DENSITY}

Views supporting mixed-use communities, public infrastructure, abundant daylight, proper scale, and surgical infill development are expected to create a lively experience within the urban environment. However, each notion must be placed in context of the slab towers to understand the specific relationship to each type of density: experiential, population, physical, and land-use. Illustrated in Figure 22 the complex relationships form a web where architectural elements influence physical density and land-use intensity, while planning strategies are more effective at drawing people to the specific neighbourhood. In some way, each component illustrated in the web comes back to the overall experiential density and each person's interpretation. "Depending on a range of individual and sociocultural factors, a person (inhabitant, or visitor) will evaluate and react differently to [experiential] density" (Berghauser Pant \& Haupt, 2010, page 79-80). To ensure that each individual has a pleasant experience while increasing density around residential apartments, it is critical for the design choices to accentuate the human scale between the overbearing towers. Natural daylight must also be able to reach each interior space as the physical density increases; otherwise the pedestrian will feel overwhelmed by the adjacent building heights.

In addition to characteristics required to improve experiential density around clusters of slab towers, physical density on the site will also have to be increased to accommodate the growing population. Since there is an abundance of open space surrounding the towers, as criticized by Steward, Thrope and McCelland (2013), increasing land-use intensity is the most effective method for acquiring additional physical density. Generating this area by surgically placing low-rise infill around slab towers will maintain the existing urban fabric, which is considered ideal by Toronto's Official Plan (2010), and form an environment that is better scaled to the experience of a pedestrian. Scale's relevance also extends to the height and width of slab towers which have the potential to block a significant amount of sunlight from the ground. Haupt and Berghauser Pont (2010) make it clear that lighting is an essential component in generating physical density and preventing the sensation of overcrowding, so the new infill needs to avoid being situated in a shadowed area. This will likely result in the formation of voids on the site which could become the kind of public spaces like plazas, courtyards, and walkways that Bascaramurty (2012) discusses. In addition, outdoor areas can form parks and landscaped zones to activate the site and facilitate a mixed-use program (Gehl, 2011). Together, these approaches form an understanding of how experience and new development can come together to improve the current conditions surrounding residential apartment towers and increase density. 


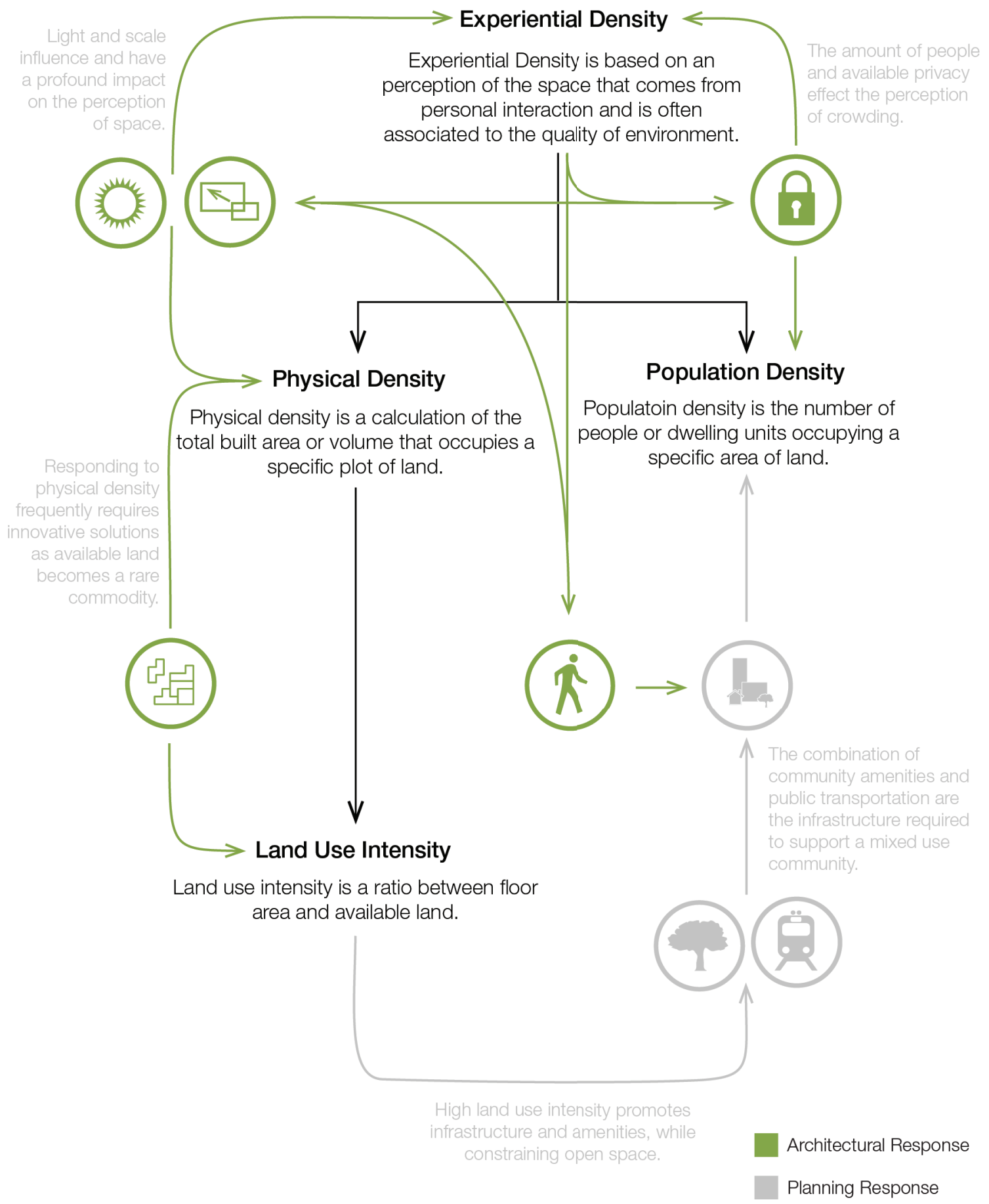

Figure 22 Architectural and planning principles that effect key forms of density, (Sauder, 2014). 
6 STRATEGIES FOR GENERATING EXPERIENTIAL DENSITY AROUND SLAB TOWERS 


\subsection{STRATEGIES FOR GENERATING EXPERIENTIAL DENSITY AROUND SLAB TOWERS}

General relationships between various forms of density and design ideals, along with the understanding of existing conditions in Toronto's growth centres illustrate several key themes that impact the experience of density in the urban environment. These similarities range from walkability, scale, mixeduse programming and amenities, landscaping, setbacks, privacy, and infill to name just a few. All of these concerns can be treated universally when generating higher levels of density in Toronto. However, when it comes to improving experiential density within the many residential apartment sites that are spread across the city, these identified approaches must be applied in a very specific manner to address the particular conditions found around slab towers. Conditions include, but are not limited to: the shadows cast from the tower, empty side walls found on many slab buildings, large side yards that disrupt the street wall's continuity, long uncomfortable walking distances, distinct breaks from a common property line running down the centre of the block, vast unused open spaces, abrupt transitions from tower to grade, and an uninviting ground plane. These concerns, along with the more general approaches to creating quality environments and additional density can be brought together and formulate a set of clear strategies that address Toronto's residential apartment blocks. The resulting group of strategies include: Fragment, breaking down the urban block; Activate, creating scaled outdoor courtyards to attract visitors and program diversification; Infill, generating additional physical density; and Mediate, transitioning between extremes. Together, these will maximize the city's efforts to grow and the best possible use of Toronto's remaining open land. 


\subsection{FRAGMENT}

The first of four strategies to address experiential density between slab towers is Fragmentation. Aiming to reduce the large scale of the site into more walkable distances, fragmentation breaks down the urban block using multiple pedestrian pathways. Shown in Figure 23, a primary street is introduced and divides the larger block in half along the shared rear property line (as discovered in the initial residential apartment typology analysis) and secondary pathways cut perpendicularly through the tower's large side yards. Spaced at intervals similar to nearby low-rise residential areas, the secondary pathways also helps to puncture the long monotonous sidewalk along city roads and further increases the access points into the site's interior. The combined network of pathways begin to occupy the unused space inside of the cluster of residential apartments and alleviate the current sensation of abandonment common to these types of urban blocks. Additionally, new circulation routes create shortcuts residents can use to move through the neighbourhood and interact with a rather isolated building form.

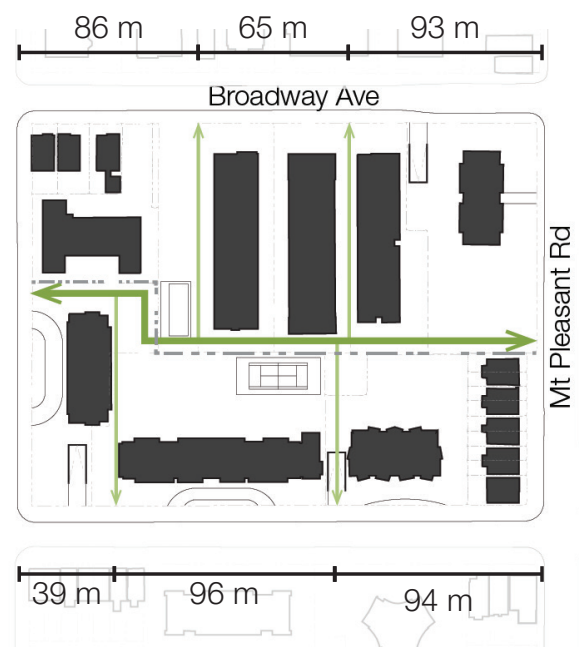

MT PLEASANT AND BROADWAY

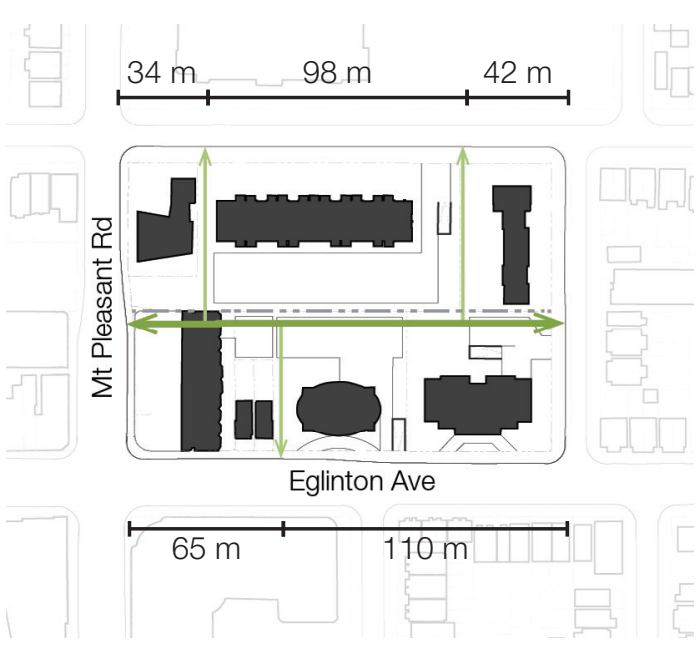

MT PLEASANT AND EGLINTON
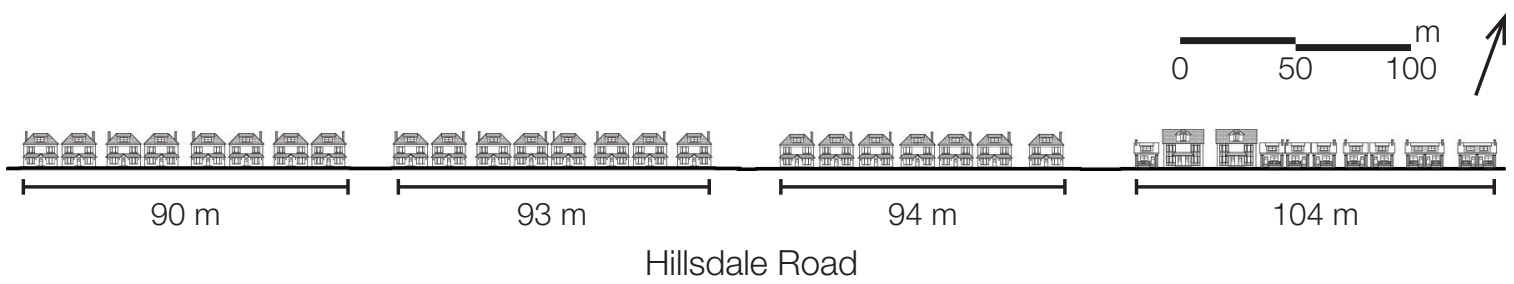

Figure 23 Fragmenting the Urban Block, (Sauder, 2015). 
Creating a pedestrian friendly environment away from the busy street traffic requires new design standards to enforce characteristics that respond directly to human experience. To create this, the primary pedestrian street will require a right of way no less than nine meters to abide by Ontario Building Code (2006) regulations, however the space must not be left as an empty road. Instead it should be bordered with vegetation, seating, varying paving textures, and shaded areas to maintain an active and lively environment where residents of the surrounding towers will want to spend their time. Secondary pathways also require similar characteristics and experiential qualities to the primary pedestrian street, but at a reduced scale to suit the peripheral nature of the circulation. Looking at precedents shown in Figure 24, narrowing the width of secondary paths still maintains a comfortable walking environment and permits an increased land-use intensity by reducing the area required for public use. Additionally, the restricted width slows the pace of traffic and encourages the general public who are using the block as a shortcut to travel along the primary street. Thus narrowing the right of way creates an ideal network to occupy and break apart the overbearing scale of the existing urban block occupied by a cluster of slab towers.

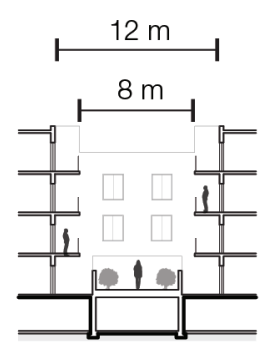

26 Laidlaw St Toronto, Canada

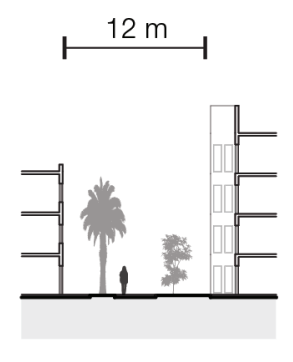

Pacific Cannery Lofts Oakland, United States

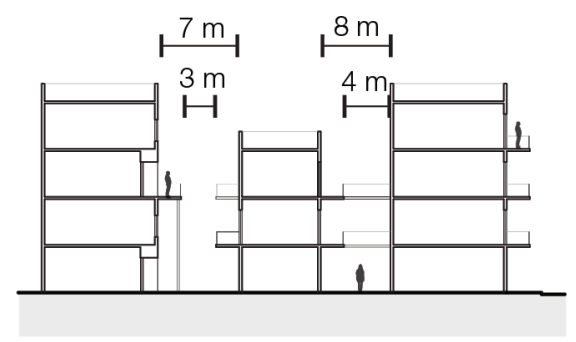

Harold Way Apartments Los Angeles, United States

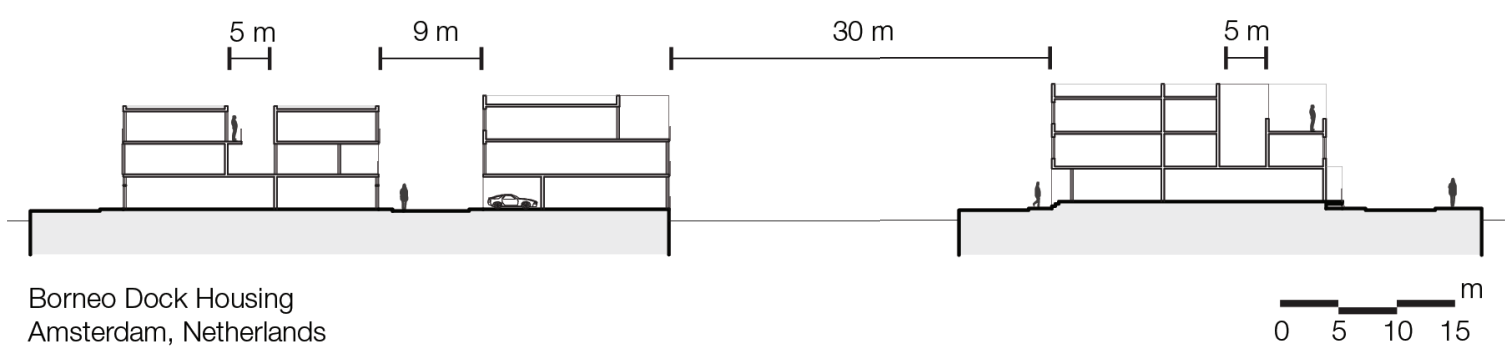

Figure 24 Pedestrian Street Precedent Study, (Sauder, 2015). 


\subsection{ACTIVATE}

The second strategy applied to clusters of residential apartments is Activate, which involves occupying the unused space between slab towers with multiple courtyards that each have a unique character (Figure 25). Sitting at intersections of pedestrian circulation, these outdoor spaces are much better suited to human scale in comparison to the previous open fields and also encourage the general public to spend time within the interior of the urban block. Differing from the pathways themselves, each courtyard should have a distinctive experience to slow the pedestrian movement and act as a gathering area. Whether this is done through changes in programing, materiality, lighting, size, height, or boundary is all dependent on the specific site and neighbourhood conditions. However, a focal courtyard should be located close to the entrance of the primary pedestrian street to entice people into the site and service larger public gatherings. Lighting and shadows cast from adjacent towers will also have a profound impact on the overall experience of each area. A courtyard placed in direct sunlight can create a livelier environment, while the shadows would form a much more cool and relaxed atmosphere. Once the courtyards have been strategically placed and programmed to give each a unique identity and function on the residential site, it becomes a new type of amenity for the residents of the residential towers as well as an asset to the community. Additionally, as the residential apartment block increases in density, these active outdoor spaces will help to generate a comfortable environment and improve the quality of living conditions for the residents.

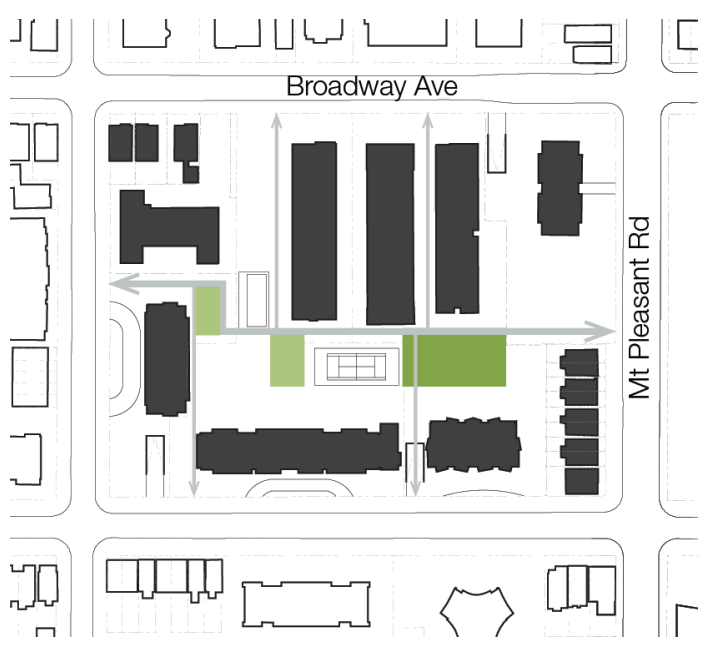

MT PLEASANT AND BROADWAY

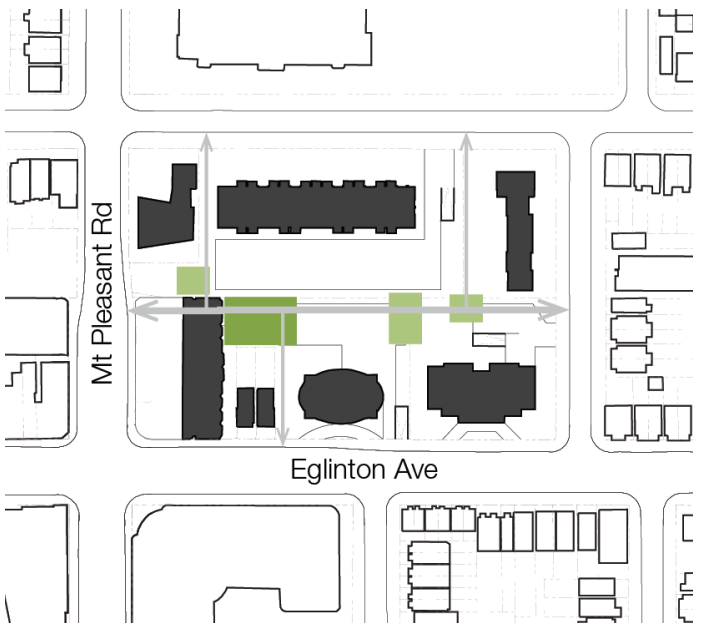

MT PLEASANT AND EGLINTON

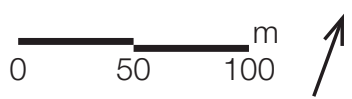

Figure 25 Activate - Placing Courtyards on the Urban Block, (Sauder, 2015). 


\section{$6.3 \quad$ INFILL}

Following the layout of pathways and courtyards, the third strategy involves Infill. This is the most important of the four different strategies for increasing the physical destiny around a slab tower. Infill becomes a surgical procedure where a project leaves the existing components intact (the slab towers, pedestrian streets and pathways, and courtyards) and occupies the remaining voids. Shown in Figure 26, the new structures create a physical wall that borders and defines the new public outdoor spaces in the centre of the block. Transforming the unused park space, the defining wall brings life to the pedestrian street as the infill is occupied with new mixed-use programming and population density increases. Again, light and scale play a critical role in determining how infill will influence the human experience. To prevent any more harsh shadows, the new buildings will need to be low or mid-rise and stepped back in areas to allow for greater light penetration. The scale of infill should also correlate to the existing slab towers and function similarly to a podium by creating a transition in height that is more appropriate for the pedestrian. Ideally, manipulating heights and step backs of the new infill will produce a variety of areas within the site's interior where the surrounding tower's presence are blocked from view, encouraging an immersive environment where the experience is focused on the ground plane.

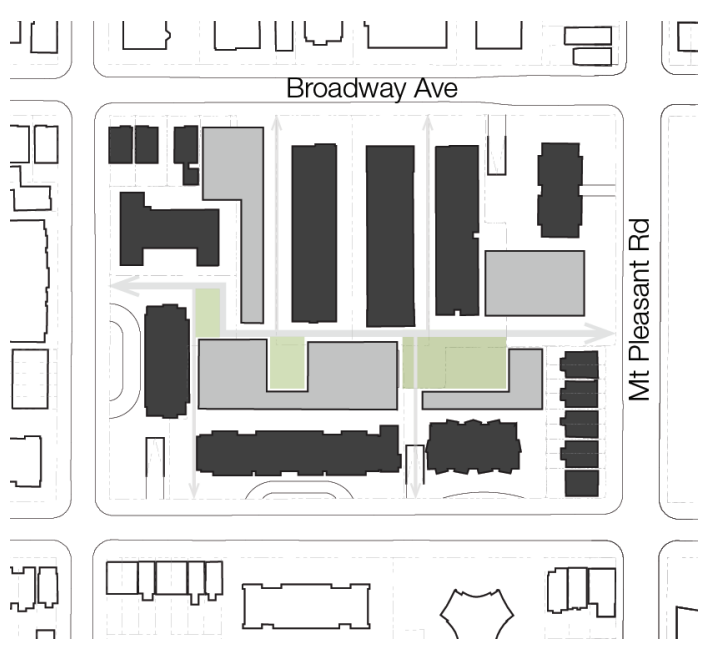

MT PLEASANT AND BROADWAY

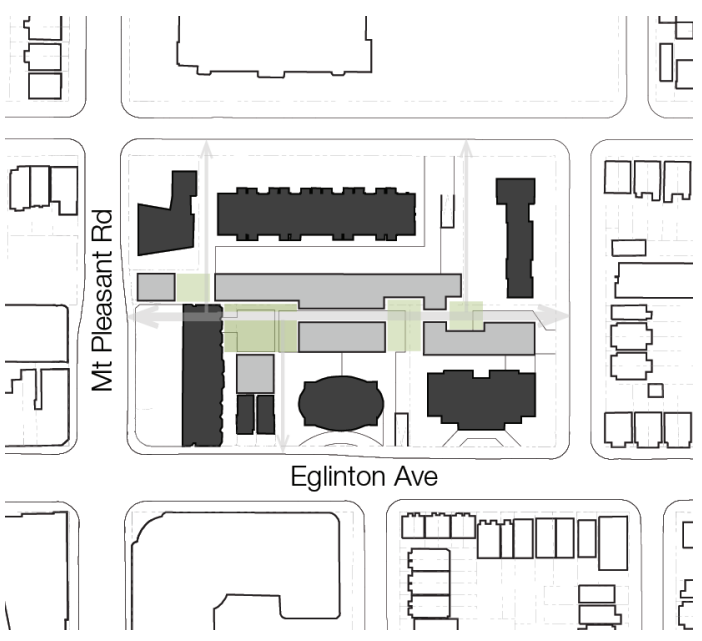

MT PLEASANT AND EGLINTON

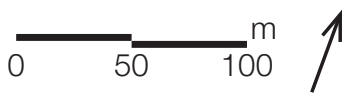

Figure 26 Infill - Creating a Boundary Wall, (Sauder, 2015). 


\subsection{MEDIATE}

Mediate, the final strategy brings together many of the concerns that are found in theory around density. Applicable in a variety of areas throughout residential sites, mediate primarily refers to the separation between two spaces within the project. Approaching the cluster of towers, the separation between the city street and primary pedestrian pathway are the first areas where the strategy comes into play. Entrances should draw traffic into the centre of the block, while also creating a transition where the hectic car orientated environment is left behind to be immersed in the calming interior. Illustrated in Figure 27, the second area mediation becomes applicable to is the distances between the pedestrian circulation and infill. With each low-rise building entering at grade, privacy for residential units and accessibility for commercial/office units becomes a concern. Therefore, setbacks that reflect proportions of front yards found in the low-rise residential neighbourhood study (refer to Figure 17) can

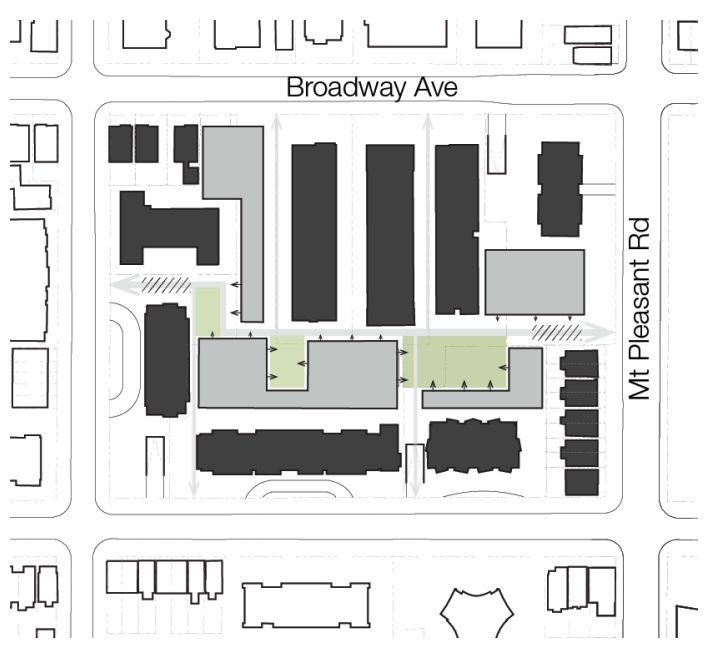

MT PLEASANT AND BROADWAY

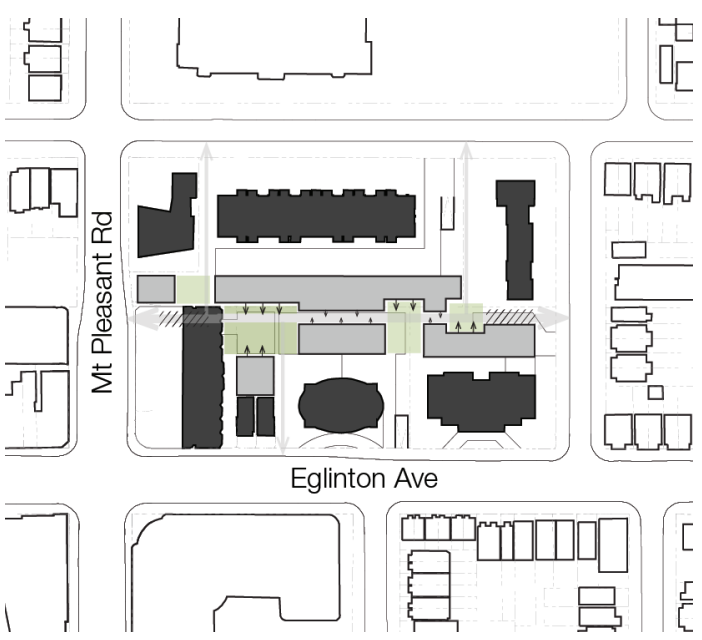

MT PLEASANT AND EGLINTON

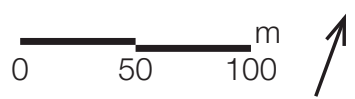

Figure 27 Mediate - Transitioning Between Two Spaces, (Sauder, 2015). 
mediate between the two spaces. Additionally, elevating and recessing entrances as seen in Figure 28, or implementing vegetation can also be used as a tactic for privacy by physically separating the unit's entrance from the pathway. Ensuring this type of environment is created allows the inhabitants to feel secluded in their own space and prevent overcrowding as density increases. Contrary to the residential units, the commercial/offices require a transition between the unit and pathway that will encourage people to enter. Here previous studies suggest a small setback that becomes part of the public realm using paving, landscaping, or various other design elements. Incorporating the setback for the mixed-use programming into the pedestrian street, allows these units to directly interact with the public space and further enhances the experience of the urban block.

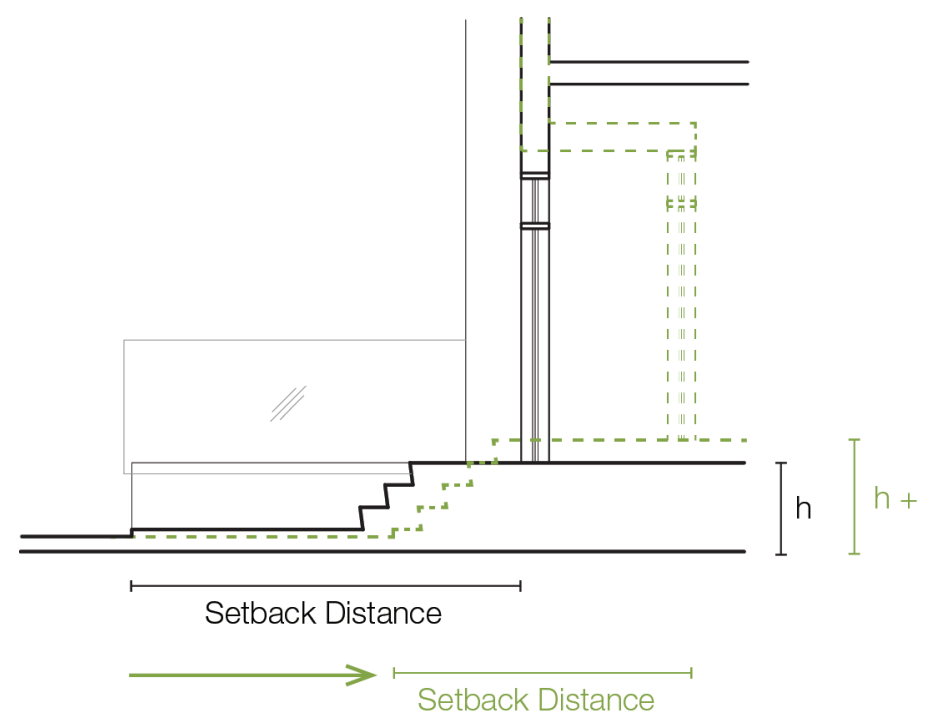

Figure 28 Creating Additional Privacy for Residential Units, (Sauder, 2015).

Together, the four different strategies-fragmentation, activate, infill, and mediate-generate the major approaches to addressing experiential density within the residential apartment block. However, within each of these strategies there are many subtopics that deal with other aspects of generating quality spaces in the urban environment including: privacy, pedestrian realm, reintroducing a strong landscape, lighting, and scale. Combining all these different topics into an approach for densification form the requirements for universally increasing density on the four residential apartment block studied earlier, as well as other clusters throughout the city. 
7 IMPLEMENTING EXPERIENTIAL DENSITY:
DESIGN PROPOSAL 


\subsection{IMPLEMENTING EXPERIENTIAL DENSITY: DESIGN PROPOSAL}

\subsection{SITE SELECTION AND ANALYSIS: MT PLEASANT AND EGLINTON}

The four strategies - fragment, activate, infill, and mediate - are intended to form a type of density which focuses on the human experience and can be universally applied to various centers throughout Toronto that also contain clusters of slab towers. Now after applying the strategies on two sites, the thesis will select one block of residential apartment towers to develop in more detail. From the four clusters of residential apartment, the Mt Pleasant and Eglinton block (Map 6) has been selected to test the fragment, activate, infill, and mediate strategies because of its proximity to the earlier Yonge and Eglinton neighbourhood study. The analysis showed that this area is located within two of Toronto's growth areas, avenues and centres, and is rapidly being developed and densified. Additionally, this site falls on the proposed light rail transit line that will be running along Eglinton Ave, with a stop at the Mt Pleasant intersection. This causes the site to be within proximity to a major transit hub, which is considered an ideal condition by authors like Kirkman (2010), who talk about density and improving the experience of the urban environment.

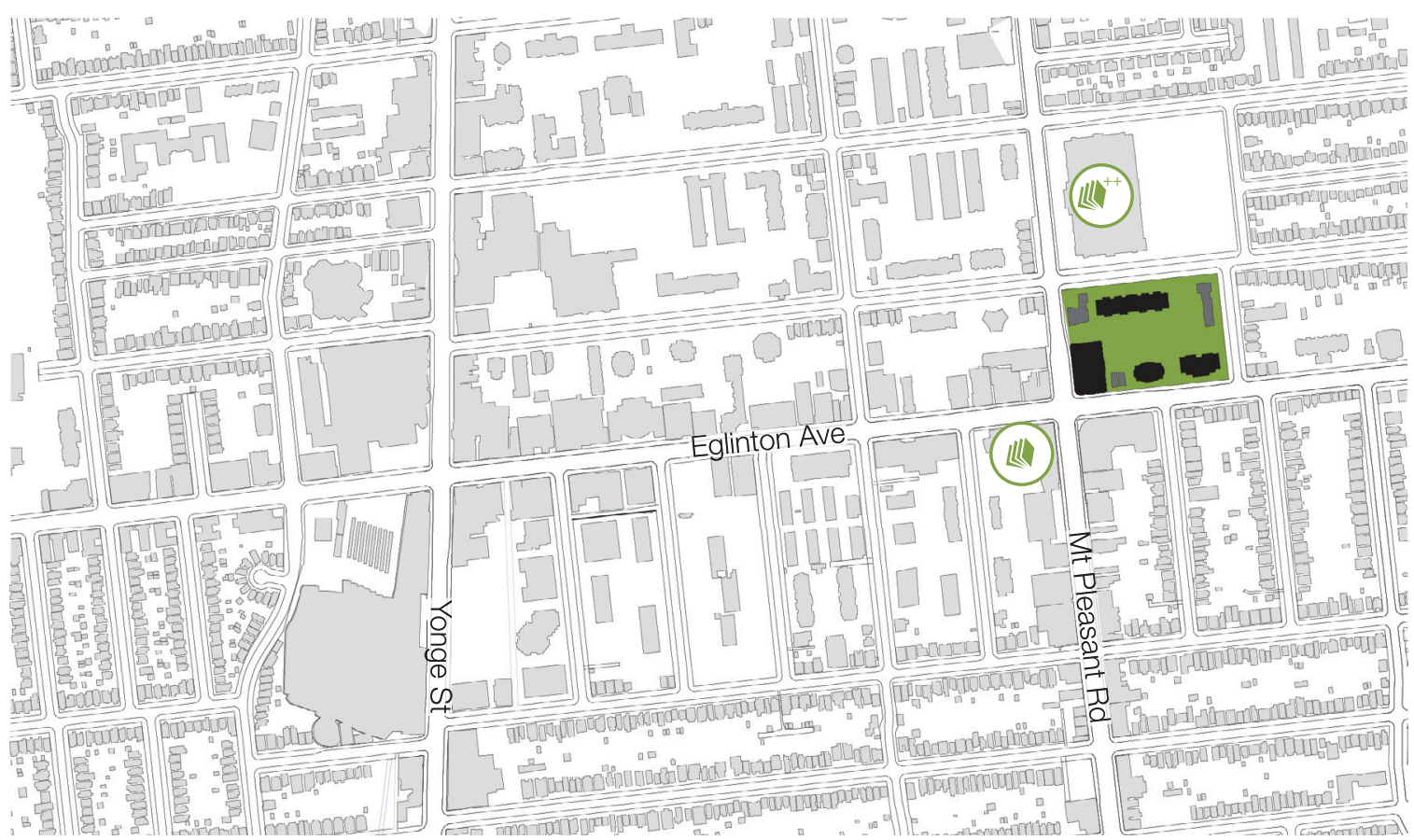

Residential Apartment Block

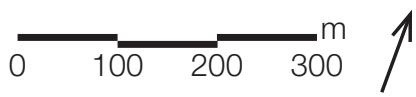

Map 6 Identifying the Mt Pleasant and Eglinton Block within Neighbourhood Context, (Sauder, 2014). 
The site also embodies many features which are typical for groupings of slab tower throughout the city. Sitting on the perimeter of the block are four different residential apartment slab towers, a new condominium, a church, and two detached homes (soon to be demolished). Meanwhile, parking lots and a large area of empty lawn occupy the centre of the block (Map 7). In addition to the more typical characteristics, the selected site also contains features that are specific to the neighbourhood. This includes nearby businesses, schools, and proposed light rail transit (LRT) which will all impact the implementation of the four proposed strategies. Immediately north, is a large high school and athletics field which brings increased traffic along Mt Pleasant Avenue in the morning and mid-afternoon as students venture to the nearby mom and pop shops. An elementary school also sits on the south-east corner of the Mt Pleasant and Eglinton intersection which brings young children and parents through the site during similar times of day. Despite these unique conditions, the strategies are still well suited for the site, as every other cluster of residential towers will also have their own specific characteristics on top of the typical traits.

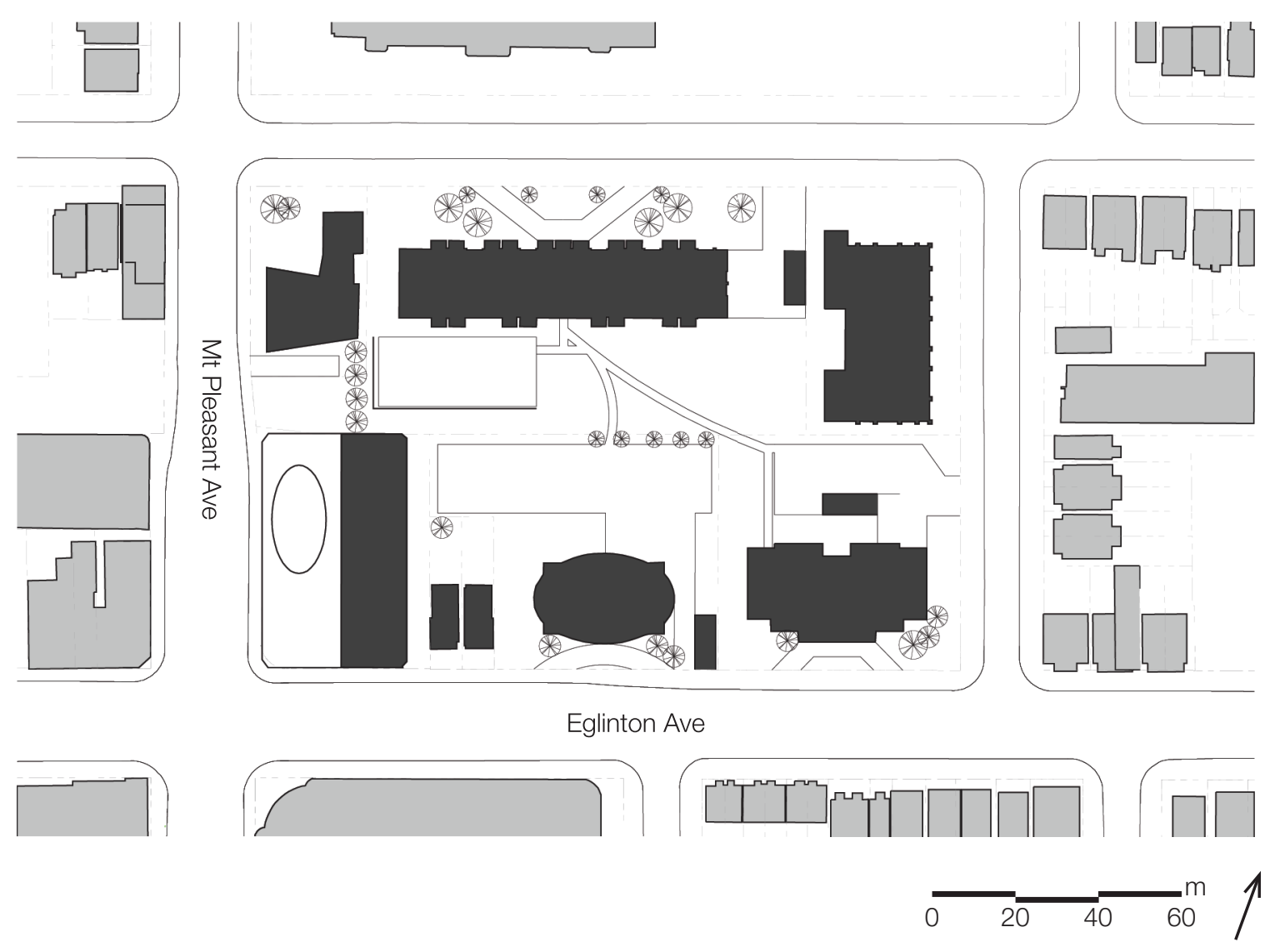

Map 7 Residential Apartment Block, (Sauder, 2014). 
One of the most significant conditions specific to the Eglinton and Mt. Pleasant is the readily accessible transit. Currently, bus lines run along both Eglinton Avenue and Mt. Pleasant Road with a stop on the corner of the two streets, as seen in Map 8. The site is also an eight minute walk from the Eglinton subway station, which makes getting around the city quite accessible. Additionally, the planned light rail transit (LRT) will have a station at Eglinton and Mt. Pleasant, with the primary entrance to be located on the south-west corner of the Residential Apartment block as seen in Map 9. Together, the wealth of transportation infrastructure surrounding the neighbourhood makes it an ideal location for further densification and occupation of the ground plane. It also suggests there may be a possibility to reduce the parking requirements in favor of additional land-use intensity and public spaces between the existing slab towers to engage with the pedestrian.
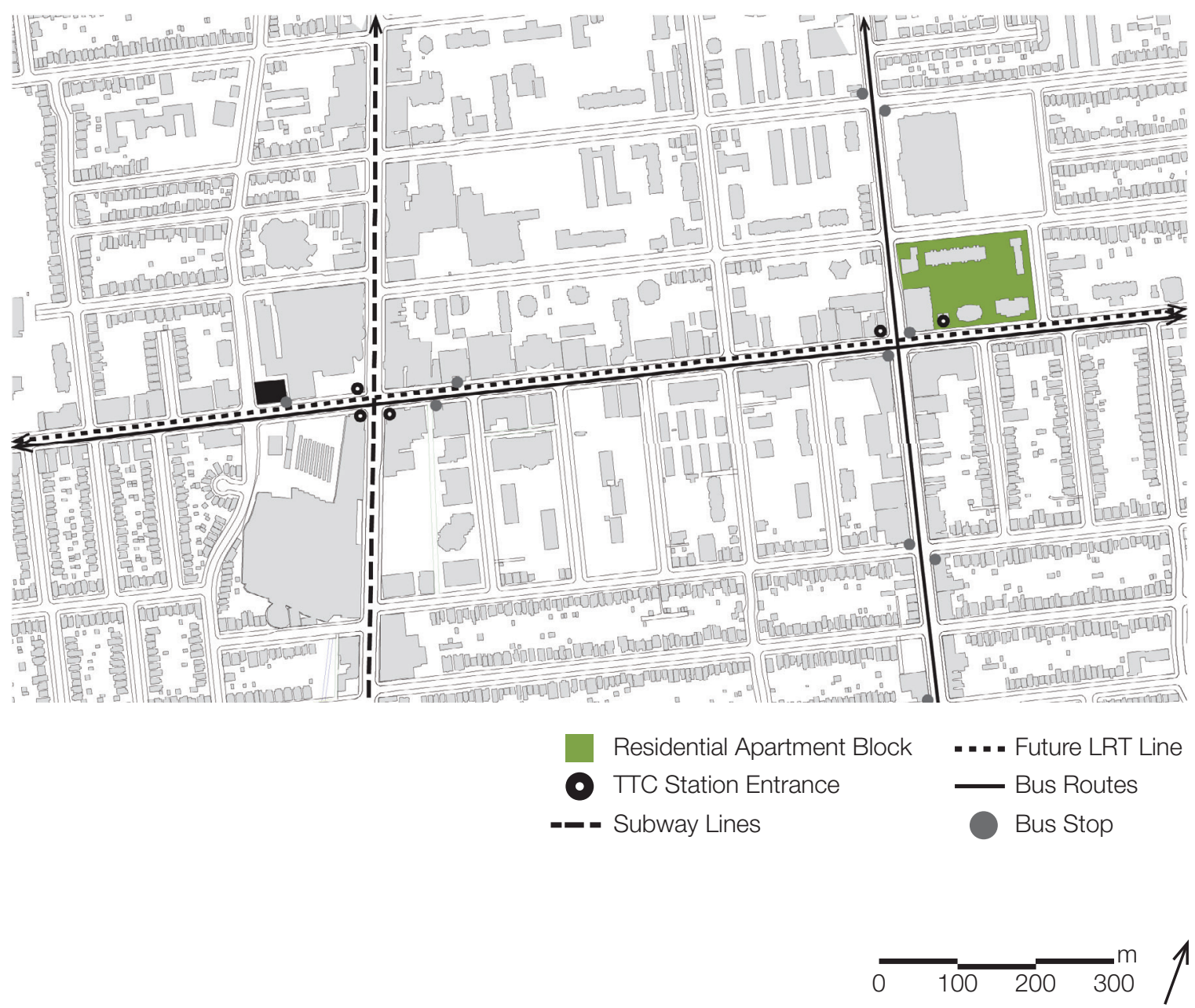

Map 8 Local Transit Routes, (Sauder, 2014). 


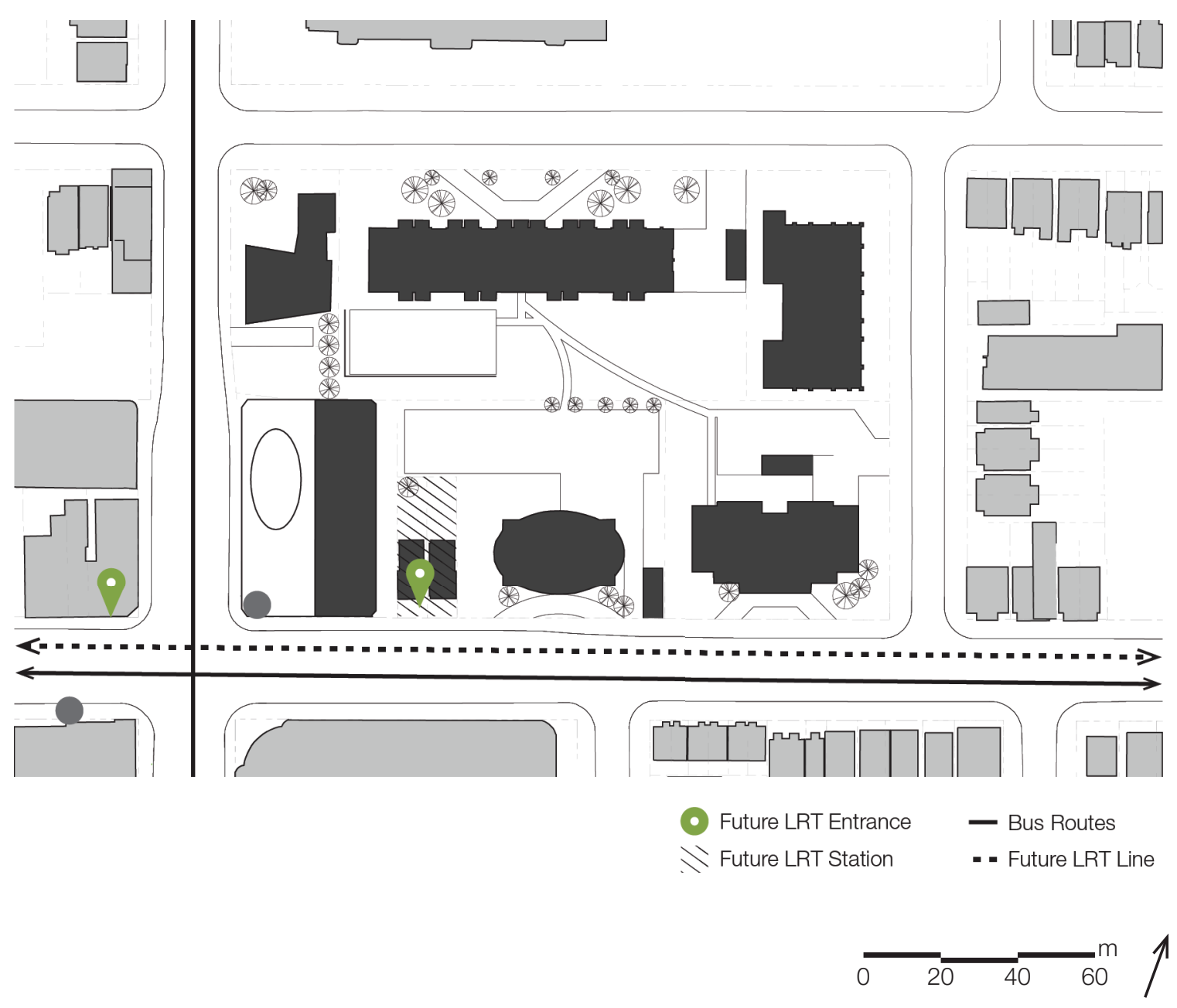

Map 9 Planned LRT Stations, (Metrolinx, 2014). 
In order to intensify the Residential Apartment block and also improve the experience, the new intervention considers the shadows cast on the site. This is particularly important when dealing with urban blocks that may have multiple towers sitting on the perimeter. In the case of the Eglinton and Mt. Pleasant, shown in Figure 29, there are five existing towers that restrict light from entering the interior of the site. However, the large setbacks between the different towers still let a good amount of light enter throughout the day. Evenings, especially in the winter months, and September mornings also cast large shadows over portions of the site. Shadows during these times have been be taken into consideration for the placement of the new development. Otherwise, there will not be enough lighting and the space will feel congested to the inhabitants and general public.

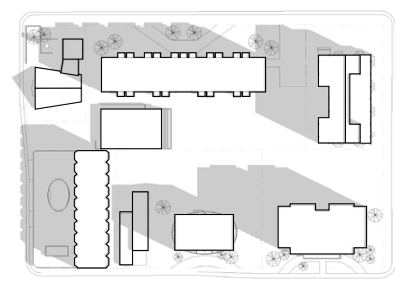

June 21

9:00 am

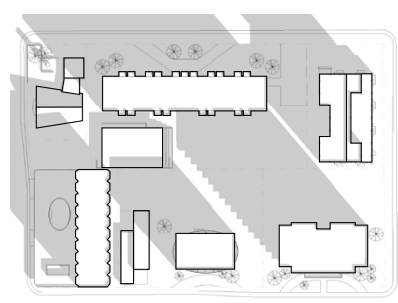

September 21

9:00 am

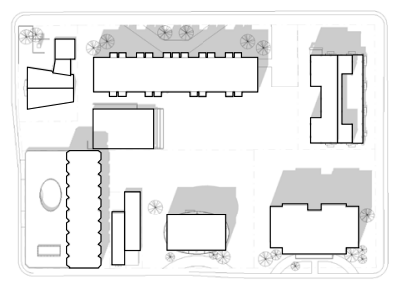

June 21

12:00 pm

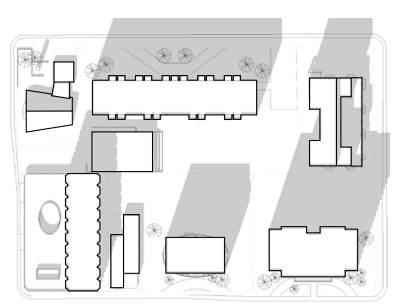

September 21

12:00 pm

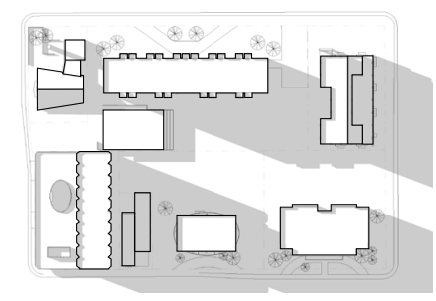

June 21

5:00 pm

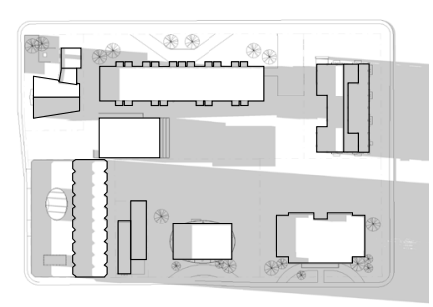

September 21 June 21

5:00 pm

Figure 29 Residential Apartment Shadow Study, (Sauder, 2014). 
After looking at characteristics specific to the Eglinton and Mt. Pleasant block of residential apartments, the strategies that support densification and pedestrian experience can be applied in a more informed way. Acknowledging the abundance of transit options helps to take the site's focus away from automotive parking and turn it to the pedestrian and the future LRT entrance designates an important node on the block that could become a focal point for the entire neighbourhood. The light study also helps predict where pathways, courtyards and infill will best fit amongst the slab towers. With this knowledge and the information collected from previous research and exploration, informed decisions can be made to approach the improved experience and density of the site. 


\subsection{PROJECT MASSING AND PROPOSAL}

This section explores different levels of experiential density to create a lively environment between groupings of slab towers. However, the demands of quantifiable densities on physical forms also play a critical role in shaping the experience. This is seen in Charkabarti's (2004) discussion on density and massing, where he illustrates how the same physical density is achievable using different land use intensities (see Appendix A for illustrations). In this situation, a low-rise development with a large footprint ca accommodate the same number of inhabitants as a tower occupying a smaller area,

VARIATION A

Massing Illustrating a $10 \%$ Increase in Density
Massing Illustrating a $20 \%$ Increase in Density

Massing Illustrating a $30 \%$ Increase in Density
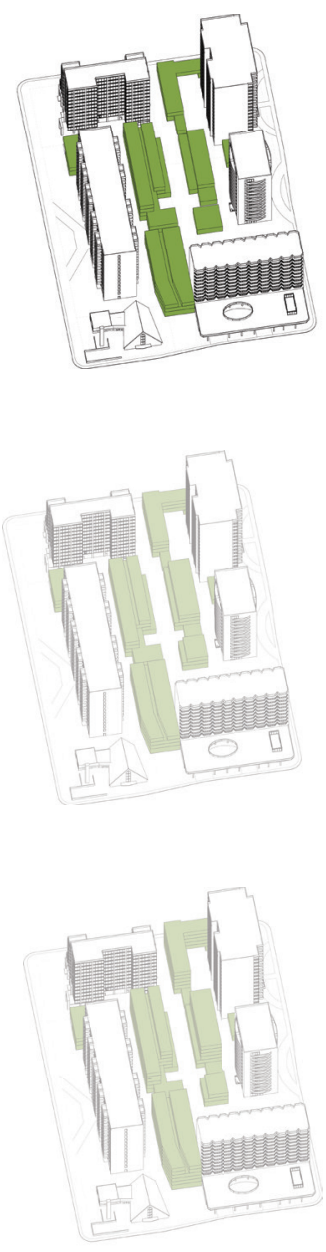

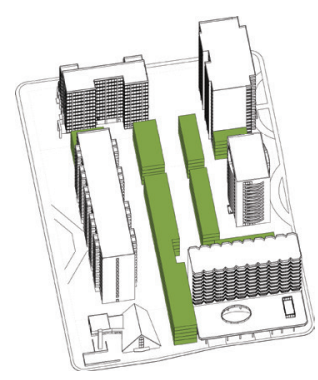

VARIATION B
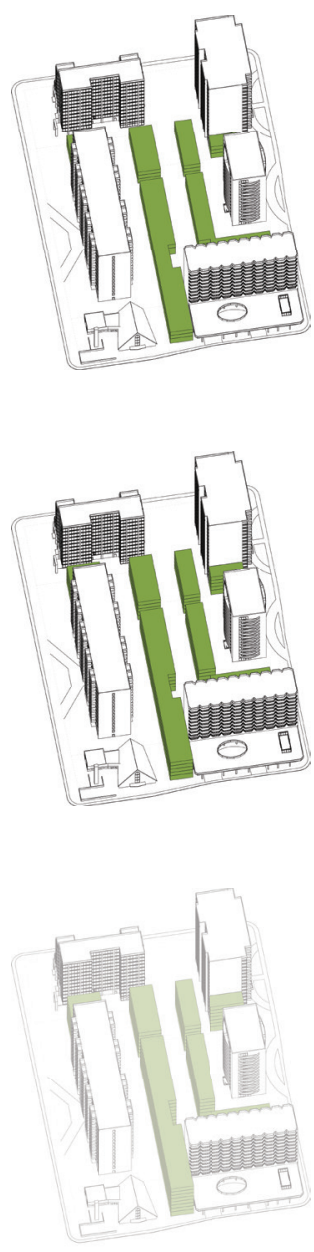

Figure 30 Massing Variations Exploring the Effect of an Increased Physical Density on the Mid-block Experience (Sauder, 2015). 
while creating a very different relationship to the ground plane. Figure 30 continues on this mindset, but begins to implement the notions of fragment, activate, infill, and mediate to establish a basis for the proposal's massing. Testing a quantitative increase in density by 10, 20, and 30 per cent, Figure $\mathbf{3 0}$ uses four variations in massing and land use intensity to determine approaches for creating experiential density. First, Variation A sculpts a mat density by sprawling over a majority of the site and stepping back as the form gets taller. This works best with a growth of 10 per cent so the massing can address the ground plane while creating pockets of outdoor space. The same strategy begins to

Massing Illustrating a $10 \%$ Increase in Density

Massing Illustrating a $20 \%$ Increase in Density
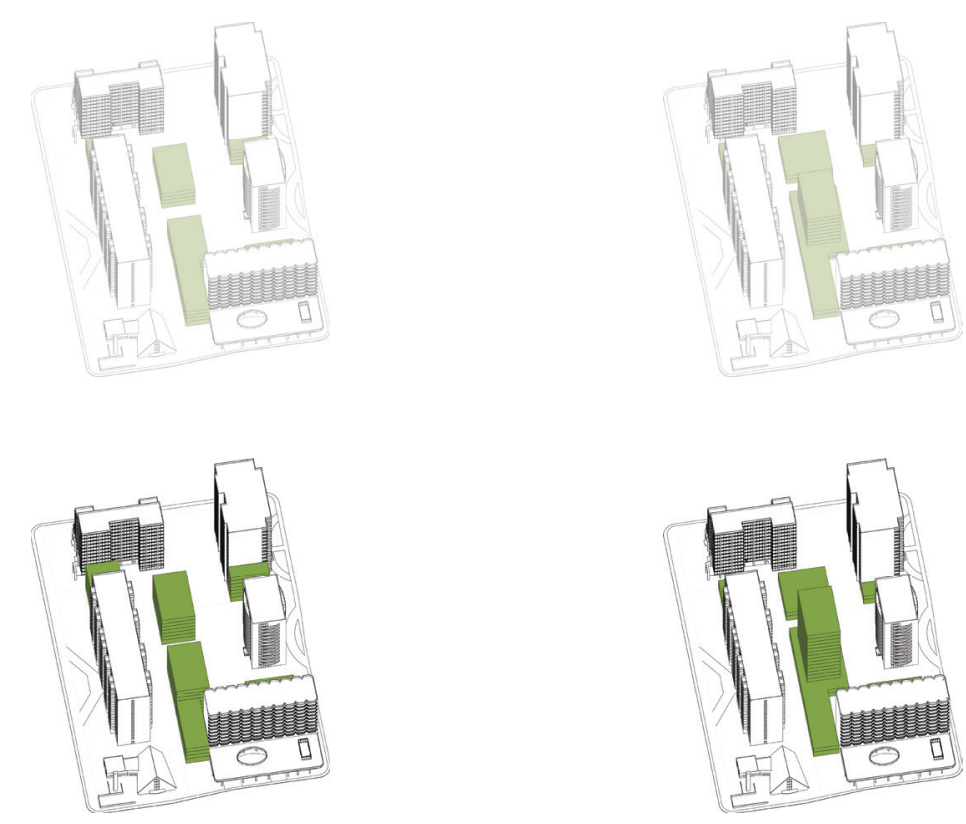

Massing Illustrating a $30 \%$ Increase in Density
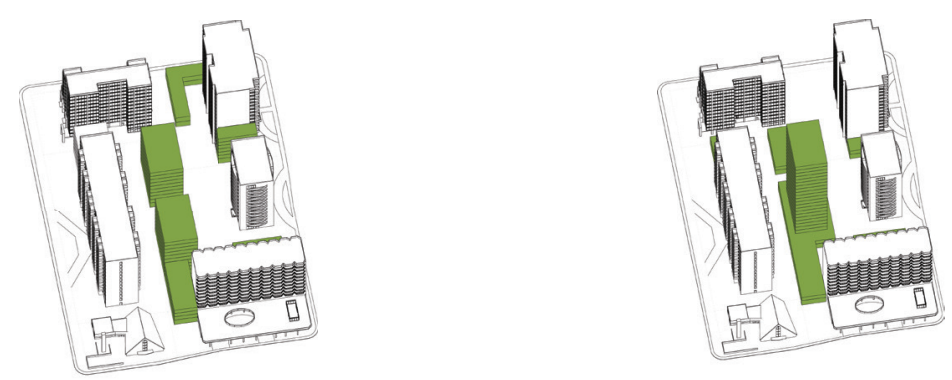

Figure 30 Massing Variations Exploring the Effect of an Increased Physical Density on the Mid-block Experience (Sauder, 2015). 
fail when density objectives are raised, making it difficult to bring enough natural light into the spaces and maintain a relationship to the pedestrian environment. Next, Variation $B$ uses narrow strips of infill to break down the site. Forming rows of low or mid-rise structures, these forms are successful at the 10 and 20 per cent increments, but fail at 30 per cent where harsh shadows and an overbearing scale negatively affect the experience. The third approach, Variation $C$, closely references adjacent slab towers by inserting two taller volumes into the site. While these forms can easily hold more density, they do not interact with the ground and are only replicating existing conditions. The last iteration, Variation $D$, also uses a tower typology, but this time a podium is added to focus on the ground. In this case, the point tower is easily able to hold 20 and 30 per cent values, but is not worth the investment to only reach a 10 per cent increase.

Comparing these different approaches to massing, a correlation between density and the ground plane appears. Both Variations $C$ and $D$ are able to reach a higher density, but they must sacrifice a connection with the pedestrian environment and public realm to do so because they rely on the tower. Meanwhile, Variations $A$ and $B$ are only able to successfully hold a 10 per cent density increase, but still maintain a stronger connection to grade and the human scale. Therefore, a compromise will be made where some quantifiable values are sacrificed in order to improve the experiential density of the urban block. While both the first and second massing meet these perimeters, Variation $B$ is rather homogeneous and would still require interior circulation to reach upper levels. Contrary to this, Variation $A$ in its 10 per cent form enables outdoor circulation to be elevated to setbacks on its upper levels and produces a variety of distinctive forms throughout the site. Due to these characteristics, the massing from Variation $A$ (Figure 31) will continue to be developed and further refined to showcase how experiential density can be achieved between clusters of residential apartment towers. 

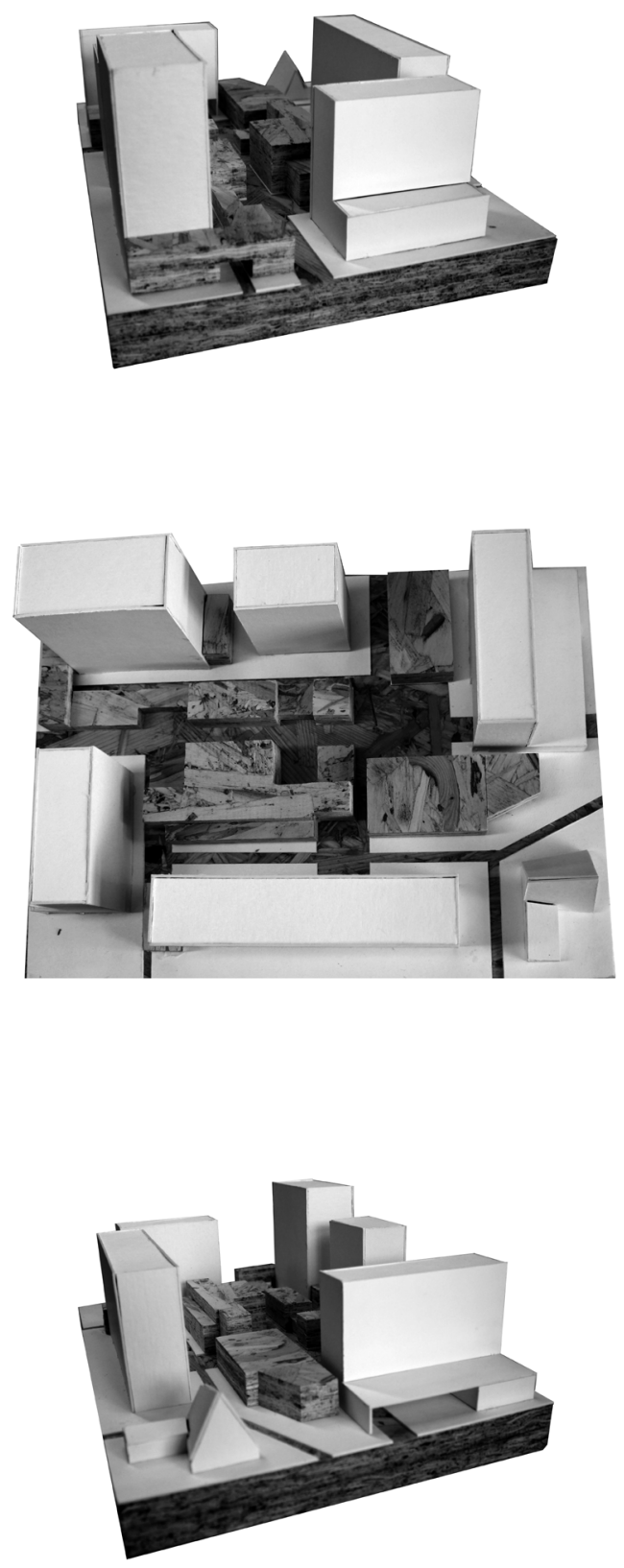

Figure 31 Images of Built Model Depicting the Overall Massing Scheme, (Sauder, 2015). 
Refining the low-rise massing of Variation A, notions of fragment, activate, infill, and mediate respond to the specific conditions of the site to form experiential density. Shown in Figure 32 the final result features a skewed primary pedestrian street that divides the urban block in half, multiple courtyards varying in size, and a series of low-rise infill which increases the site's physical density. An existing underpass bellow the south-west tower creates a unique opportunity for the primary pedestrian street to interact with the apartment building and take advantage of a neglected part of the site. Another important pedestrian pathway is formed beside the proposed LRT station to accommodate the resulting increase in traffic. This pathway intersects the main street to generate the largest courtyard to create a busy and populated centre around the LRT entrance and adjacent to the Eglinton and Mt. Pleasant intersection. Several other courtyards sit along the pedestrian street and will act as more public areas because of the higher traffic that will pass through them, while the courtyard north of the street is more secluded and will provide a more private space for the residents. From this preliminary image, the ideas and concepts are further developed to produce a much more detailed proposal to generate density, and a quality of environment that has a human scale. 


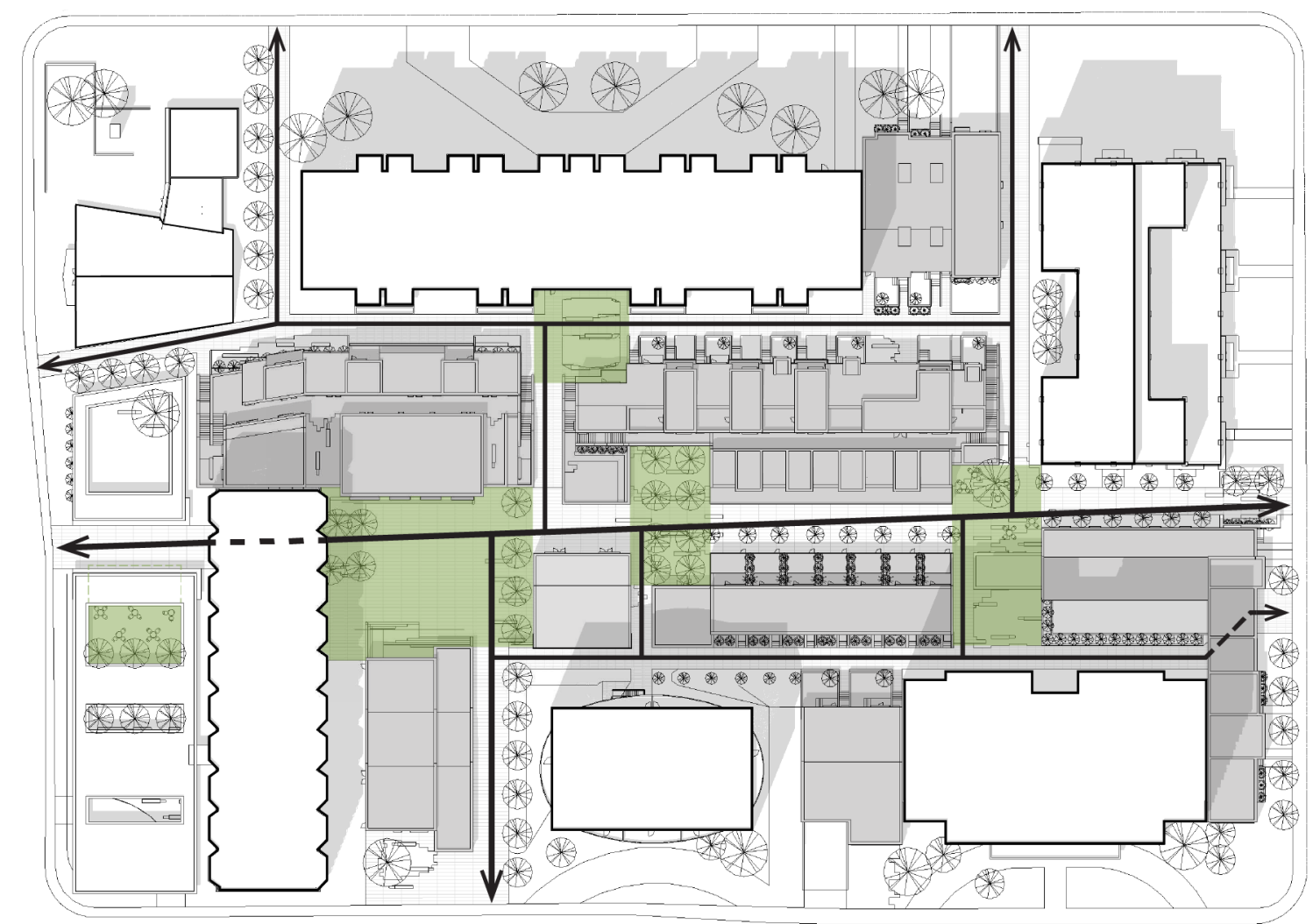

- Pedestrian Circulation Courtyard Infill

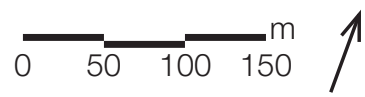

Figure 32 Schematic Proposal for Eglinton and Mt. Peasant, (Sauder, 2015). 
Following the initial application of strategies - fragment, activate, infill, and mediate - the proposal was refined to increase their influence on the experience of the site. Images shown in Figure 33 demonstrate how these strategies have been developed from the previous studies to create an extensive environment within the centre of the block which brings density back to a scale that promotes human interaction. Represented in white, the new low-rise structures strategically occupy the interior in addition to filling large gaps along the city street. Additionally, the structures define circulation routes which allow people living, working, and going to school in the surrounding area to pass through and engage with the new environment. Clearly visible in Figure 34, the circulation or primary pedestrian street breaks down the overbearing scale of the urban block and becomes the focal point of the proposal. The same street is lined with mixed-use units (commercial/offices at grade, residential above) to draw traffic into the area, while the adjacent pathways are filled with residential units forming a much quieter and secluded condition. Each of these units has direct access to the sites circulation, and the residential units all have some form of transition between the public pathway and their private unit. The resulting experience goes on to be further defined through the manipulation of physical density and the four strategies. 

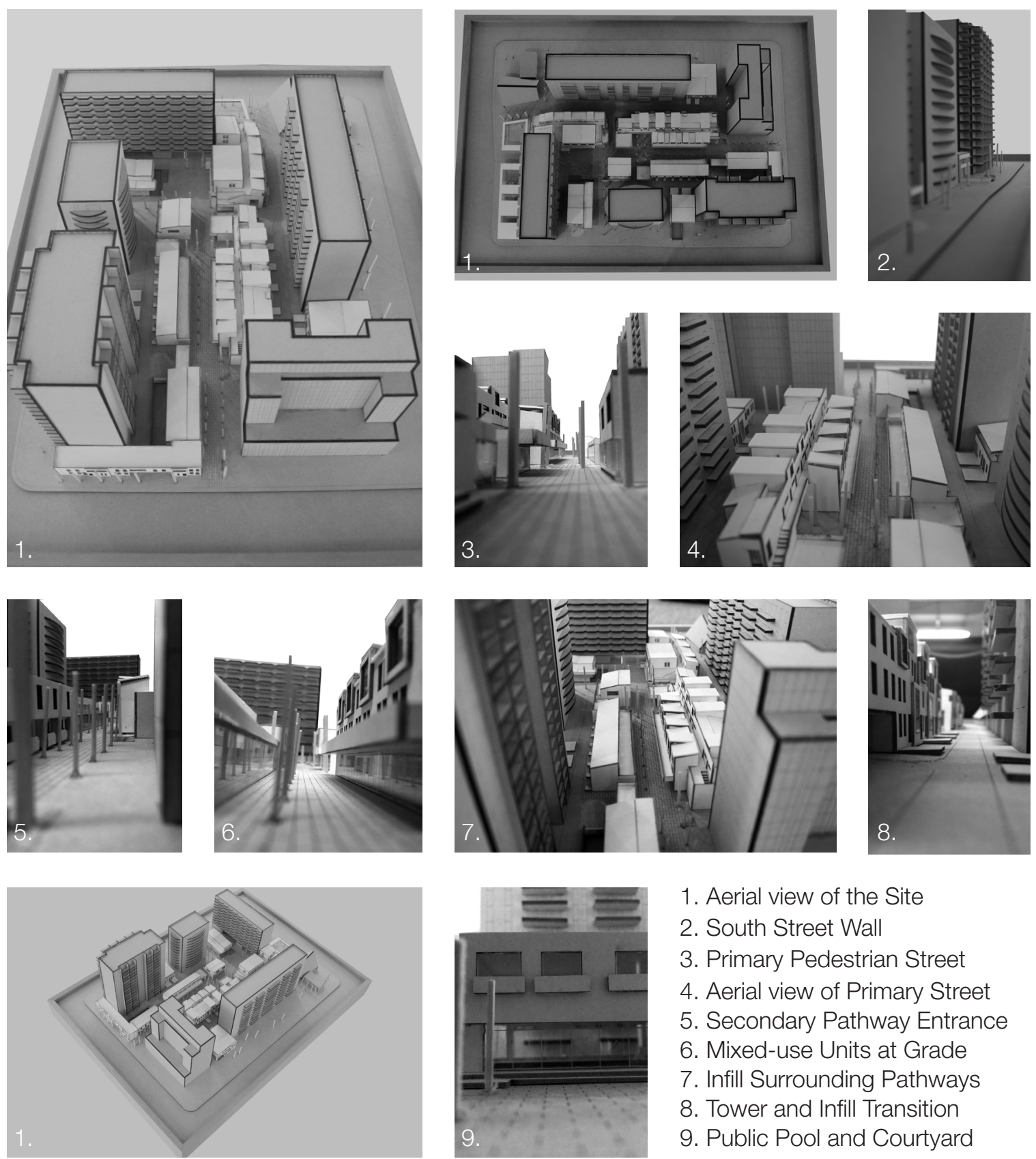

1. Aerial view of the Site

2. South Street Wall

3. Primary Pedestrian Street

4. Aerial view of Primary Street

5. Secondary Pathway Entrance

6. Mixed-use Units at Grade

7. Infill Surrounding Pathways

8. Tower and Infill Transition

9. Public Pool and Courtyard

Figure 33 Images of Built Model Depicting the Physical Characteristics of the Proposal, (Sauder, 2015). 


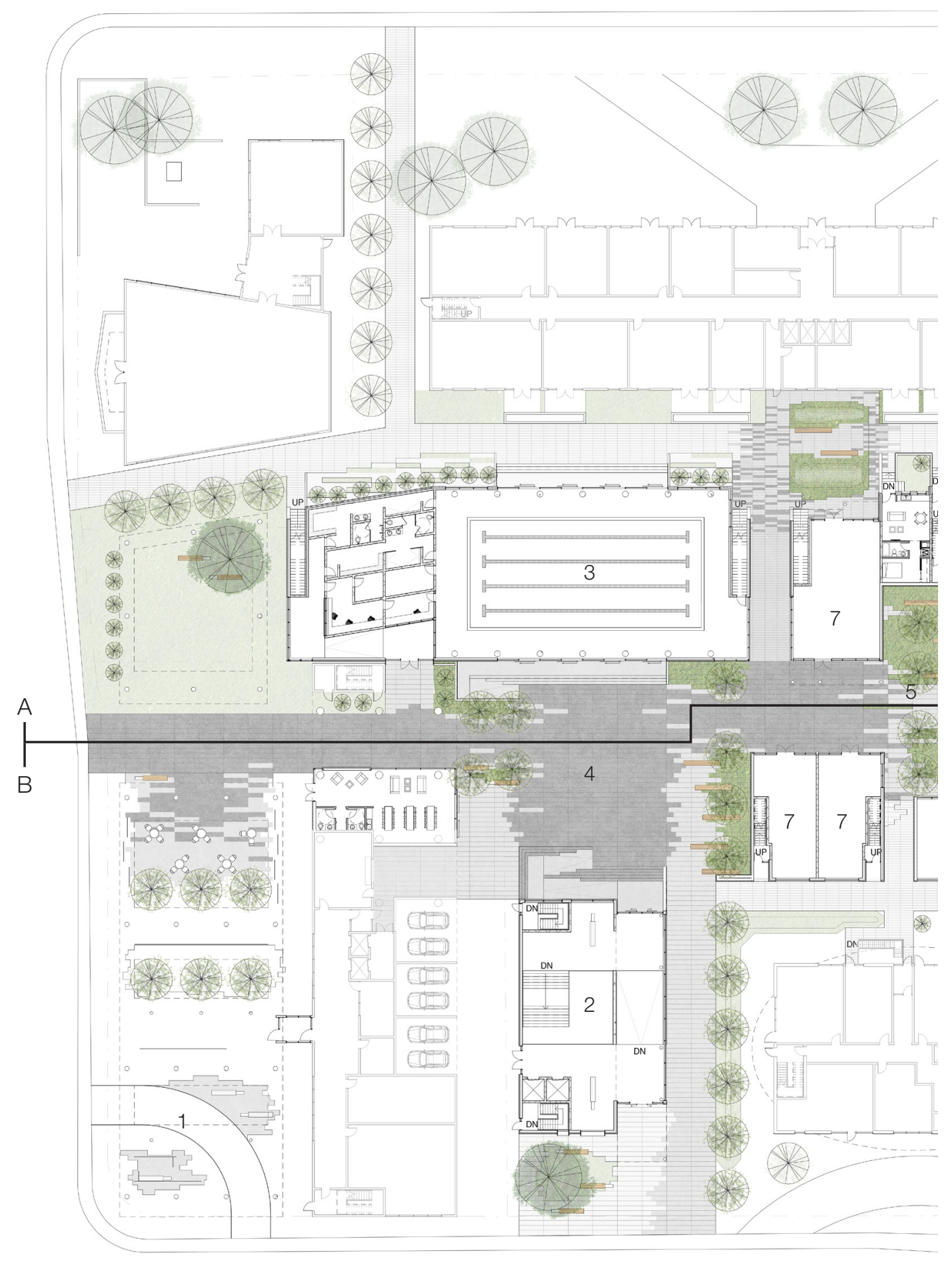

Figure 34 Site Plan, (Sauder, 2015). 


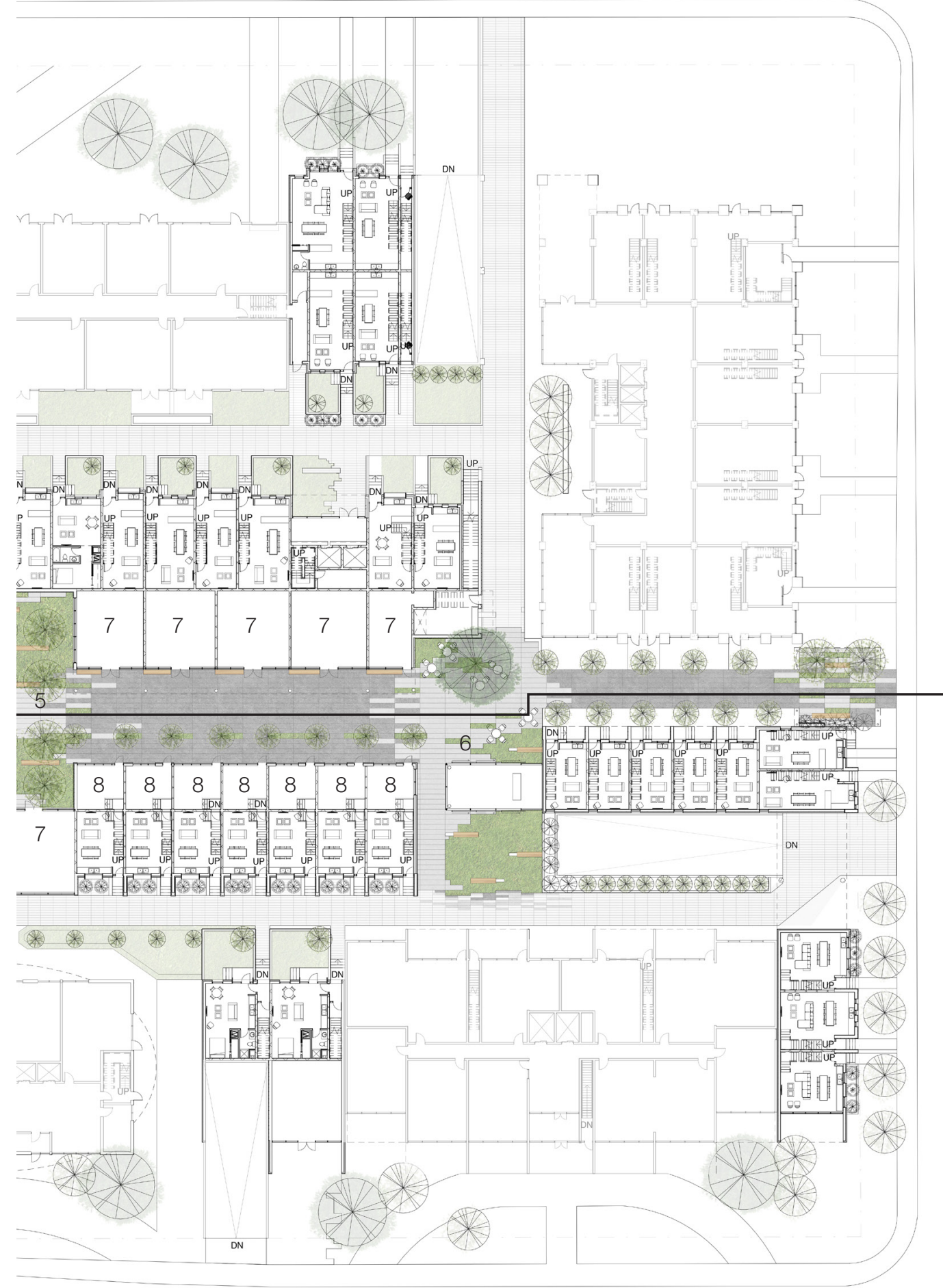

$\left.\right|_{B} ^{A}$

1. Bus Turn Around

2. LRT Entrance

3. Public Pool

4. Primary Courtyard

5. Treed Courtyard

6. Park Courtyard

7. Office/Commercial

8. Live Work

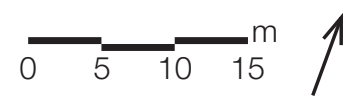




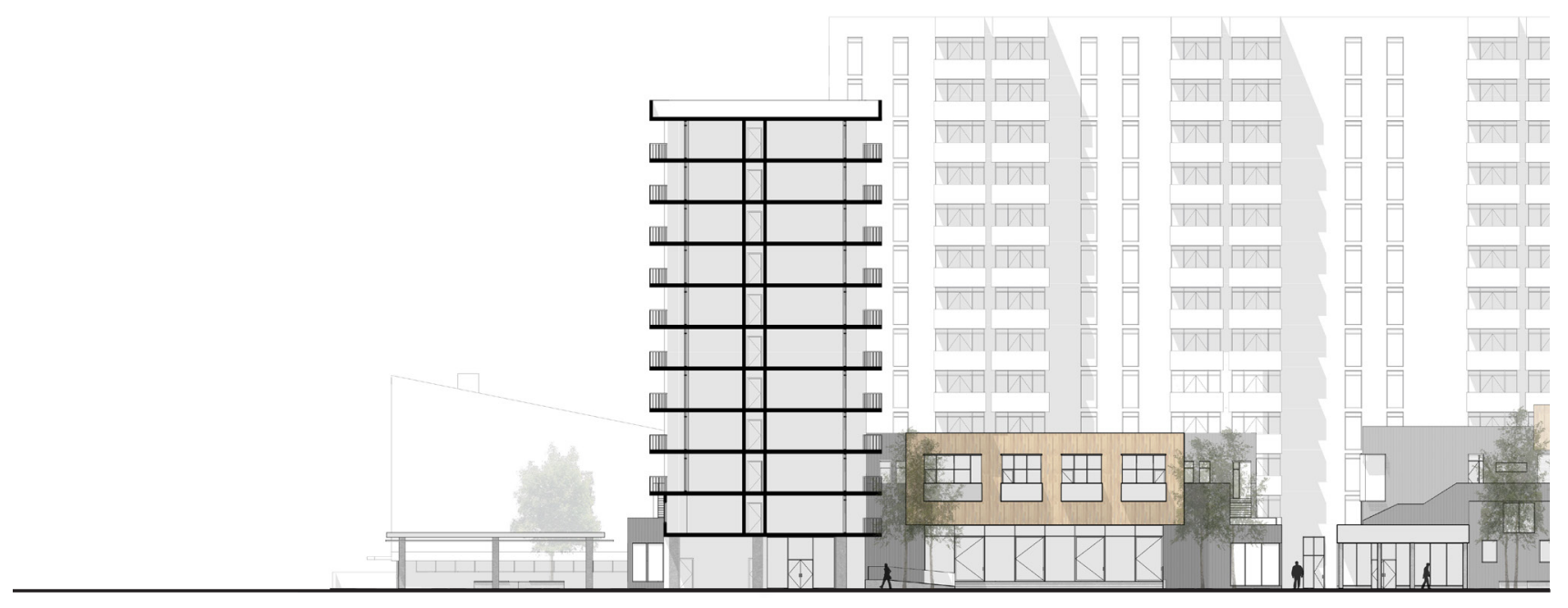

Figure 35 Site Section AA, (Sauder, 2015). 

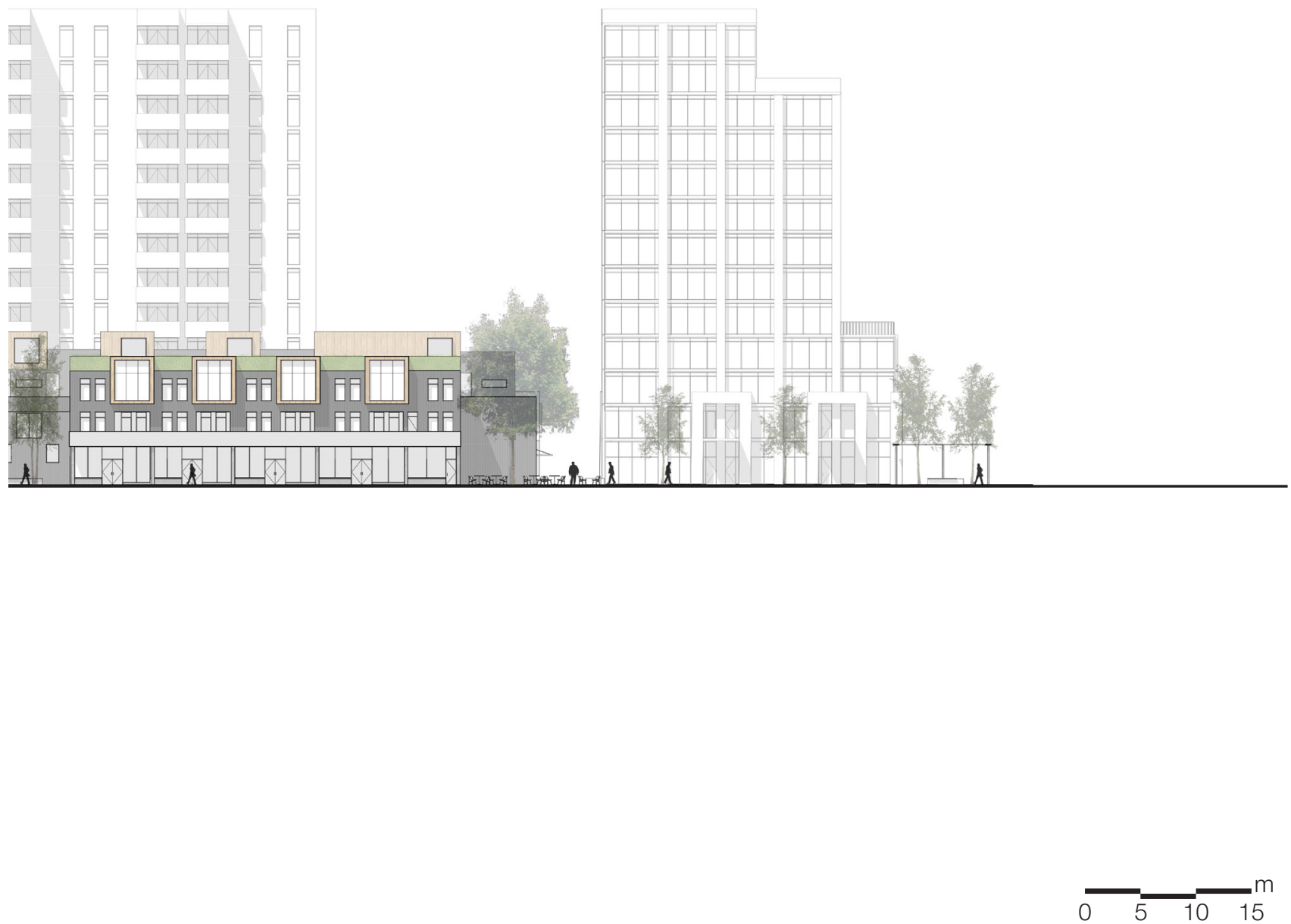


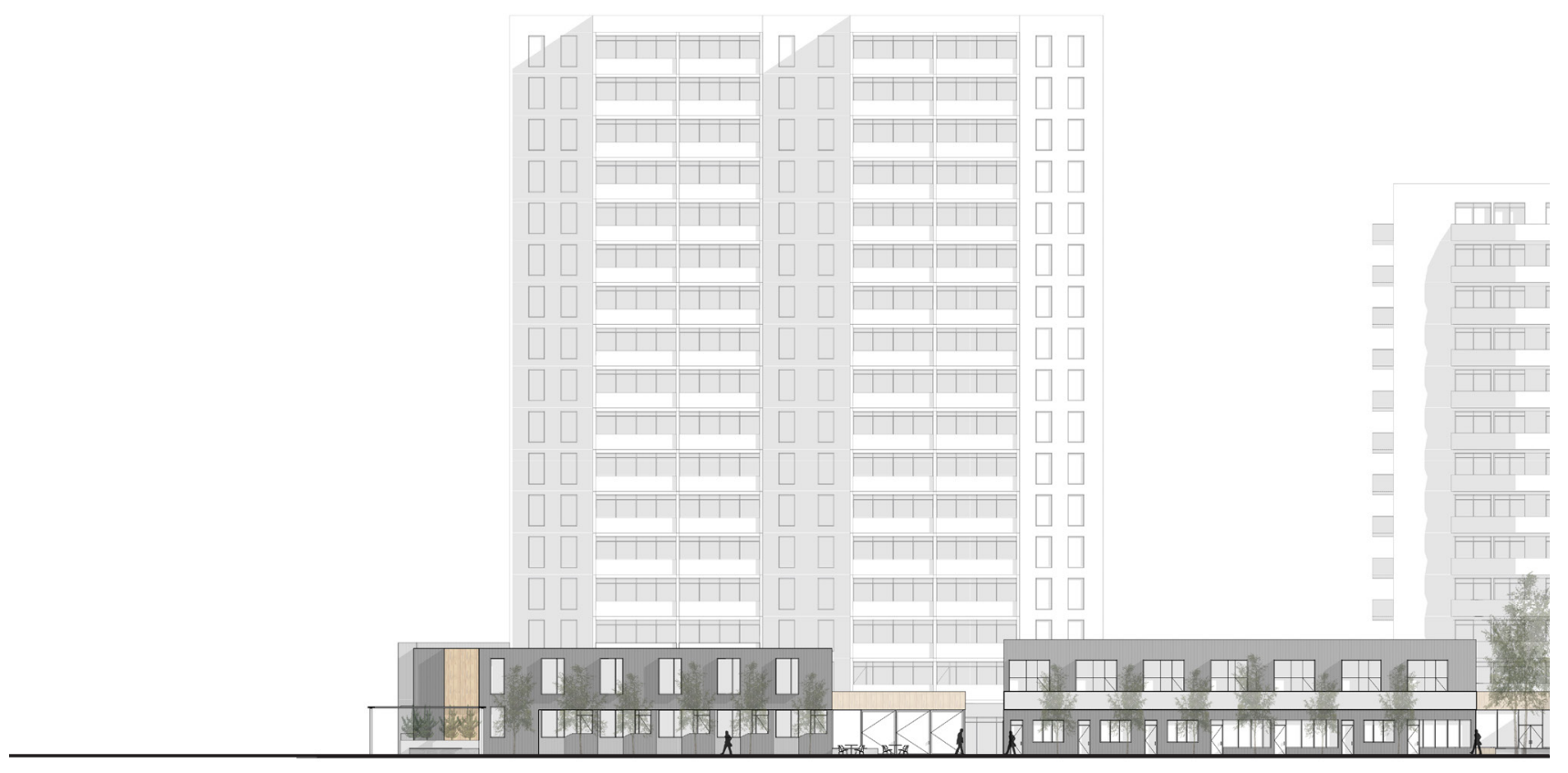

Figure 36 Site Section BB, (Sauder, 2015). 


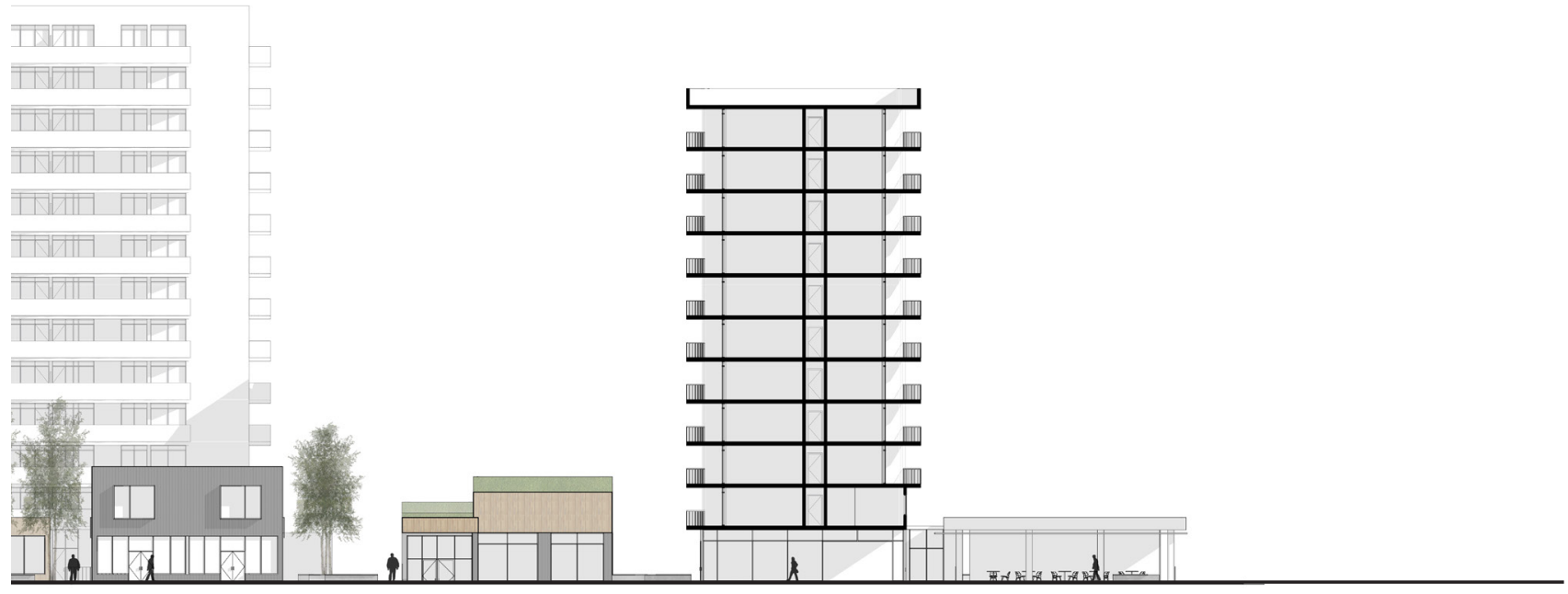




\subsection{APPLYING DESIGN STRATEGIES TO INCREASE EXPERIENTIAL DENSITY IN THE RESIDENTIAL APARTMENT SITE \\ 7.3.1 FRAGMENT}

Applying the first strategy, fragment, to the site resulted in a distinctive network of pathways throughout the urban block. Breaking down the site in this manner allows for walkable distances and a variety of routes which form more direct paths of travel. The new circulation encourages shortcuts through the block for neighbouring residents trying to reach the transit at the Mt Pleasant-Eglinton intersection, which in turn brings more foot traffic through the cluster of towers. The site itself is fragmented using similar proportions found in nearby low-rise residential streets (refer to Figure 37) that are much more relevant to the human scale then current block sizes. Dividing the area in half from east to west, the primary pedestrian street acts as the major traffic route through the site and follows along the common property line. In doing so, new infill on either side of the pedestrian circulation does not cross over boundaries and abides by city zoning regulations more easily. North-south pathways also tend to fall on property divisions to take advantage of the side yards between towers where the edge along city street can be broken down to enhance the network. As illustrated in Figures 38 and $\mathbf{3 9}$, the previously wasted space between each apartment building is occupied with secondary pathways which gives the side yard purpose and allows passing traffic a view into the interior of the block. 

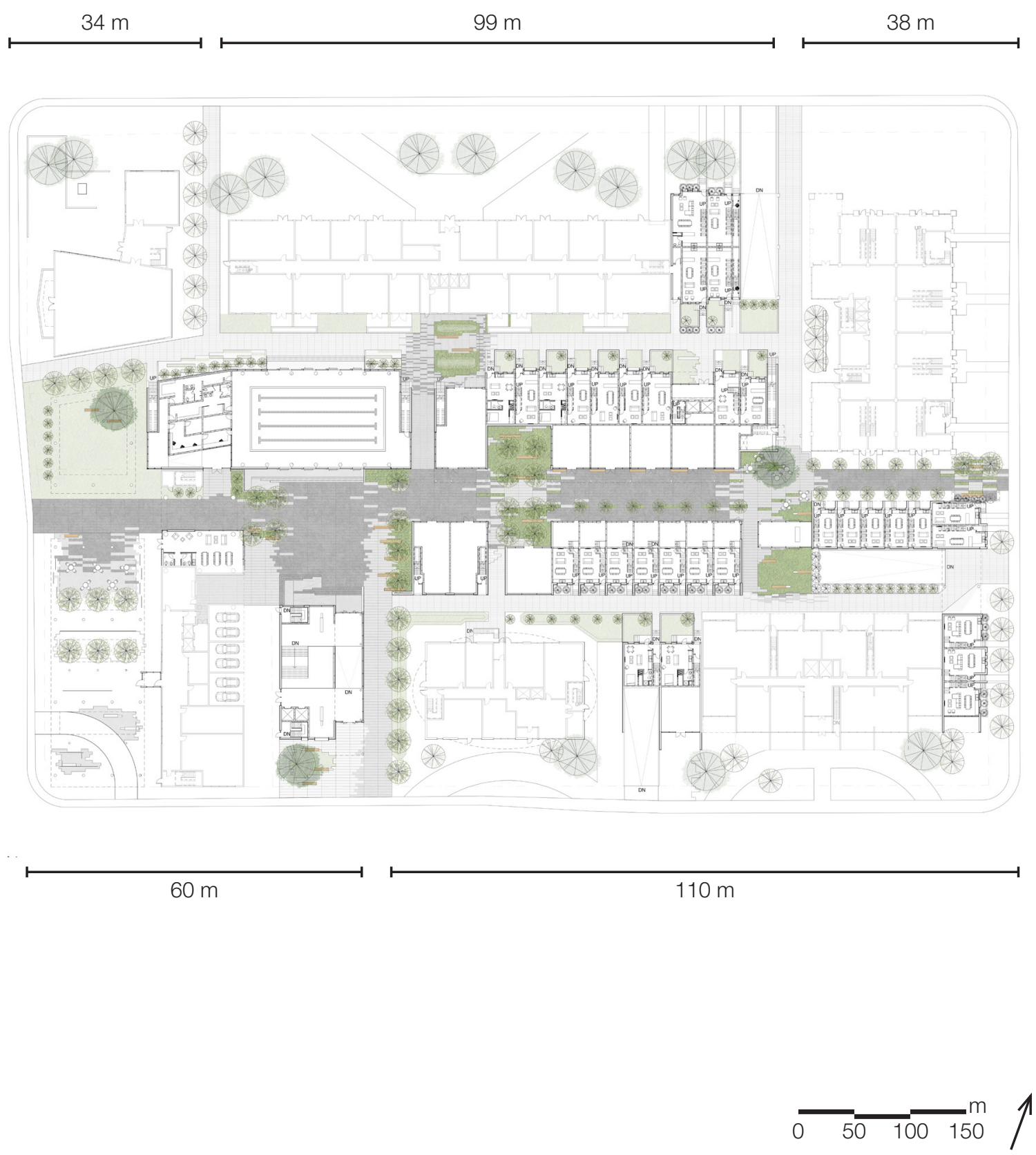

Figure 37 Site Fragmentation - Reflecting the Scale of a Low-rise Residential Block, (Sauder, 2015). 

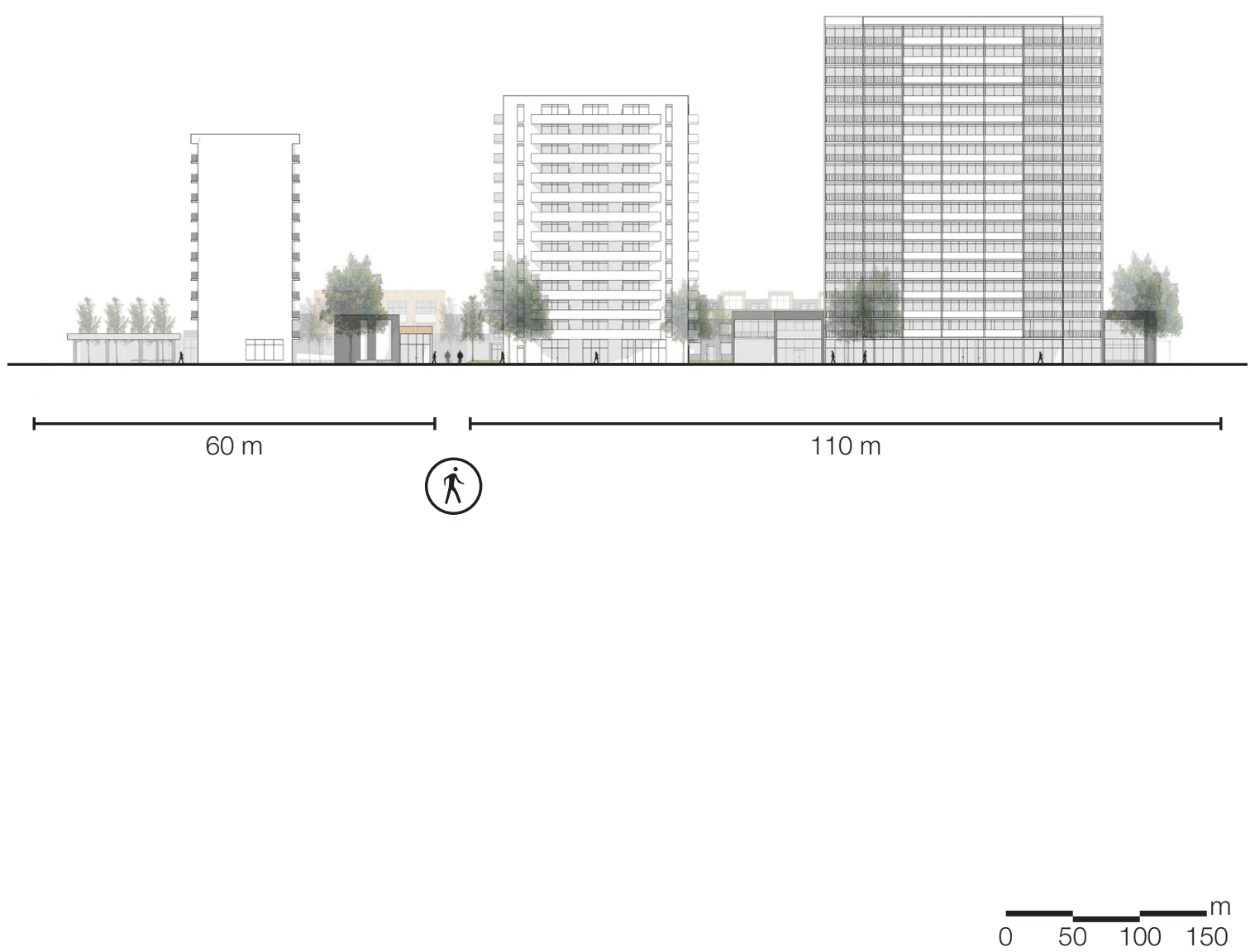

Figure 38 South Elevation Illustrating Fragmentation of Block Facade, (Sauder, 2015). 

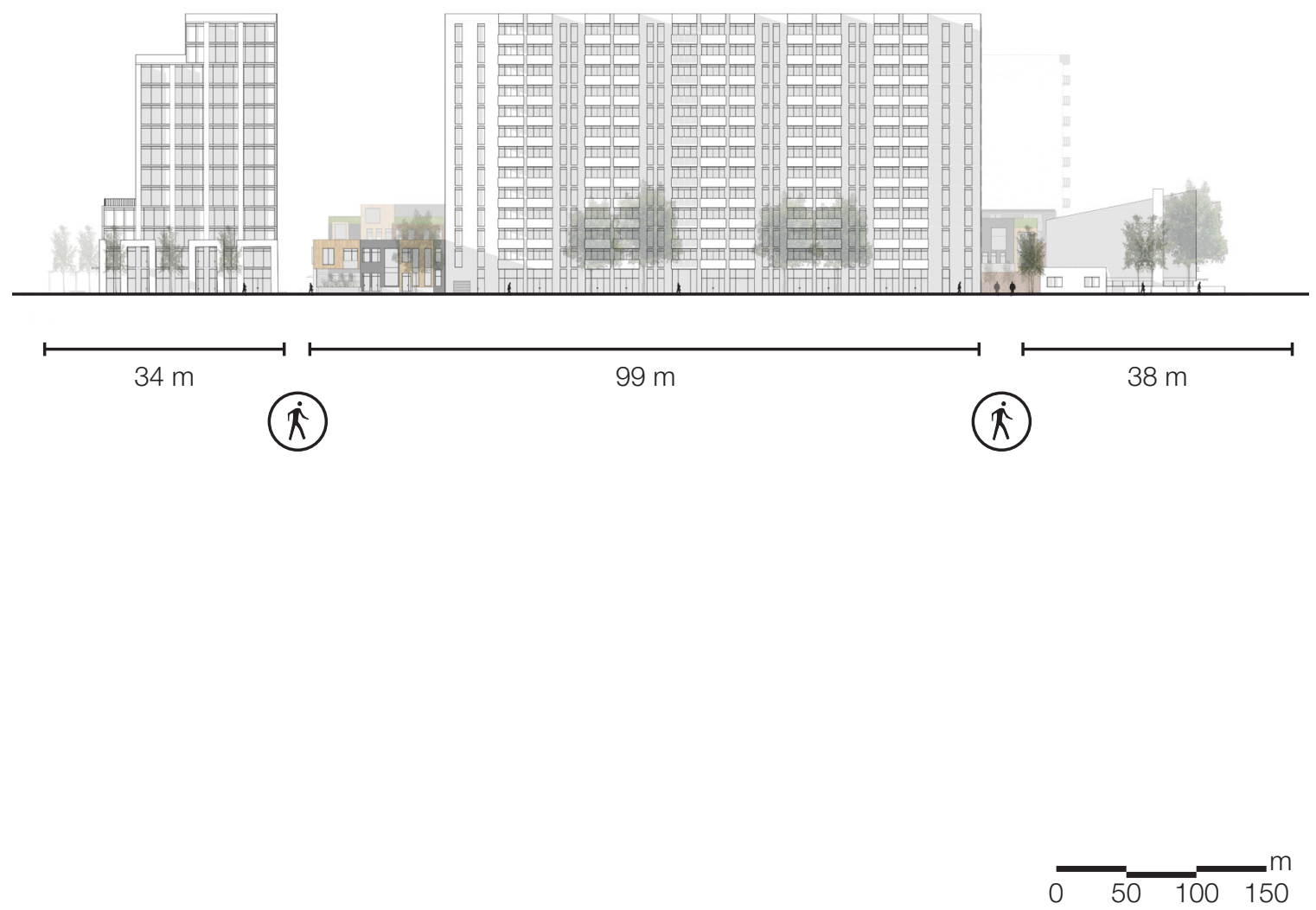

Figure 39 North Elevation Illustrating Fragmentation of Block Facade, (Sauder, 2015). 
Entrances and pedestrian pathways along the perimeter of the site are important for reducing the scale of the block, but are not the only components of fragmentation to be addressed. Since dividing the area along the common property line, the primary pedestrian street now closely reflects the same long walking distance found on city streets. Although it is still fragmented with secondary pathways, the experience can be further enhanced by emphasizing areas where the pedestrian street is broken down with the placement of a courtyard (Figures 40 and 41). At these intersections, the outdoor spaces generated in the activate strategy also play a critical role in the perception of the pathway. Their placement defines a critical moment where circulation intersects, resulting in a dramatic change of environment and a slowing of traffic to embrace the characteristics of the area before continuing on the primary street to their destination. Without creating these areas, the walking distance will become uncomfortable, long, and homogenous.
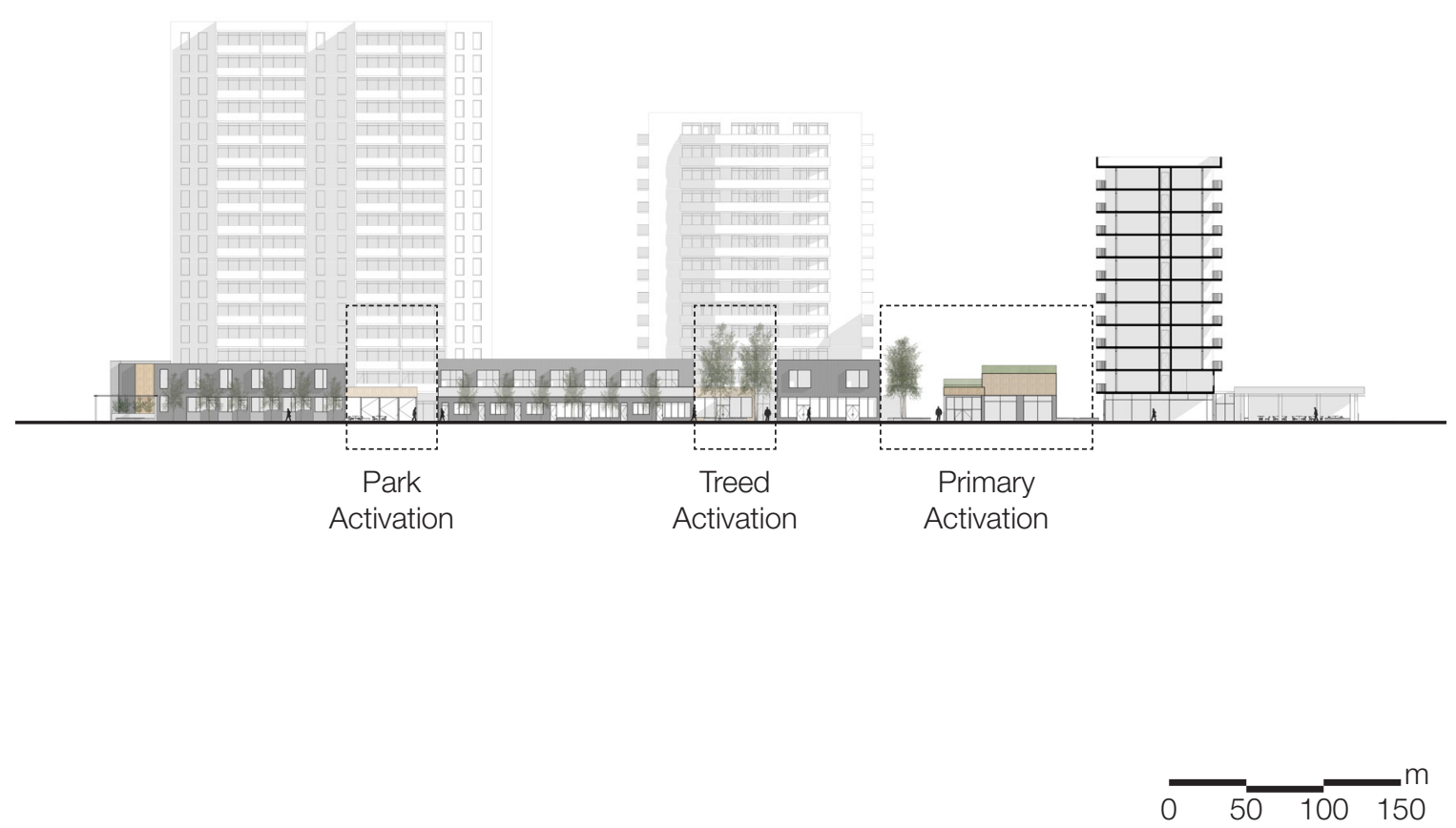

Figure 40 South Longitudinal Site Section - Illustrating Courtyards Role in Fragmenting the Primary Pedestrian Pathway, (Sauder, 2015). 

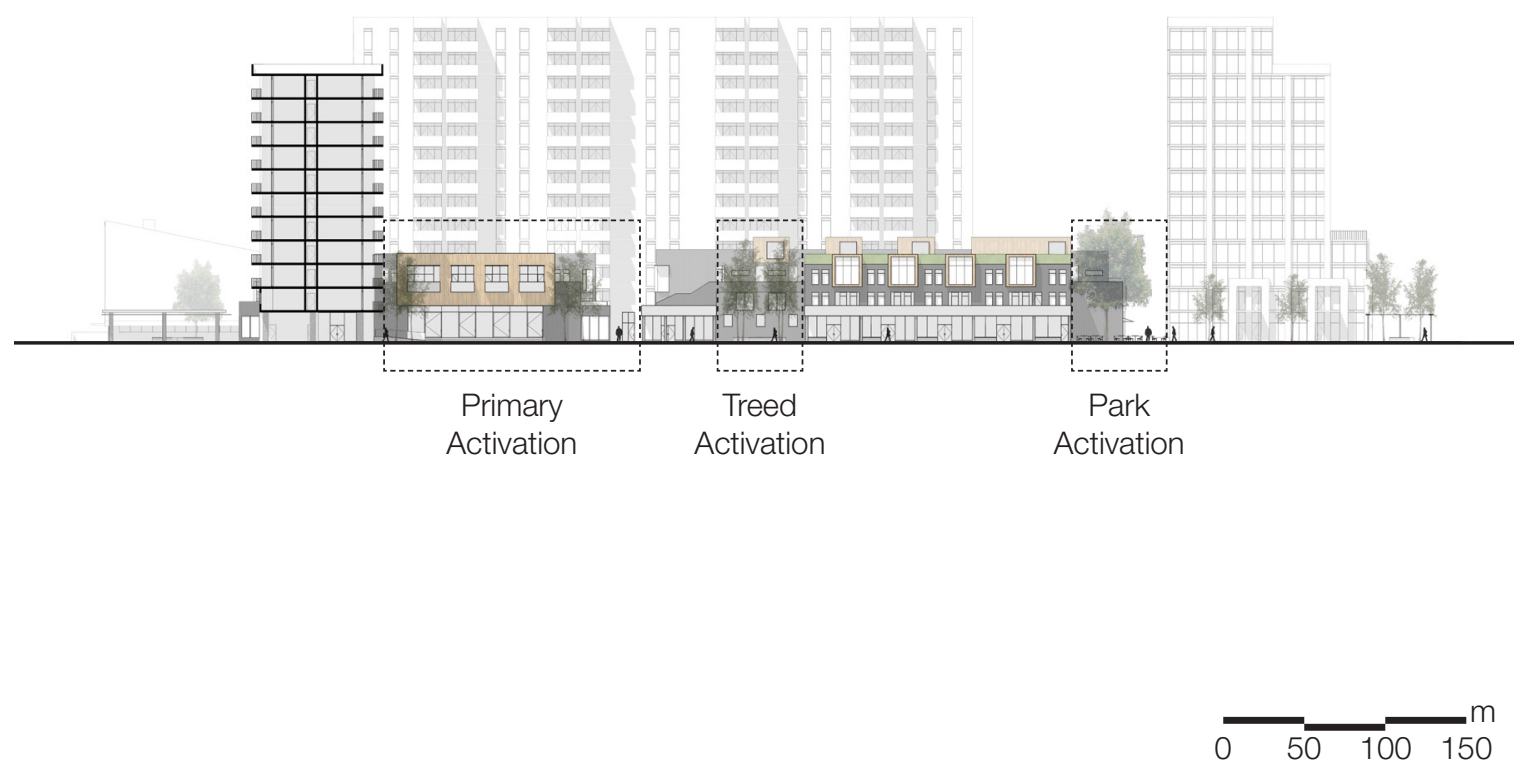

Figure 41 North Longitudinal Site Section - Illustrating Courtyards Role in Fragmenting the Primary Pedestrian Pathway, (Sauder, 2015). 
In addition to dividing the large block into more walkable parts, fragmentation also plays an important role in defining the experience of the pathways themselves. Looking more closely at a typical section of the primary street (Figure 42), a comfortable walking environment is formed by manipulating the proportions of the space to reflect human scale. The required nine meter right of way $(O B C, 2006)$ is broken down into three sections, with the centre being left wide enough to accommodate two vehicular lanes (using the three meters minimum width) for service vehicles to access the site (Toronto Centre for Active Transportation, 2012). Bordering the pedestrian street are smaller pathways defined by trees and colonnades. Smaller and slower paced walkways run along the edge of the street, allowing pedestrians to meander and interact with the new mixed-use programing at grade, while the centre is wider to promote an accelerated walking tempo and allow access for the occasional service vehicle. Additionally, the experience along the pedestrian street is also influenced by the amount of natural daylight hitting the ground. Stepping back, the live-work units on the south side cast less shadows and soften the boundary line that encloses the street, permitting the space to feel open and light despite the overhead towers. Vegetation defining the street also helps reinforce these conditions (Figure 43) by selecting sparsely branched trees, like the Ginkgo, which allow for a filtered light to pass through, while restricting views to the above towers. The resulting spaces formed through fragmentation is a pleasant walking environment where the pedestrian's focus is on the spacious street created through fragmentation.

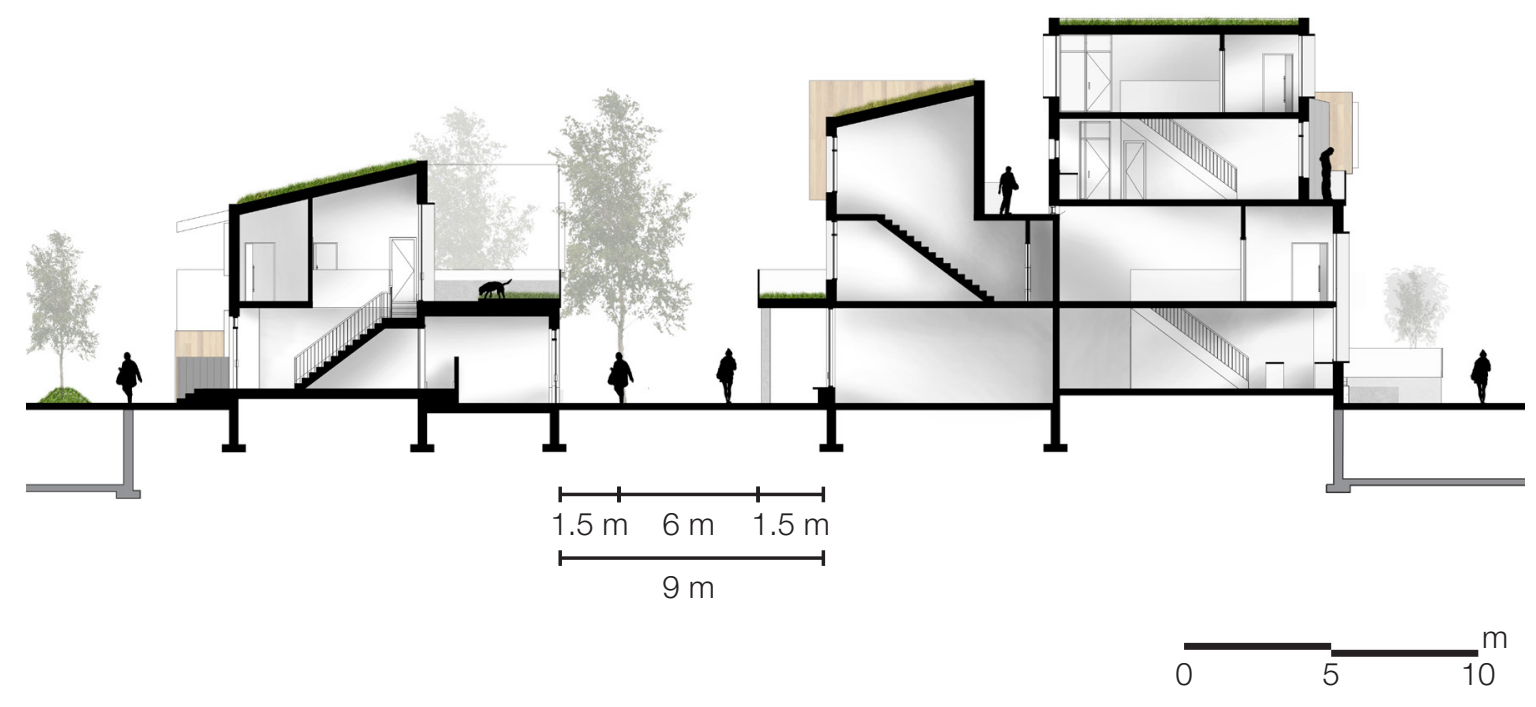

Figure 42 Primary Pedestrian Street Typical Section Showing Proportions that Relate to the Human Scale and Resulting Lighting Conditions, (Sauder, 2015). 

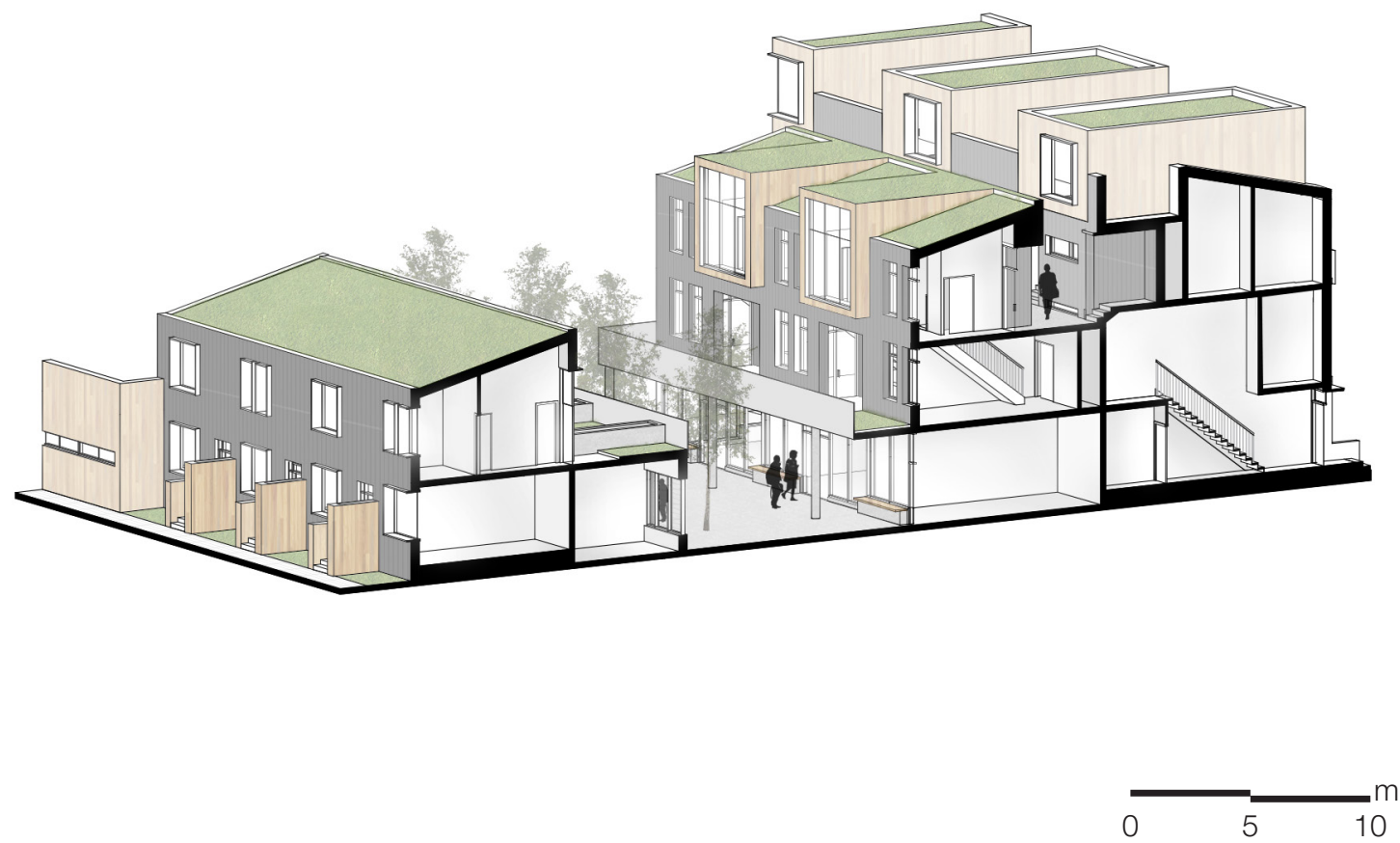

Figure 43 Environment Created Through Design Factors to Influence a Pleasant Walking Experience, (Sauder, 2015). 


\subsubsection{ACTIVATE}

As introduced in the pervious section, activate closely interacts with new circulation to create defined outdoor areas that have distinct characteristics and experiences. Together, the courtyards and pathways form a series of voids along the central axis of the site and play a crucial role in the perception of the additional density (Figure 44). New infill defines a majority of the courtyard's boundaries and distinguishes each activation from the primary pedestrian street using variances in scale, lighting, vegetation, and materiality. Additionally, the programming surrounding each activation is a mix of public amenities, offices, and commercial functions to help maintain diversity. Not only preventing homogeneity, each activation also plays a greater role in bringing life to the public environment and providing scaled outdoor spaces for the inhabitants. Originally, outdoor space was limited to large and deserted fields of grass and parking lots, which were too big without a specific function. Activation takes a different approach by offering multiple outdoor spaces throughout the site which are restricted to sizes the human can relate to. No longer feeling overpowered by overbearing towers and open field, scale and the variety of different spaces encourages residents to actually spend time outdoors and become inventive about how each space is experienced.
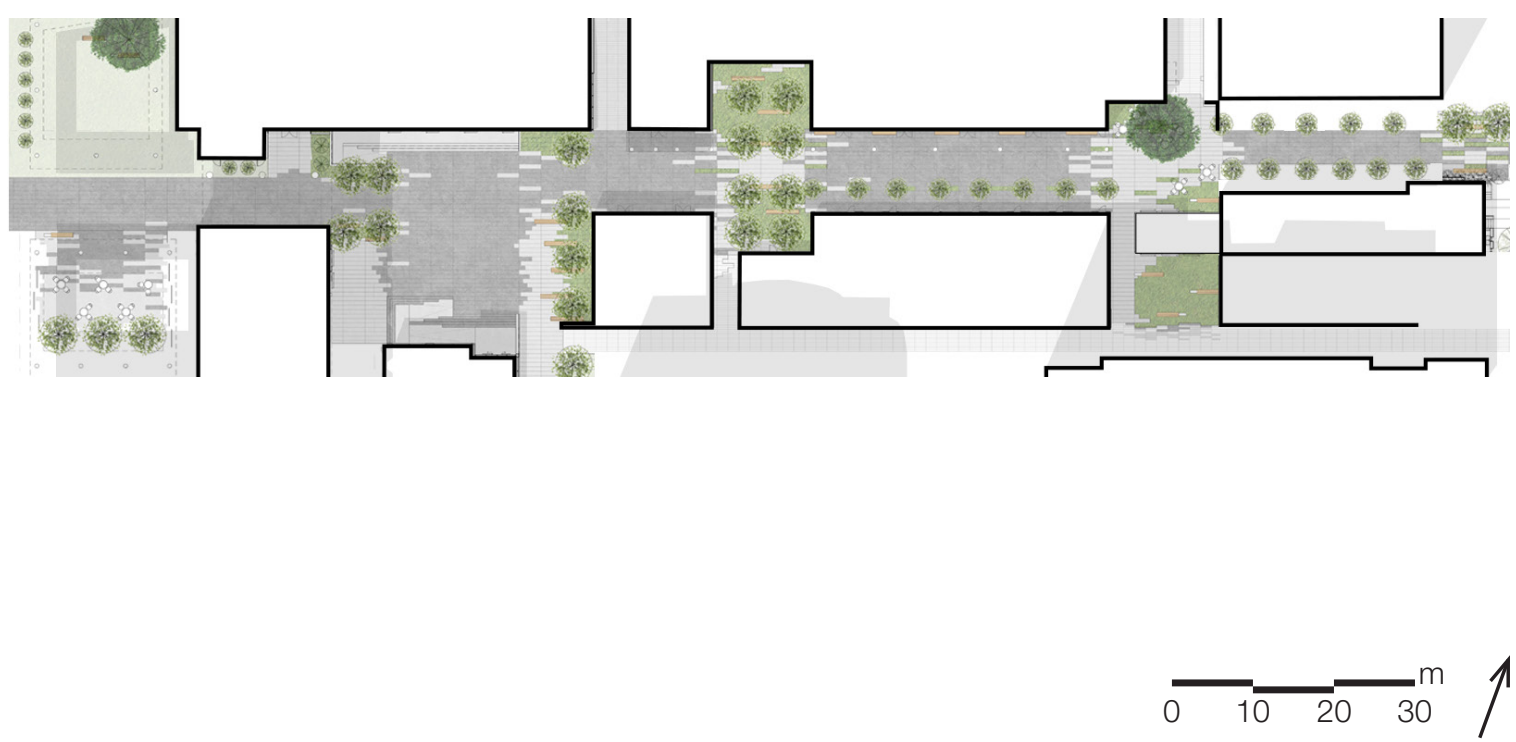

Figure 44 Voids Along the Central Axis Are Used as a Critical Component in Defining Experience, (Sauder, 2015). 
First of these active outdoor conditions is the primary courtyard as shown in Figure 45 and 46. Prominently located, this activation sits at the entrance of the pedestrian street closest to the Eglinton and Mt. Pleasant intersection, and behind the new LRT entrance. Therefore, more traffic will pass through the courtyard then others which should be reflected in its size to prevent congestion. A larger scale and central location also encourage this courtyard to act as a space for public functions and gatherings, while the others remain smaller and more relaxed areas. For pedestrians to experience this particular courtyard as the focal activation, the space must maintain a certain level of flexibility and openness. Seating, landscaping and other permeant fixtures are pushed towards the perimeter of the space, leaving the centre clear of obstructions. Additionally, new infill surrounding this courtyard caters to public amenities by placing an indoor pool across from LRT entrance. Bordering facades enclosing the LRT station, pool, and community room all remain open to promote as much interaction between the public interior and exterior environments as possible. The result is a busy and lively space that can contribute to community functions and act as an important public amenity. 

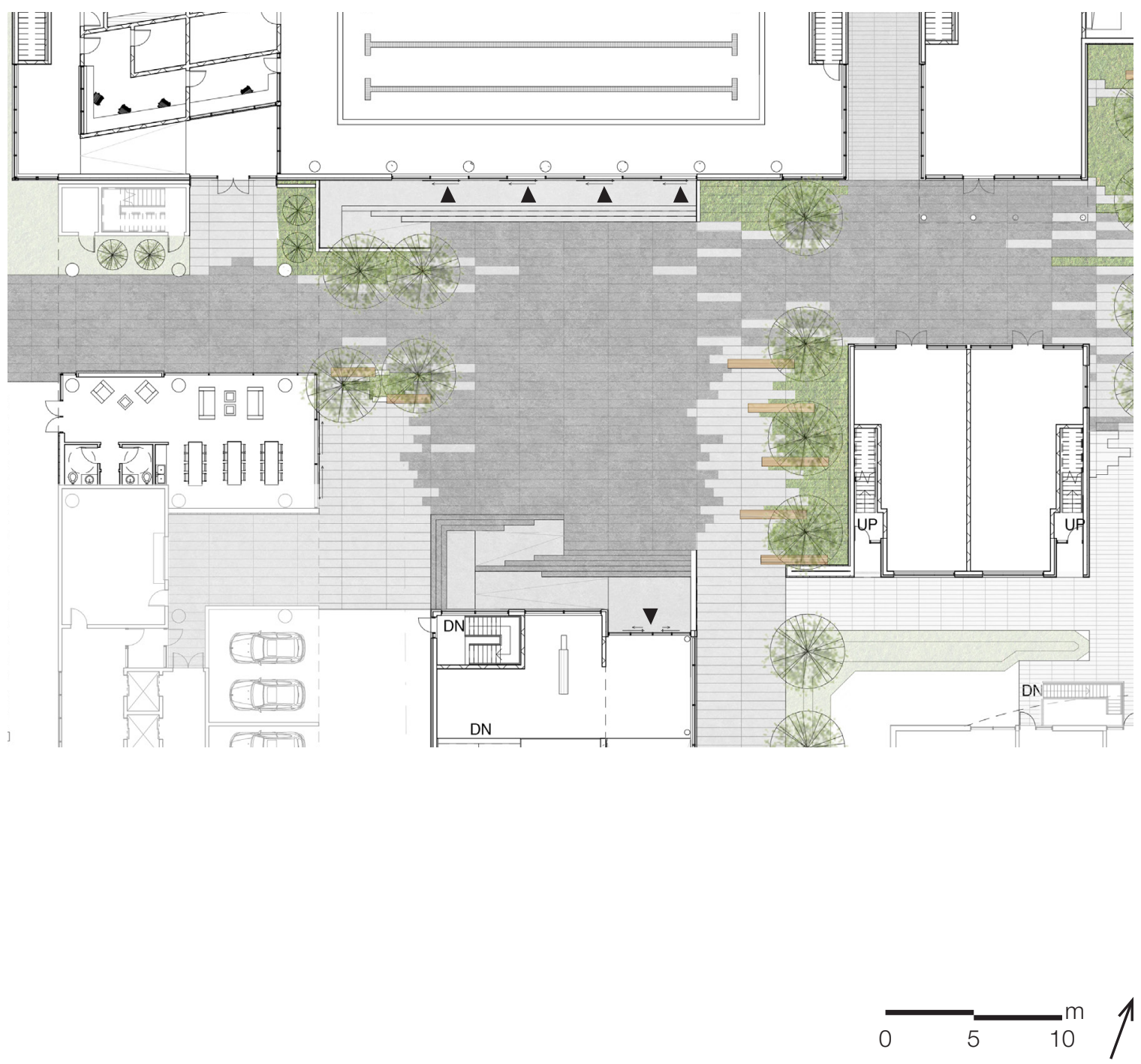

Figure 45 Plan of the Primary Courtyard, (Sauder, 2015). 

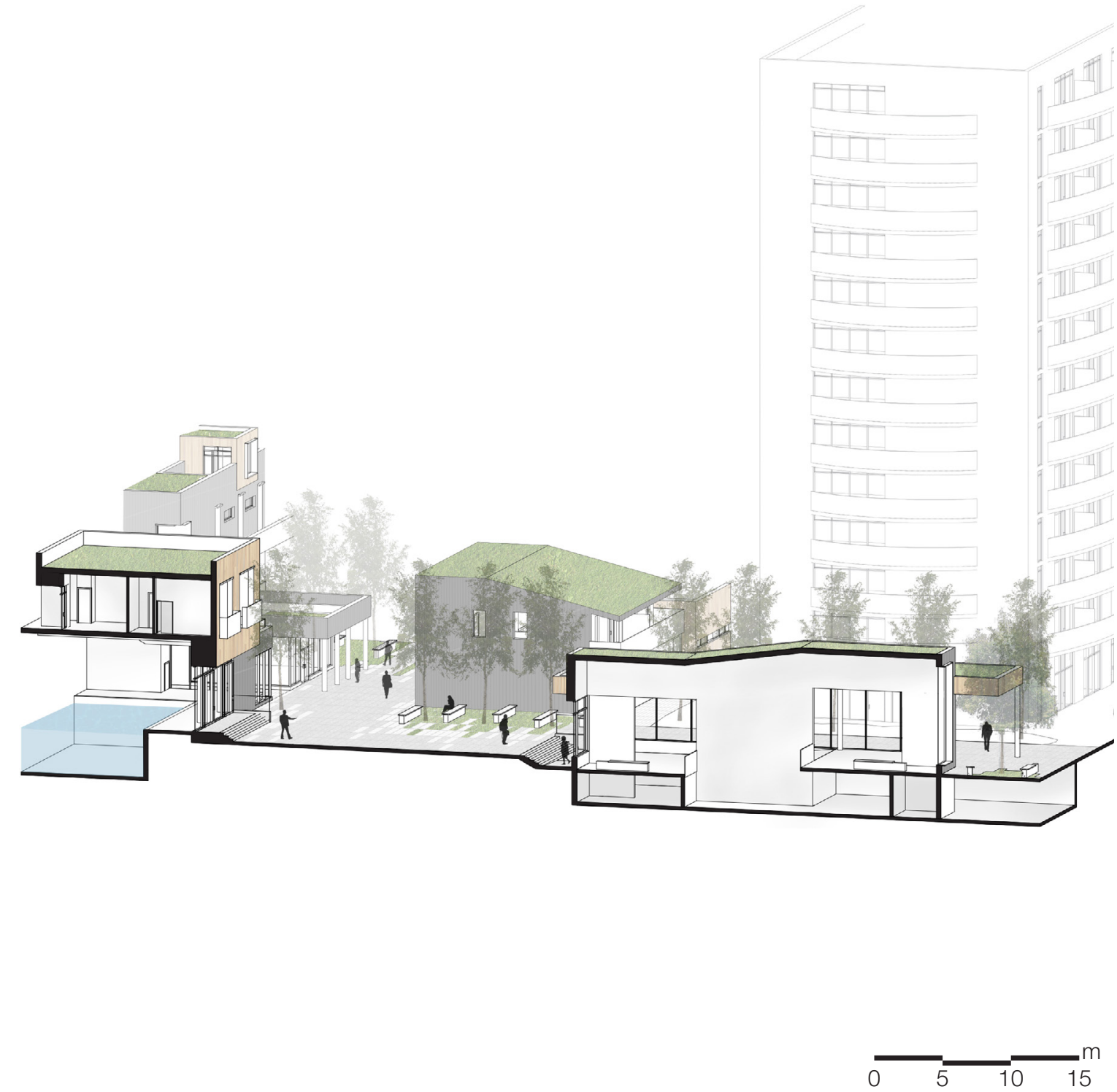

Figure 46 Primary Courtyard Surrounded by Public Amenities to Bring Traffic Through the Urban, Block (Sauder, 2015). 
The second or middle activation is located in the centre of the pedestrian street. Much smaller size, as well as more landscaping for cover, this space has a very different experience then the primary courtyard. Enclosed on all four sides by the low-rise infill and somewhat removed from the towers, this space begins to reflect a quiet oasis (see Figure 47 and 48). The change in paving from hardscape to softscape slows the pedestrian down, and the variety of shaded seating provide spaces for rest. Tree canopies also plays a critical role in the perception of this space by acting as a screen from the elevated residential units and towers above. It also helps to obscure the pedestrian's view of the towers, so their scale is less repressive to someone using the space. The choice of tree is also critical. Again, the Ginkgo tree is a good example that will grow enough canopy coverage to deliver privacy, while still allowing light to filter through. Since the towers will cast harsh shadows, light becomes a commodity and should be utilized to its full potential in all of the outdoor spaces. The end result and condition of this courtyard becomes an ideal node or destination instead of just a passage. This will help draw residents out of their units and into the public realm.
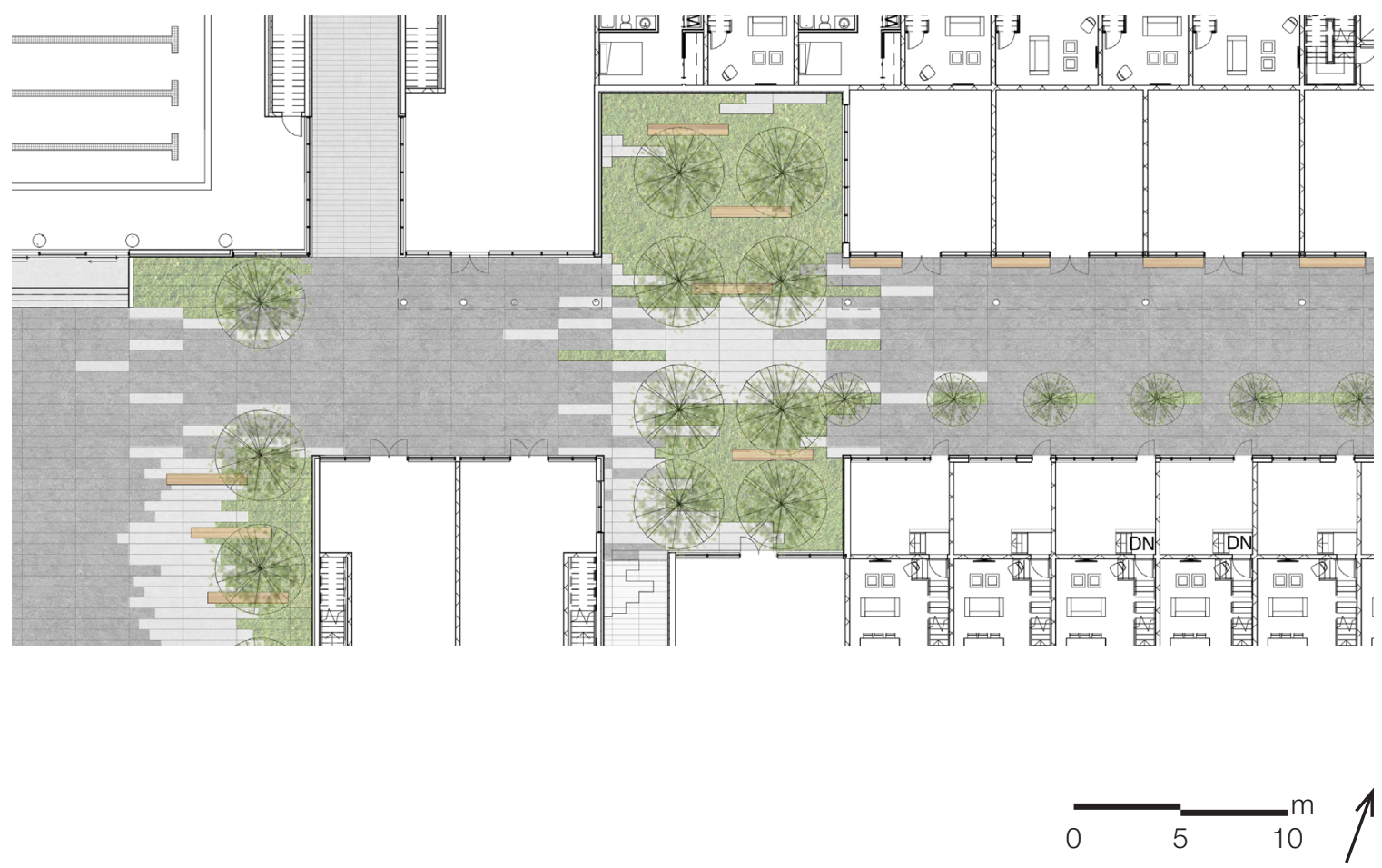

Figure 47 Forested Courtyard Plan, (Sauder, 2015). 

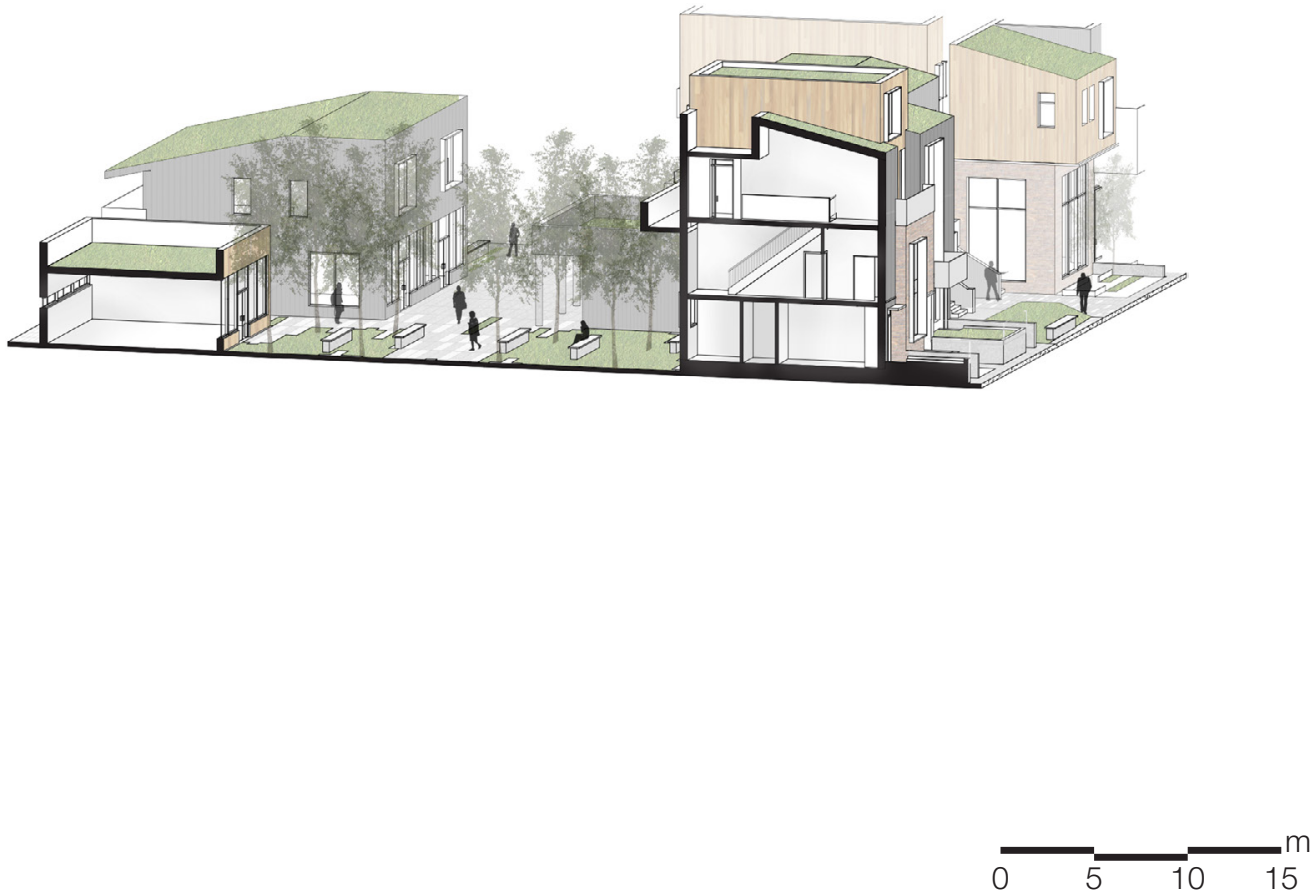

Figure 48 Forested Courtyard Crating a Relaxing Environment with Tree Canopies, (Sauder, 2015). 
Finally, the remaining activation sits on the east end of the block, closest to Rawlinson Ave, and creates another distinctive experience. Seen in Figure 49 and 50, the courtyard is intended to act as a place to socialize, lounge, and play for residents and the general public. Due to shadows that typically cover portions of the activation in the morning and early afternoons, the boundaries are kept much more open to prevent the space from feeling dark and unwelcoming. On the south edge, the courtyard's defining edge consists of a pathway and the north-east corner is made by fixed seating instead of a wall that would enclose the space like other activations. Openness is also maintained through the piece of infill that occupies the centre of the courtyard by selecting operable glass doors to enclose the space. This enables the infill to be opened and read as a pavilion or canopy instead a solid structure. Additionally, paving around the pedestrian street allows the infill to spill into the exterior environment, while the shaded soft scape provides a cool space for children to play. In doing so, the activation creates a more casual experience for residents to gather, or pedestrians to stop and rest.
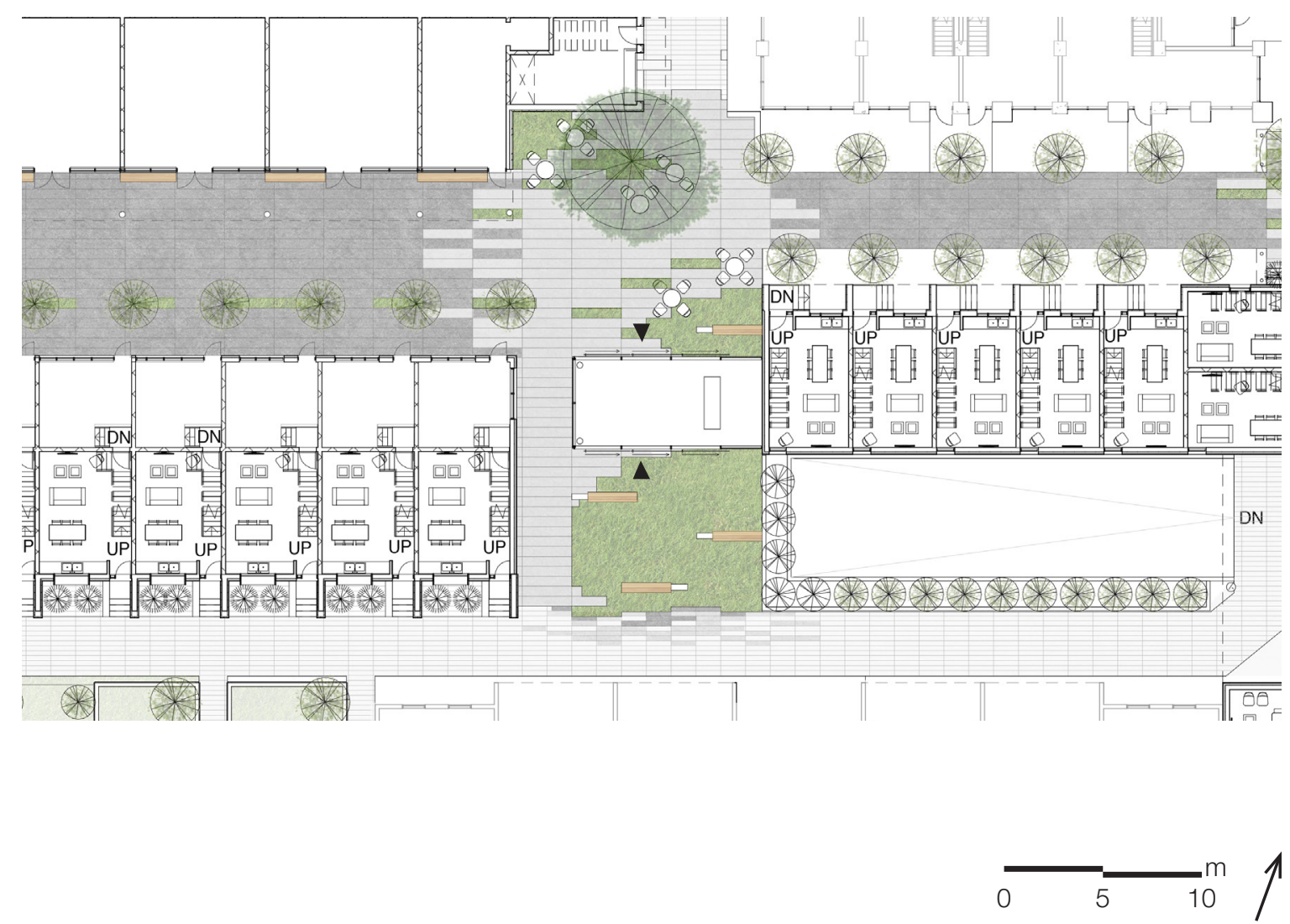

Figure 49 Parked Courtyard Plan, (Sauder, 2015). 


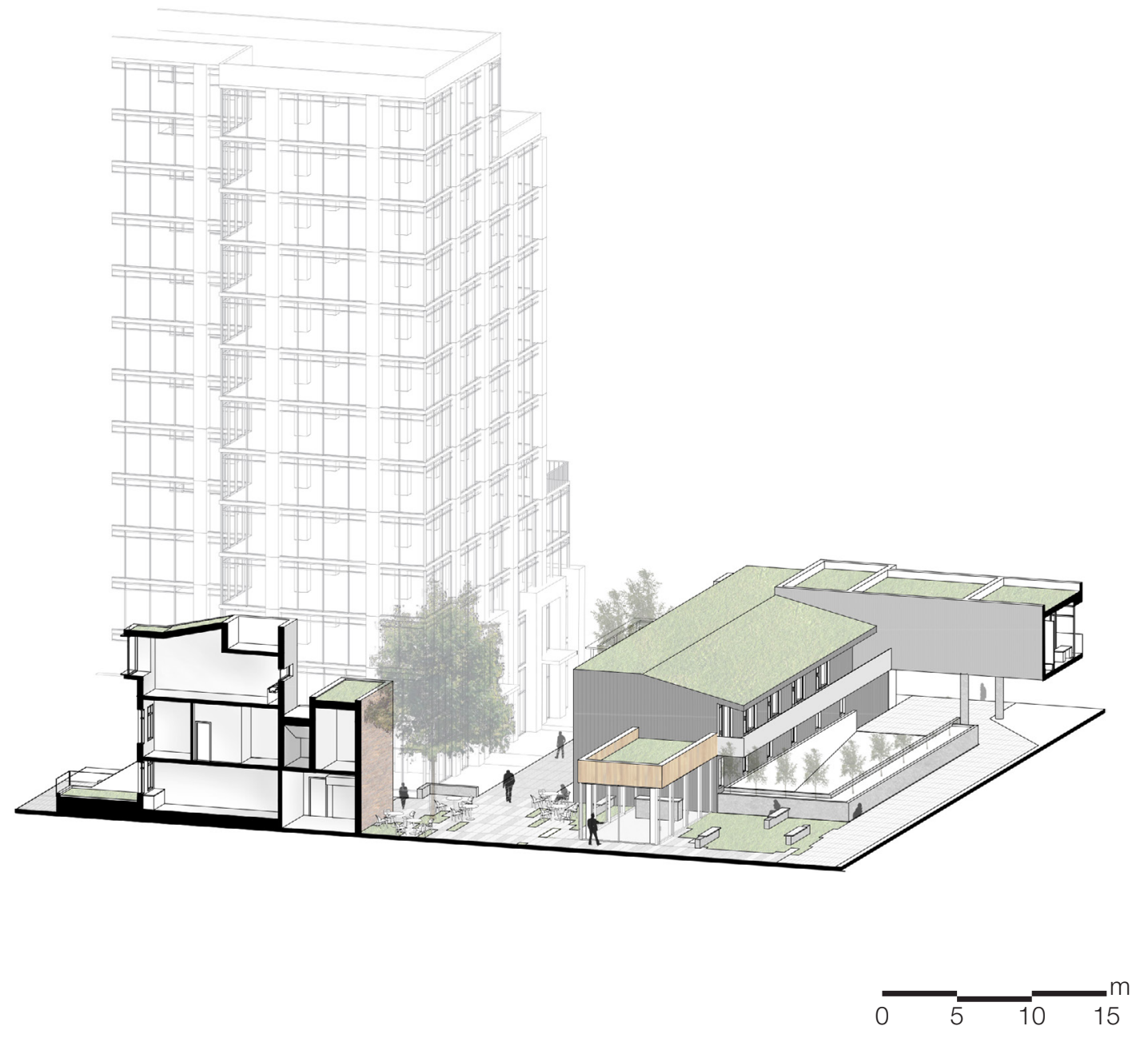

Figure 50 Parked Courtyard Opening to Form a Larger Activation, (Sauder, 2015). 


\subsubsection{INFILL}

Defining the edges of each activation, infill forms a series of mixed-use units that bring new physical density and increased land-use intensity to the site. As see in Figure 51, the infill acts as solid elements in contrast to the voids created in the fragment and activate strategies. Therefore, the new structures are also broken down to define the edges of outdoor spaces and prevent infill from becoming an oversized obstruction in the previous open field. Fragmenting infill's footprint also allows more light to pass into the site and emphasizes exterior spaces as primary focus of design.
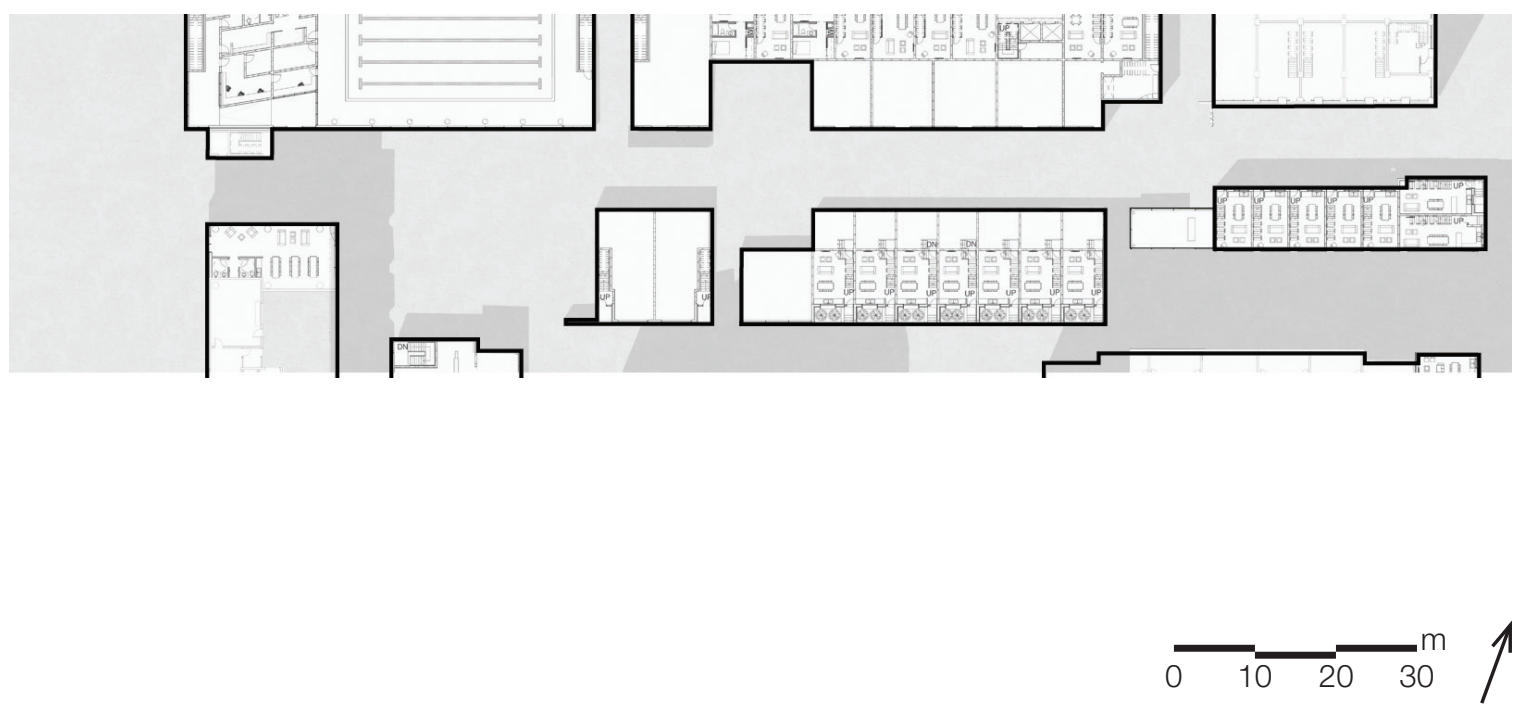

Figure 51 Defining Boundaries of Infill, (Sauder, 2015).

Continuing to activate the pathways and courtyards, each new unit has a direct connection to the public realm as seen in the various plans (Figures 52-58). Linking the public with private residents generates a sense of familiarity for inhabitants and allowing them to bond with the area as if they were living in a conventional low-rise neighbourhood. Permitting more access to grade and incorporating the highest level of population density, without sacrificing quality of experience, requires each unit to become very narrow and multi leveled. A second level of units is added above with an elevated exterior pathway so residents have the same connection to the outdoors as bellow. 


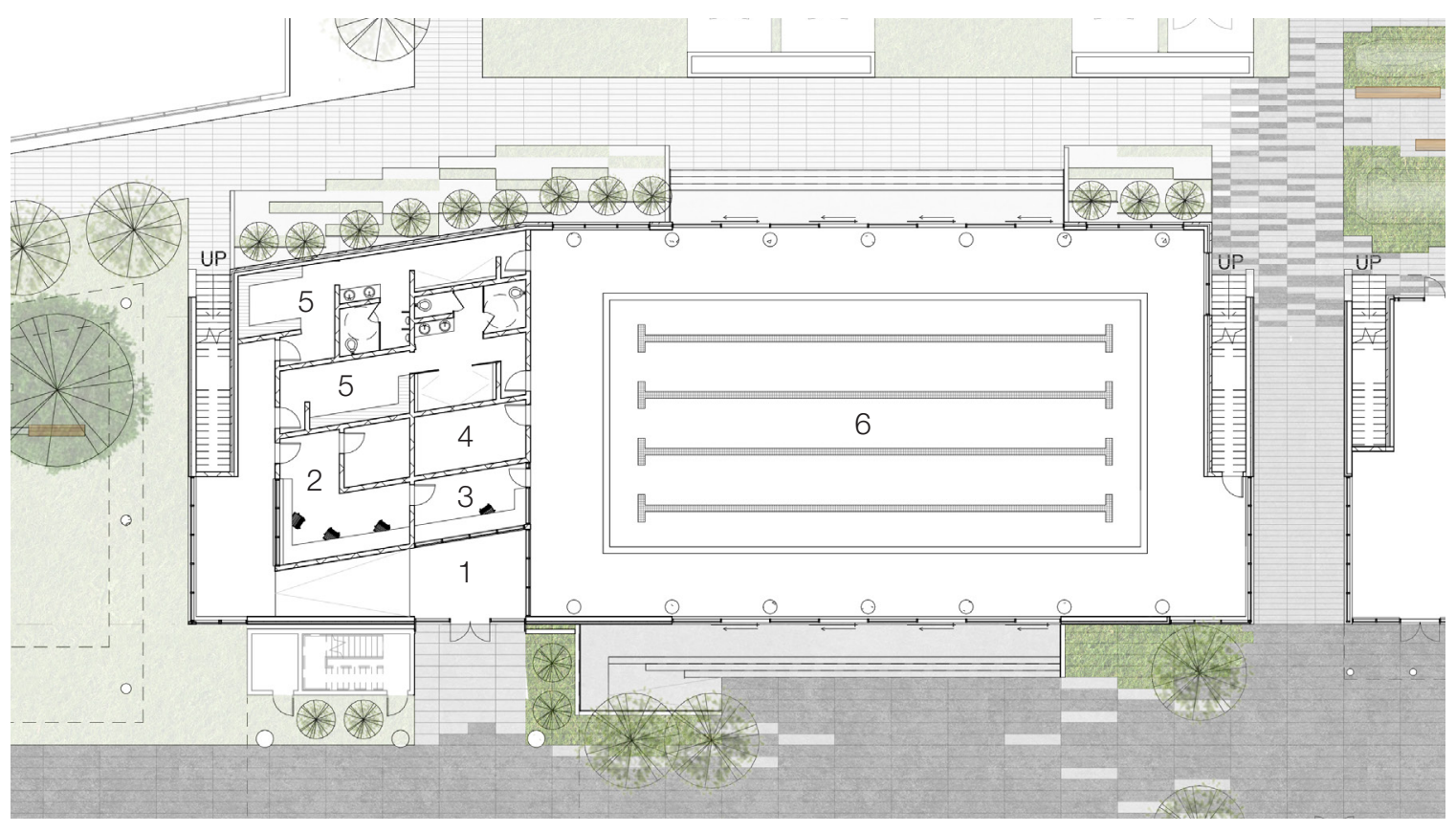
1. Entrance
2. Admin. Office
3. Guard Office
4. Pump Room
5. Change Room
6. Pool

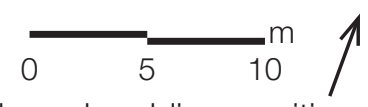

Figure 52 Public Pool and Residences - Level 1, Bringing temporary density through public amenities, (Sauder, 2015). 


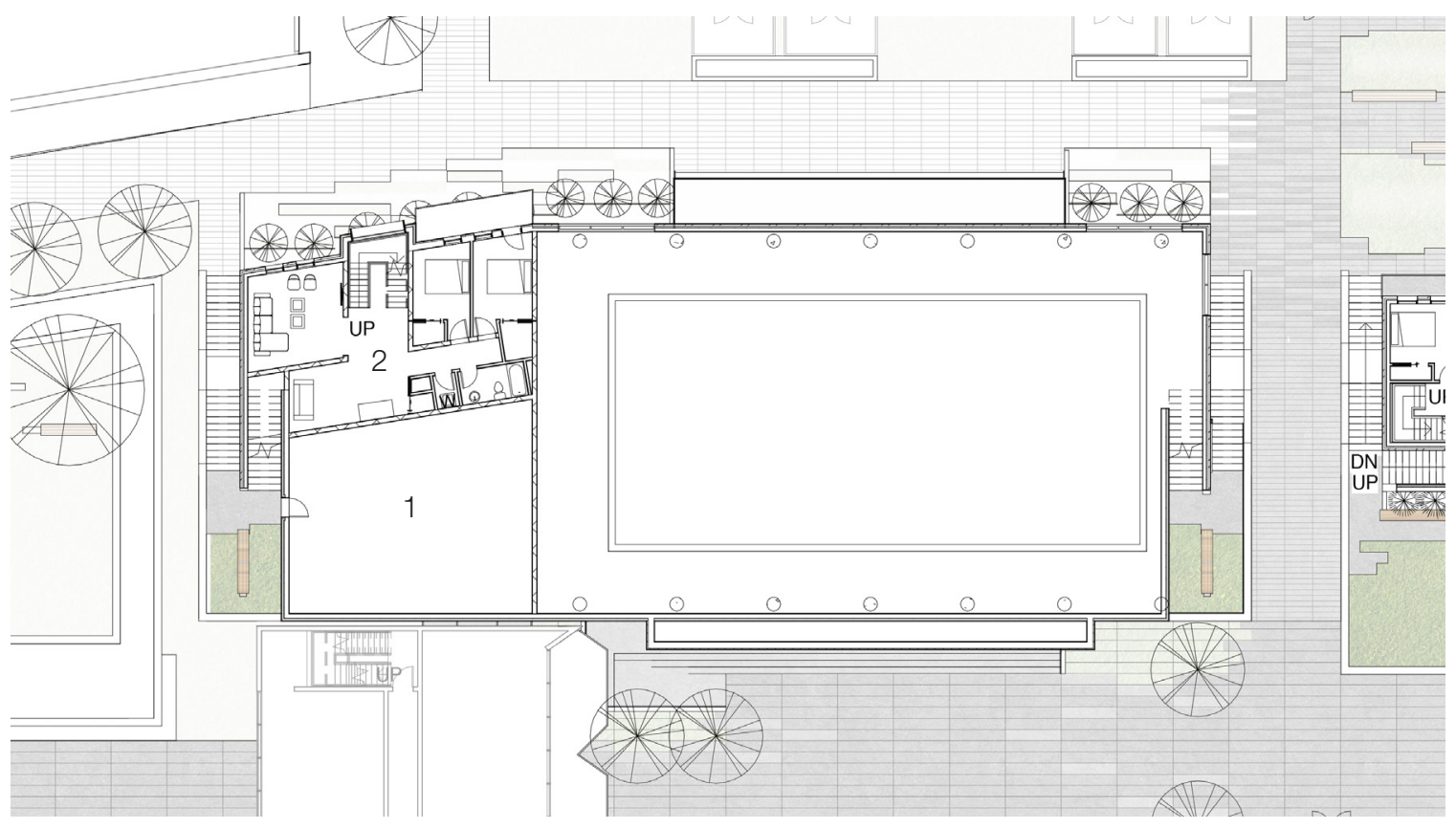

1. Mech. Room

2. Residents

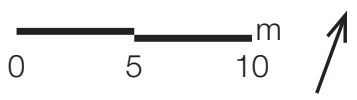

Figure 53 Public Pool and Residences - Level 2, (Sauder, 2015). 


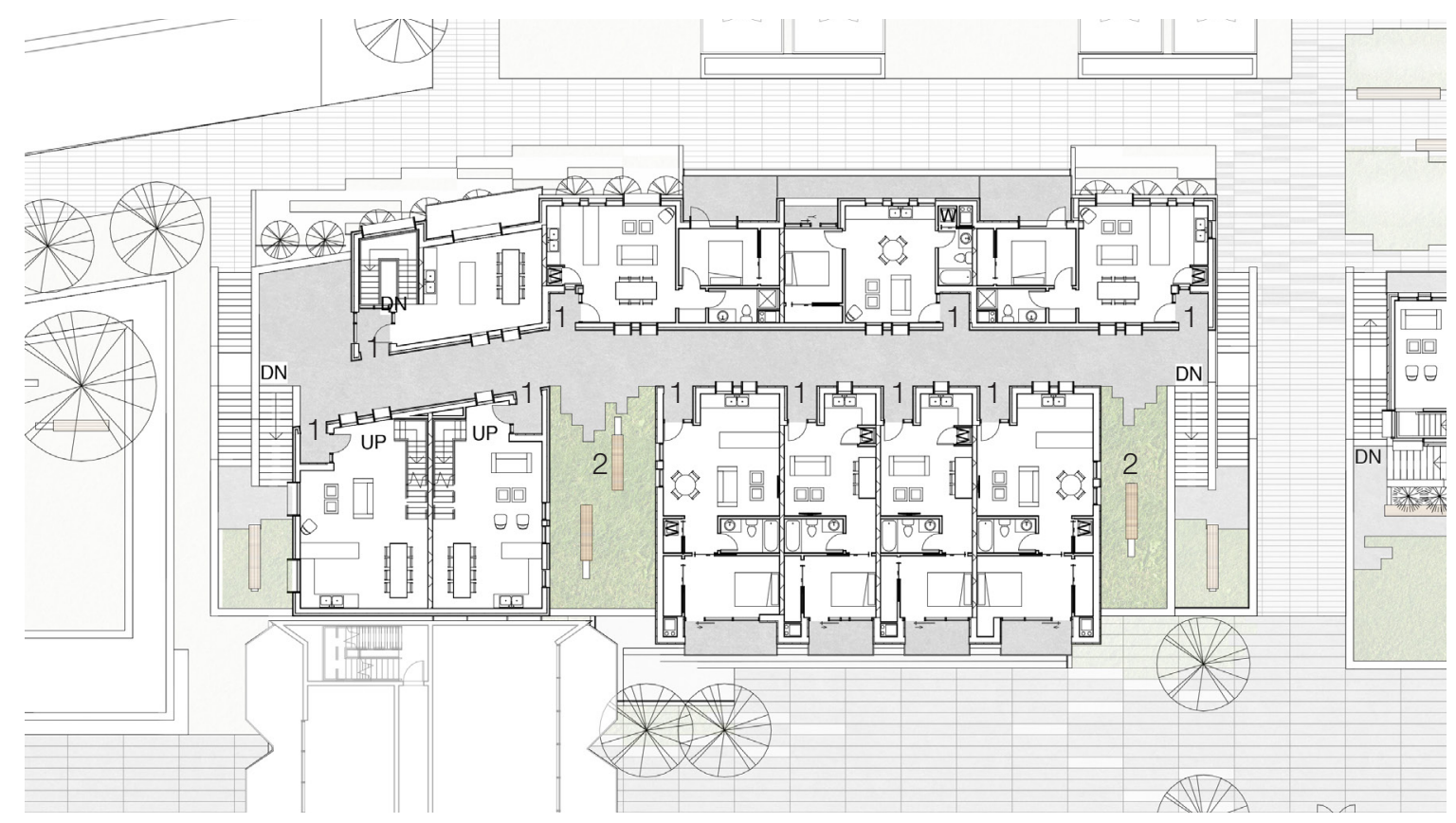

1. Residents

2. Secondary Activation

Figure 54 Public Pool and Residences - Level 3, Elevated Units with Access to Outdoor Circulation, (Sauder, 2015). 


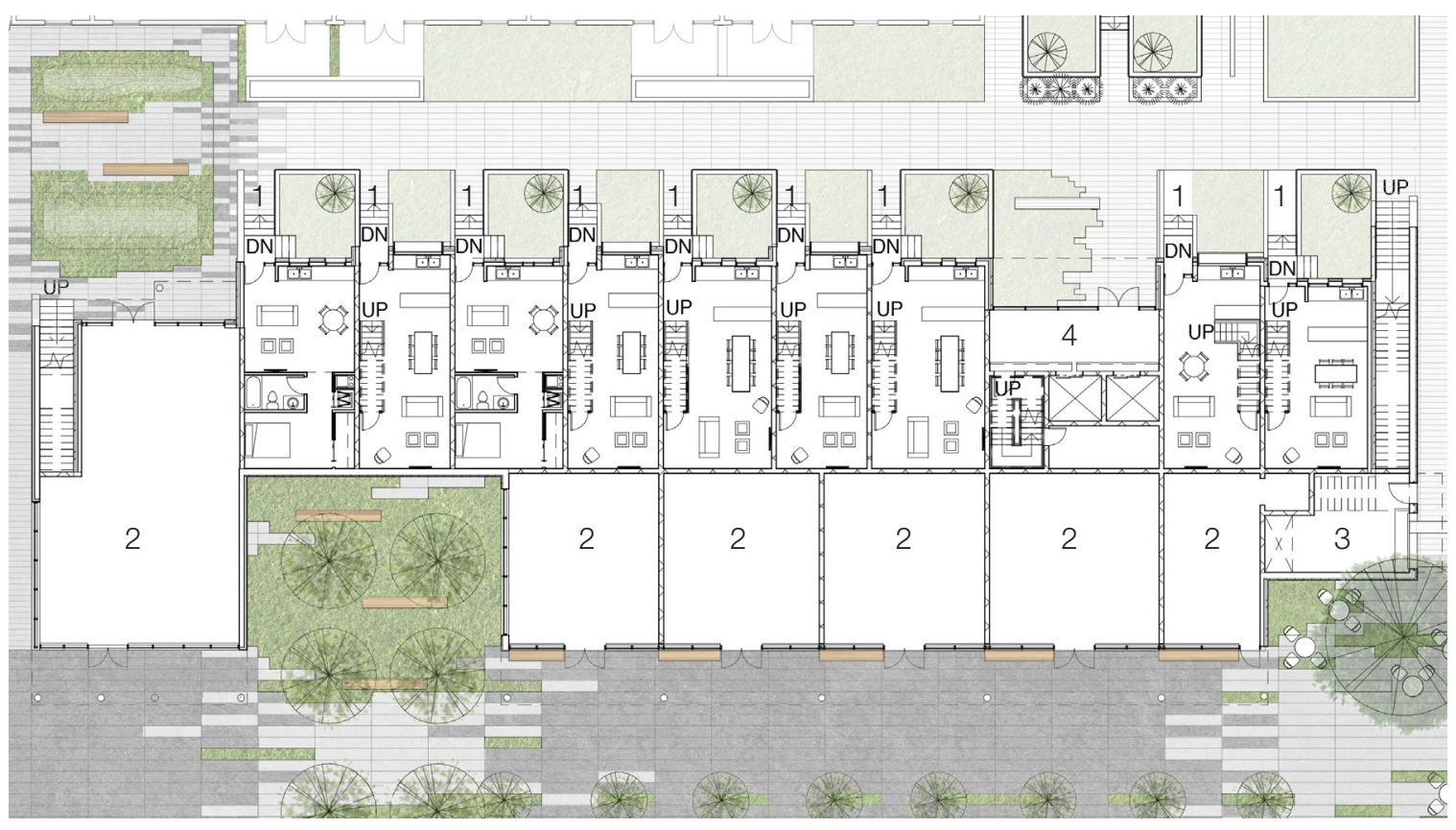
1. Residents
2. Commercial/ Office
3. Services
4. Elevator Entrance

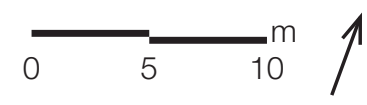

Figure 55 Commercial/Offices, Live-work and Residences - Level 1, (Sauder, 2015). 


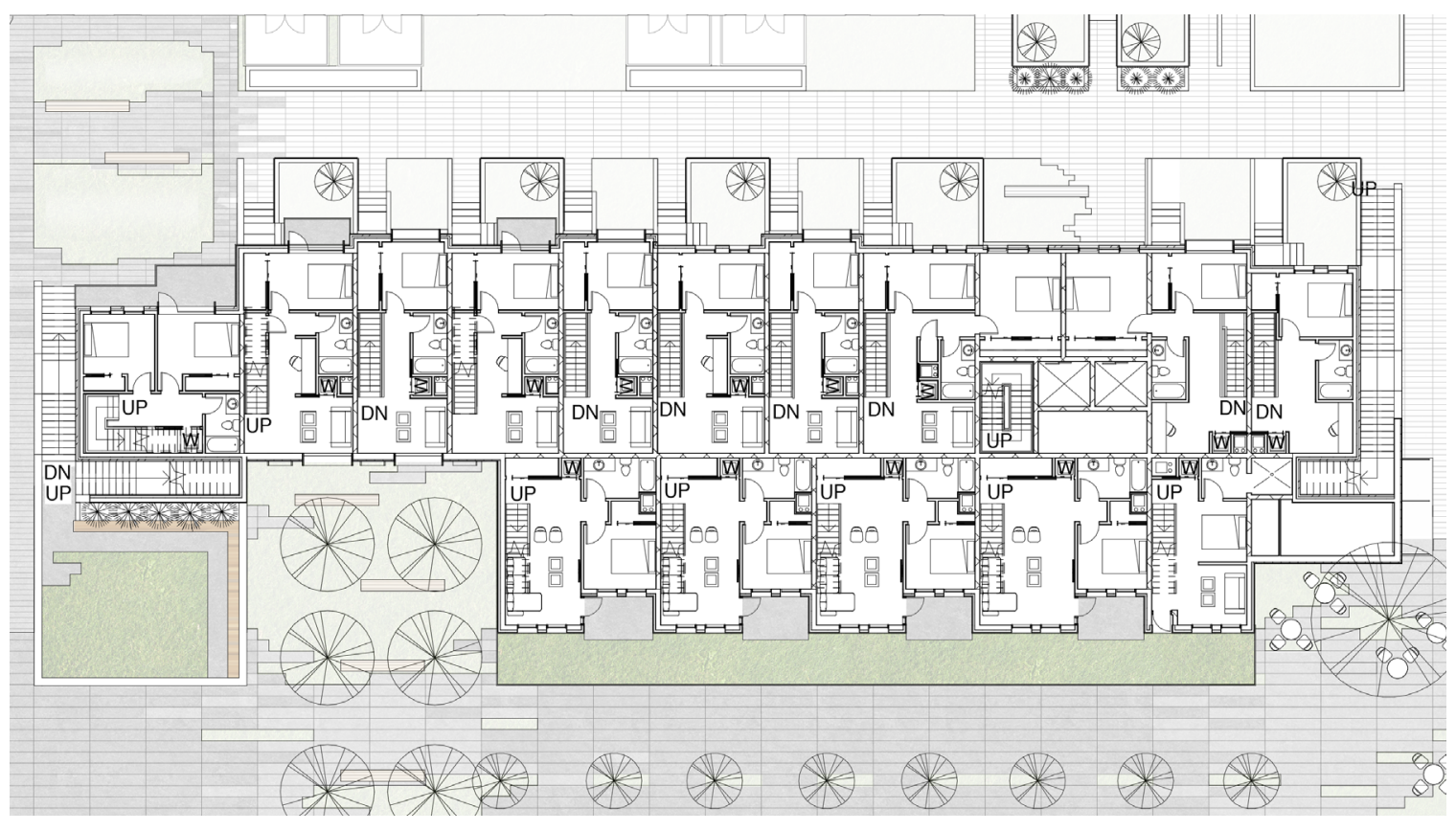

1. Secondary Activation

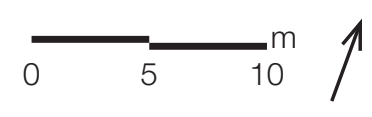

Figure 56 Commercial/Offices, Live-work and Residences - Level 2, (Sauder, 2015). 




1. Residents

2. Elevator Entrance

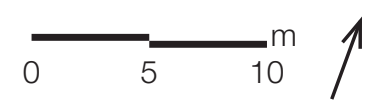

Figure 57 Commercial/Offices, Live-work and Residences - Level 3, (Sauder, 2015). 

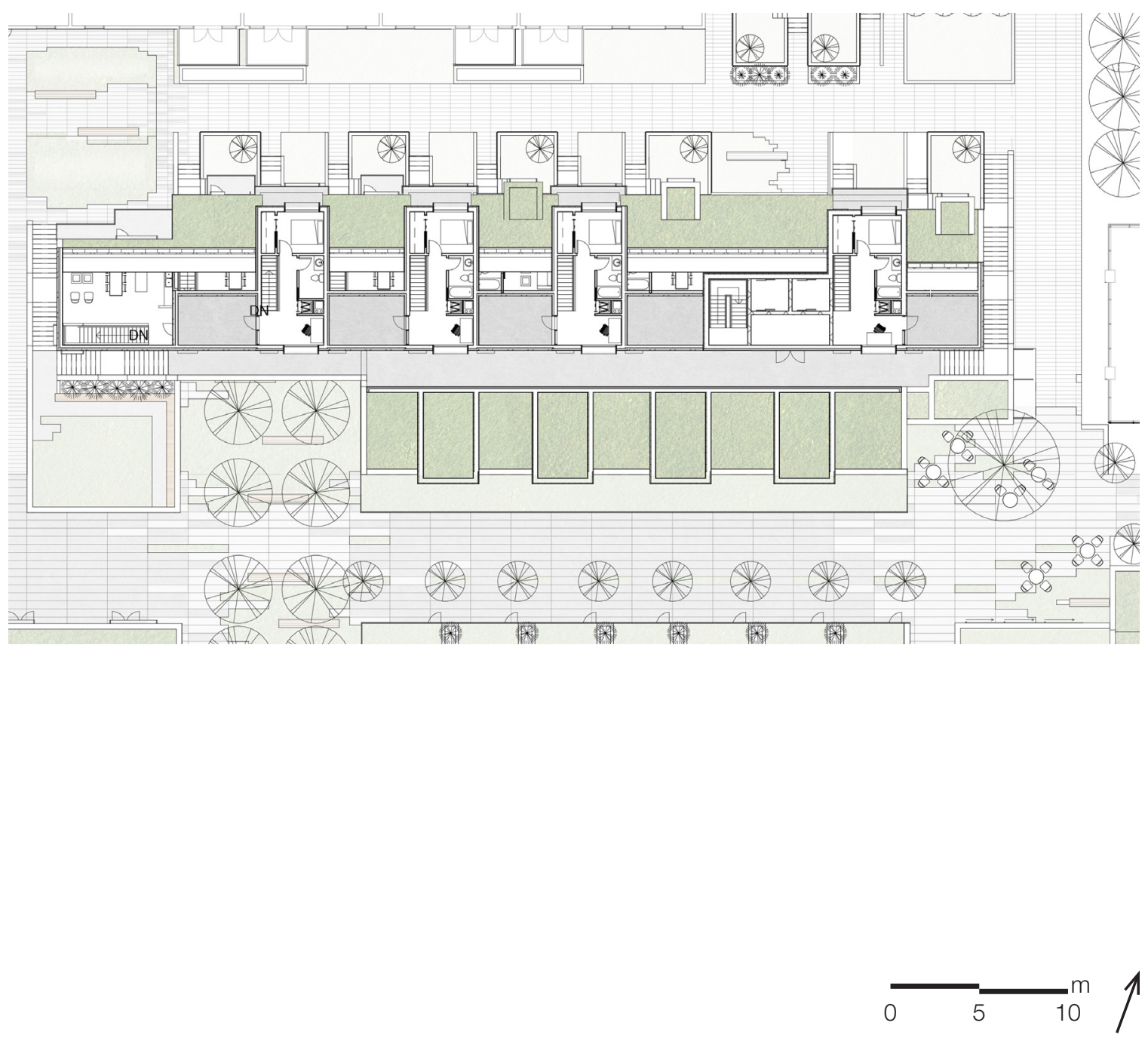

Figure 58 Commercial/Offices, Live-work and Residences - Level 4, (Sauder, 2015). 
To understand the physical connection each residential unit has with pedestrian circulation, a typical section is shown in Figure 59. Live-work and commercial/office units have an entrance at grade to the primary pedestrian street, while residential units are raised and accessed through secondary pathways. Additionally, elevated units each have an exterior space that overlooks the pedestrian circulation to create a visual link to the ground plane. Setbacks, undulating facades, and the colonnade canopy make up the outdoor areas that form the visual link as well as forming additional living space. The section also reveals sloped green roofing used for reducing the building scale along the ground level circulation and creating a visually appealing surface. Rooftops seen from residential units above are also reminiscent of the former unused grass field and help the new physical density to seamlessly integrate into the site without feeling overbearing.

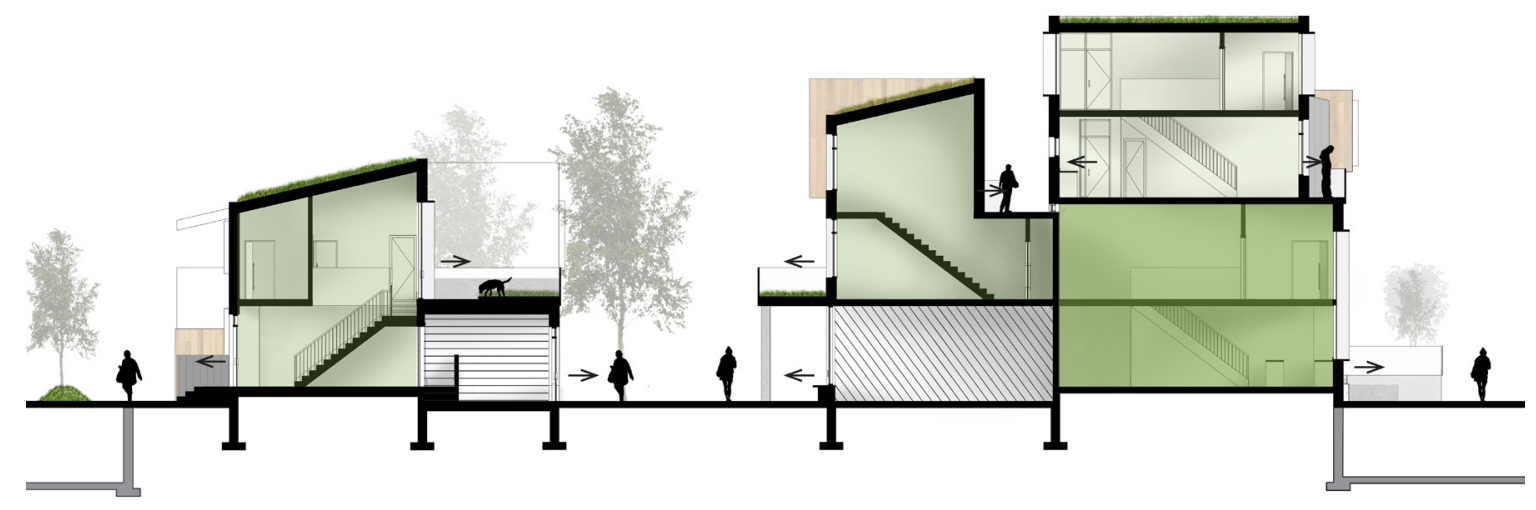

Residential Unit Mixed Use Unit

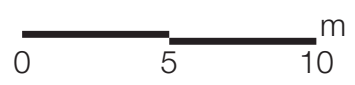

Figure 59 Typical Infill Section Showing Unit Variation and Connection to the Outdoor Environment, (Sauder, 2015). 
In addition to carefully controlling the exterior perception of density, the design also ensures the interior units maintain the same pleasurable experience. Selecting typical units, Figure 60, exemplifies common considerations that were taken to prevent crowding, despite the higher density. Recessed entrances bring the inhabitants into the kitchen first, the most public area of the home, which opens into the remainder of the living space. Large glazing in the kitchen brings natural daylight deep into the deep units, and the sense of spaciousness is increased with high ceilings. All areas of the home considered to be private are on the second level. Sleeping quarters are pushed to the outer edge of the infill to allow for daylight, while circulation and washrooms are pushed to the back. In cases where there is not enough natural light entering a unit, a second bedroom will be sacrificed to ensure the spacial quality is preserved.

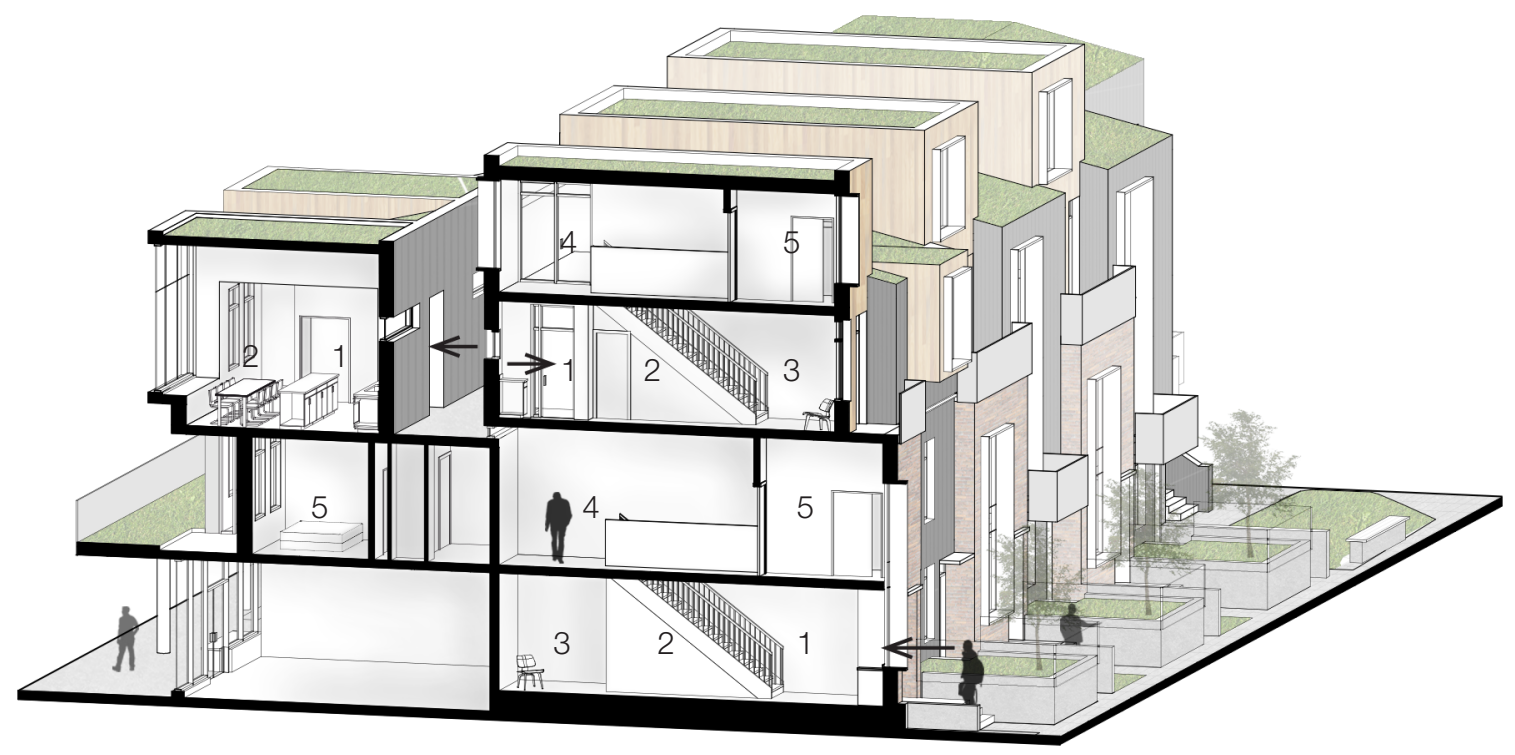

$\begin{array}{ll}\text { 1. Kitchen } & \text { 4. Den } \\ \text { 2. Dinning } & \text { 5. Sleeping } \\ \text { 3. Living } & \end{array}$

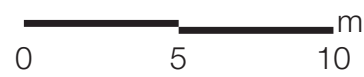

Figure 60 Typical Residential Unit Layout and Considered Design Factors, (Sauder, 2015). 
The result of these light and open units, in addition to the multiple commercial/office, is an increase in physical and population density, as well as land-use intensity for the urban block. With 63 additional residential units and nine commercial/office units, the infill is able to accommodate a variety of the Yonge-Englinton centre's growth. Shown in Table 2, the estimated population density of the site grows from 0.08 to 0.1 people per squared meter, representing a ten per cent increase in permeant residents. Also, a potential 15 per cent increase in temporary population density can also be attributed to the new public pool, LRT station, and commercial/office programing. Despite these new quantities, additional traffic migrates through the pedestrian friendly site (Figure 61) to reach nearby schools, or use the block as a shortcut. Therefore, the quantifiable statistics that are accounted for through infill are only a portion of the activity generated by emphasizing experiential density.

\section{UNIT INCREASE}

\begin{tabular}{lll}
\hline Retail/Office & 9 Units & $613 \mathrm{~m}^{2}$ \\
Live Work & 7 Units & $696 \mathrm{~m}^{2}$ \\
Bachelor & 5 Units & $243 \mathrm{~m}^{2}$ \\
1 Bedroom & 20 Units & $1,323 \mathrm{~m}^{2}$ \\
1 Bedroom + Den & 17 Units & $1,332 \mathrm{~m}^{2}$ \\
2 Bedroom & 9 Units & $853 \mathrm{~m}^{2}$ \\
2 Bedroom + Den & 5 Units & $616 \mathrm{~m}^{2}$ \\
\hline Total & 72 Units & $5,676 \mathrm{~m}^{2}$
\end{tabular}

\section{ADDITIONAL DENSITY CALCULATION}

\begin{tabular}{ll}
\hline Estimated Original Population: & 1,680 persons \\
New Additional Population: & 180 persons \\
\hline Total Population: & 1,860 persons \\
\hline New Population Density: & 0.01 people $/ \mathrm{m}^{2}$ \\
Increase in Density: & $10 \%$
\end{tabular}

\section{PROJECTED TEMPORARY INCREASE} IN POPULATION

\begin{tabular}{ll}
\hline Retail Occupancy: & 166 persons \\
Public Pool Occupancy: & 83 persons \\
Total Temporary Population: & 249 persons \\
\hline $\begin{array}{l}\text { Temporary Increase in } \\
\text { Population Density }\end{array}$ & $15 \%$
\end{tabular}

+ additional population migrating through the now pedestrian friendly site

Table 2 Additional Density Generated Through Infill, (Sauder, 2015). 


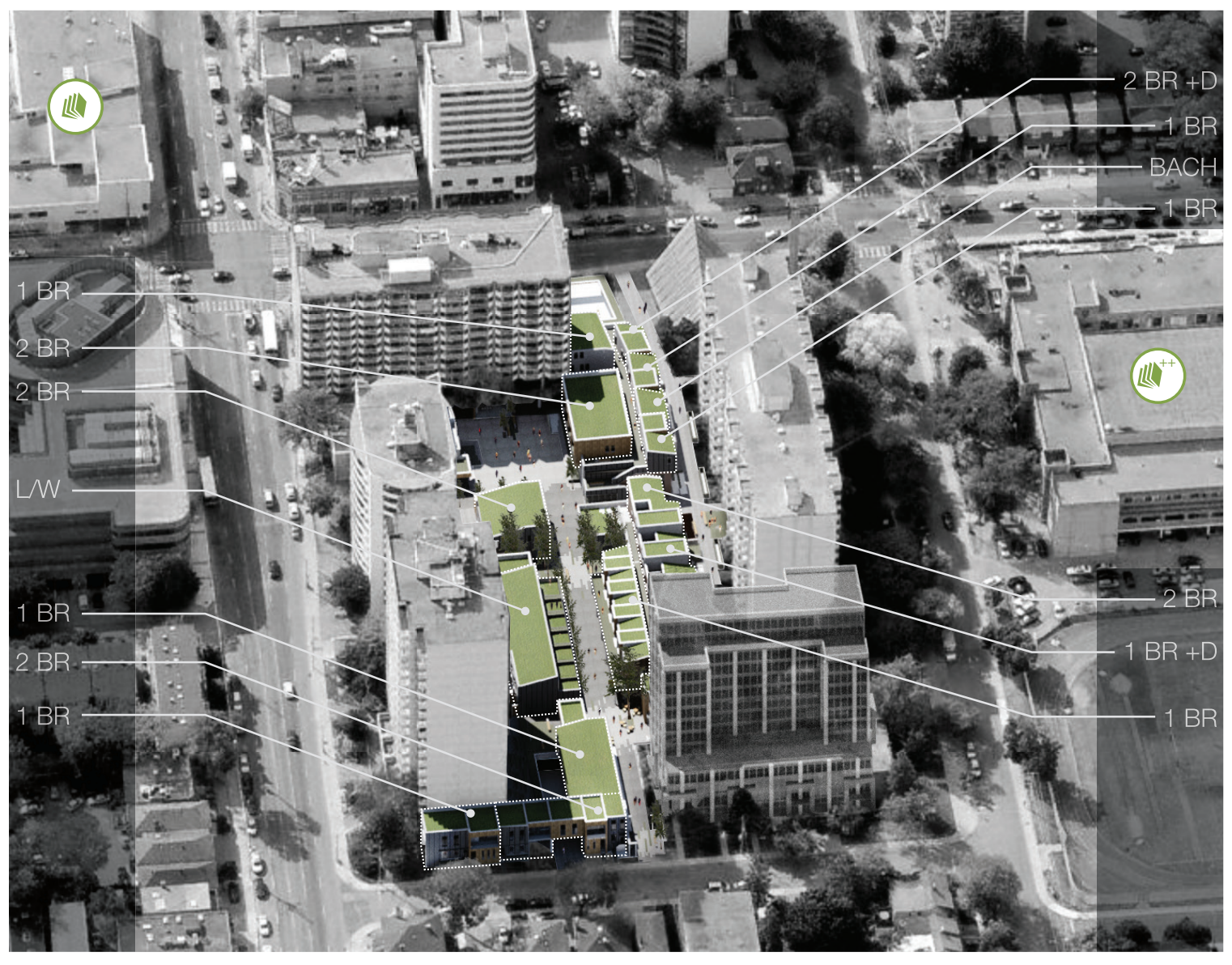

Figure 61 Formation of Pathways Breaking Down the Oversized Block Which Increase Traffic And Activity (Aerial Photo Retrieved From Bing Maps, 2015, Image By Sauder, 2015). 


\subsubsection{MEDIATE}

Density brought to clusters of slab towers and distributed throughout the interior of the block with fragmentation, activation, and infill effectively create a pedestrian friendly experience and are tied together in the final strategy, mediate. Continuing to look at the units generated through infill, mediate is carefully used to distinguish private residential programing from public pathways. Referencing the earlier low-rise neighbourhood study, Figure 62 illustrates design decisions used to formulate the required separation. Imposing setbacks between pedestrian circulation and unit entrances distances the two spaces from one another, while elevating outdoor yards strengthens the division and ensures the area maintains a similar openness to a conventional residential street. Additionally, all entrances

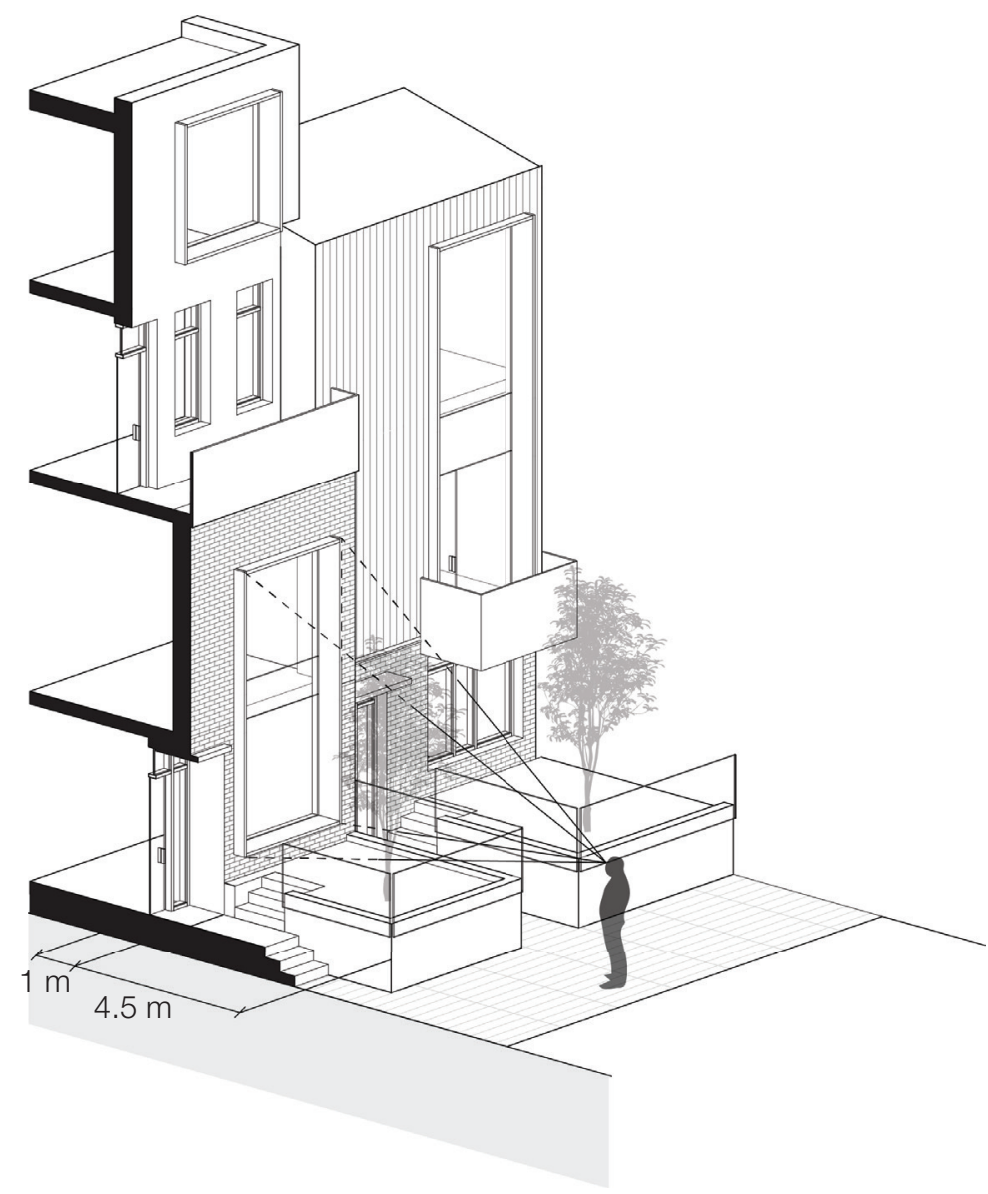

Figure 62 Transitional Areas Between Pathways and Residential Units to Mediate Privacy, (Sauder, 2015). 
are recessed or covered to emulate the transitional area of a front porch, where the space is neither in the public street or private domain. Contrary to the niched entrances, large windows required for bring natural daylight into the interior pose concern for residential privacy. To resolve this, window frames are extruded to restrict angled views and trees planted in setback create a visual barrier between the path and facade. These decisions also play a critical role in the separation of infill from adjacent towers. Shown in Figure 63 an additional setback and new vegetation exist between the pathway and residential apartments which also enhances the privacy of the existing units. These elements in conjunction with tactics placed in front of infill mediate the differences between spaces and impose privacy between units, helping to avoid the sensation of overcrowding.

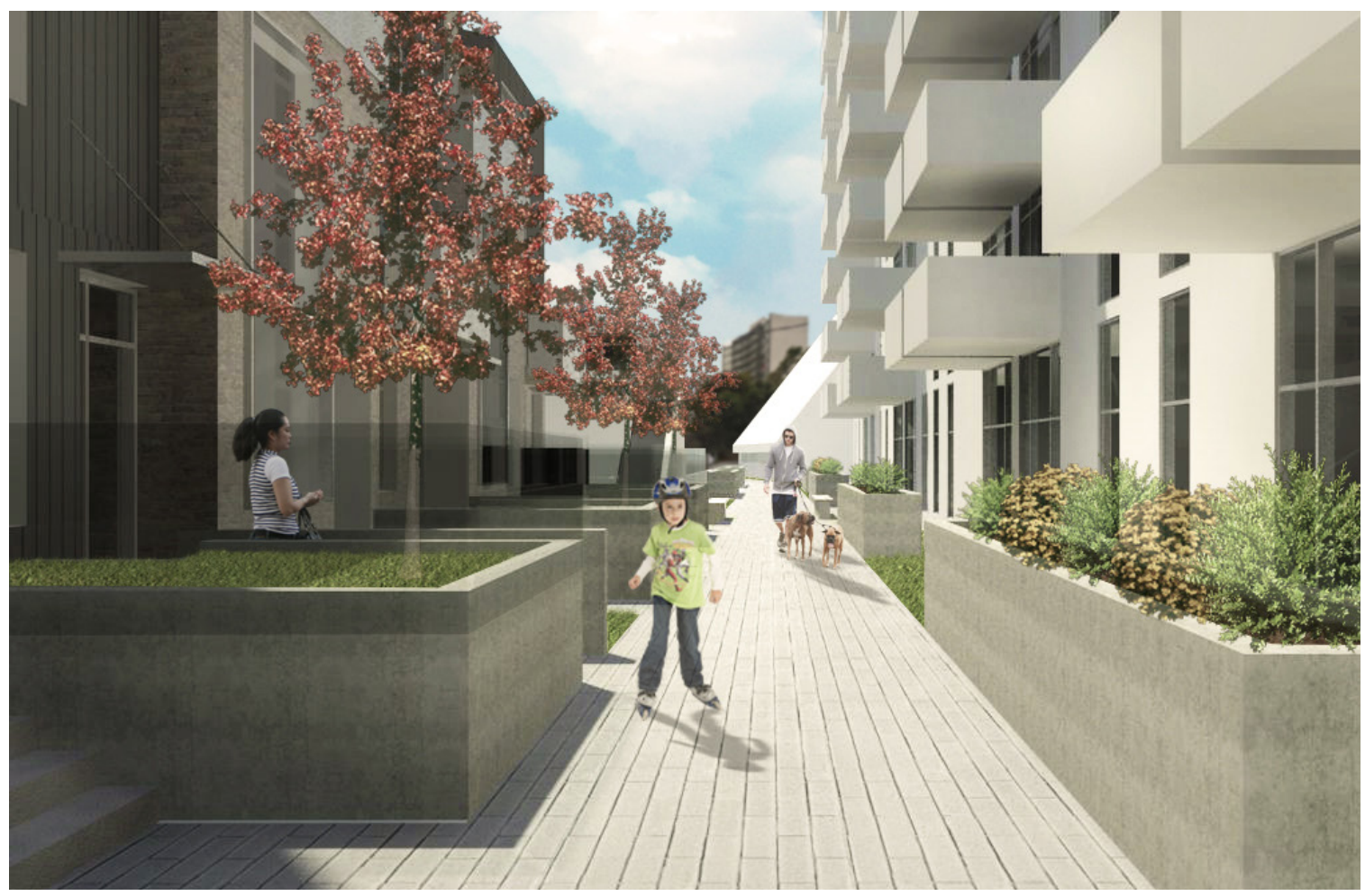

Figure 63 Resulting Environment Between Infill and Slab Towers Created Through Mediation, (Sauder, 2015). 
Apart from mediate's role in creating privacy and separation between pathways and residential units, it also plays an important role in the experience of the public realm. Focusing on the primary activation, mediate is used to draw pedestrians into the site and generate a lively and open experiences unlike the closed off residential units. As seen in Figure 64 the LRT entrance contains a long gradual ramp to draw people towards the courtyard and bring them to the interior of the block. Changes in elevation signify to the pedestrian they are leaving the city street, and entering an new public environment on the other side. Enclosing the ramp as part of the LRT station fabricates a physical barrier pedestrians must travel through, but the glazed walls maintain a visual connection and make pedestrians aware of the communal area beyond. Once in the primary activation, the space itself appears very open and solid boundaries are replaced with more glazing to unite the public interior and exterior. Immediately across from the LRT station lies the pool with an operable translucent facade so the spaces can actively engage one another. However, as the wall opens additional changes in elevation maintain the perimeter of the courtyard and distinguish the two space.

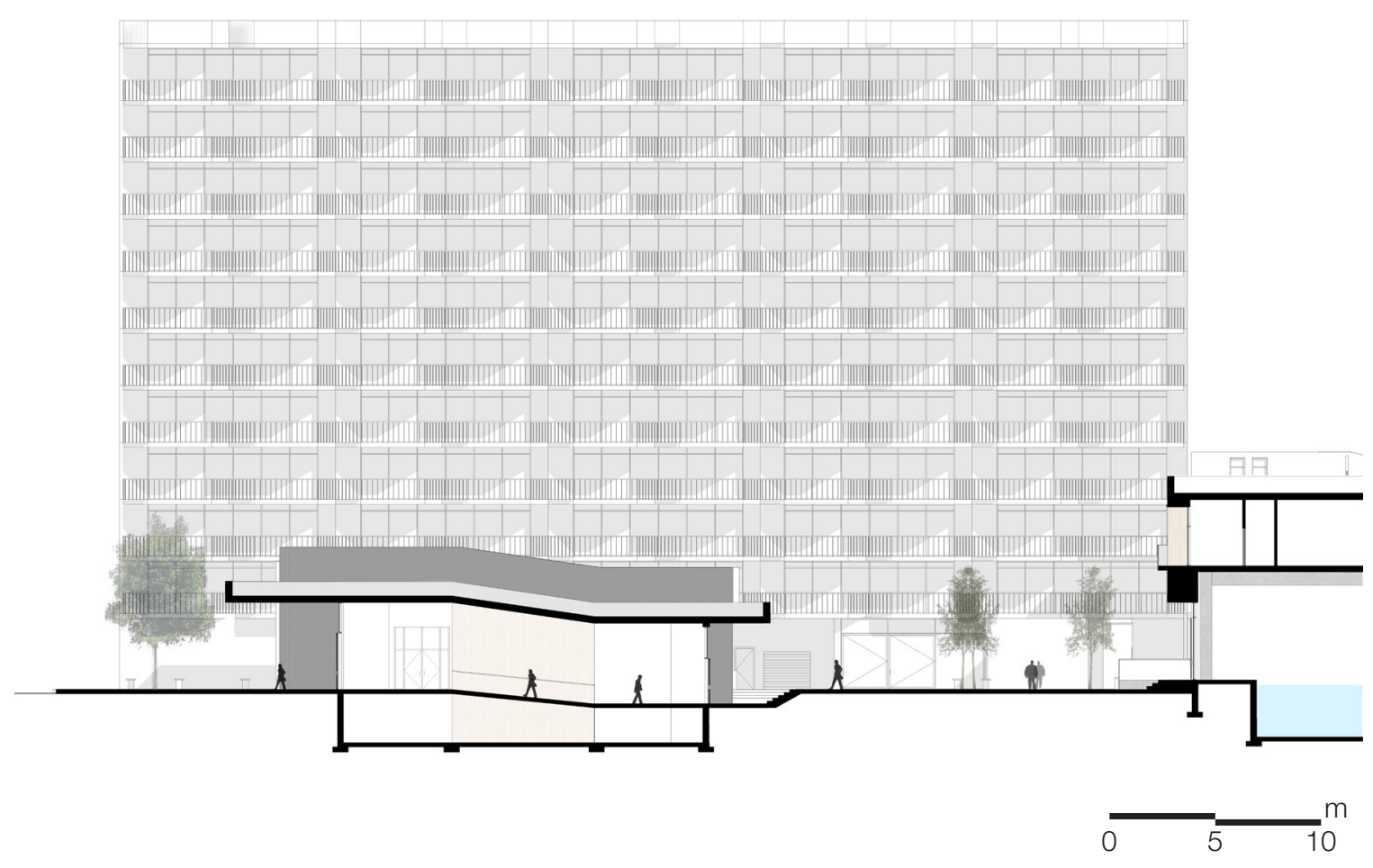

Figure 64 Section of Primary Activation and Mediation's Role in Maintaining Openness, (Sauder, 2015). 
Finally, the use of mediate extends to entrances of the primary pedestrian street. These areas are crucial in ensuring the pathways stand out and draw people into the site from the surrounding neighbourhood. Interacting with the unique condition of a passage bellow an existing tower, the entrance from Mt Pleasant into the primary activation also makes distinguishing the area even more challenging. However, a colonnade running along the perimeter of the pathway visually distinguishes it from the adjacent courtyard and park without creating a physical barrier. Additionally, breaking the canopy covering the abutting spaces over the street brings in a stream of light into the dark underpass. Highlighting the passage, lighting and colonnades create a break in the street facade and encourage people to meander through the underpass. This space also acts as another area for mediate as it quickly becomes shadowed beyond the canopy opening and slows the pedestrian's pace. Building anticipation, the shadow comes to an abrupt end as the confined space suddenly opens into the large courtyard. Going through the progression of environments removes the new development from the surrounding context and gradually prepares the public for the change in experience.
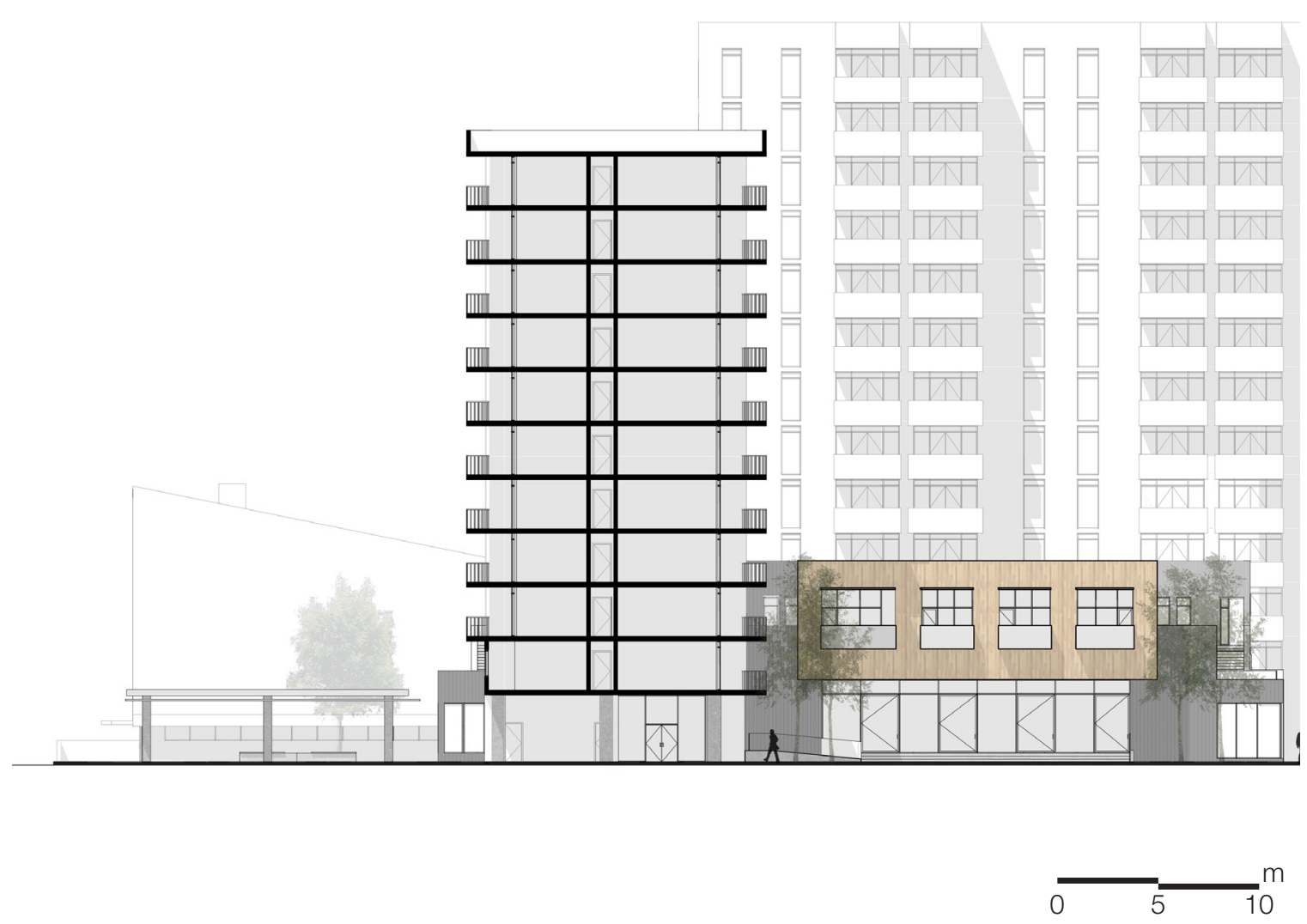

Figure 65 Section Showing Site Entrance and Underpass, (Sauder, 2015). 
In this proposal, manipulating experience through mediation, fragmentation, activation, and infill creates a very specific design that caters to the conditions of the site as well as the more general properties associated with slab towers. As this proposal shows in Figure 66, the design continues to become more refined and respond to elements like the LRT or underpass bellow an existing apartment tower. The result is a unique design that caters to the experience of a pedestrian and the formation of public spaces. Meanwhile, infill and increased density take a secondary role to experiential density and improving the neighbourhood as a whole. 


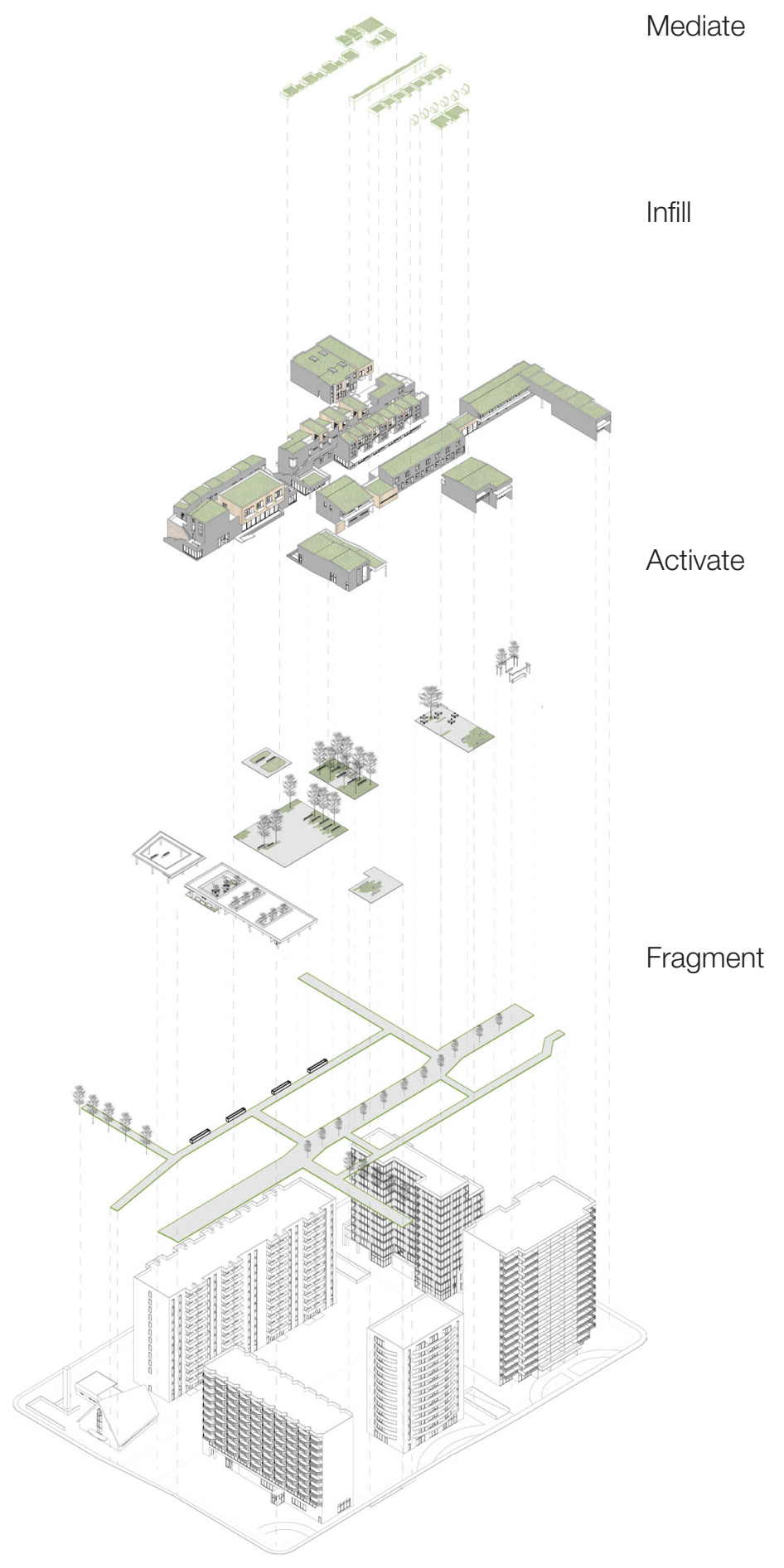

Figure 66 Exploded Axo Breaking Down Design Strategies: Fragment, Activate, Infill, Mediate, (Sauder, 2015). 


\section{EXPERIENTIAL SEQUENCE IN THE RESIDENTIAL APARTMENT TOWERS}




\subsection{EXPERIENTIAL SEQUENCE IN THE RESIDENTIAL APARTMENT TOWERS}

Applying the principles of fragment, activate, infill, and mediate to the Mt Pleasant and Eglinton block completely transformed the unused land from a barren field surrounded by towers, to a network of pathways and buildings. However, new quantifiable densities and a significant increase in landuse intensity are not the only factors to change. The public realm, activity, walkability, and other qualitative characteristics of the block were also significantly altered through the proposal. In doing so, the alternative densification strategy had a significant impact on the overall experience of the site. Affecting many different people living, working, or visiting the neighbourhood, the new environment is best understood by walking through the primary pedestrian street. Captured in Figures 67 - 71, the images illustrate conditions along the primary street and the qualitative aspects affecting each area. In each case, daylight and scale play a crucial role in bringing pedestrian attention back to the ground plane and away from the peripheral towers.

First impressions of lighting and scale enhancing the space are seen at the pedestrian street entrance along Mt Pleasant Road (Figure 67). The original canopy over this area cast a large shadow over a worn out bus turnaround, causing people to avoid the corner of the block. Replacing it with a new fragmented canopy that opens for light to flood in, immediately highlights the corner. Decreasing the height of the structure also makes it part of the pedestrian realm instead of an extension to the tower. Protruding foliage softens the hardscape adjacent to the busy city street and brings attention back to the ground as the eye ventures up the tower. Opening the primary pedestrian street also draws views back to the public realm as sight lines extend beyond the residential tower and into the warm and inviting primary activation. 


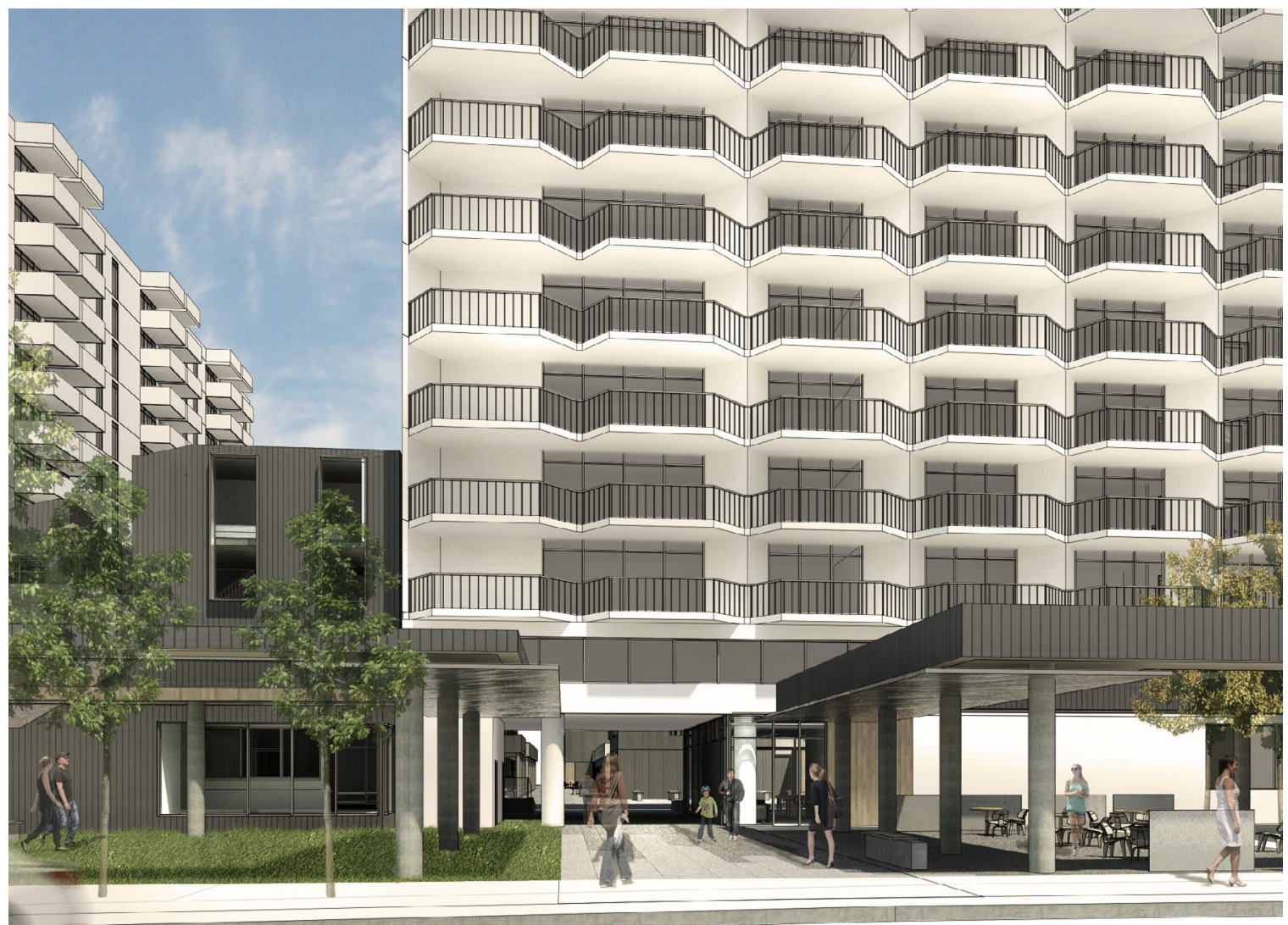

Figure 67 Perspective of Mt Pleasant Entrance to the Primary Pedestrian Street, (Sauder, 2015). 


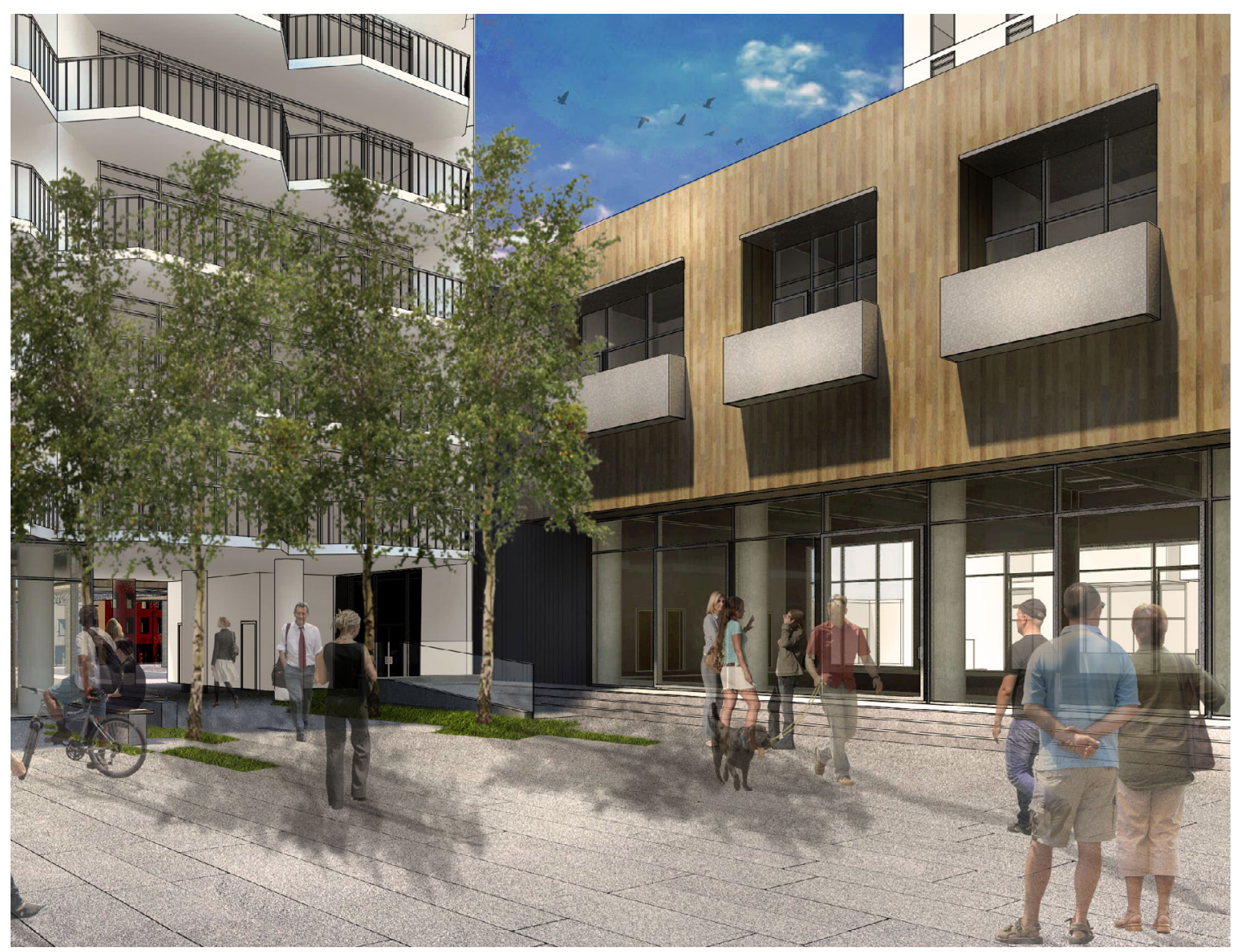

Figure 68 Perspective of Primary Courtyard Looking Towards Pool and Mt Pleasant Entrance, (Sauder, 2015).

Passing through the entrance and into the primary courtyard (Figure 68) the pedestrian is suddenly met with a brightly lit and wide open space. Instead of being dwarfed by the adjacent tower, attention in the large activation focuses on the floating wooden facade over the public pool, bringing the focal point to a scale the pedestrian can relate to. Openness is maintained through glazed facades which also help the public to visually interact with the pool and other surrounding buildings. Traffic to and from the LRT station and swimming centre keeps the area lively, but the activation's size prevents it from feeling congested with additional people. The final result is a lively and airy environment within the interior of the block. 


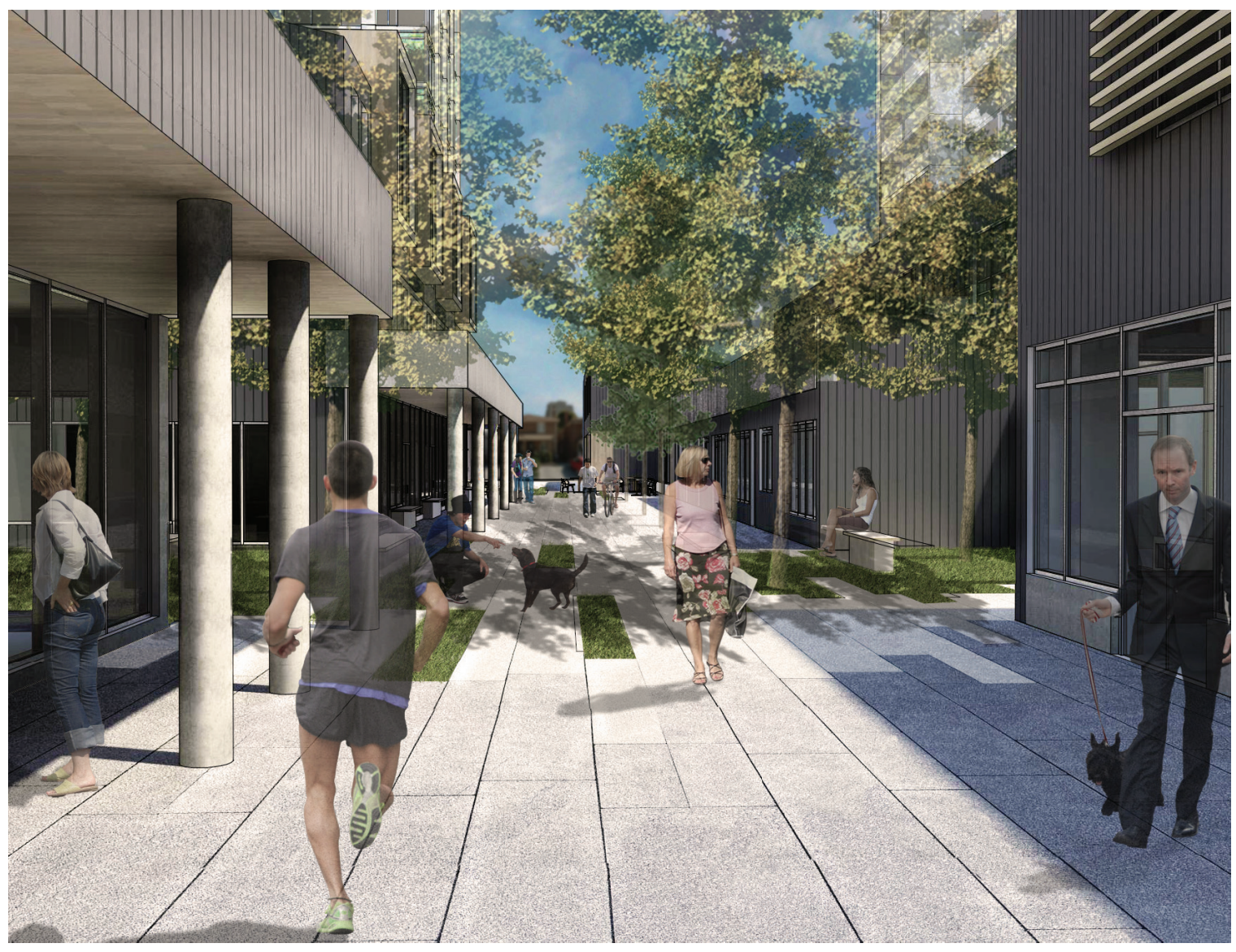

Figure 69 Perspective of Primary Pedestrian Street Looking Through the Entire Site, (Sauder, 2015).

Moving forward along the primary pedestrian path, the street becomes more defined as infill comes closer together, as seen in Figure 69. The narrower setting and abundance of trees completely removes the adjacent towers from view, making the pathway feel like a serene park environment. Additionally, natural daylight in this area has a playful effect as foliage cast soft shadows over the paving and grass. A series of entrances along the stretch of paving open the facades and help keep the space feeling active. 


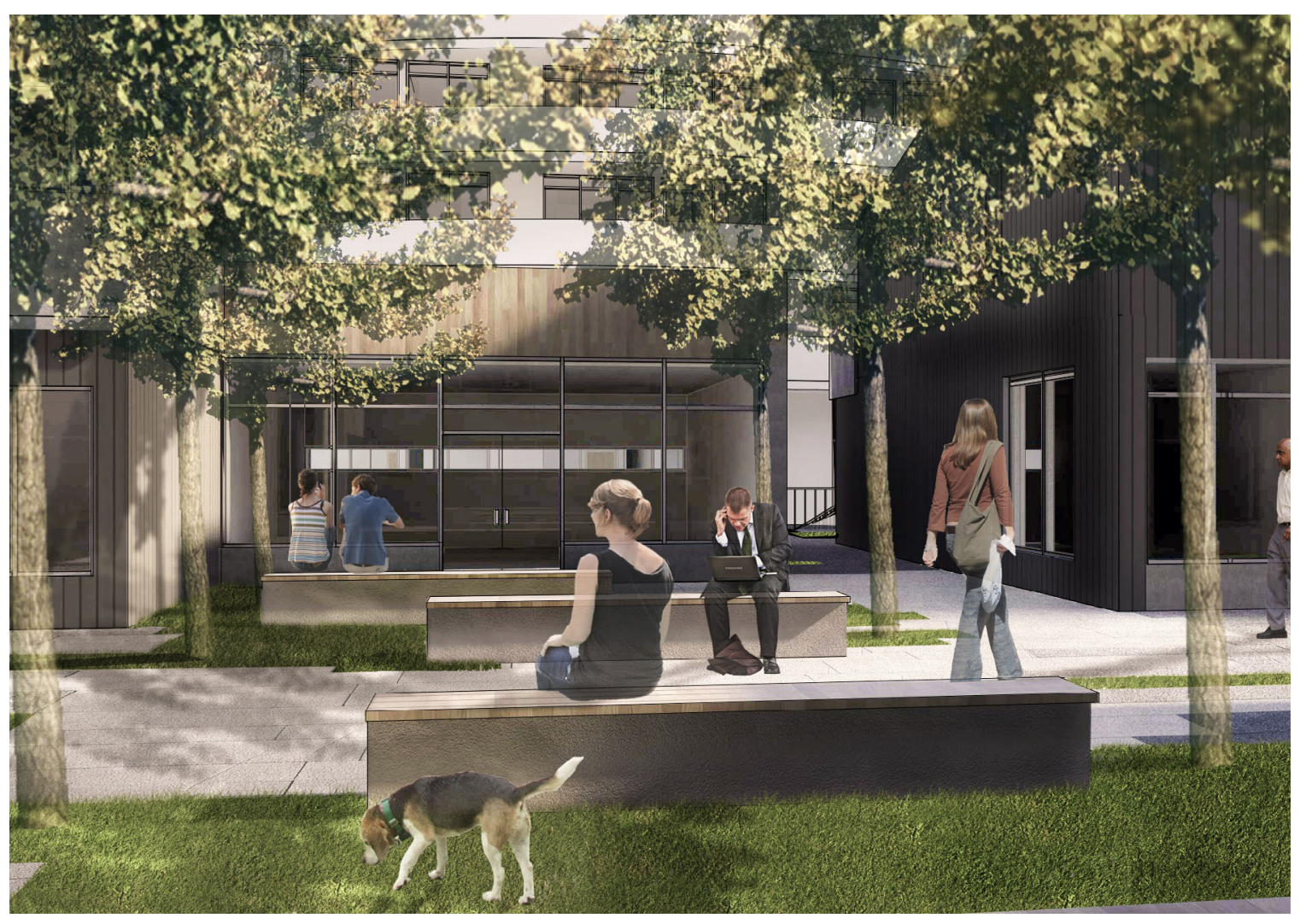

Figure 70 Perspective of Treed Courtyard with Filtered Light, (Sauder, 2015).

As the primary path intersects the treed courtyard (Figure 70), the pedestrian is met with a sudden sensation of calm and relaxation form the change in environment. Altering from granite paving to grass, the ground texture forces traffic to slow down, and higher boundary walls create a more secluded atmosphere. A canopy of trees enhances the peaceful environment and hides the tower's presence, while still allowing light to gently filter into the activation. The overall experience of this courtyard encourages the pedestrian to sit down and relax in the secluded park. 


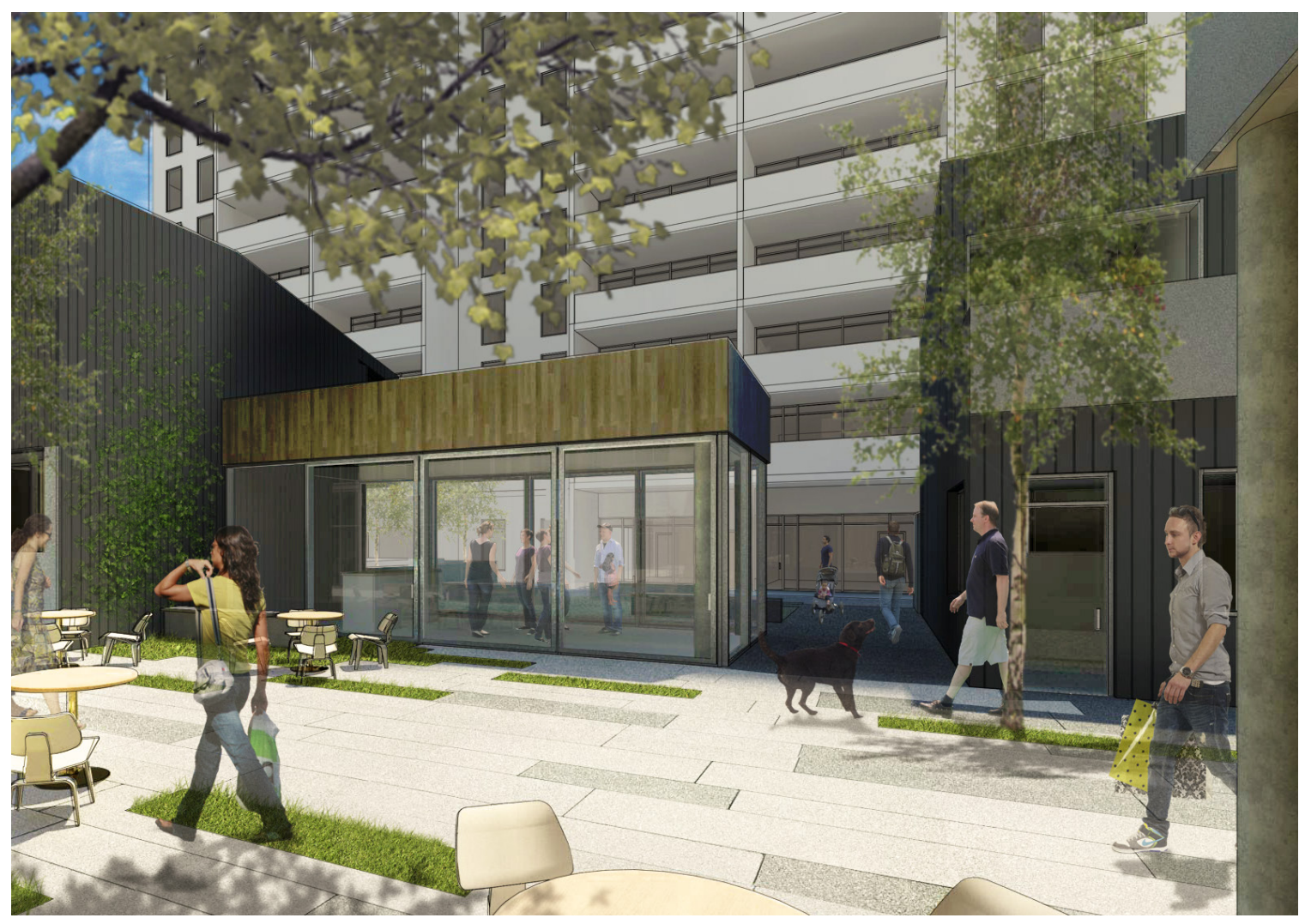

Figure 71 Perspective of Park Courtyard Extending Through Pavillon to Abut Secondary Pathway, (Sauder, 2015).

In Figure 71, the pedestrian arrives at the third courtyard before reaching the end of the block. Unlike the other outdoor spaces, the adjacent towers have a much stronger presence here and cast large shadows over the public areas. To prevent the space from feeling overwhelmed, the boundaries are more open and tree canopies are kept to a minimum. Also closely integrated into the pathway, the courtyard feel much busier and active then the previous treed activation. Sitting in the centre, a pavilion with movable glazed walls allows the space to open up and act as a friendly place of congregation. 
Together these outdoor spaces aim to enhance the public realm of the block using the earlier strategies. However, lighting and scale are additional considerations which have a profound impact on the way space is used, understood, and experienced. Closely linked to the perception of crowding, lighting and scale can also contribute to the experience of interior spaces. A section in Figure 72 shows the potential for units along pedestrian pathways to be bright and comfortable environments despite their limited area. Additionally, the activity from within each unit can spill into balconies and patios to further enhance the liveliness of the primary pathway. Approaching density in this mindset, poses an alternative method for accommodating urban growth in a manner that focuses on improving the public realm.
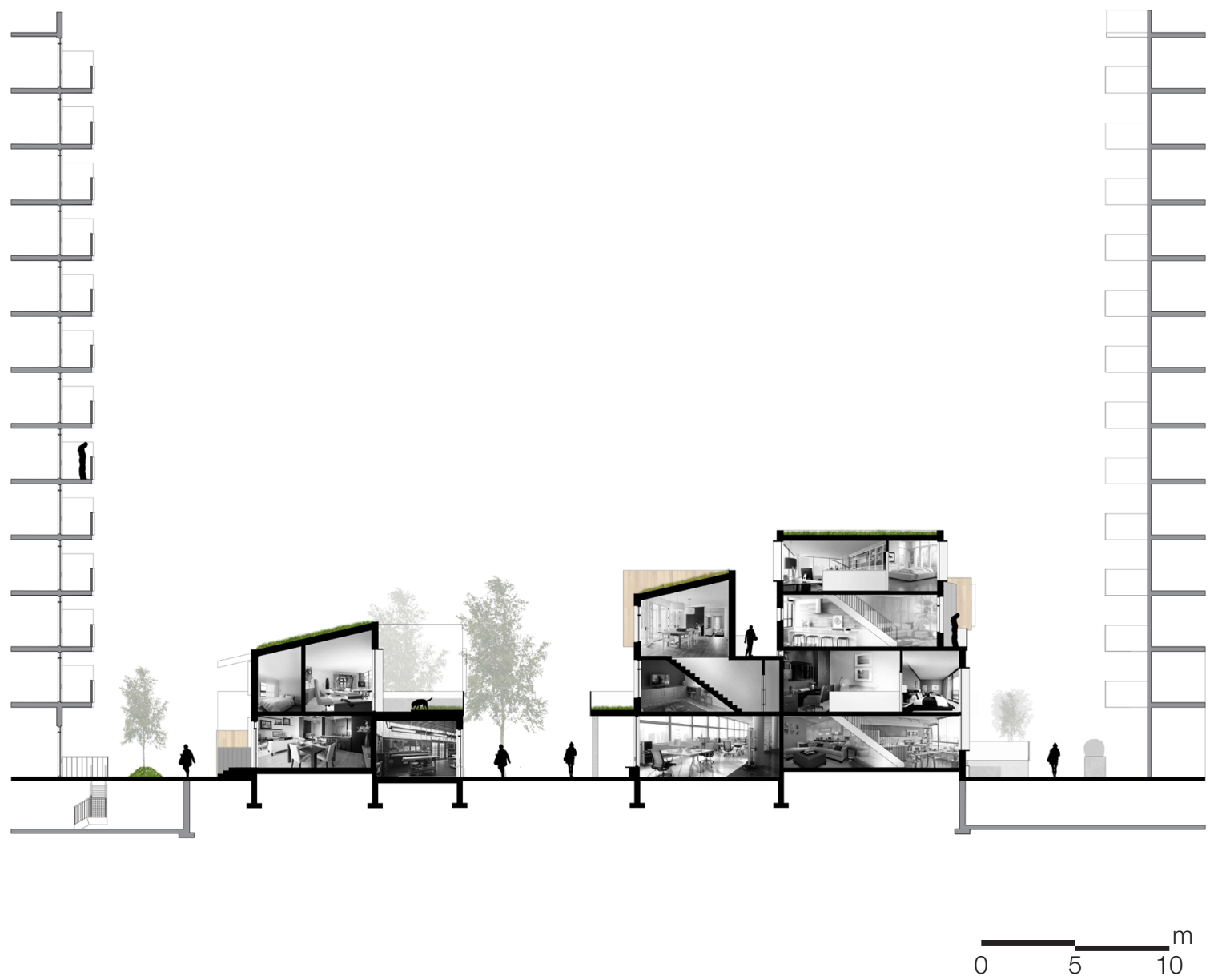

Figure 72 Experiential Section Showcasing Interior Environments, (Sauder, 2015). 
10 CONCLUSION: USING EXPERIENTIAL DENSITY AS AN ALTERNATIVE METHOD FOR URBAN GROWTH 


\subsection{CONCLUSION: USING EXPERIENTIAL DENSITY AS AN ALTERNATIVE METHOD FOR URBAN GROWTH}

The proposal at Mt Pleasant and Eglinton, which was created using infill on neglected property between clusters of slab towers, is an alternative approach for enhancing the public environment while also increasing density. When proposals of this nature "contribute to the public realm, they encourage people to meet and converse. They engage the passer-by. They stimulate rather than repress people's natural human potential" (Rogers, 1998, page 74). In doing so, an experiential density is created to coincide with increases in physical density throughout the centre. Using walkability, lighting, and scale to influence an individual's perception supports the views of Kirkman, Pont and Haupt, O'Toole, and Chakrabarti to improve design approaches in the urban context. Additionally, emphasizing experiential density opposed to quantitive values follows suit with many goals laid out in Toronto's Official Plan (2010) to make more public amenities and improve connectivity throughout the city. Both the Official Plan and various authors' views played a critical role in defining the four strategies - fragment, activate, infill, and mediate - used to further increase experiential density

Applying the ideals of fragment, activate, infill, and mediate to the cluster of towers found at Mt Pleasant and Eglinton, this thesis has primarily focused on the development of a stock of Toronto's fastest growing centre. In addition to its rapid growth rate, the Yonge-Eglinton centre maintains a close connection to transit and has an active mixed-use community at its core. Moving closer to the perimeter, the neighbourhood takes on a very different quality and is primarily made of either single family homes or oversized blocks of high-rise slab towers which lack walkability and amenities. This made the centre an ideal opportunity to explore the affects of experiential density in comparison to the other growth areas identified in the Official Plan (2010). Fragment, activate, infill, and mediate can be adopted by other groupings of oversized blocks and slab towers situated in densely developed areas. One applicable example that stands out in Toronto is St James Town, known for its high density, slab towers, and downtown location. Additionally, other areas around the globe which are still actively relying on the slab tower typology to accommodate their growing urban populations, such as "Moscow, Barsilia ,Mumbai, and Shangha" (Urban, 2013, page 3), can learn how quantifiable densities can be complemented with attention to the human experience through the framework of this thesis.

Beyond the wider applications of this thesis, research and development can continue to focus on achieving even higher quantifiable densities between slab towers. While an increase of 10 per cent in residential population and 15 per cent in temporary mixed-use density has proven to be achievable, continued investigation may reach even higher values while maintaining the same level of experiential density. Furthermore, continued research could also enhance the perception of the block by encouraging slab towers to engage with the new infill and existing city streets. Accomplishing this through a second phase of development, the ground floor units can be replaced with mixed- 
use programing and extended into the large setbacks as illustrated in Figure 73. Creating a podium like condition, the tower is able to bring a sense of human scale back to the city street, while also transitioning its height to blend with the new mid-block development. Additionally, renovating the towers gives vertical residents a sense of ownership over the new horizontal amenities and encourages them to engage the public outdoor spaces. This technique can reference similar methods of tower renovation seen in Toronto's St. James neighbourhood, where the ground level is extruded to form a podium (The Toronto Blog, 2011). By continuing research and design through these strategies, the oversized urban blocks of slab towers can further improve the public realm and respond to concerns over growing density in urban areas.
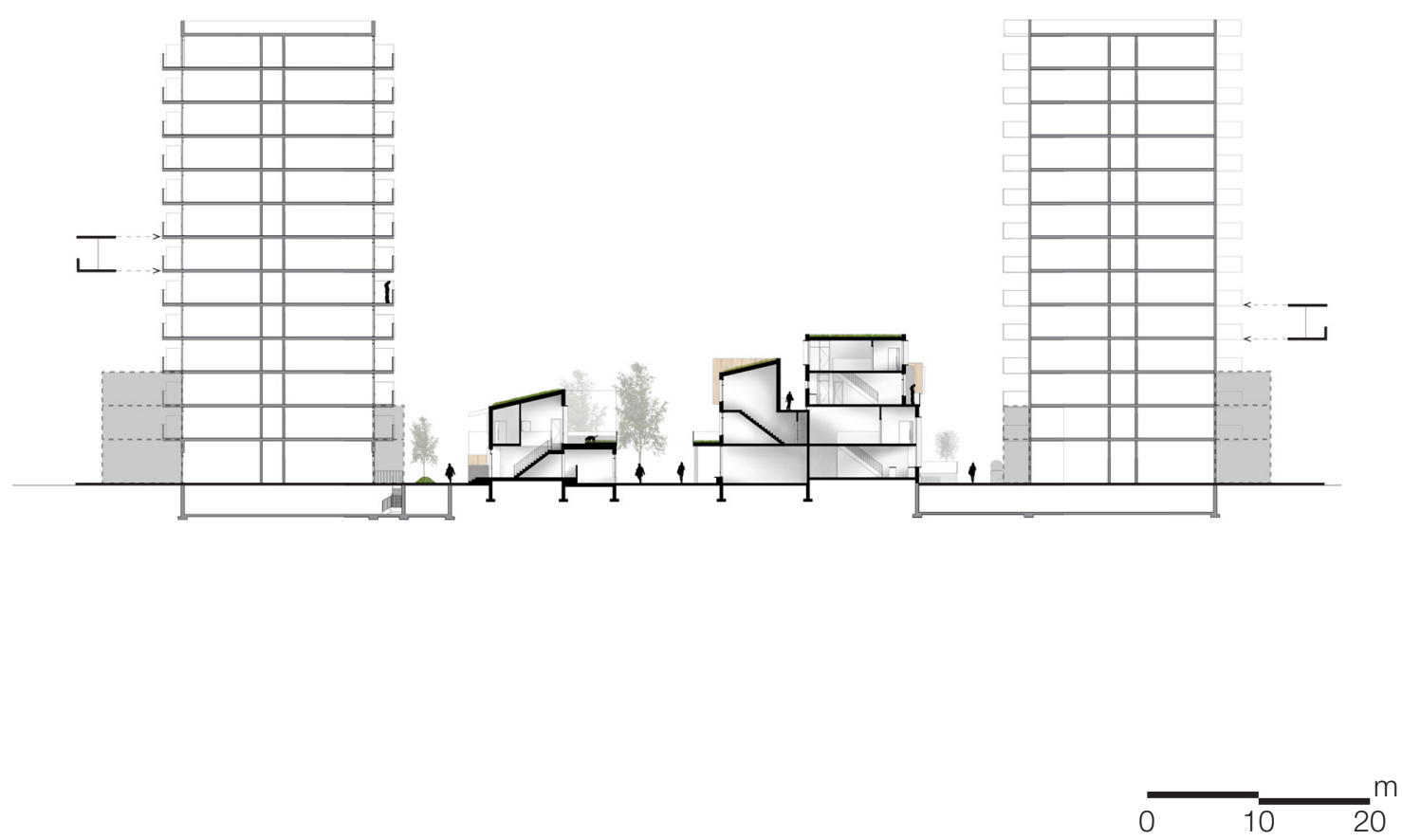

Figure 73 Replacing the Slab Tower's Ground Floor Units with Mixed-use Programing to Generate a Podium and Further Engage the Pedestrian (Sauder, 2015). 
This thesis has challenged development norms to achieve an experiential density that focuses on the human interaction with the urban environment. In doing so, formerly unused and oversized pieces of land between slab towers are broken down through a network of public pedestrian circulation, and occupied through various outdoor spaces and low-rise infill to give the area purpose. The intended result is a new mixed-use community with a lively and active ground plane. Focusing on this qualitative characteristic, the thesis sought to avoid overcrowding and issues with privacy that are commonly associated with density. Also creating a park like atmosphere, accessible to residents and the general public, improves the perception of the overall neighbourhood as Toronto's population continues to climb. Understanding the need to house a growing population, this thesis uses alternative forms of infill around clusters of residential apartment towers as an opportunity to investigate intensification's effect on experiential density. 
APPENDIX 


\section{A. $\quad$ EXPLANATIONS OF QUANTIFIABLE DENSITIES}

Density is a term used in everyday discussion which is defined by the Oxford Dictionary as the "physical degree of consistency measured by the quantity of mass per unit volume" (Oxford, 1993). However, this explanation remains extremely broad, and needs to be broken down in order to be understood in an architectural context. The definition uses the term 'units' which allows density to be interpreted in many different ways to generate conditions that are specific to quantifiable subjects. For this thesis, the interpretations of the definition will focus on: physical density - the area of volume occupied by humans; population density - the number of people (or households) within an allotted amount of space' and land-use intensity - the area of land covered by built forms (Pont \& Haupt, 2010). However, the quantifiable aspects from physical, population, and land-use densities are not the only way to evaluate density in an architectural context. The notion of experiential density - the impression or perception within a space - is another form of density that focuses on the qualitative conditions which are a direct result of the built form. A few of these experiential conditions include: lighting, scale, texture, openness, and privacy. All four variations are correlated. Changing a variable for one definition of density can have a profound impact on the others. For example, the same physical density can be achieved with a high or low land-use intensity if the building height is increased. However, a taller building will create a different experiential density then a shorter one and can dramatically change the perception of the city. Recognizing the relationship between quantitative and qualitative conditions will allow for a holistic understanding of density within the urban context and enable this thesis to be approached from a different architectural position.

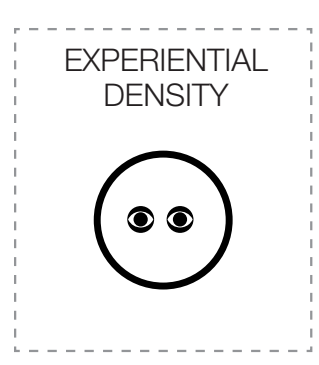

Qualitative Density

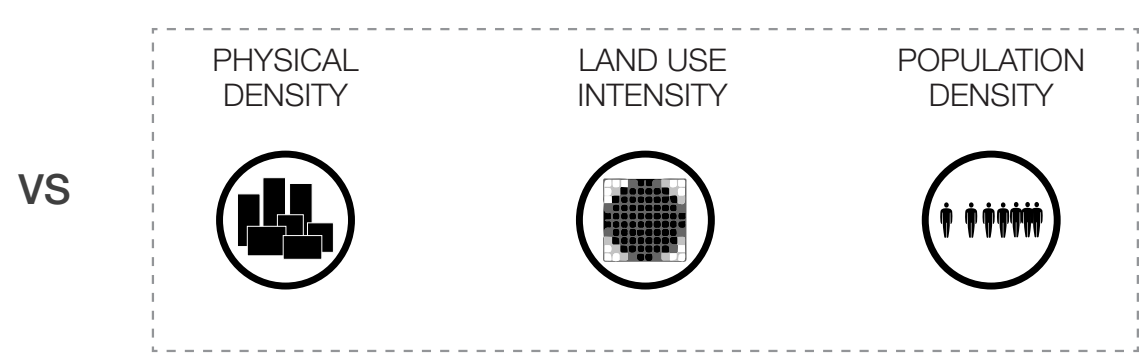

Quantifiable Densities

Densities Relating to Urban and Architectural Design (Sauder, 2015) 
To intensify urban growth, the population density will also increase. This density "can be expressed in terms of the number of people or houses in an area..." (Berghauser Pant \& Haupt, 81). The increase in this particular form of density becomes more reliant on economic conditions and planning factors within the city. As previously discussed, people migrate to the city because of ammenities found in a mixed-use and infrastructure-rich environment. However, developments must also be available to house the expanding population. This enables architects to make an impact on the perceived and physical density of the neighbourhood as developers construct new projects to house the higher population density and the businesses it attracts. So by designing and influencing the additional space needed to accommodate the growing society, the architect is indirectly involved with increasing the population density.

In addition to the perceived density and population density, the architect's skills heavily influence the density of the built form. This falls into two different categories, the physical density and the land-use density. These two densities are directly related to the built form that appears on a specific site or neighbourhood. Physical density is understood as the amount of space humans occupy and can be quantified through area or volume (Berghauser Pant \& Haupt, 2010). This enables the architect to manipulate the space in ways that will accommodate the highest volume of usable space to increase the physical density. There is also usually a direct relationship between the physical density to the population density. Generally, the larger the physical density is, the higher the population density it can hold. For example, the high-rise condo tower typically has an extremely large physical density in comparison to a cluster of town homes, and can also hold a significantly higher number of people. However, the quality of space that is created in a town house has the potential to be much more friendly to the human scale and experience then the high-rise tower.

Closely related to physical density is the land-use intensity which is the intensity that is built on a specific site and the difference between built space and non-built space (Berghauser Pant \& Haupt, 2010). The building form and type of development can have a significant impact on the land-use development. As seen bellow, Chakrabarti (2013) illustrates how the same area of land and physical density can result in dramatically different building forms and land-use densities. A high-rise tower is able to house the same amount of physical space as a compact low-rise parisian styled development. By controlling both the physical and land-use densities designers have the ability to influence the site which could result in a high-rise tower with a spacious park, like the residential apartments, or mid-rise buildings that leave less space for infrastructure and amenities but create a much more comfortable street life. 
30 Dwelling units per acre as low-rise apartments Horizontality has a limited ability to accommodate open-space uses on the ground plane.
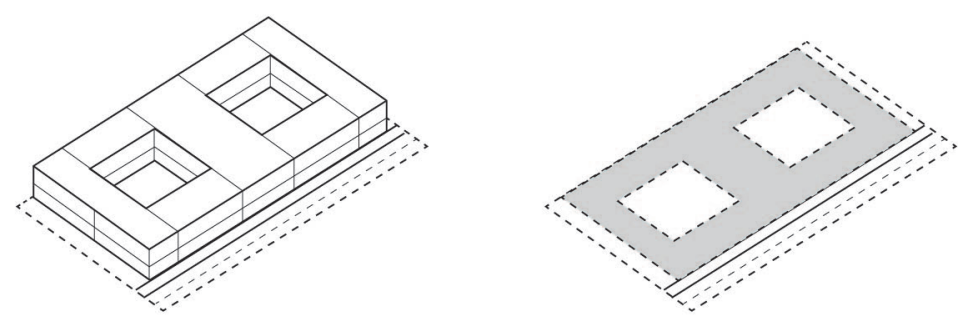

30 Dwelling units per acre as mid-rise apartments Verticality allows for greater open-space uses on the ground plane.
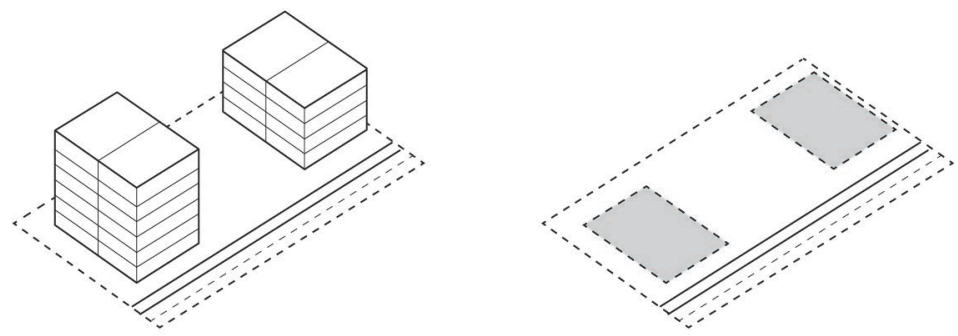

30 Dwelling units per acre as high-rise apartments More height allows for the maximization of open-space uses on the ground plane and the vertical intensification of amenities in the tower.
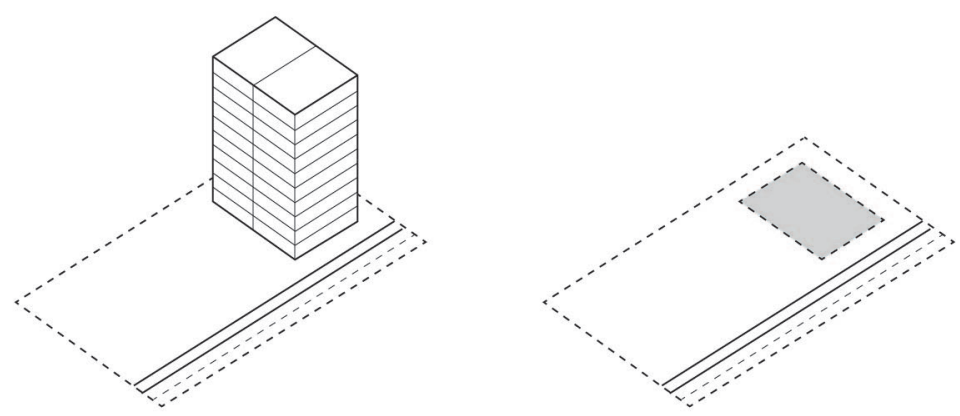

Density can take many forms with varying qualities (Charkabarti, 22). 
B. ADDITIONAL STATISTICS ON GLOBAL DENSITY

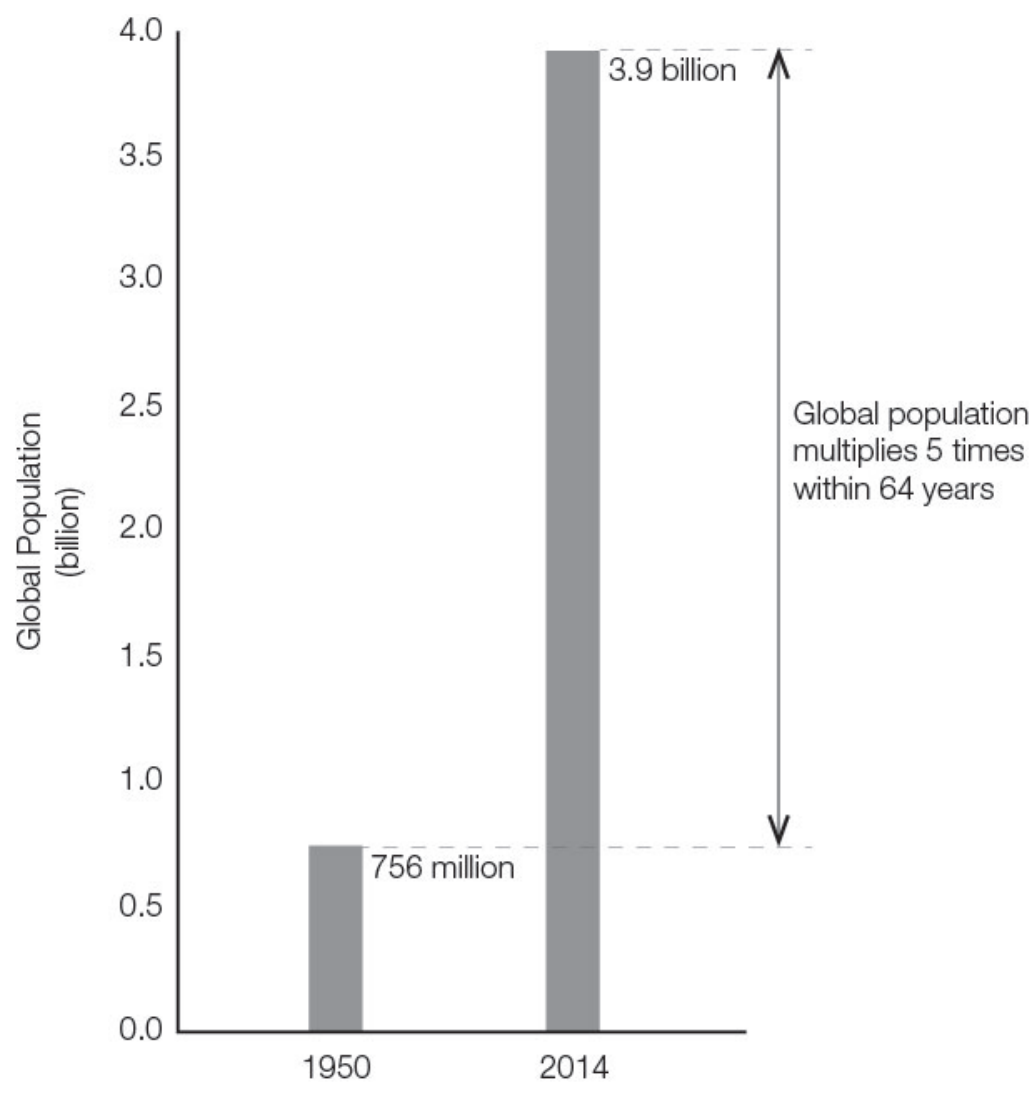

Global Population Growth (United Nations, 2014) 
Urban and rural population as proportion of total population, by major areas, 1950-2050
Africa
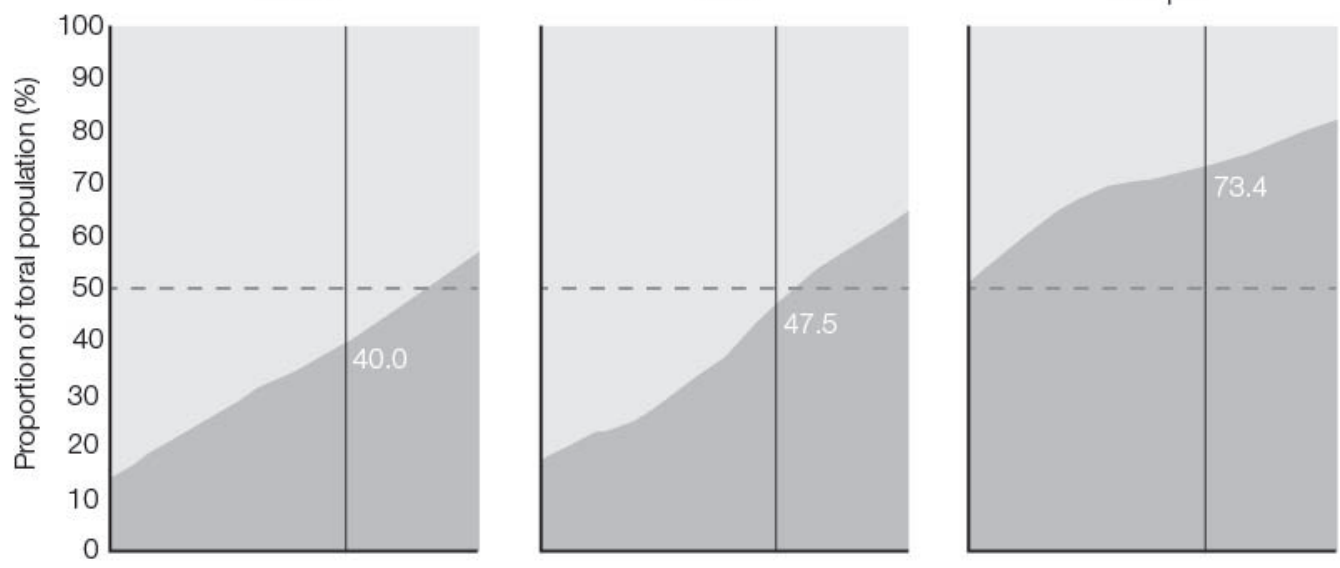

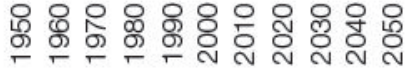

吕 \&

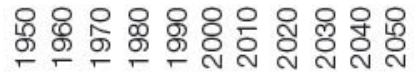

Latin America and the

Carribean
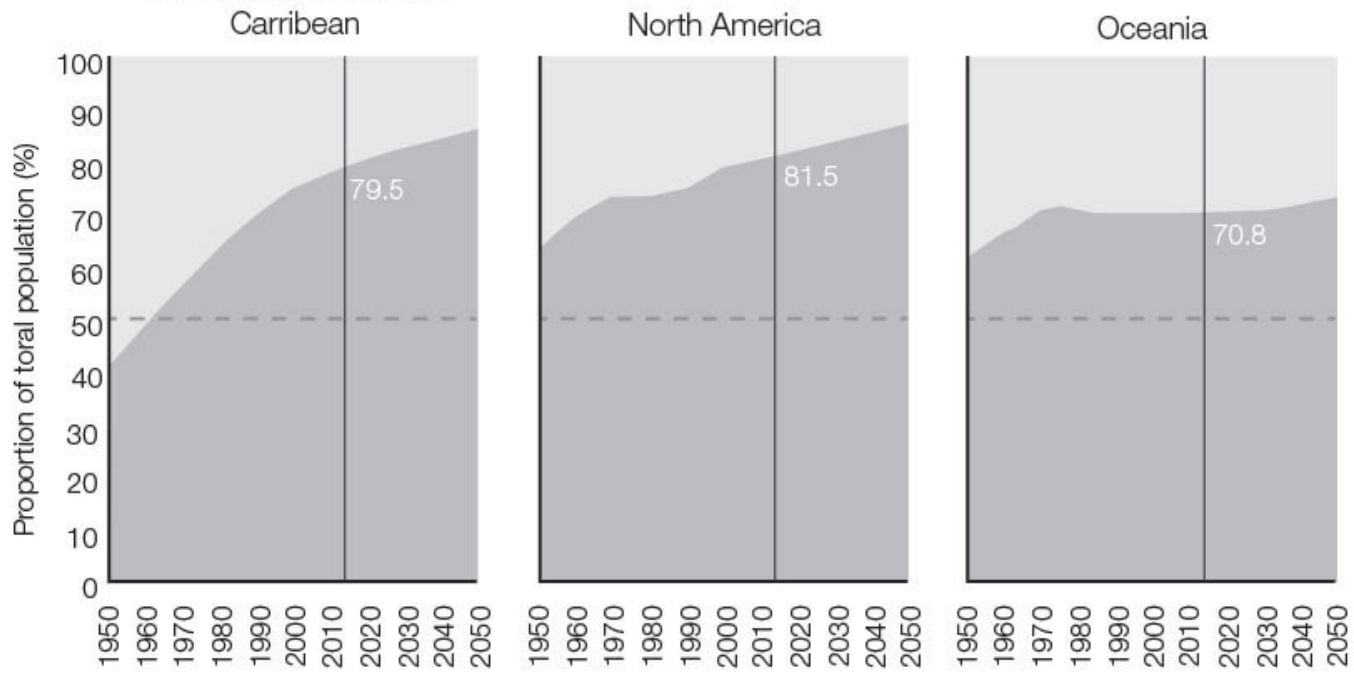

Urban Population

Rural Population

Average Annual Rate of Change of the Percentage Urban by Major Areas, 1950-2050

(United Nations, 2014) 
A return to the core: population growth in the Greater Toronto Area

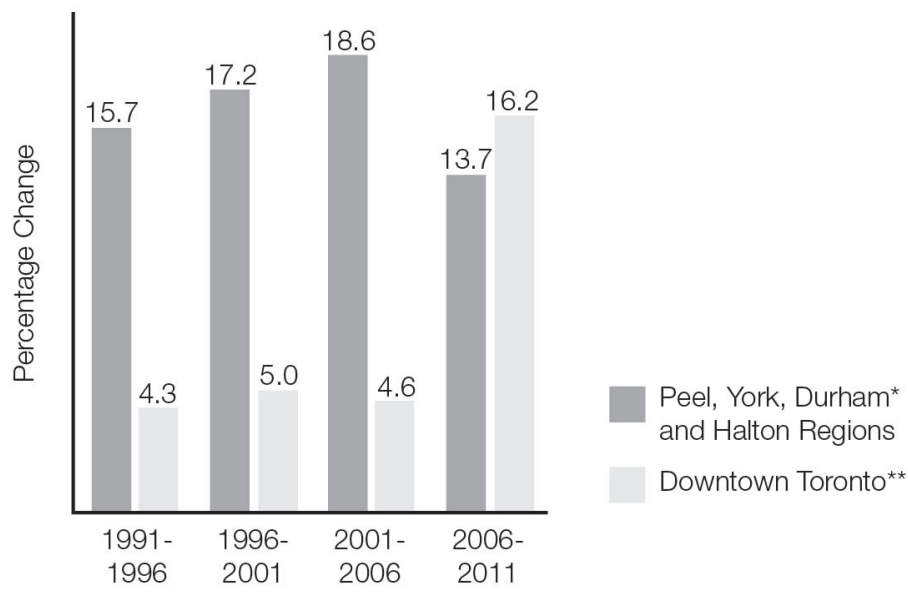

*Durham mostly refers to Ajax and Pickering.

${ }^{\star \star}$ Ridings of Trinity-Spadina and

Toronto Centre.

Rate of Change in Toronto's Population Growth Showing an Increasing Number of People Setteling in the Downtown (O'Toole, 2012). 


\section{DESIGN EXPLORATION: WORKING MODELS}
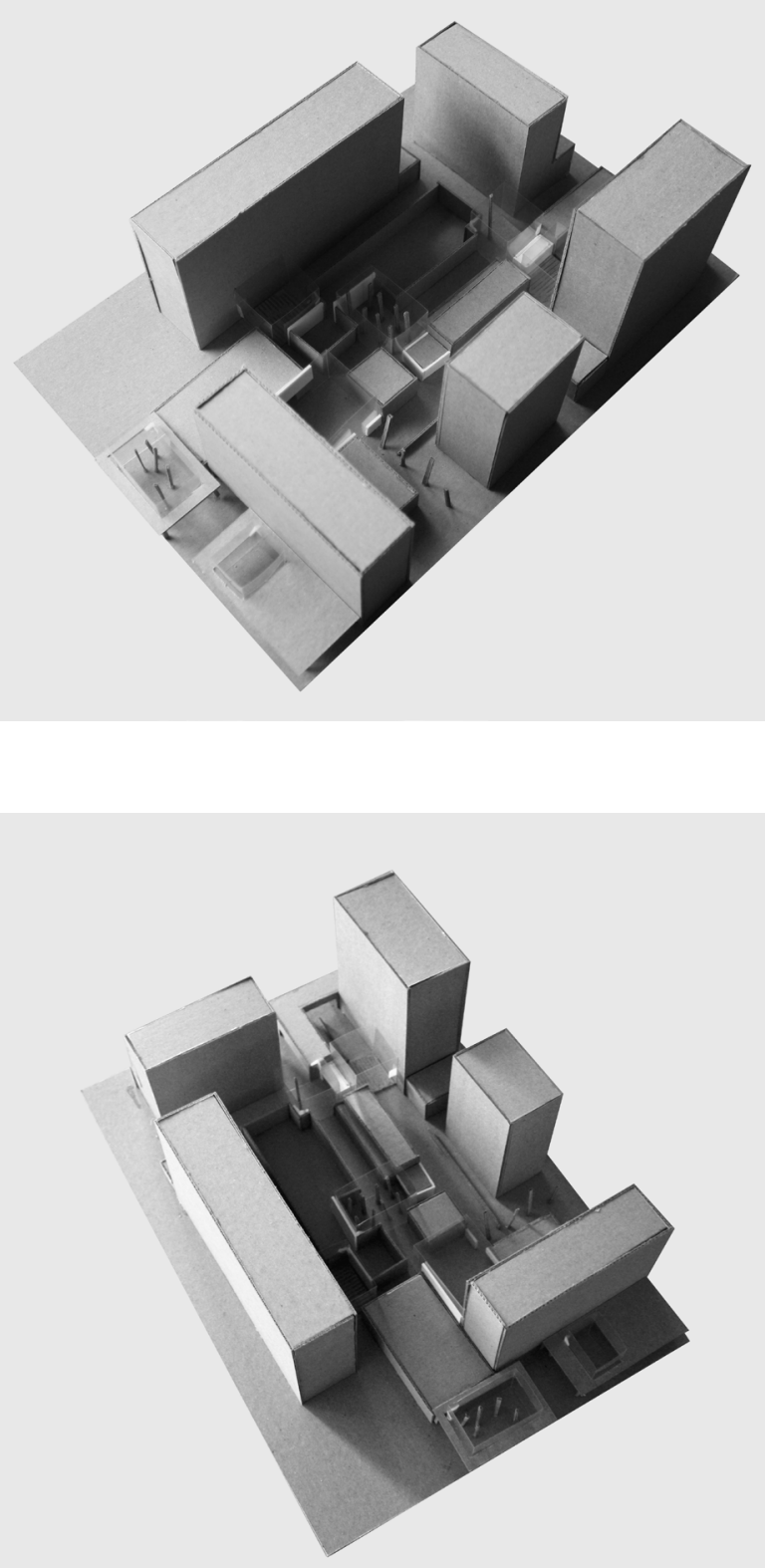

Conceptual Exploring the Relationship Between the Solid Infill and Voids Formed for the Fragmentation and Infill (Sauder, 2015). 

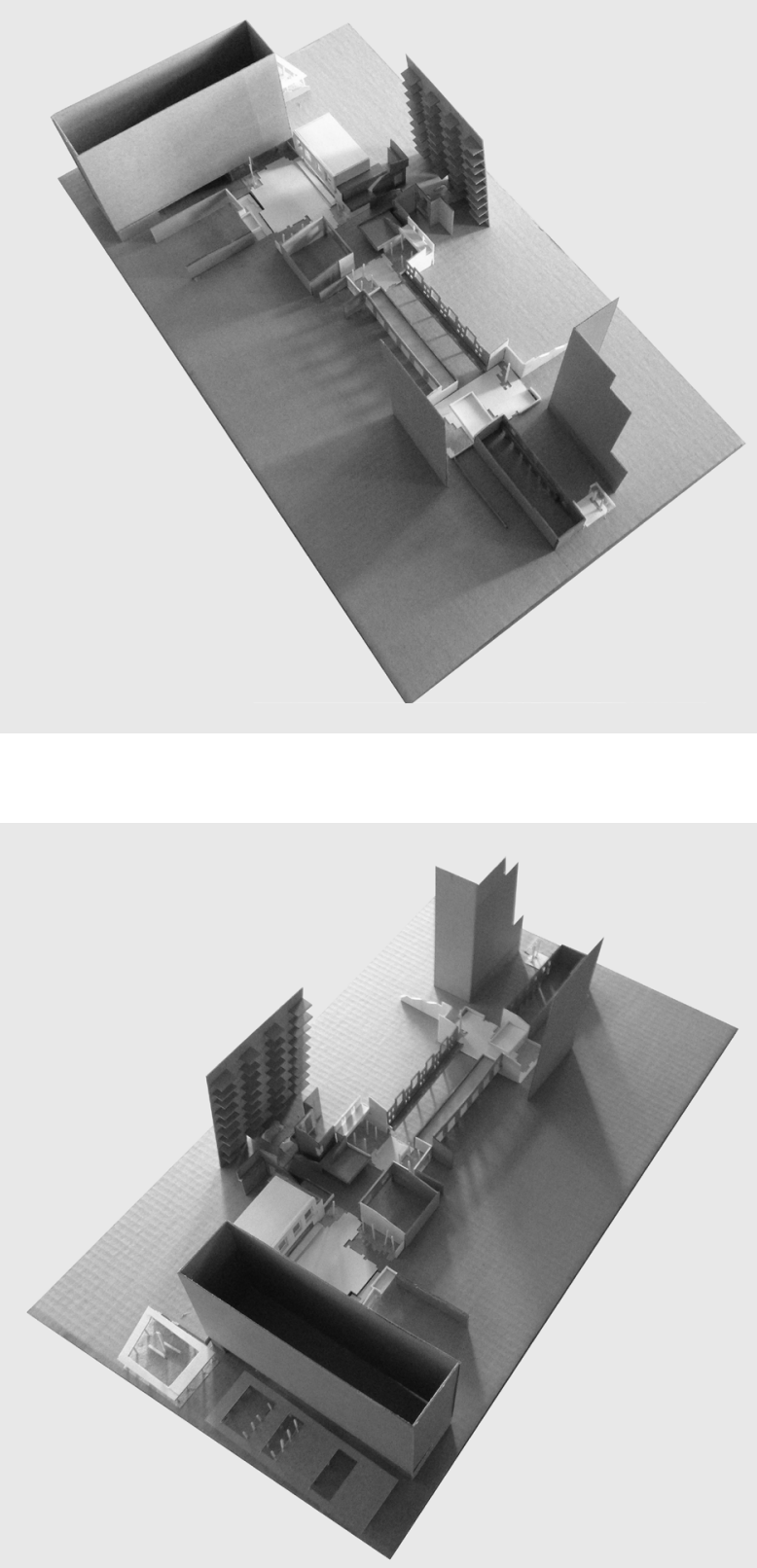

Working Model Depicting Activation Boundaries (Sauder, 2015). 


\section{DESIGN ITERATIONS}
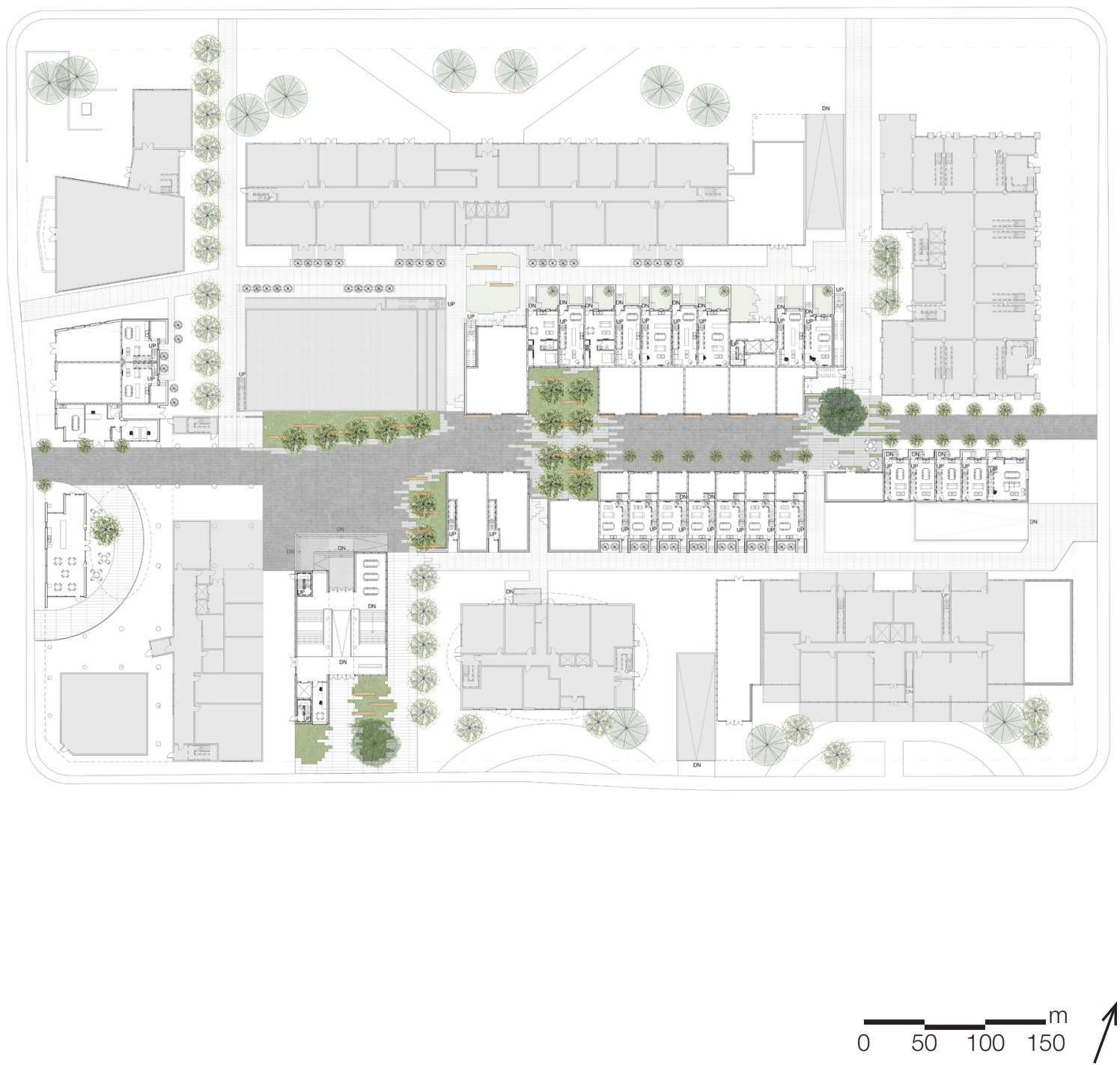

Early Site Plan (Sauder, 2015). 


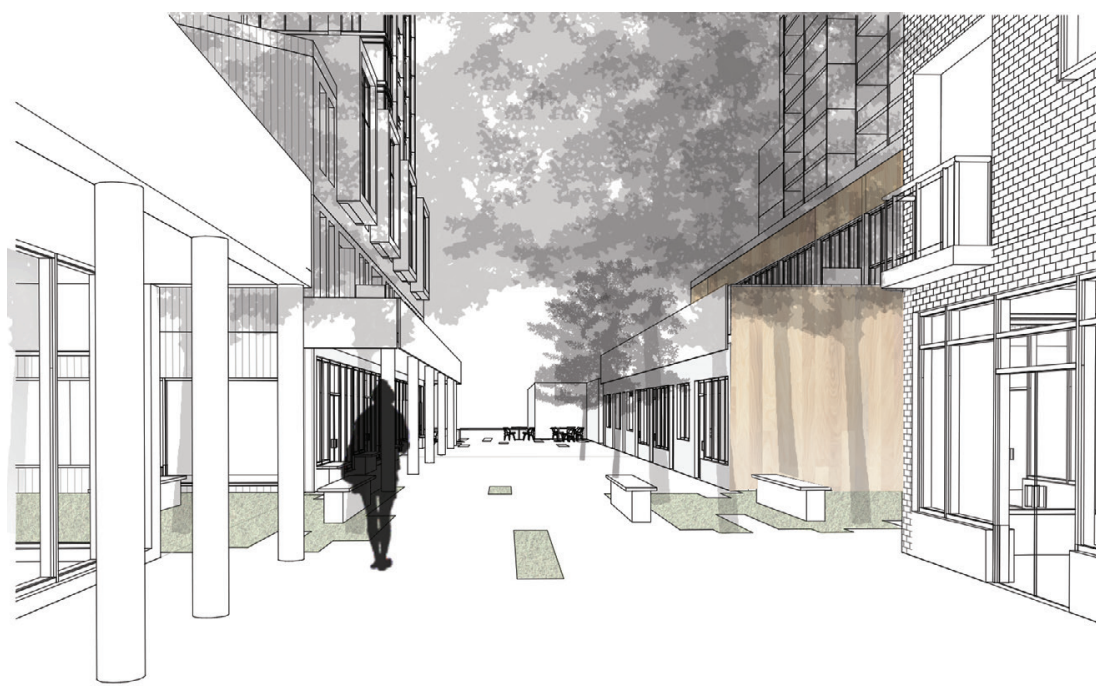

First Material Exploration of Pedestrian Street (Sauder, 2014).

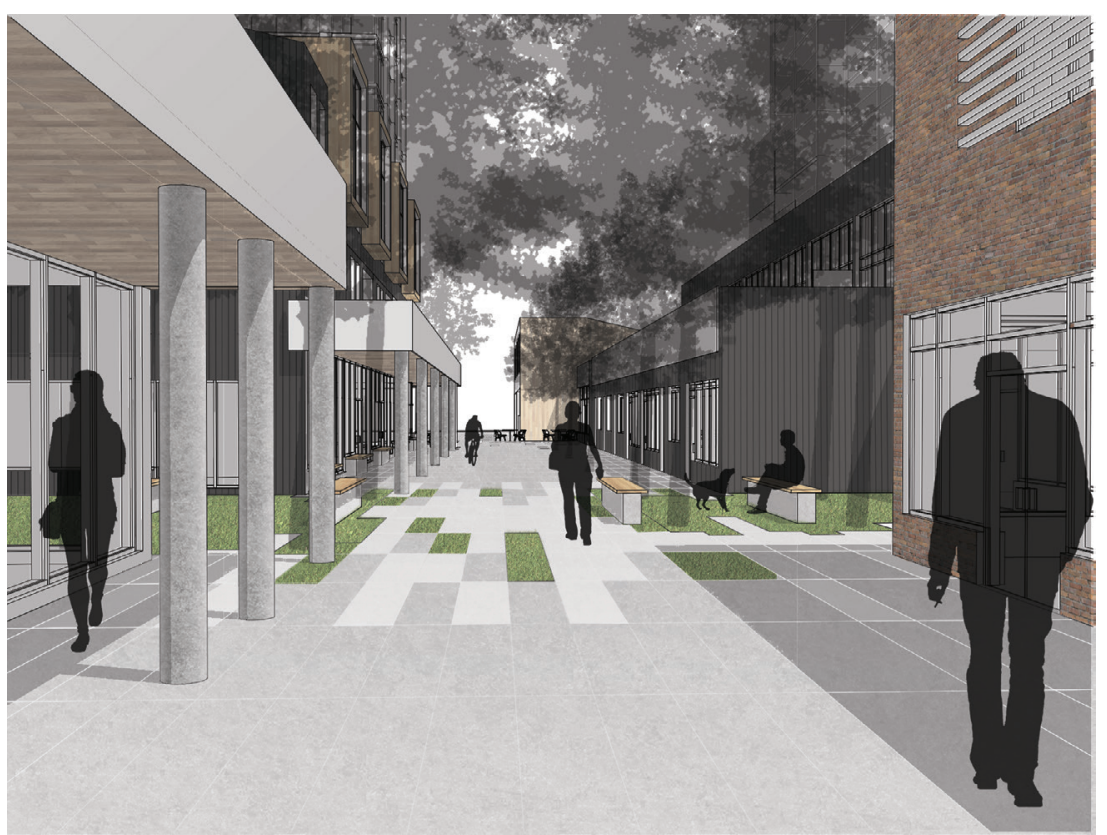

Early View into the Primary Pedestrian Street (Sauder, 2015) 


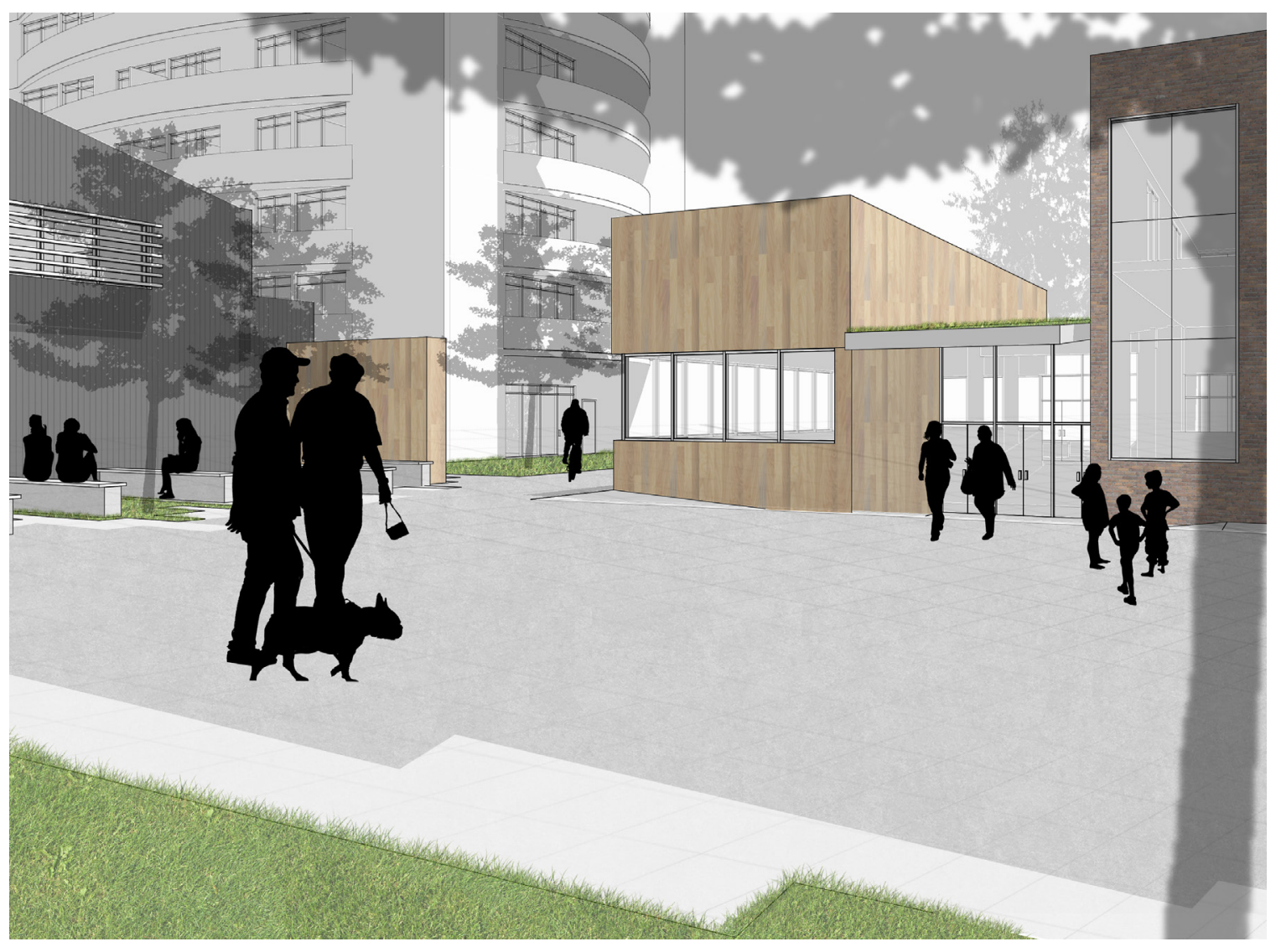

Early View of Primary Activation Looking Torwards LRT Station (Sauder, 2015) 


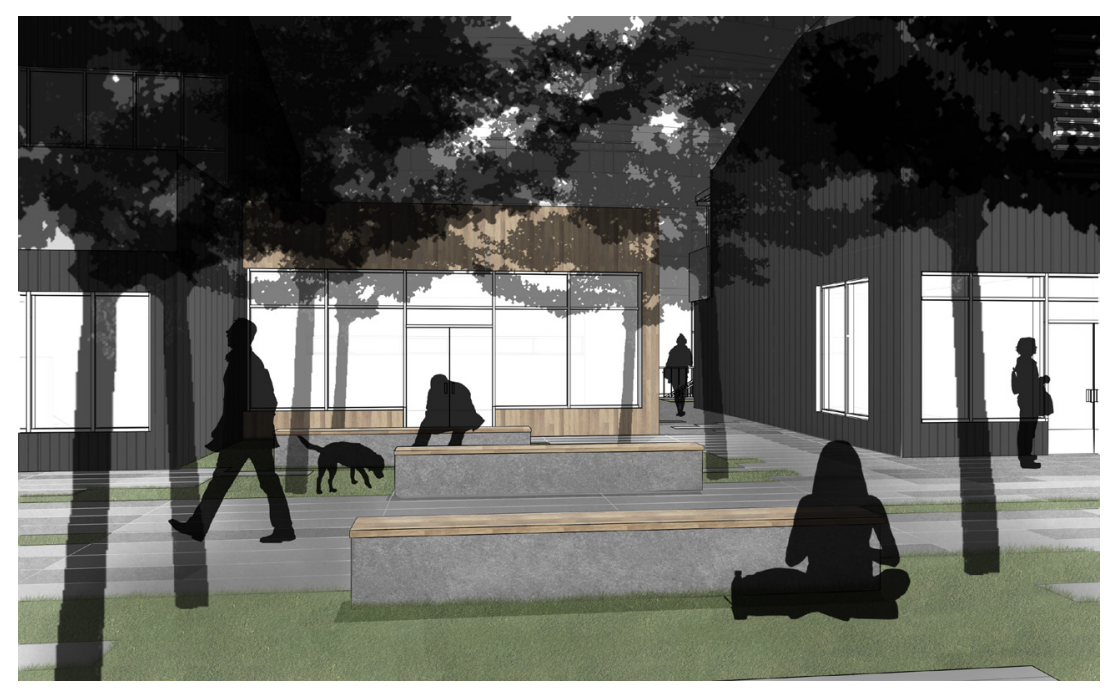

Early View of Treed Activation (Sauder, 2015).

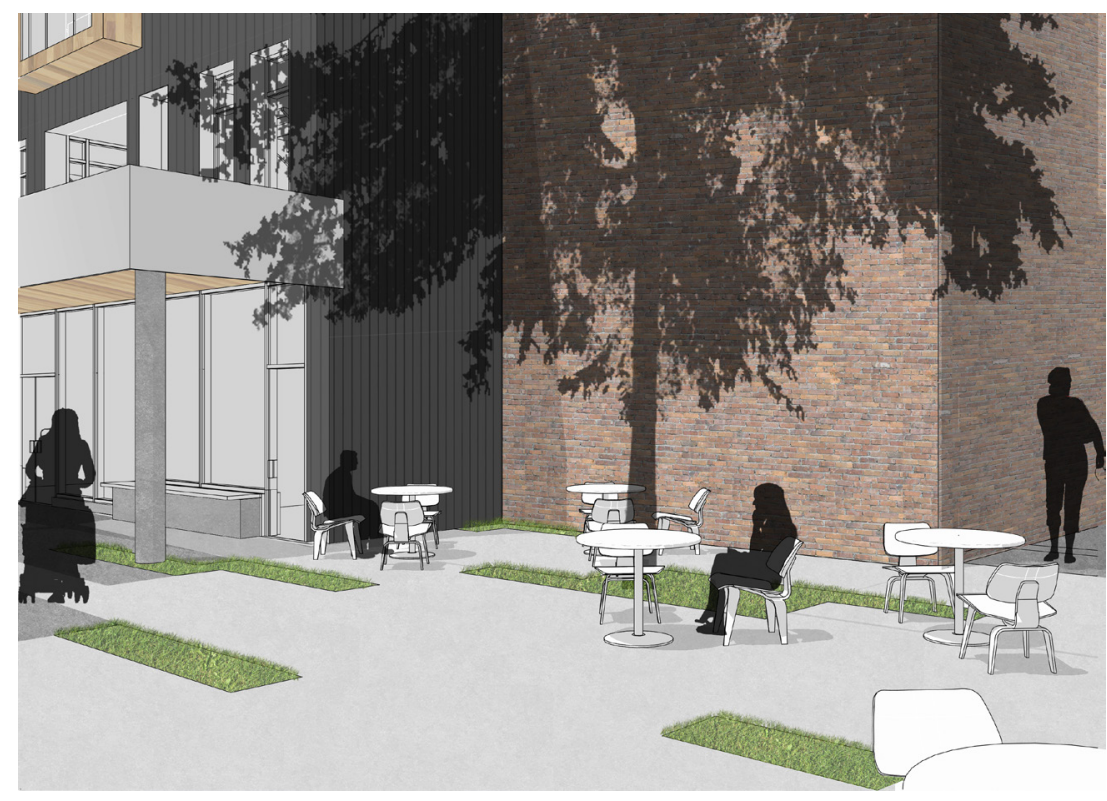

Early View of Thrid Activation-Now Titled Parked Activation (Sauder, 2015) 

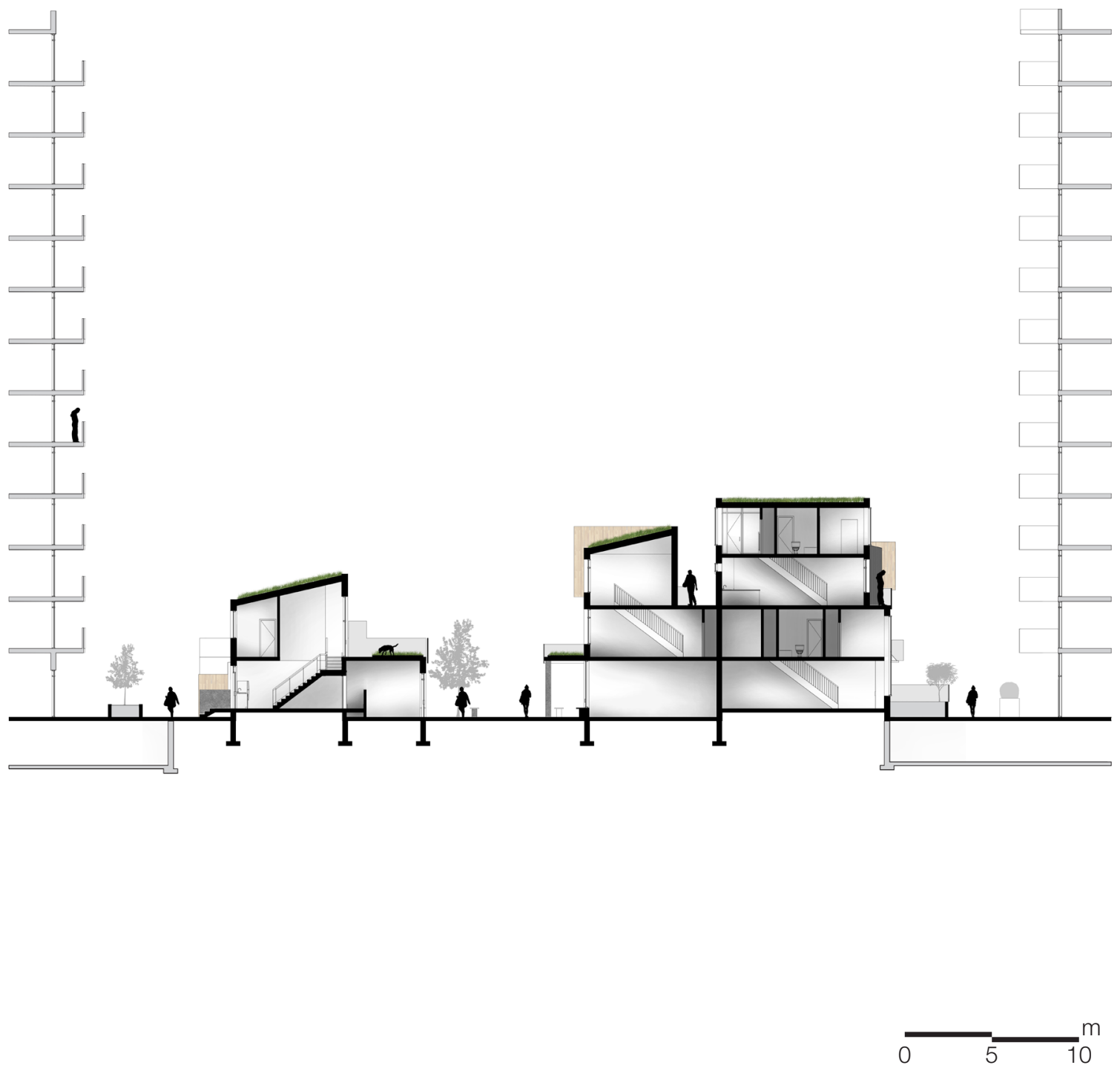

First Iteration of Site Section (Sauder, 2015) 

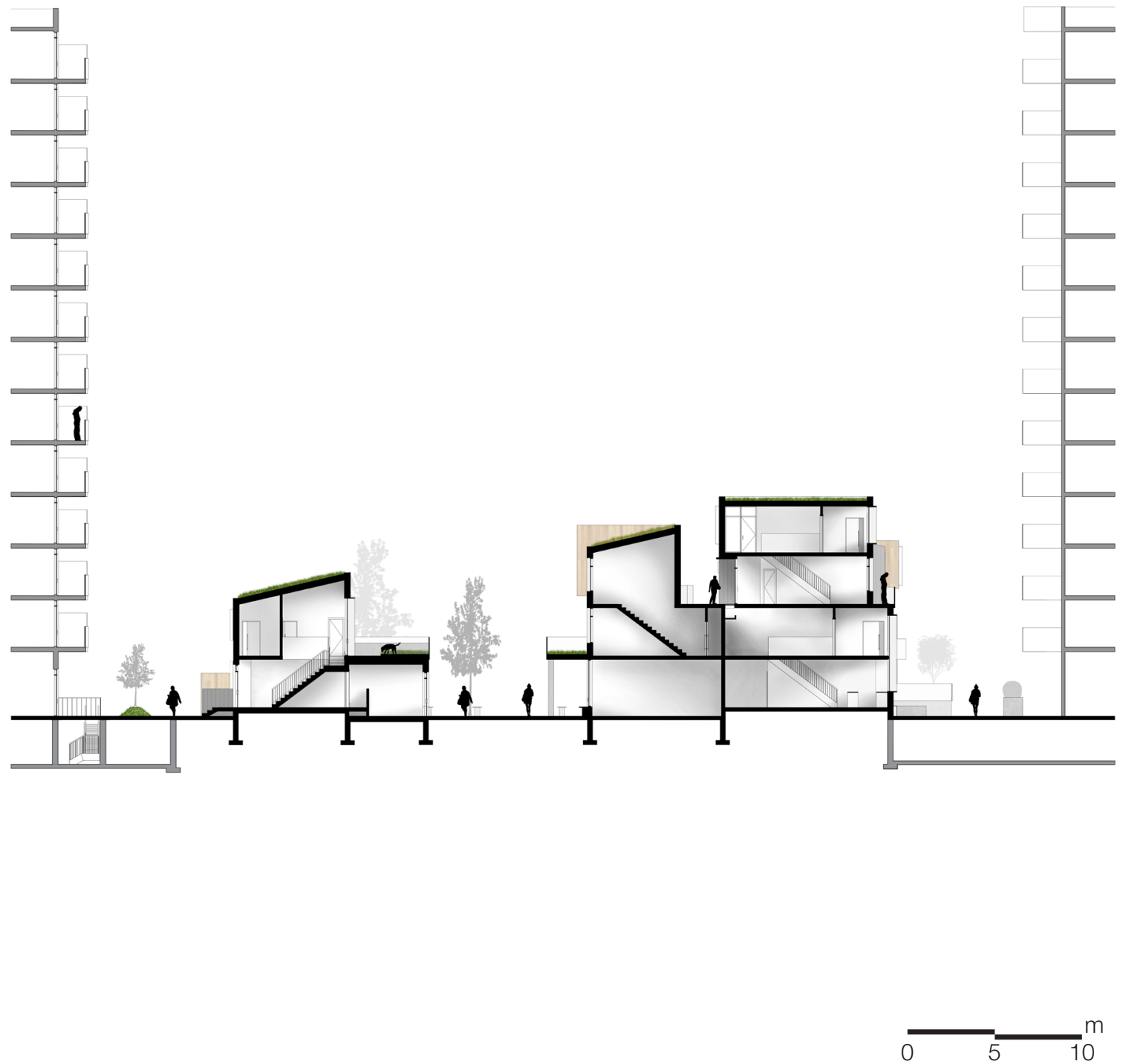

Second Iteration of Site Section Aiming to Bring More Light Into Residential Units (Sauder, 2015) 


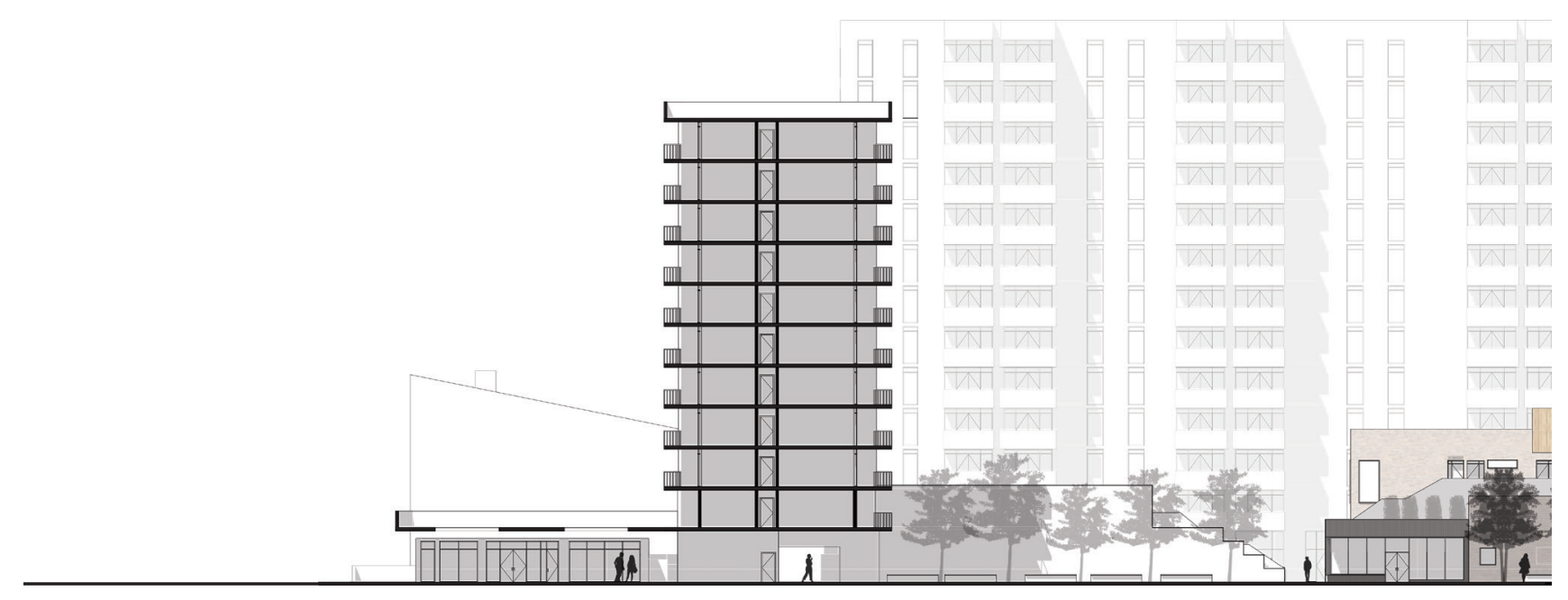

Early Section of Pedestrian Street Facing North (Sauder, 2015) 

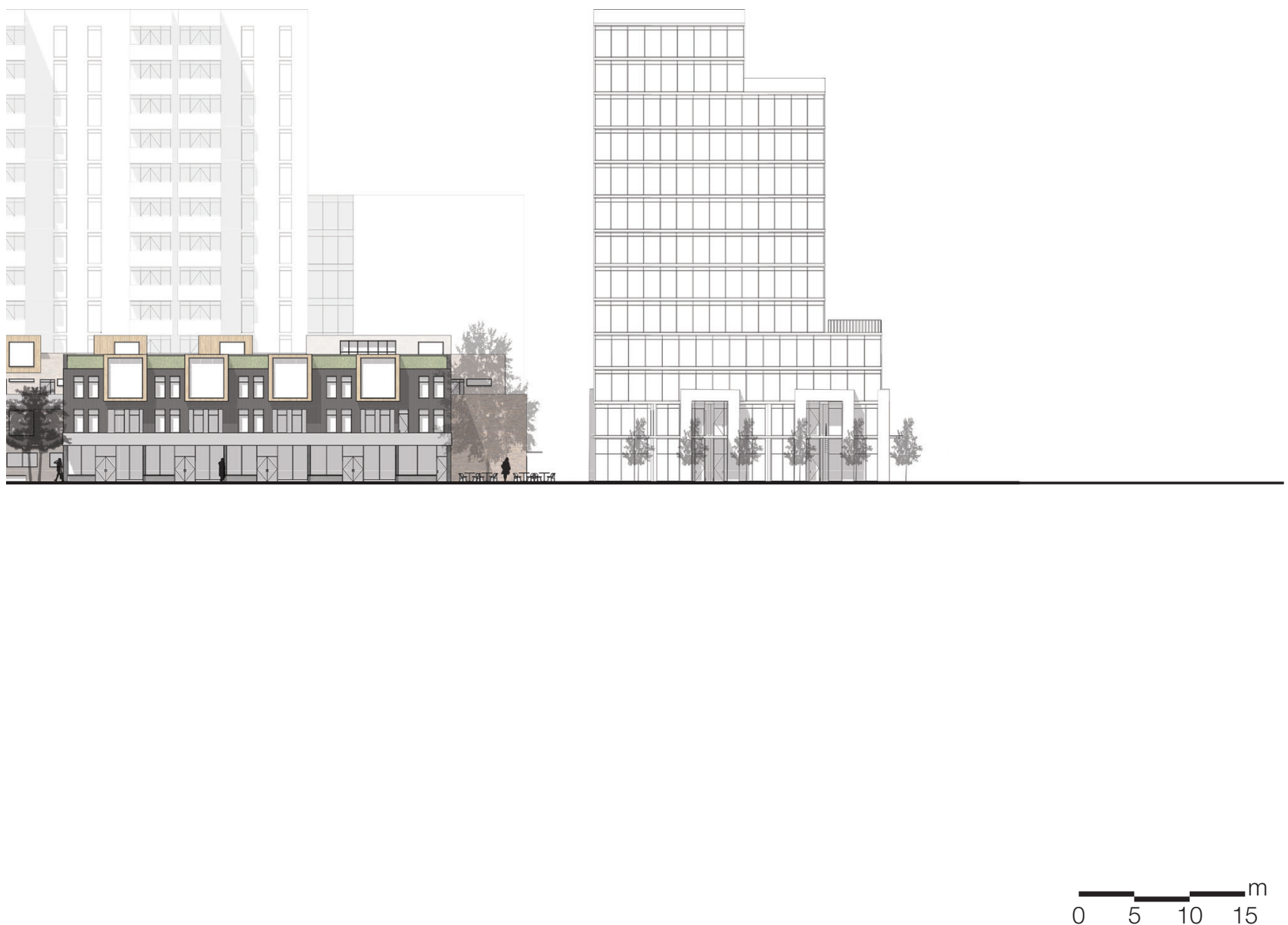


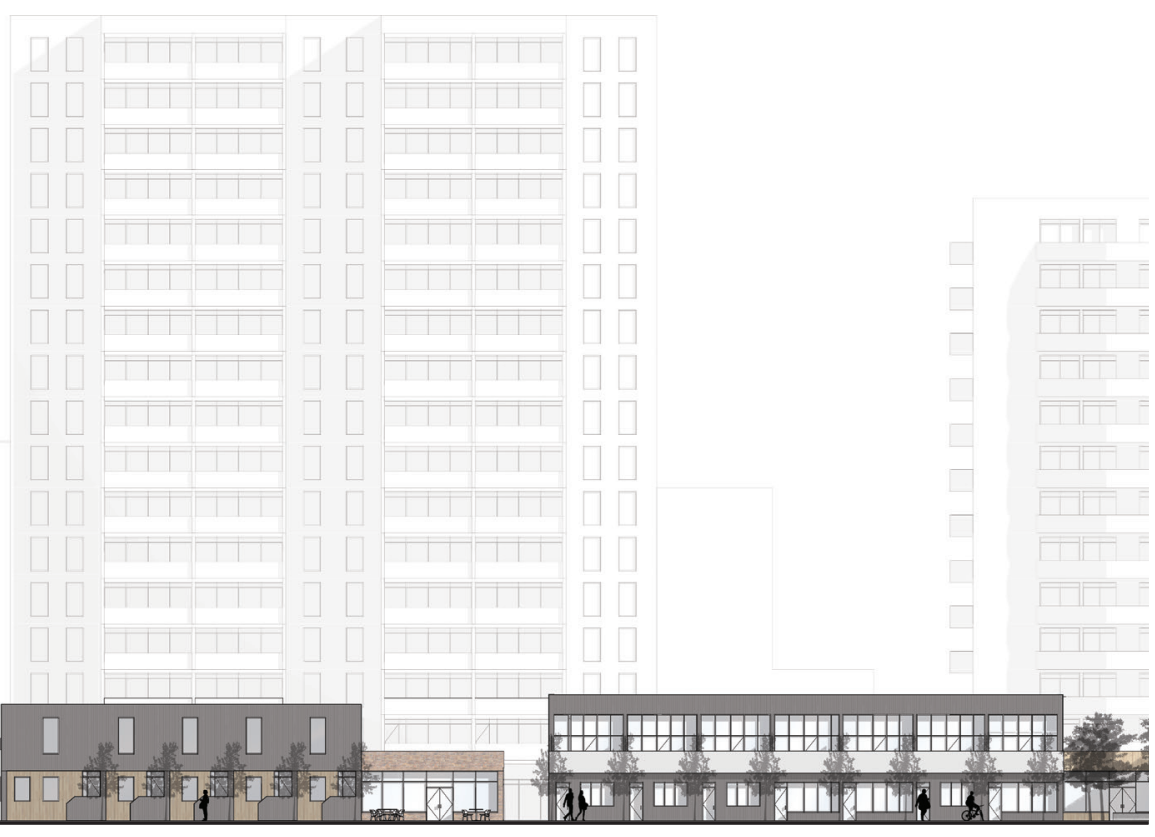

Early Section of Pedestrian Street Facing South (Sauder, 2015) 

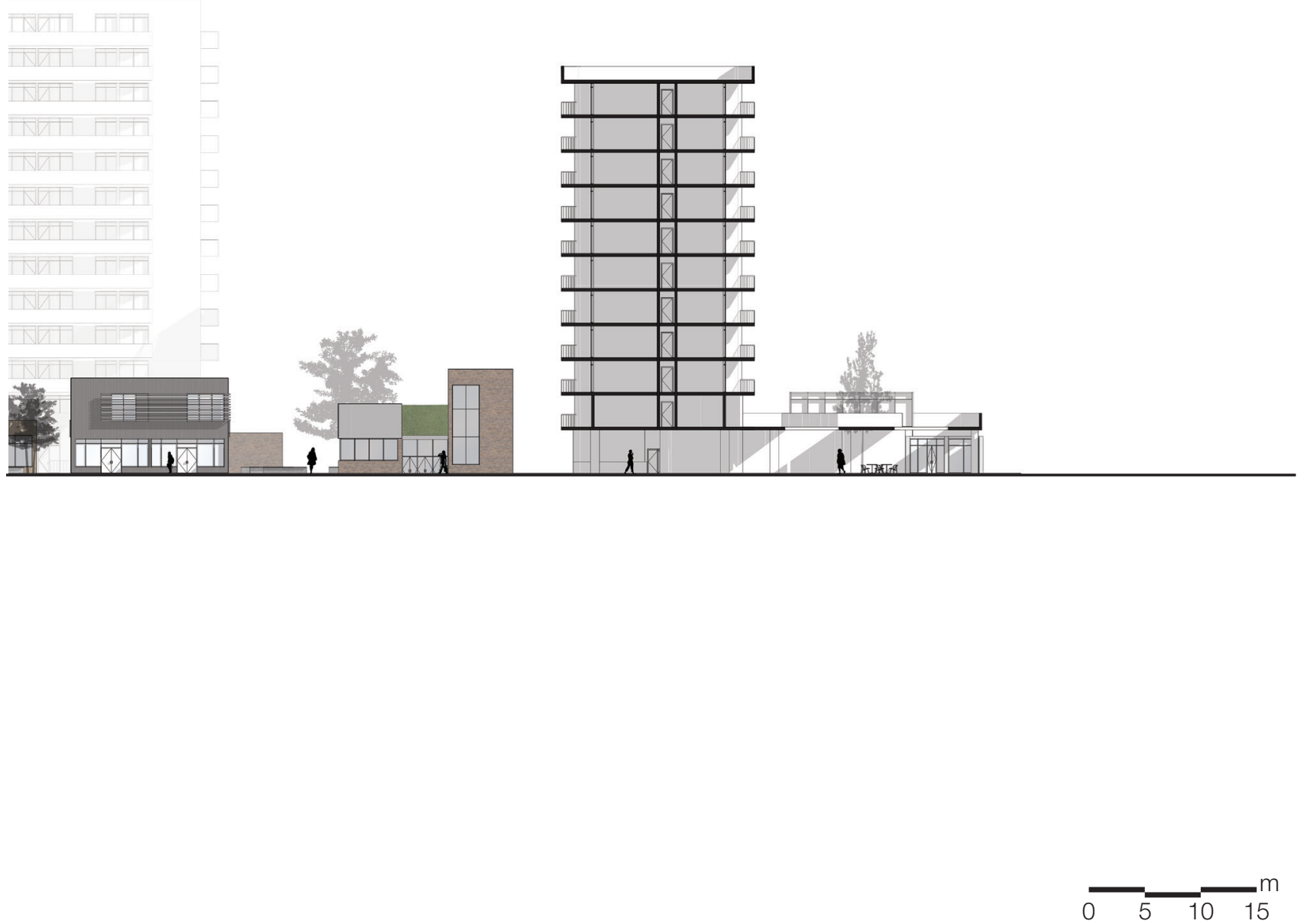


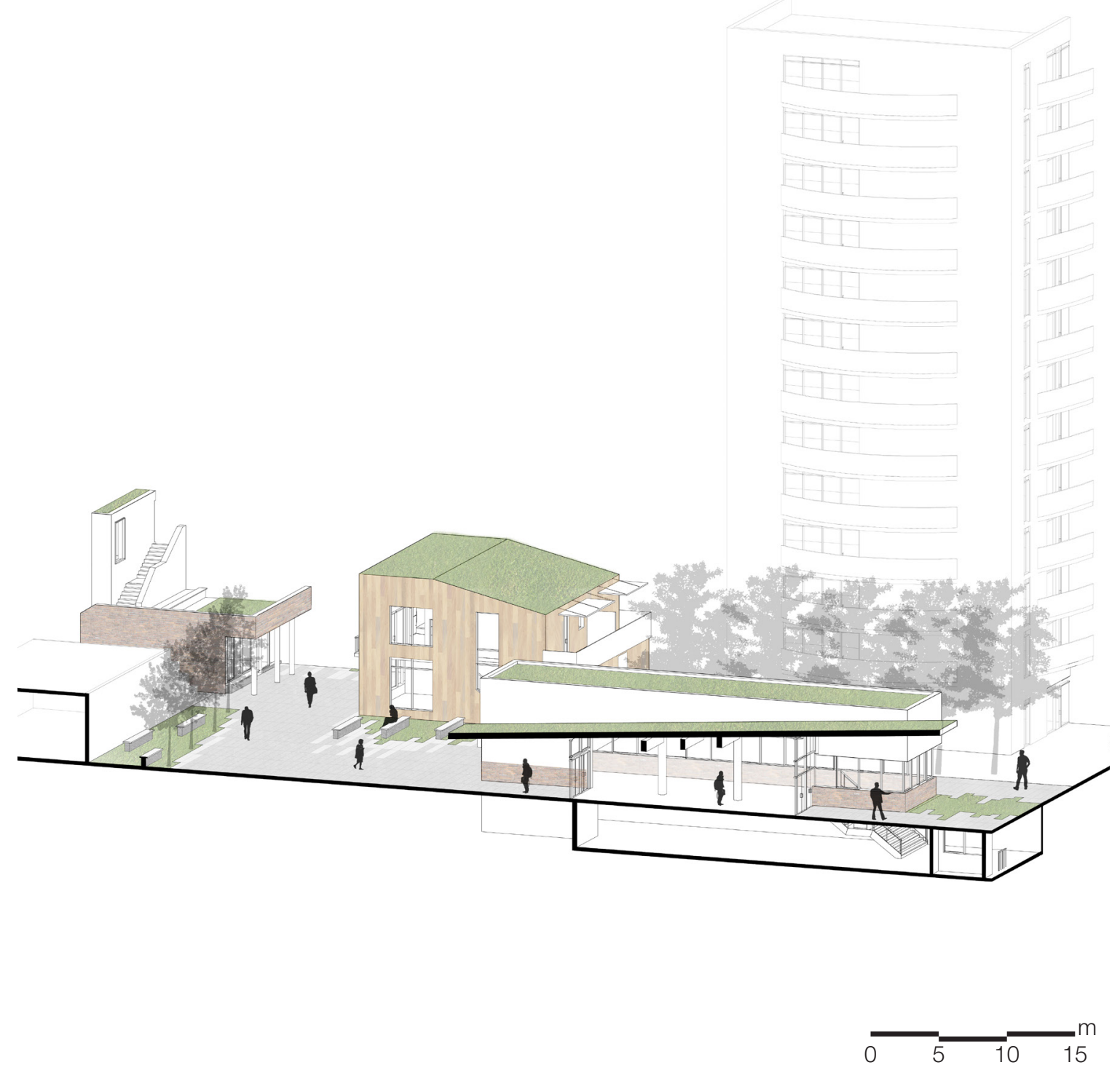

First Iteration of the Primary Activation and LRT Entrance (Sauder, 2015) 


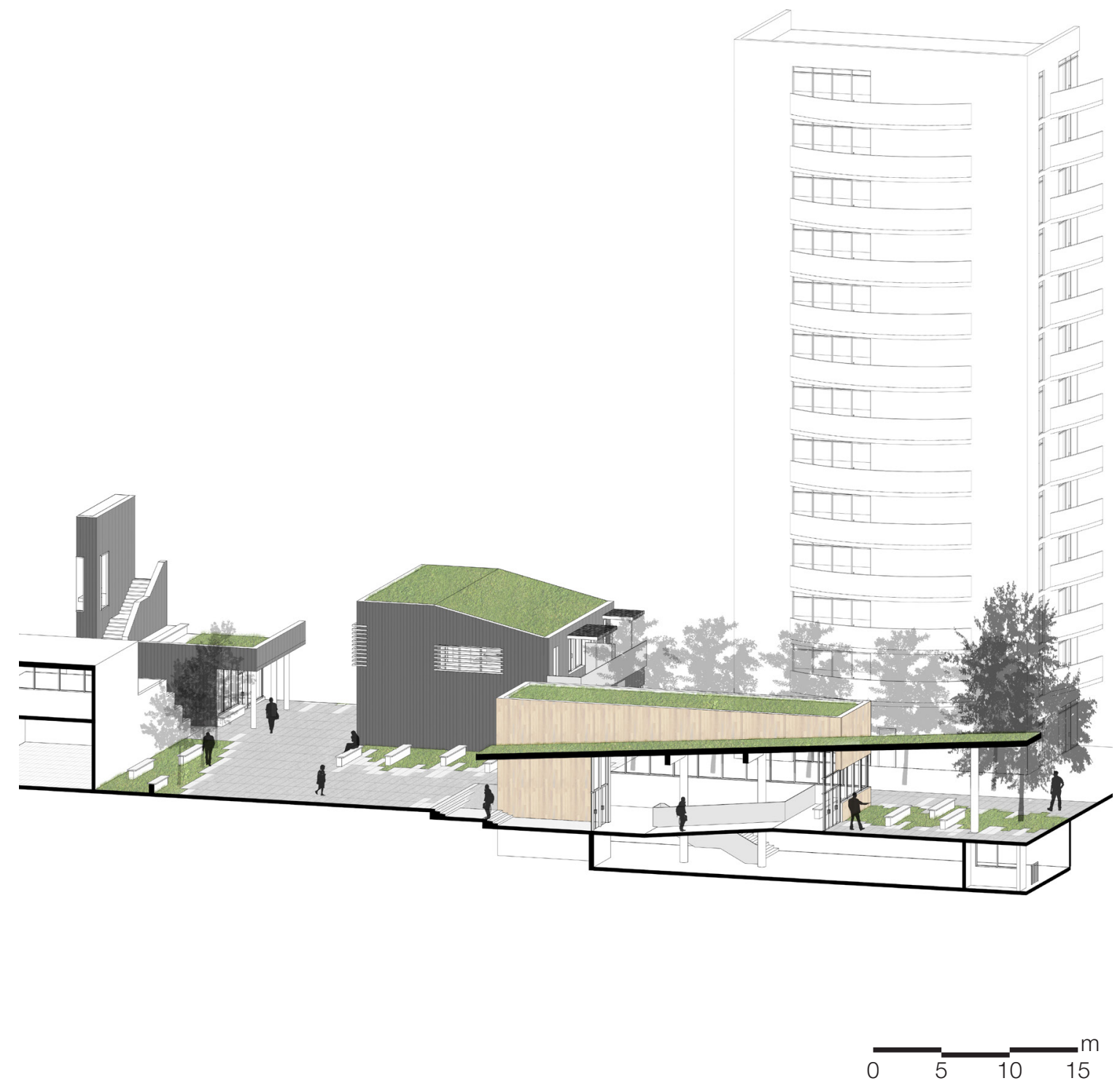

Second Iteration of the Primary Activation and LRT Entrance (Sauder, 2015) 


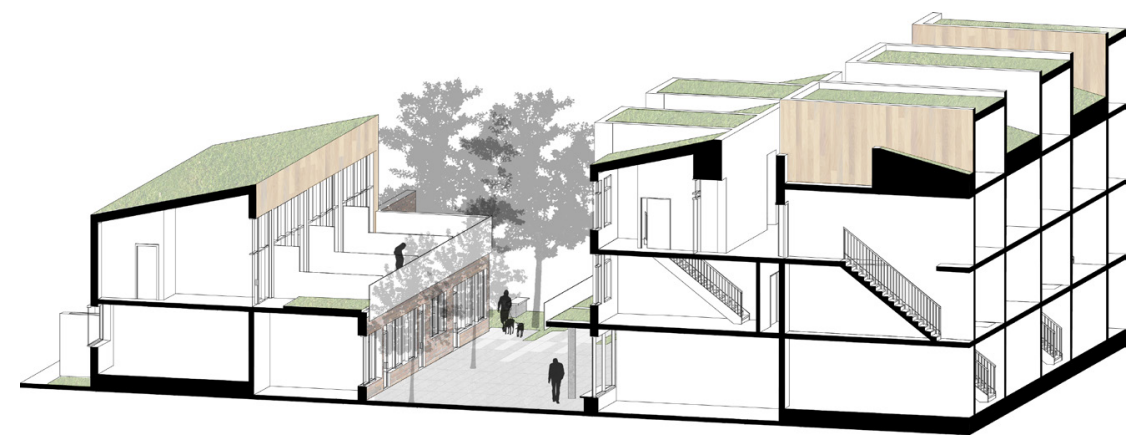

First Iteration of a Typical Section through the Primary Pedestrian Street (Sauder, 2015)
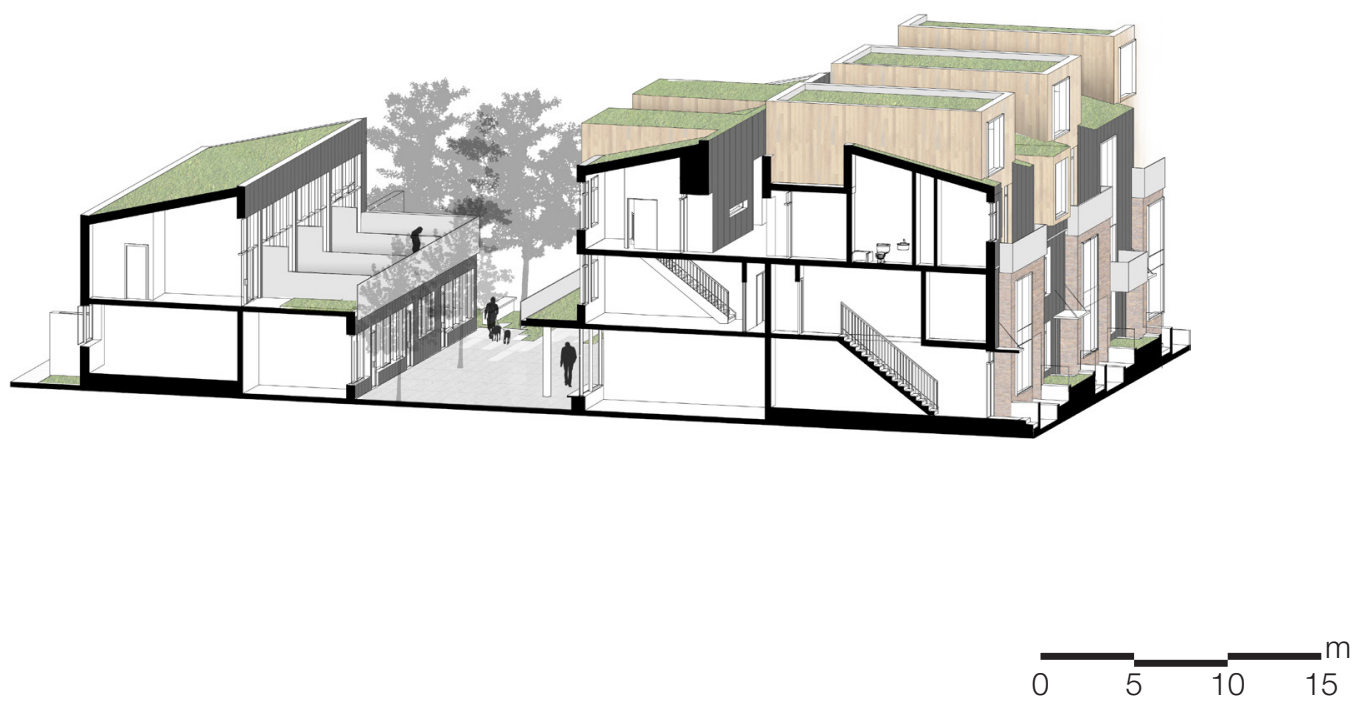

Second Iteration of a Typical Section through the Primary Pedestrian Street (Sauder, 2015) 


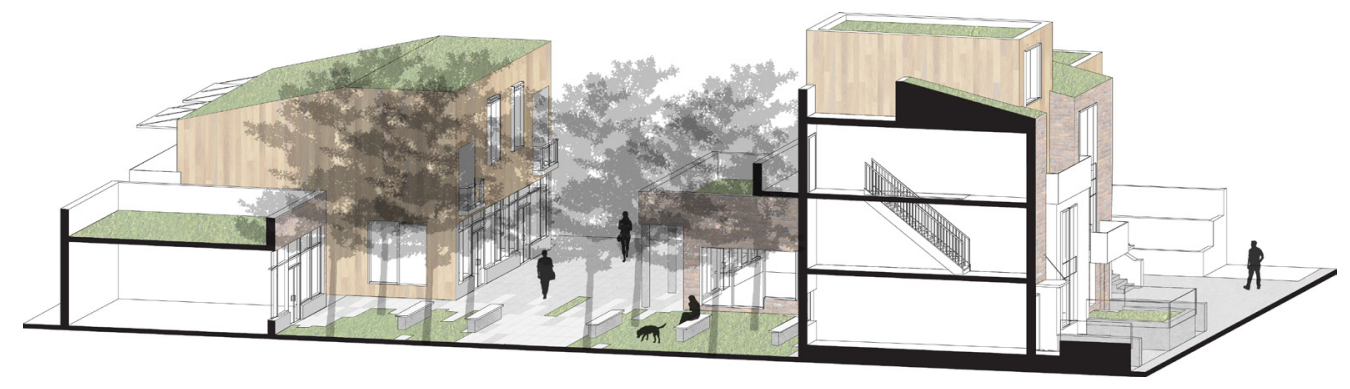

First Iteration of Treed Activation (Sauder, 2015)
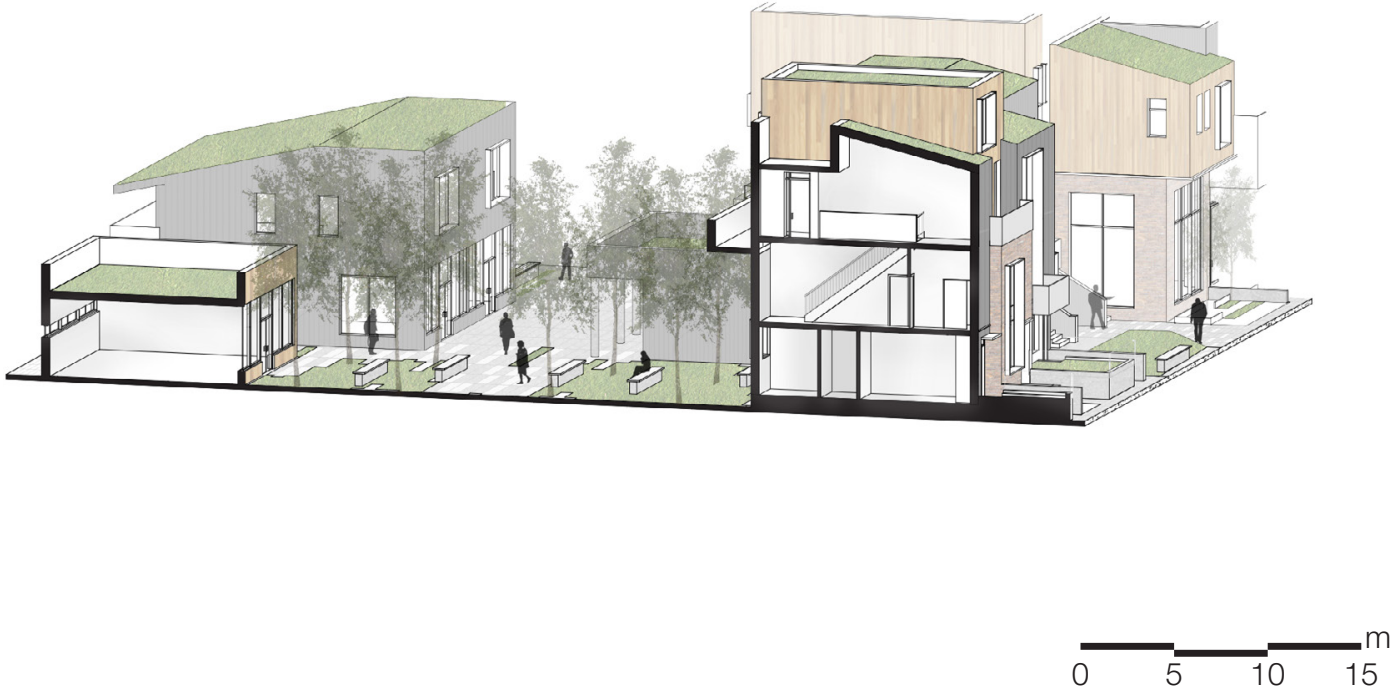

Second Iteration of Treed Activation (Sauder, 2015) 

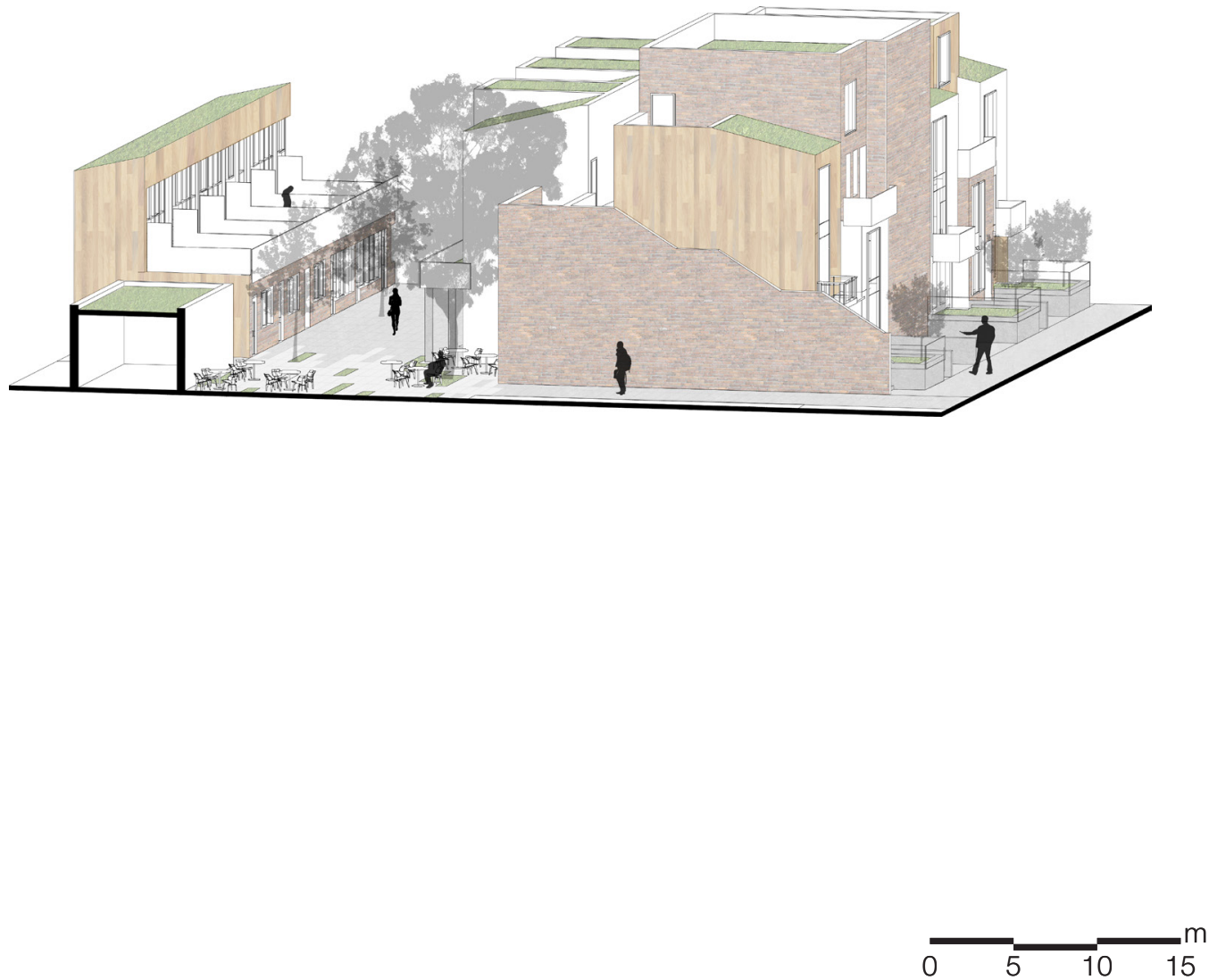

First Iteration of the Third Activation (Sauder, 2015) 

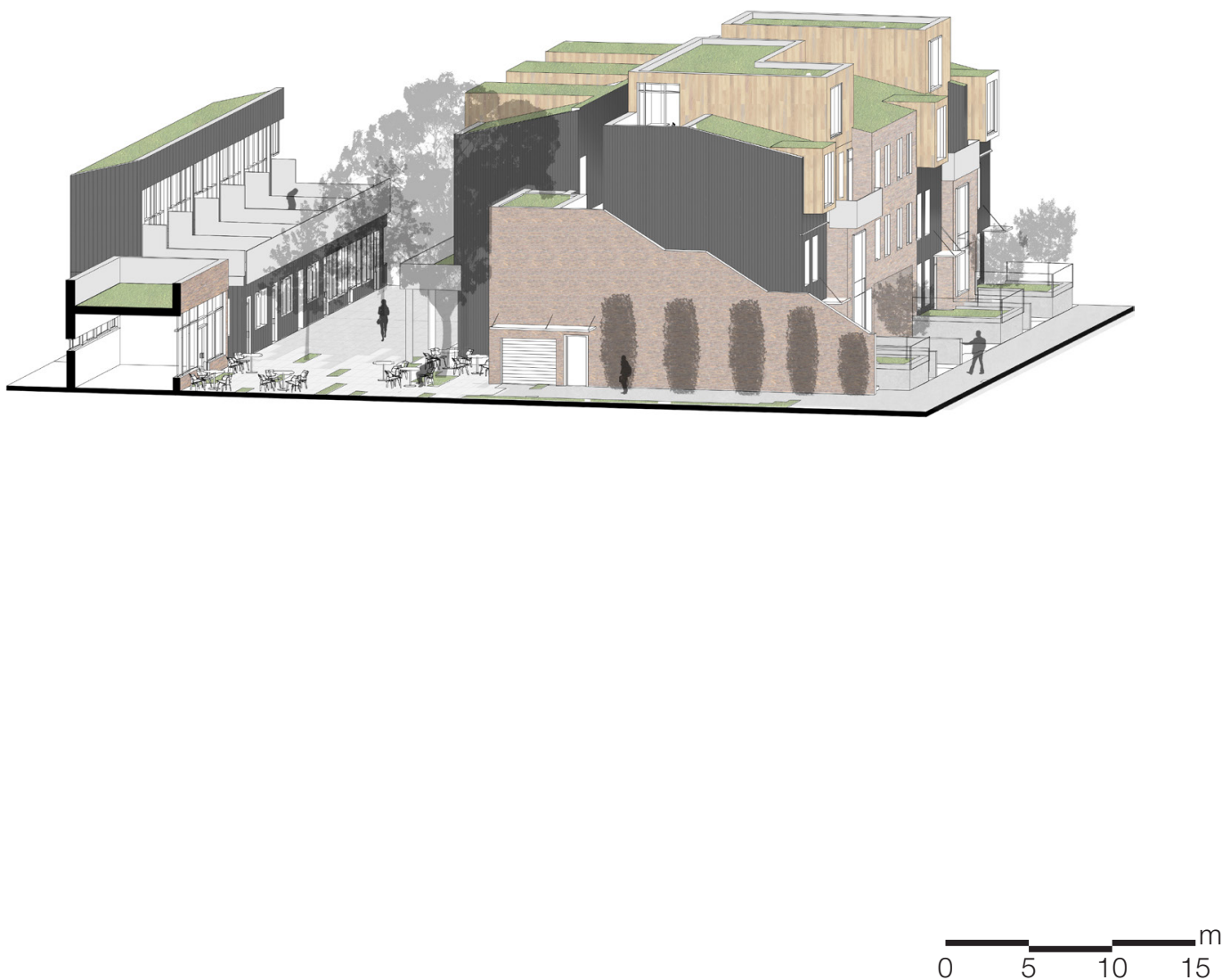

Second Iteration of the Third Activation (Sauder, 2015) 


\section{E. STUDY: EXPLORING THE IMPACT OF INFILL ON A LOW-RISE NEIGHBOURHOOD}

Looking at infill as an approach to density, an initial study turns towards an ordinary low-rise neighbourhood within the Yonge and Eglinton area. First studying infill in the low-rise block will generate a basic understanding on the impact new development can have on the experience in a residential neighbourhood. The lessons generated through this research, can then be applied to the Residential Apartment blocks. In doing so, the pedestrian qualities that make the low-rise neighbourhood can be applied here. The following sections are experiments with different strategies and forms for generating density within a low-rise neighbourhood, while considering the characters of the neighbourhood. Through these experiments, a general frame work will be created to evaluate and influence design decisions when the slab tower block is addressed. 

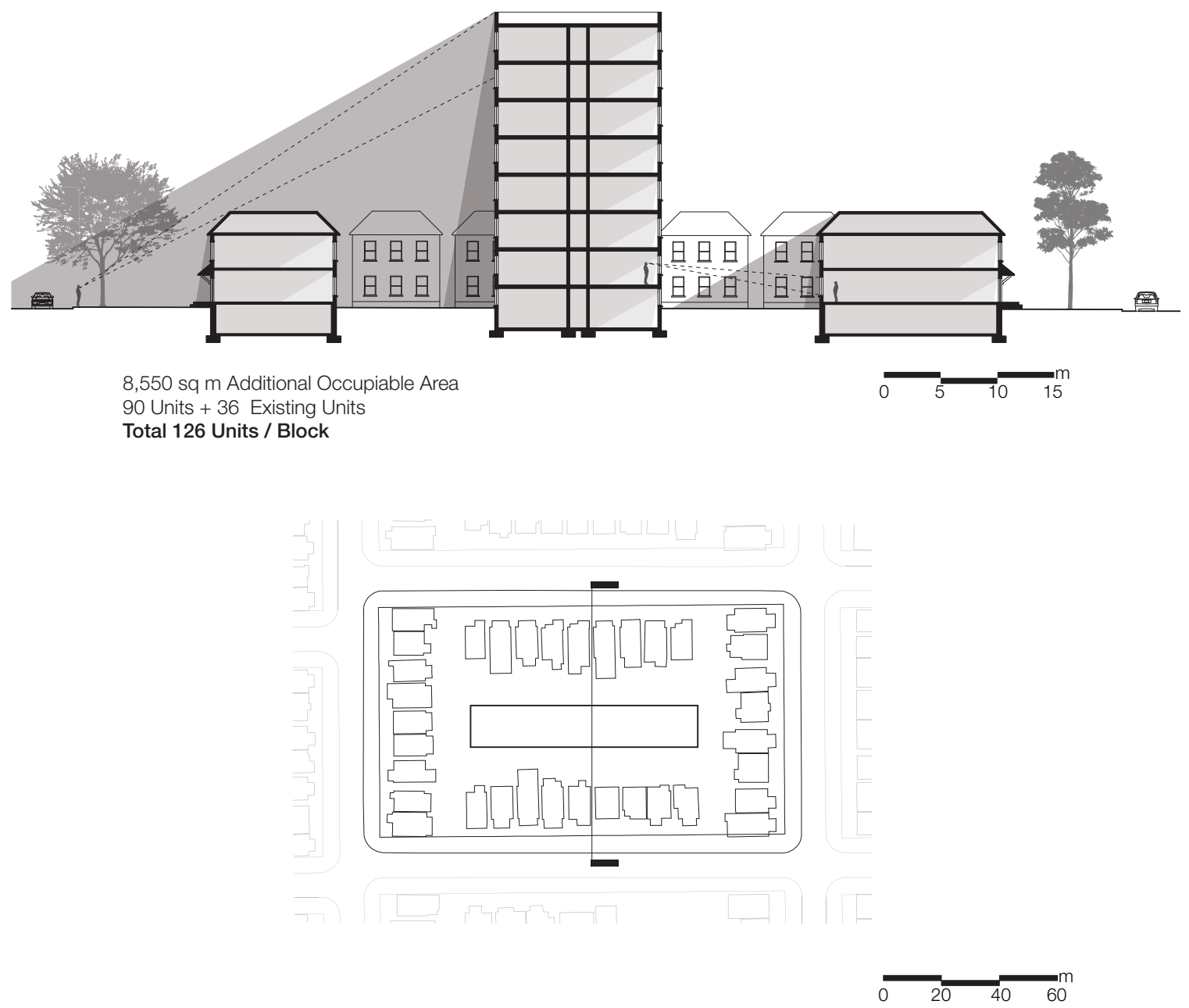

Design Research - Experimenting with Infill on a Low-rise Neighbourhood (Sauder, 2014).

In this situation, the land use intensity remains the same as the previous two iterations, but the physical density is increased dramatically. The building height is drastically increased, but this time has a major effect on the street. Shadows cover both the original building stock as well as the public area and the pedestrian sight line can clearly see the intervention. The scale of the building imposes a very heavy footprint on the immediate context and brings the wall condition from the avenues to the back yards of this block. The proximity to other houses with a large building height also overpowers the existing context and generates a change in the experience of the neighborhood. Thus this particular study can conclude that maintaining the existing facade of the street elevation is not enough to protect the perception of the neighbourhood. 


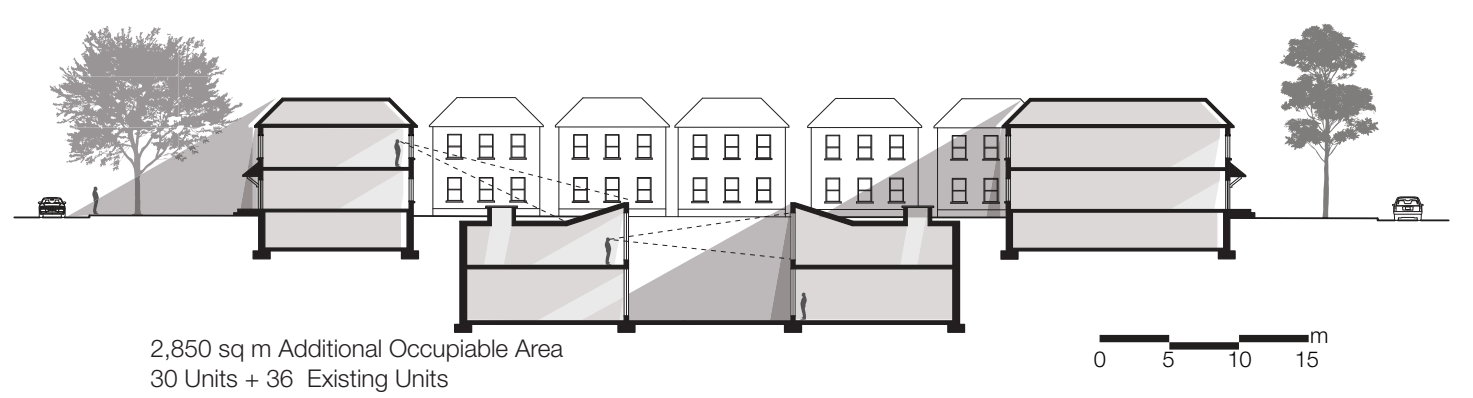

Total 66 Units / Block

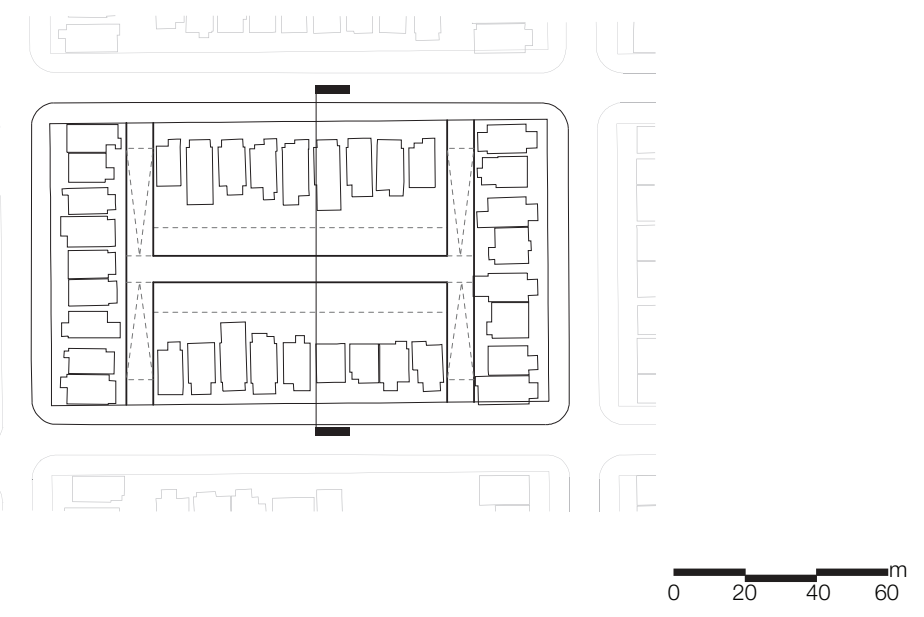

Design Research - Experimenting with Infill on a Low-rise Neighbourhood (Sauder, 2014).

Building off the stronger aspects of the previous attempt to increase density, this exploration increases the size and depth of the buried units. The result is an intervention increasing the physical density of the neighbourhood by 2,859 square meters. Due to the multiple floors, the centre lane needs to be widened to bring daylight into the units. If the site is too narrow, then alternative solutions to bring light in need to be proposed, or another strategy for increasing density should be chosen. Privacy between the parallel buried units still remains a problem in this proposal as both sides look onto the common lane. Widening this on a big lot would have the potential to address this concern. 


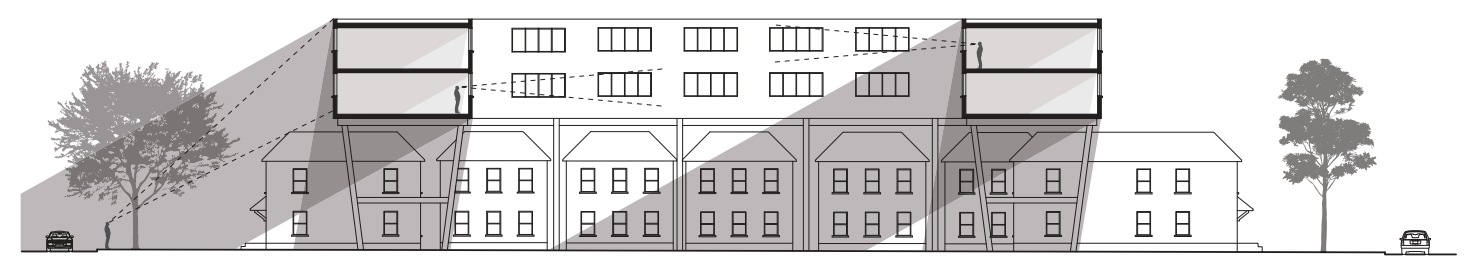

5,890 sq m Additional Occupiable Area 62 Units + 36 Existing Units

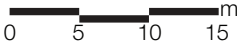
Total 98 Units / Block
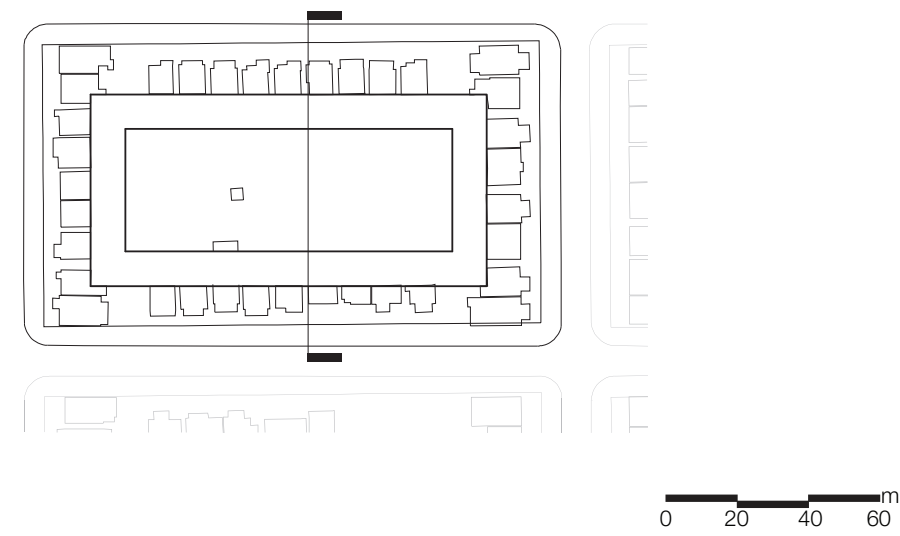

Design Research - Experimenting with Infill on a Low-rise Neighbourhood (Sauder, 2014).

With a significant density increase of 5,890 square meters, this experiment also raises the structure above the ground plane. However, this time it is elevated over the existing homes instead of the yard. As a result, there are less significant shadows on the ground and the intervention is given more of a presence on the street. Even with a stronger street presence, the intervention does not overpower the scale of the housing bellow. Also, because it is set back slightly behind the edge of the original roof line the structure does not over take the street and completely disrespect the original experience. 
Following the study of individual strategies to increase density within the low-rise residential neighbourhood, a comparison (seen on the right) was conducted to understand how and why specific conditions can improve or deter the quality of the neighbourhood. From these findings, it can be concluded that construction bellow grade in a residential setting raises issues of privacy, but is suited for more public and commercial programs. Construction in front of the original neighbourhood buildings is also difficult because it either overpowers the existing street frontage, or it has to interfere with the public realm. However, generating density in the between areas of the neighbourhood block can be effective if, and only if, there is a significant amount of space between each building. In the case of this particular residential neighbourhood, the side yards are far to narrow to accommodate the city's growth. However, conditions outside of low-rise residential blocks, like the slab towers, have large side yards that could be infilled with an intervention. Looking at the above grade conditions reveals that the intervention creates an unpleasant environment on the ground plane because of the massive shadows that are being cast. One lesson that can be taken from all of the various iterations from the study is the importance of transition zones. Not only does this give the residences a sense of privacy, but it allows light to enter the intervention and green space to remain in the area.
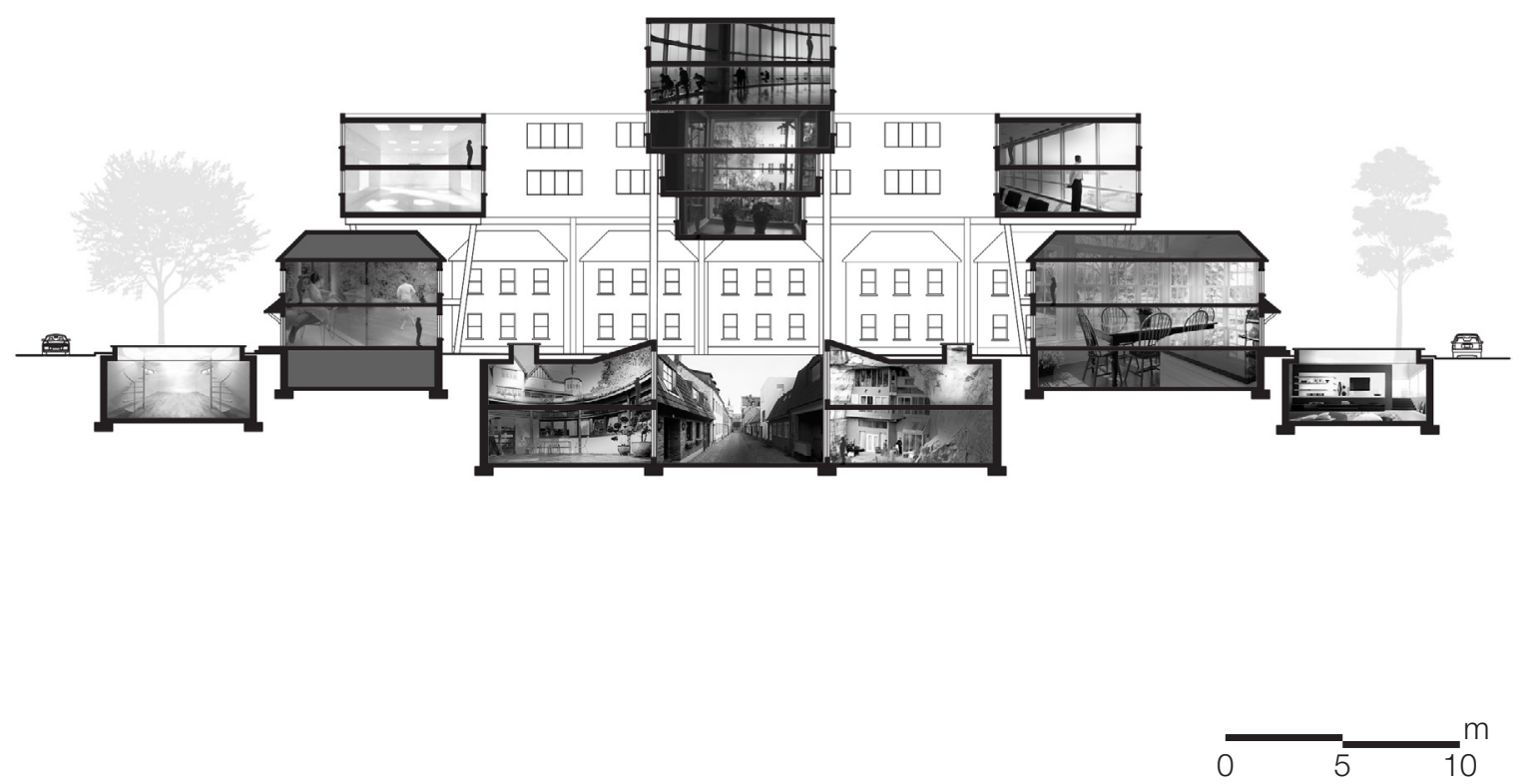

Design Research - Experience Create By Applying Multiple Sectional Strategies to a Single Low-rise Residential Block (Sauder, 2014). 


\section{Section Pros}
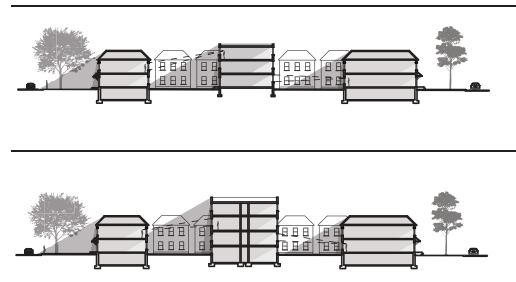

-Hidden from the street -Minimal shadows are cast -Maintains yard for transition

-Accommodates more density then the town home typology

-Hidden from the street

-Minimal shadows are cast

-Significantly increases density

\section{Cons}

-Limited privacy

-Additional area is marginal

-Limited access to new units

-Limited privacy

-Visually occupies more of the back yards

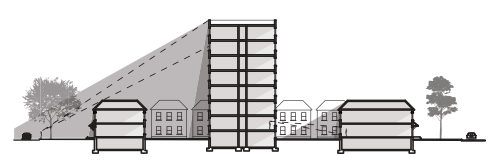

-Generates wall condition in back yards

-Visible from street

-Casts significant shadows

-Limited privacy

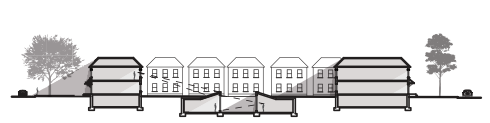

-Minimal shadows are cast

-No visual impact in back yards

-Privacy between existing structures

maintained

-Increase in density is negligible -Limited privacy between new construction

-Space is consumed for circulation

-Minimal shadows are cast -No visual impact in back yards -Privacy between existing structures maintained

-Increase in density compared to -Increase in density is still limited

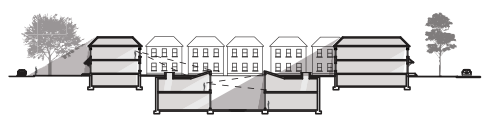
previous iteration -Limited privacy between new construction -Space is consumed for circulation -Difficult to bring light into lowest level

-Significant increase in density

-Generates wall condition in back -Hidden from street yards

-Privacy is limited

-Back yard becomes restricted

-Visibility from street does not impact character of the neighbourhood

-Makes use of yard space

-Maintains transition between street and existing residence
-Increase in density is marginal -Generating access becomes difficult

-Limited privacy from the street

Comparison Between Infill Placed in a Low-rise Residential Block and Its Affect on the Block 


\section{F. $\quad$ STUDY: APPLYING ADDITIONAL DENSITY TO SLAB TOWERS}

The lessons from the sectional experiments in the typical residential neighbourhood can be combined with the earlier studies of the low-rise commercial and residential areas around Yonge and Eglinton. These lessons in correlation with the Residential Apartment block can generate additional density within and around individual slab towers.

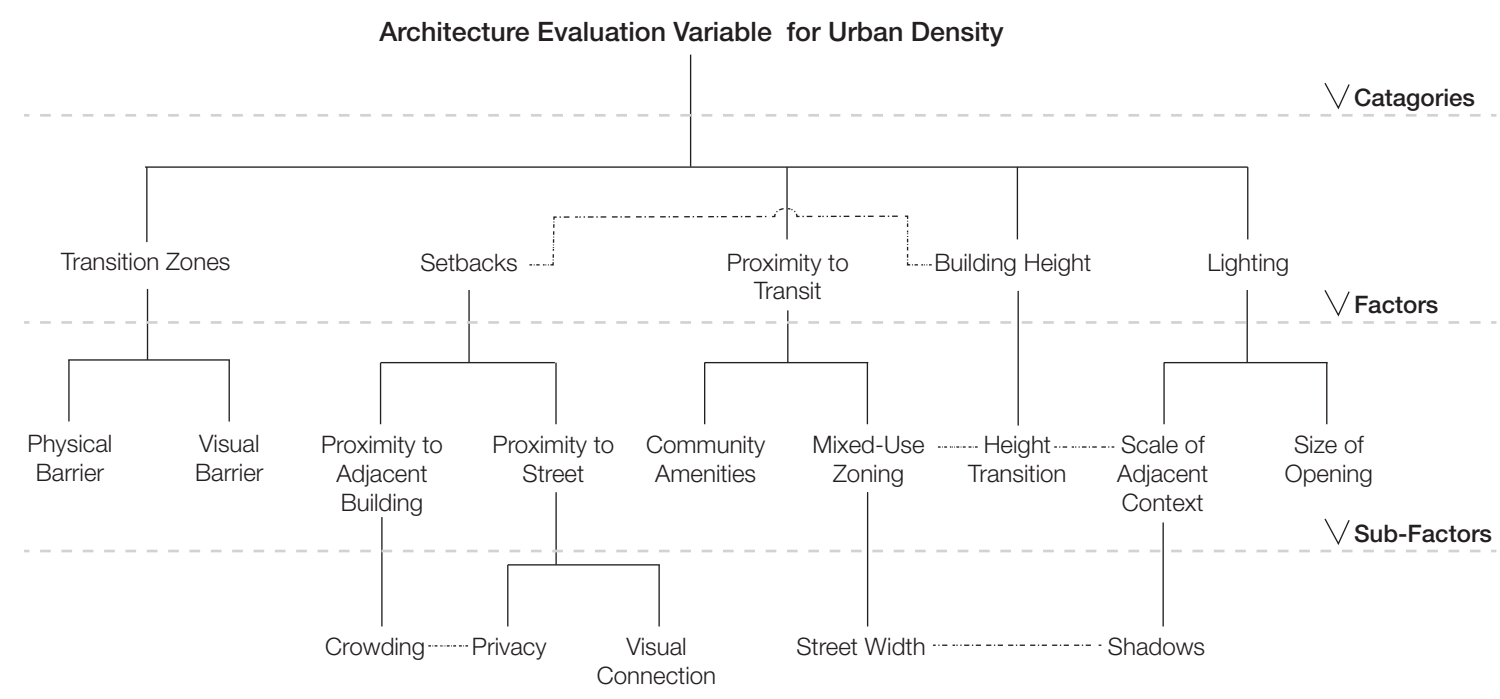

Evaluation Criteria Used to Determine Approaches and Effectiveness After Applying Additional Density to an Existing Residential Apartment Tower (Sauder, 2014). 

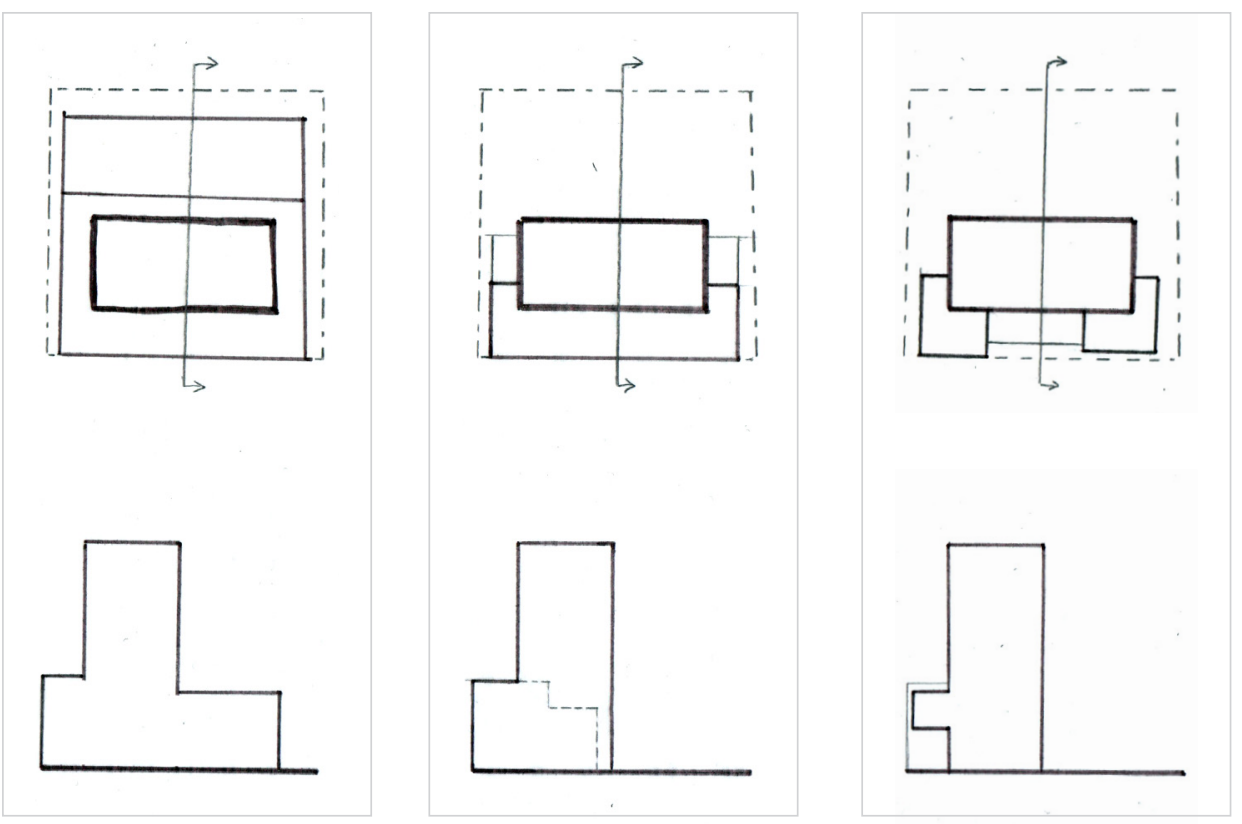

Experimenting with the Addition of a Podium to Existing Slab Towers to Generate Additional Density (Sauder, 2014).
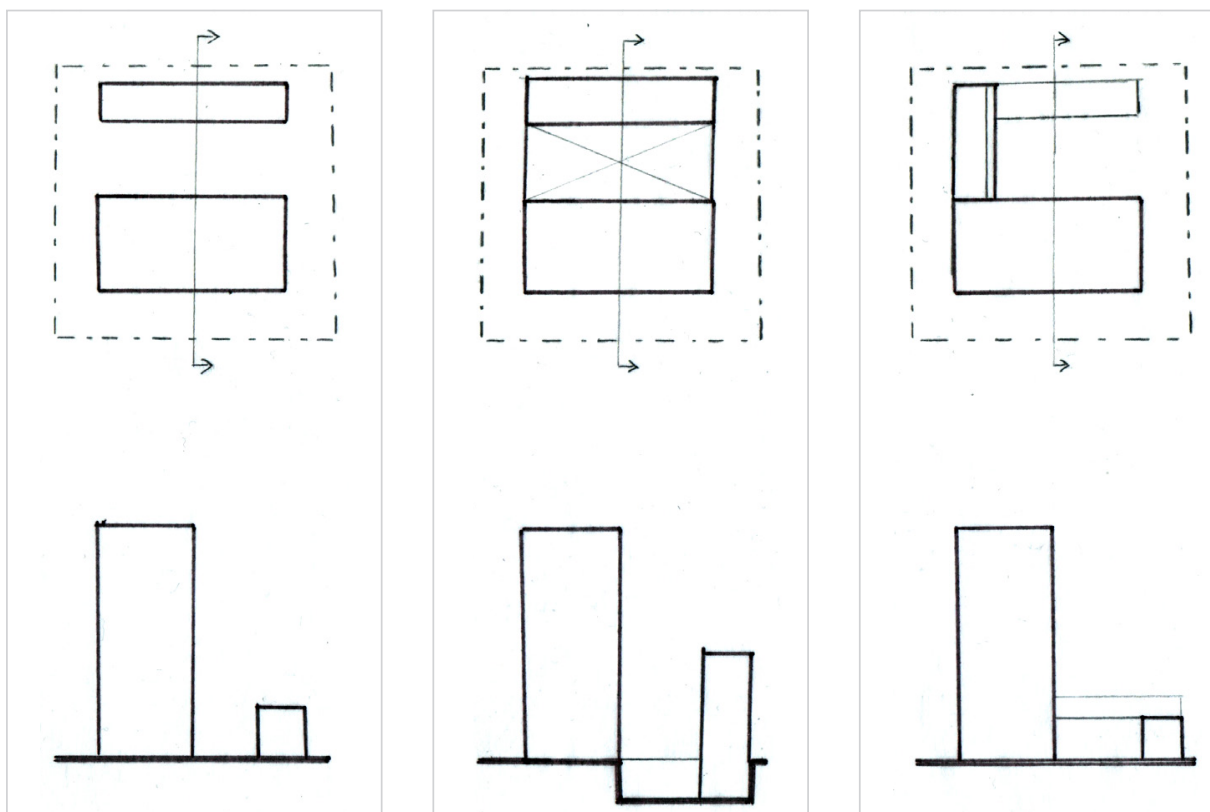

Experimenting with Infill Behind Existing Slab Towers to Generate Additional Density (Sauder, 2014) 

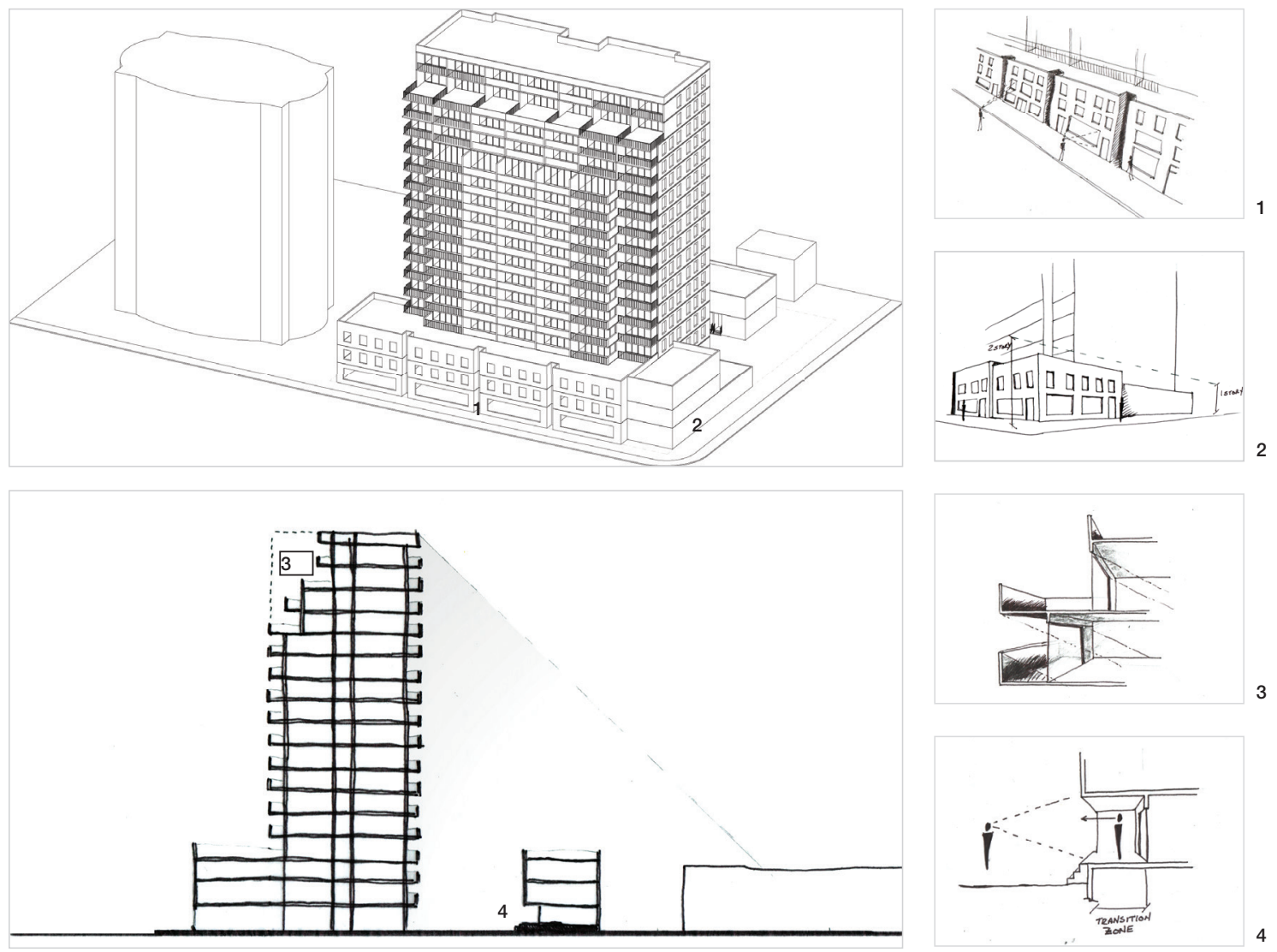

Exploration Cutting Away Parts of the Tower for an Added Transition Zone and a Podium in Front of the Tower (Sauder, 2014). 

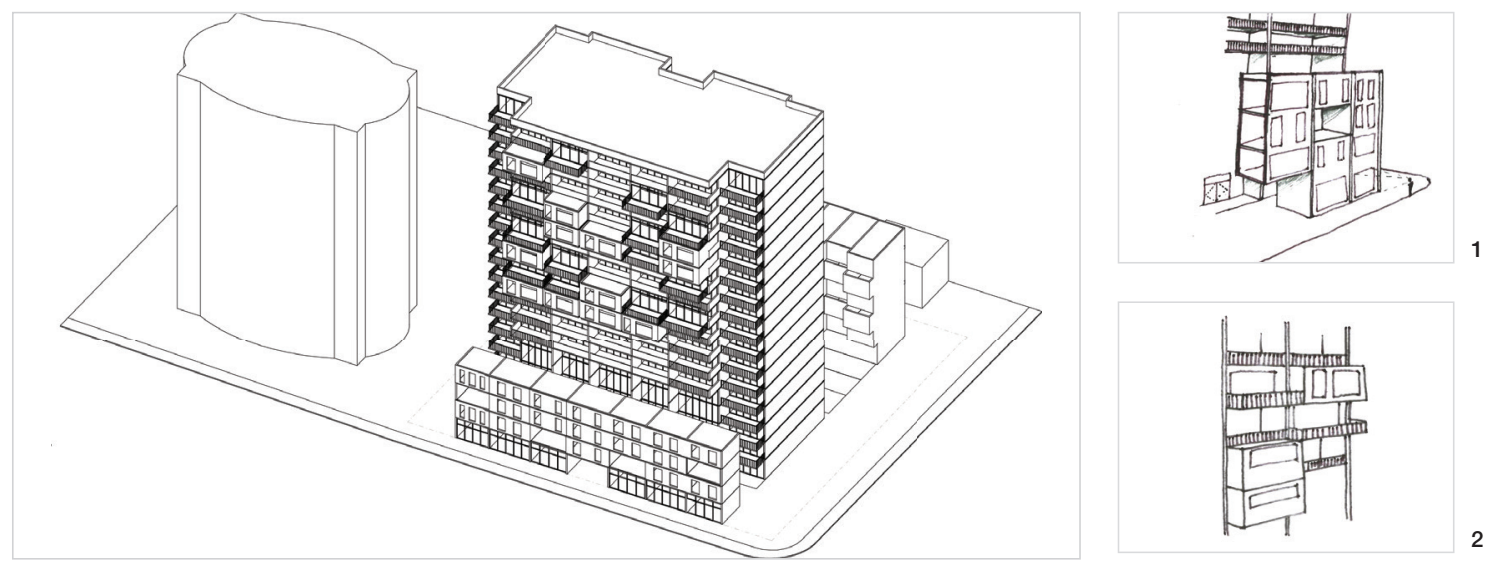

1

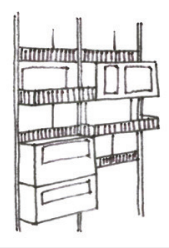

2
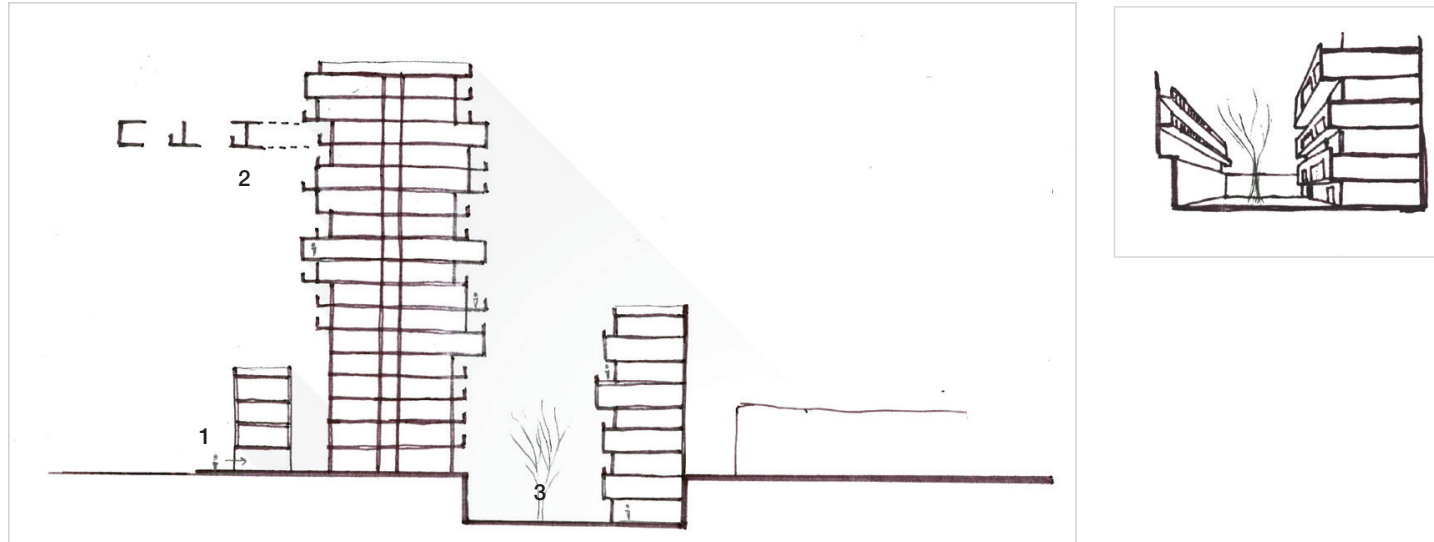

3

Exploration Extending Living Space with Balcony Additions and Recessed Infill Behind (Sauder, 2014). 

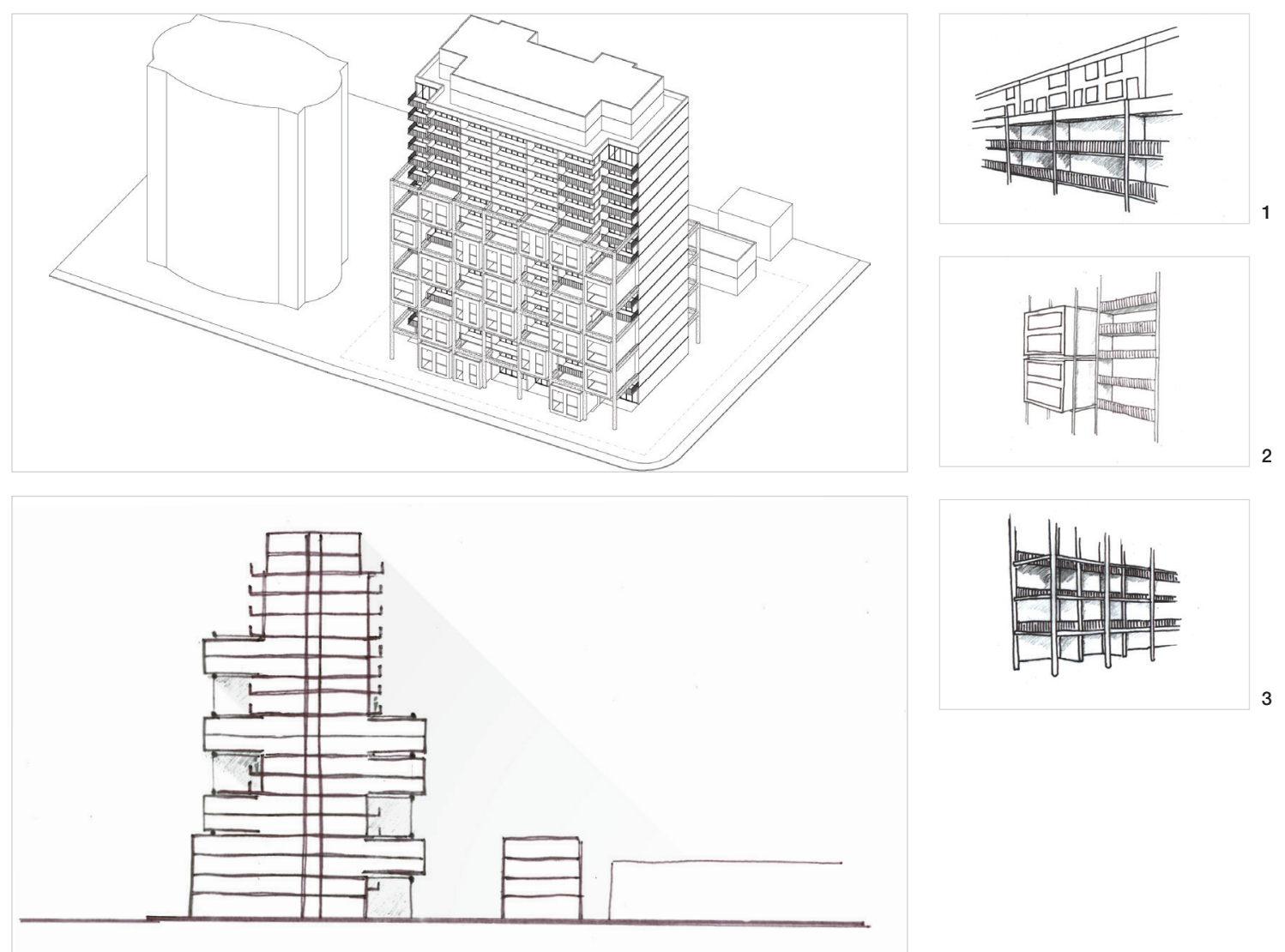

Exploration Extending Units Using an Exterior Structure (Sauder, 2014). 

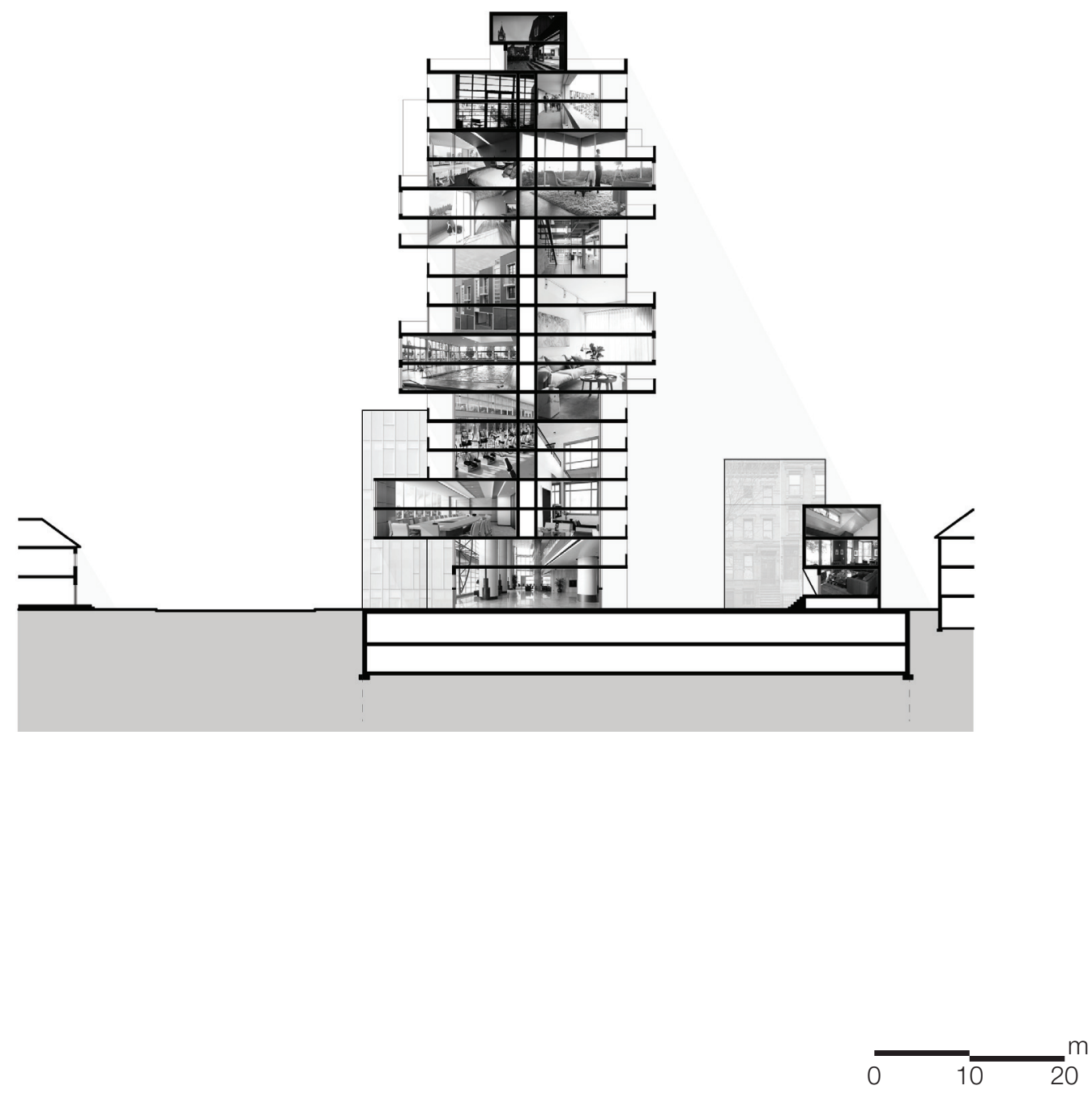

Applying Multiple Approaches to an Existing Residential Tower to Understand the Experiential Qualities that Come with the Additions (Sauder, 2014). 


\section{G. PRECEDENT STUDIES}

\section{I.I THE LORETTO LOFTS}

Architects Alliance and Quadrangle

387 Brunswick Avenue, Toronto

2007

The Loretto Lofts project converted the former Loretto Abby Day School into a condo project in Toronto's Annex neighbourhood. The conversion featured 48 new condo suits in the former school and an additional 13 new town homes at the rear of the site (Mclean, 2012). The design focuses on the interior of the site by creating a lane way condition to access the new town homes and large communal courtyard. The lane way and courtyard act as necessary circulation space and also provide space for outdoor amenities.

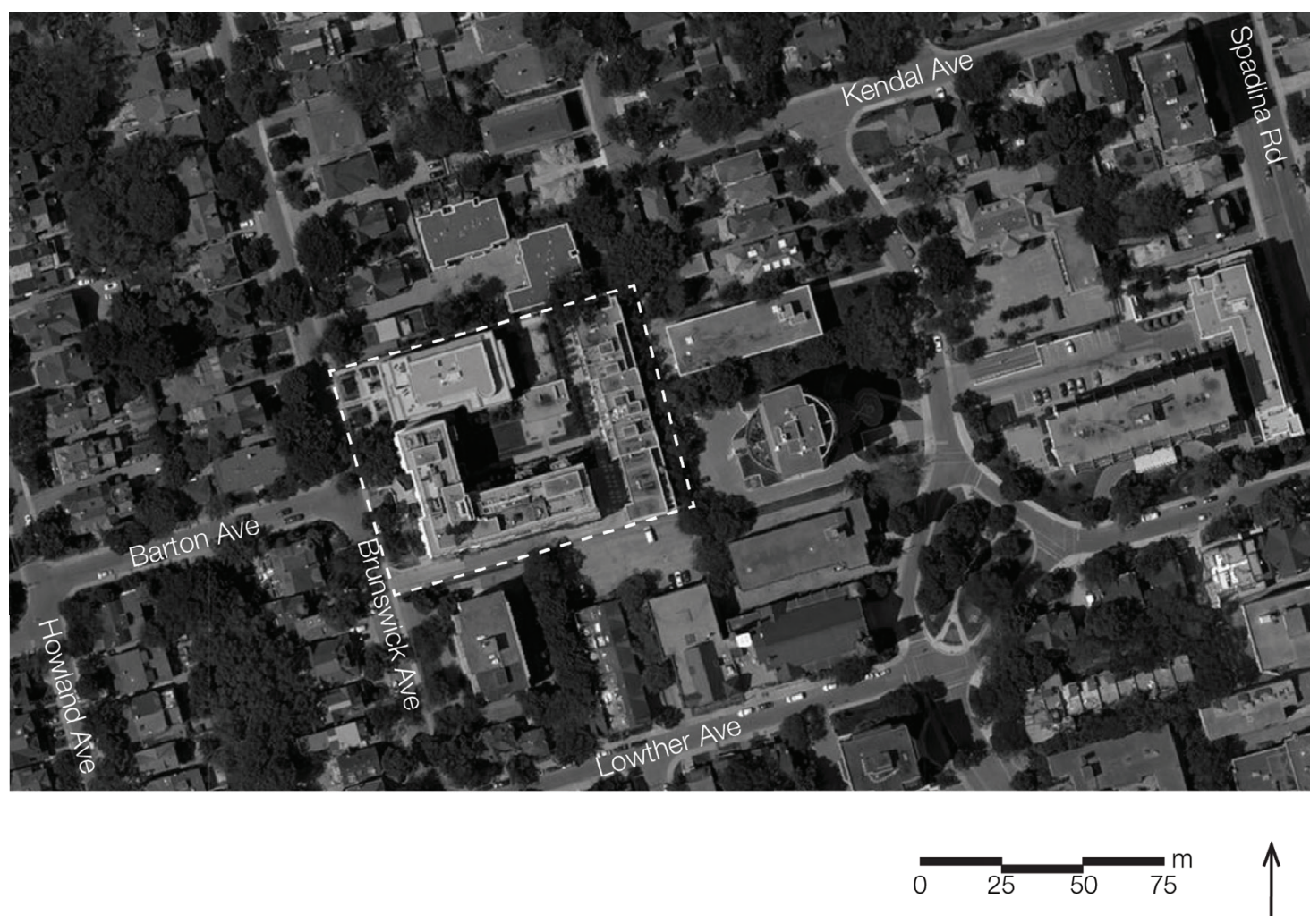

Project Location (Image Retrieved from Bing Maps, Draw by Sauder, 2014). 


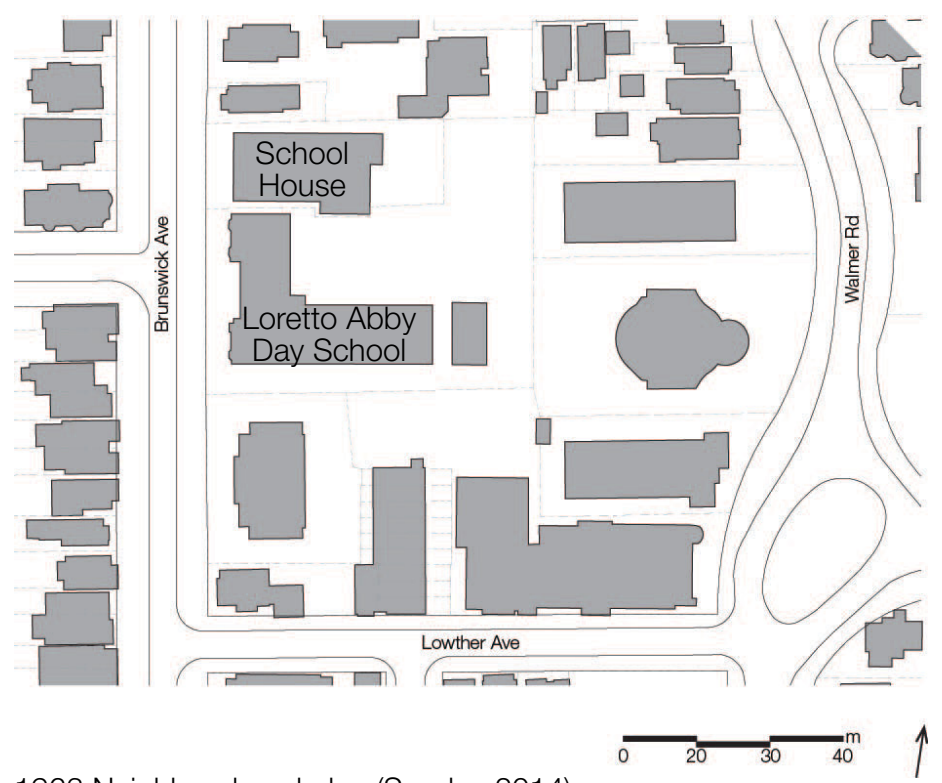

1963 Neighbourhood plan (Sauder, 2014).

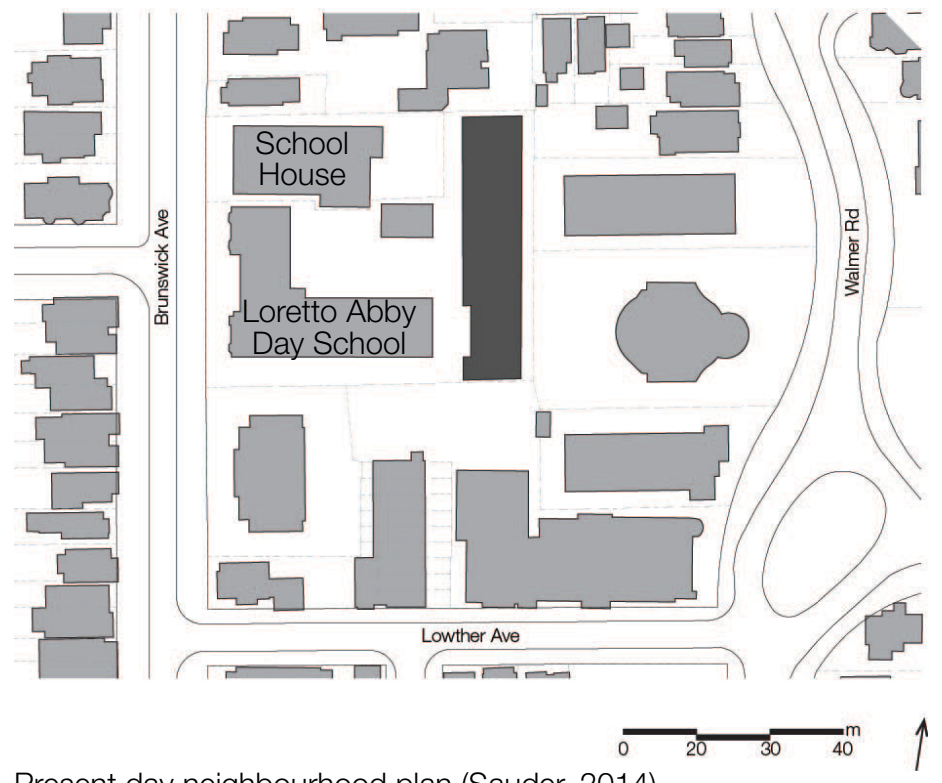

Present day neighbourhood plan (Sauder, 2014).

The above maps show how the site has transformed to support an increased physical density. The former open space at the rear of the property is now occupied by 13 town homes. The new structure turns its back to the adjacent properties and focuses its attention on the former school and school house. 


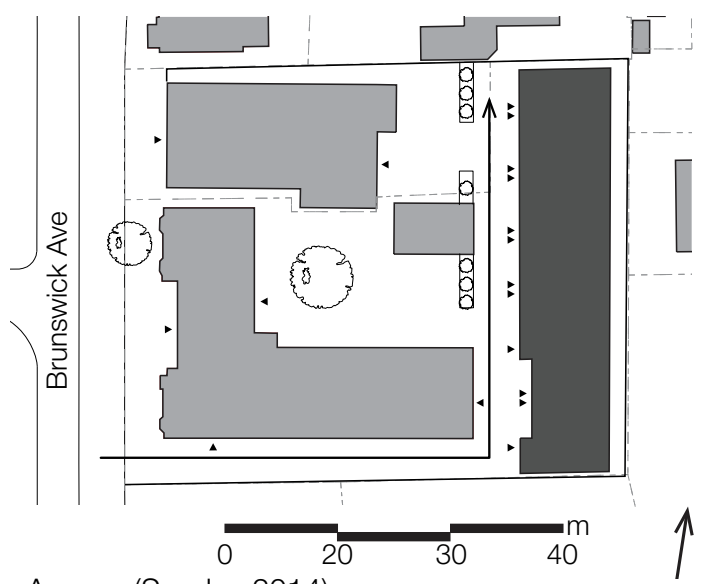

Site Access (Sauder, 2014).

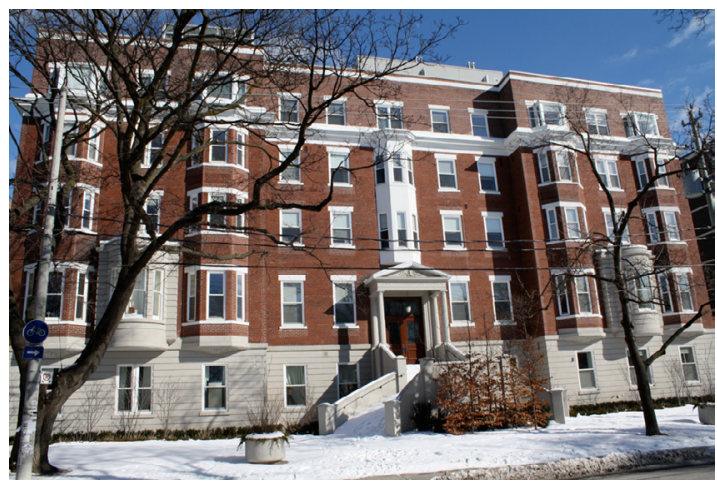

Front Facade of Original School (Sauder, 2011).

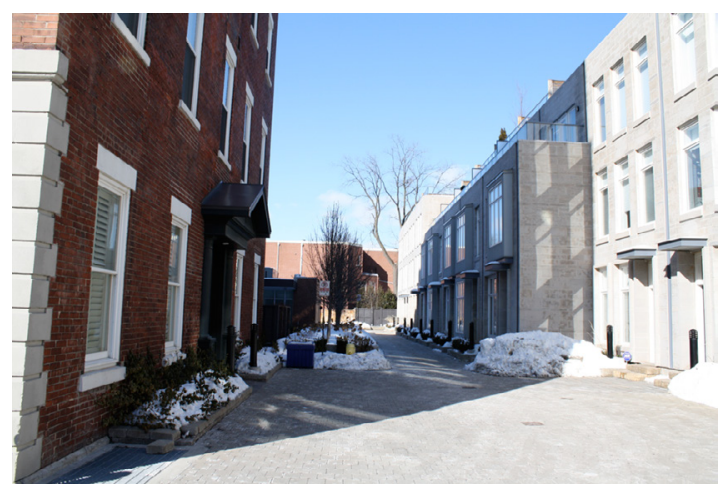

Lane Between Existing School and New Town Houses (Sauder, 2011).
The primary access point to the interior of the site is located between the existing school building and an adjacent slab tower. As seen in the images bellow, the scale of the lane changes to provide vehicular traffic access to the site, but quickly changes to a more intimate scale in front of the new structure. A small planter acts as a transition between the pedestrian walkway and the more public courtyard (shown in bottom right image). In the summer season, the foliage in this planter adds another layer of privacy and creates a front yard condition that can be found in typical lowrise residential areas.

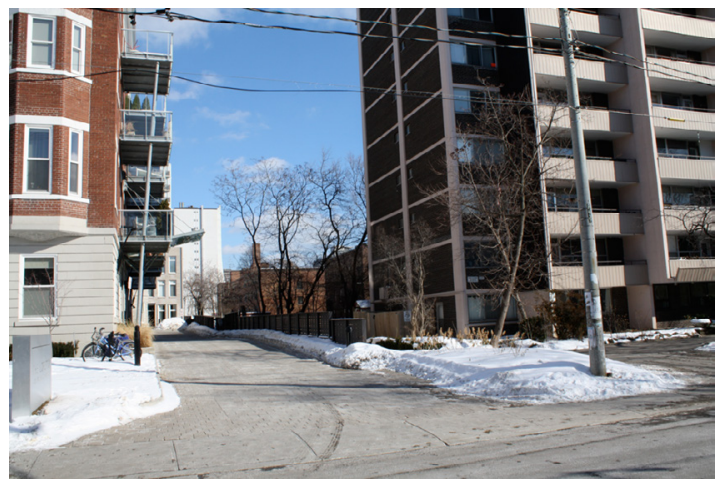

Side Lane Adjacent to existing Slab Tower Building (Sauder, 2011).

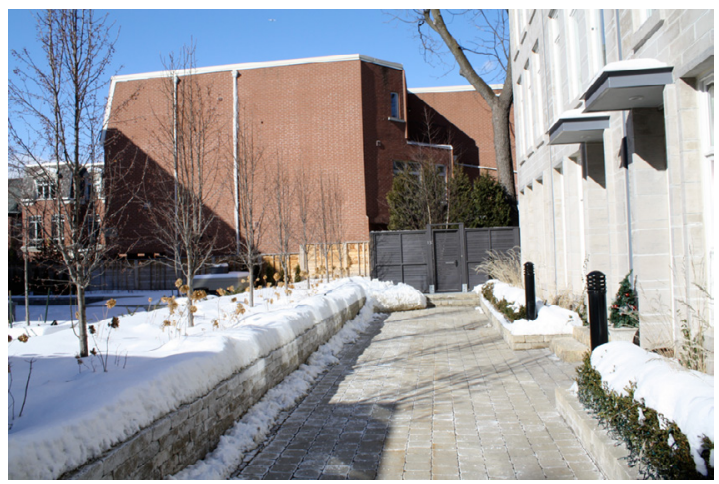

Pedestrian Access to Town Homes Adjacent to Courtyard (Sauder, 2011). 

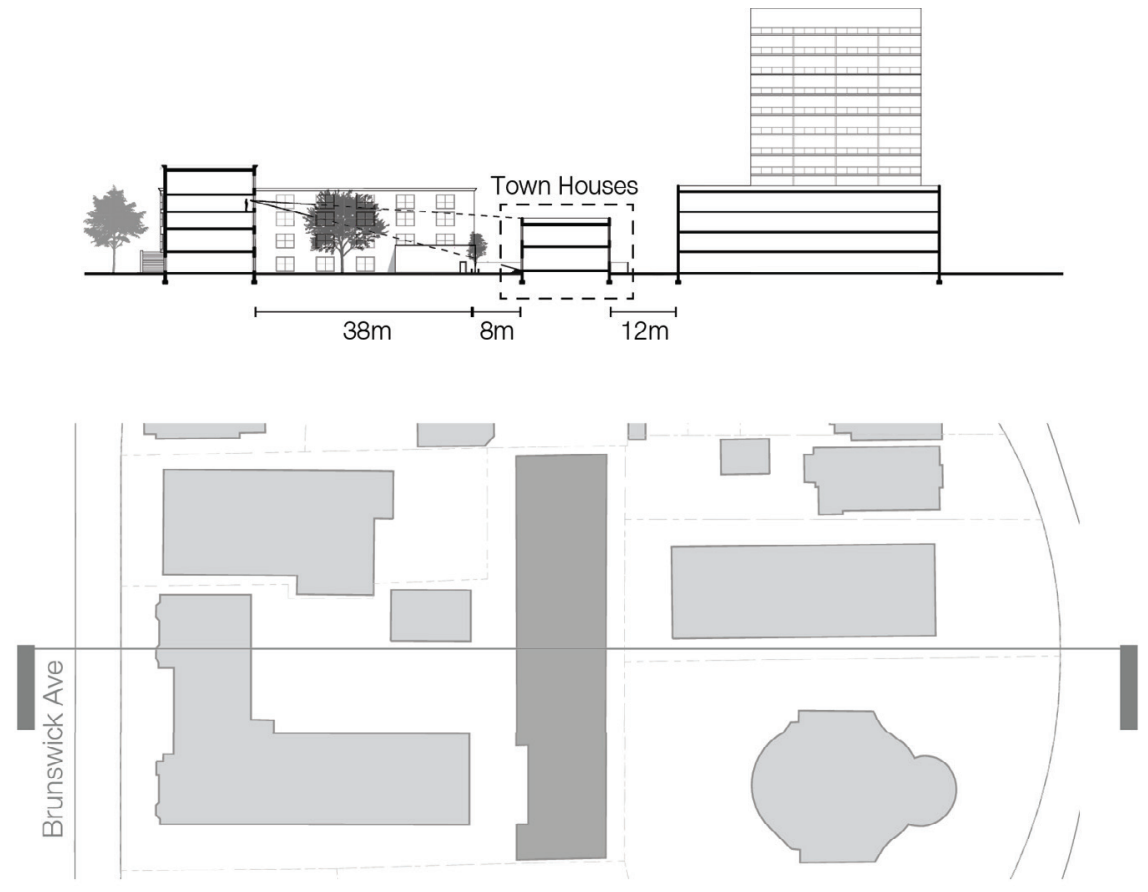

Site section (Sauder, 2014).

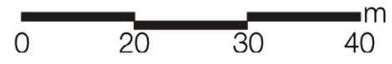

A second pedestrian pathway branches off from the lane way leading to the town houses which provides circulation for the semi public courtyard. Landscaping and bollards create a physical barrier between the actual pathway and outdoor space to maintain a clear circulation route through the site (as shown on right). Using landscaping as a strategy for designating spaces is a common occurrence in the design of this site. As seen in the site section above, it also generates privacy between the adjacent buildings by blocking direct lines of site.

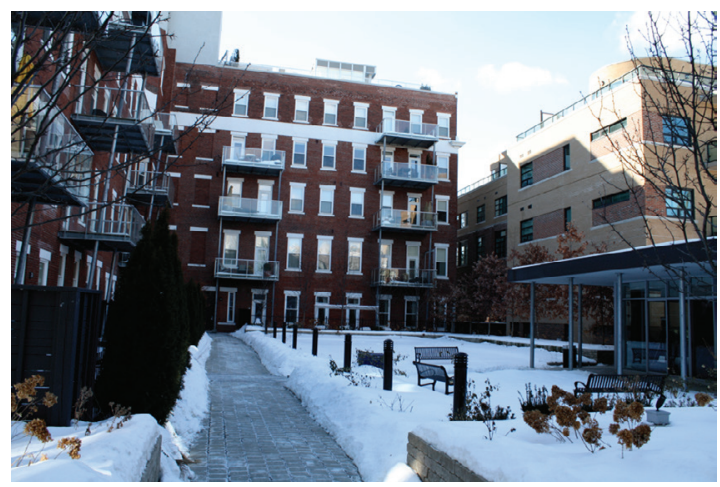

Pathway Access to Semi Public Courtyard (Sauder, 2011).

Mclean, C. (2012). The Loretto Lofts. Clive Mclean Sales Representative. Retrieved from: http://clivemcleanliving. com/neighbourhood/The-Annex/view/building/The-Loretto-Lofts/id/24/

Kulig, P. (2010). High-end Condo Goes Back to School. The Star. Retrieved from: http://www.thestar.com/life/ homes/2010/03/20/highend_condo_goes_back_to_school.html 


\section{I.II BORNEO-SPORENBURN}

West 8

Amsterdam Docks, Netherlands

1994-1996

The Borneo-Sporenburn project is a new take on density and the revitalization of a former industrial area. Privacy and individuality become important driving factors behind the design as rows on town homes line the docks, achieving a density of 100 units per acre (West 8, 1996). Each of the town homes follows one of the preset plans, but has its own unique facade to set it apart from its surrounding neighbours. Large roadways and a generous park space work with the town homes to activate the ground plane, which is typically not achieved with high density projects. Additionally, one mid-rise complex on each of the two docks further increases the density of the site, but removes these residents from the ground plane.

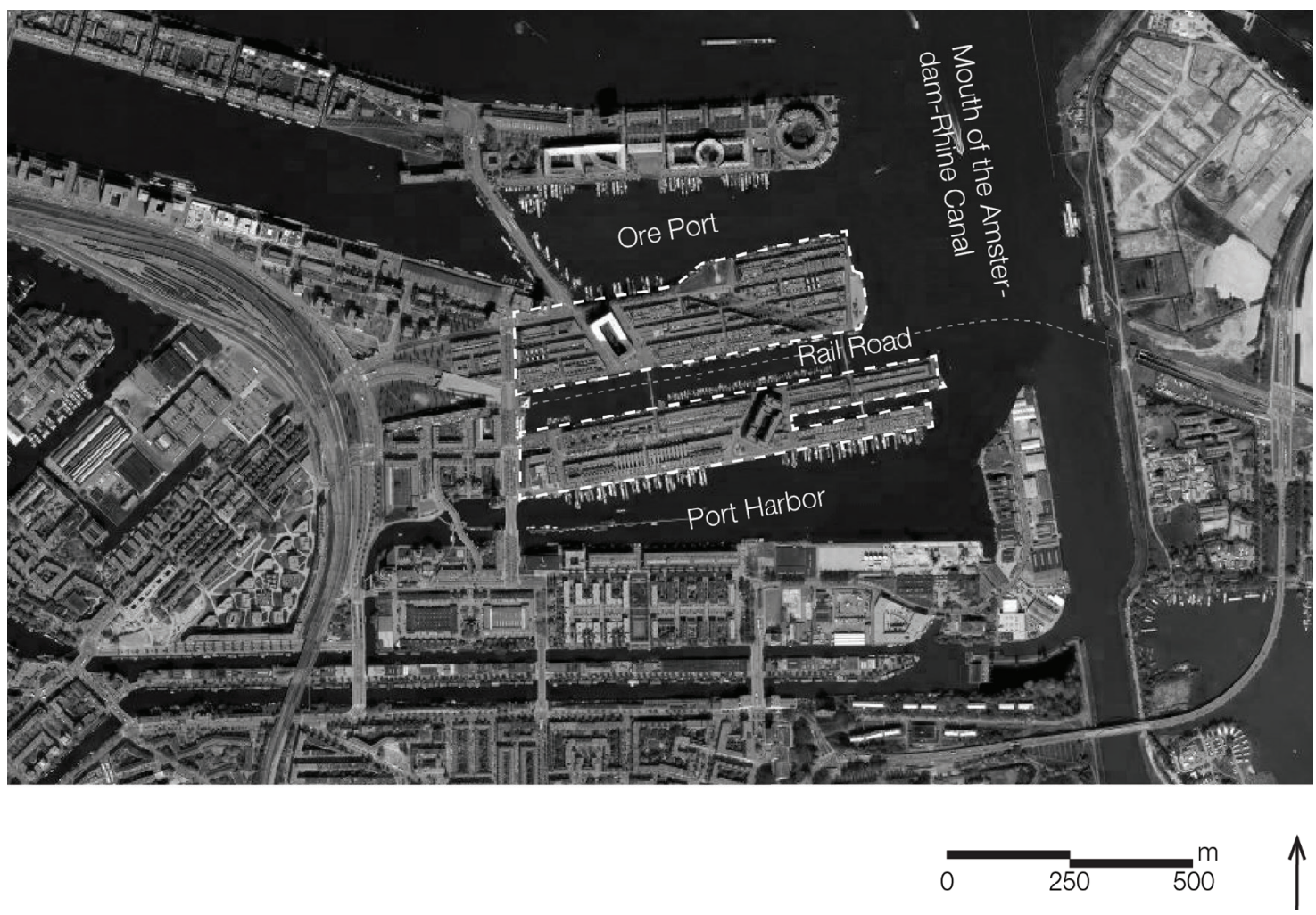

Project Location (Image Retrieved from Bing Maps, Draw by Sauder, 2014). 


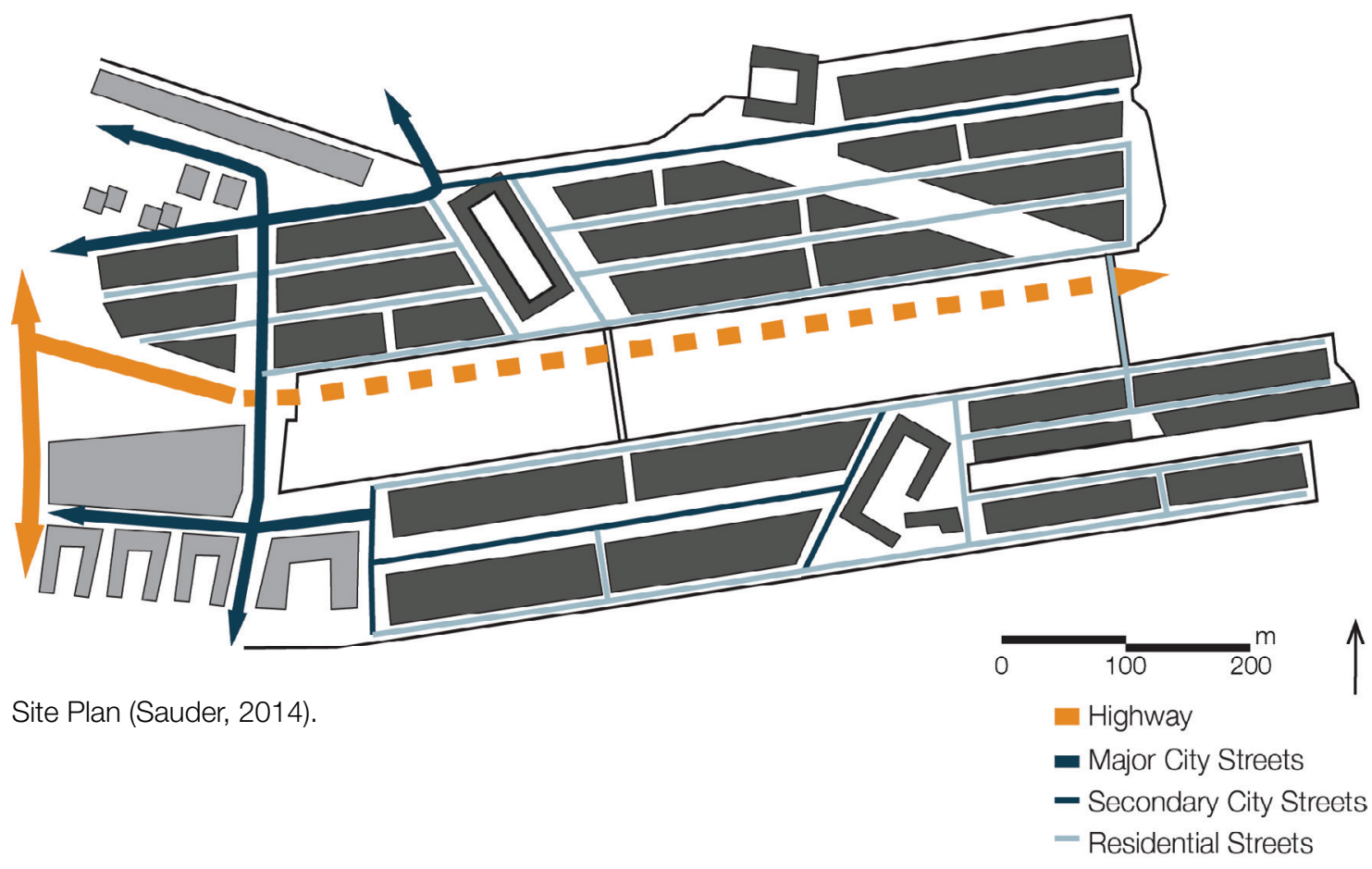

Sitting on otherwise wasted space in the city, the new urban plan for these two industrial docks activates a particular area of the city by introducing many different scaled streets. The new circulation system ties into the existing city streets to make site access points. Also, the variation in street scale distinguish dominate pathways to the public amenities within the pier and slows down traffic for the smaller residential roads. In the case of this project, both of the main streets only run through half of the pier length to the residential complex with courtyard in the center. This draws external traffic into the site to make use of the amenities, and articulates a clear and direct path, while ensuring the rest of the area is kept quiet and focused on the inhabitants. 


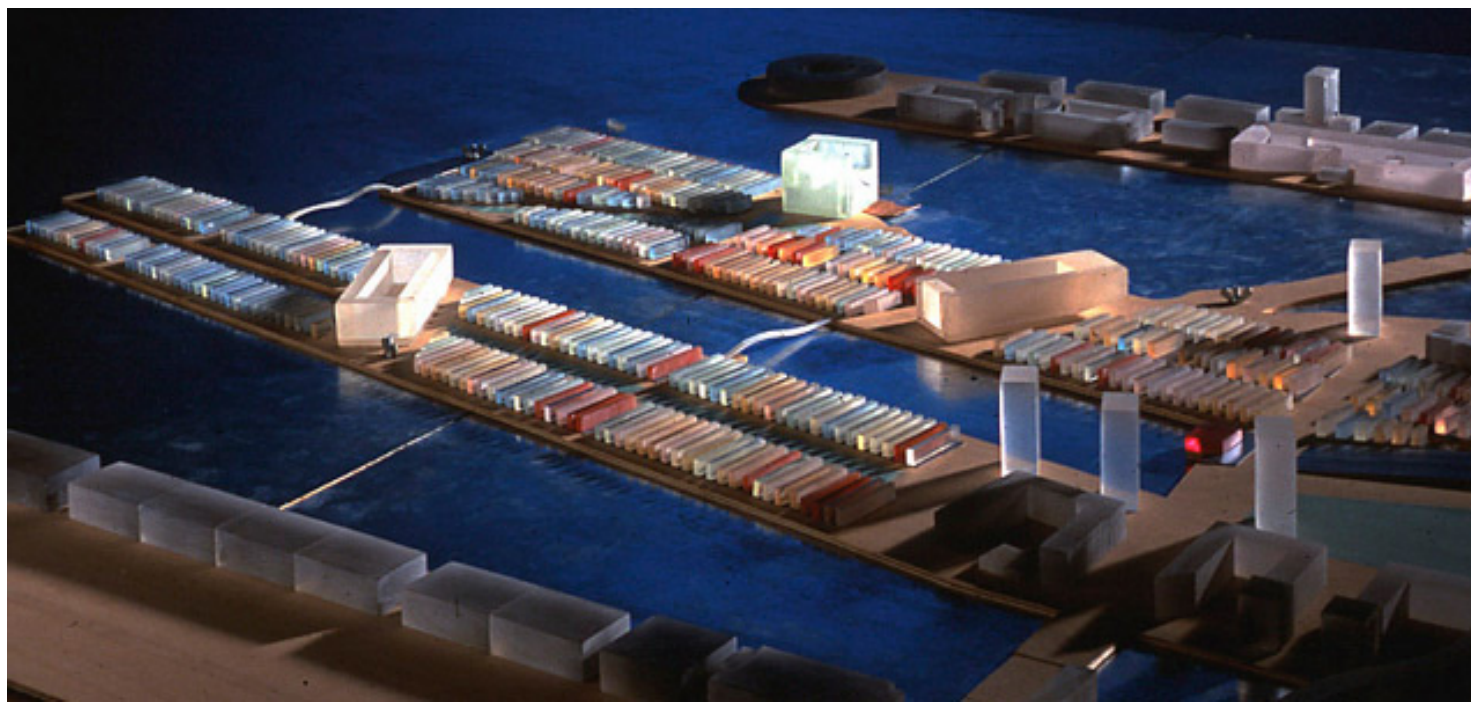

Site Massing Strategies (Image Retrieved from West 8, 1996)

The massing of Borneo-Sporenburn also plays an important role in the use of the site. A majority of the site is filled with four story buildings which line many of the smaller streets. Contrasting the low-rise buildings, are three mid-rise towers which also act as 
I.III DE CITADEL, ALMERE NEW CITY CENTRE

Architect: Christian de Portzamparc, Planner: OMA

Almere, Netherlands

2000-2006

The town of Almere was founded in 1977 as a method of accommodating the overflow density from Amsterdam (Manicipality of Almere, 2015). The original plan for the city lacked a designated down town area until OMA's master plan was formulated. Part of the new design included the protect 'De Citadel, which is a large multi use development including buried bus routes, pedestrian pathways, shopping centers, and elevated town homes. The new city center works to occupy the site by focusing on making the land usable for pedestrians while generating a sense of identity for the urban center.

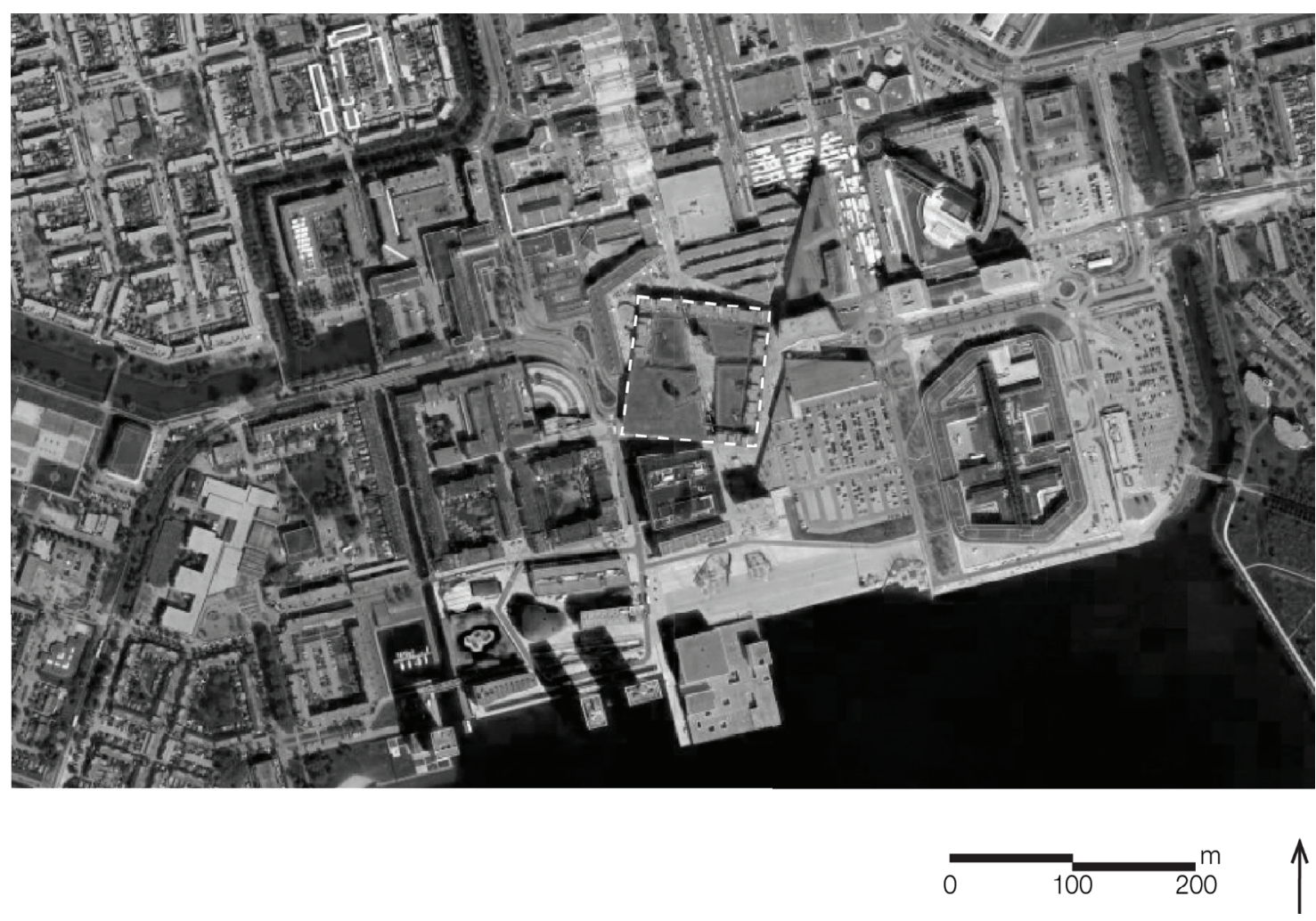

Project Location (Image Retrieved from Bing Maps, Draw by Sauder, 2015). 


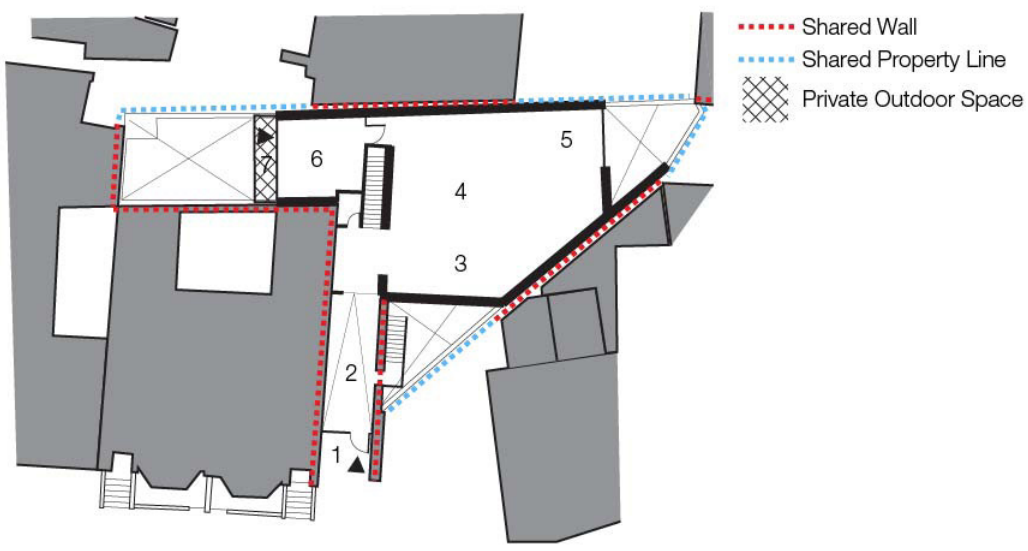

Entrance level plan and abutting walls (Sauder, 2014).

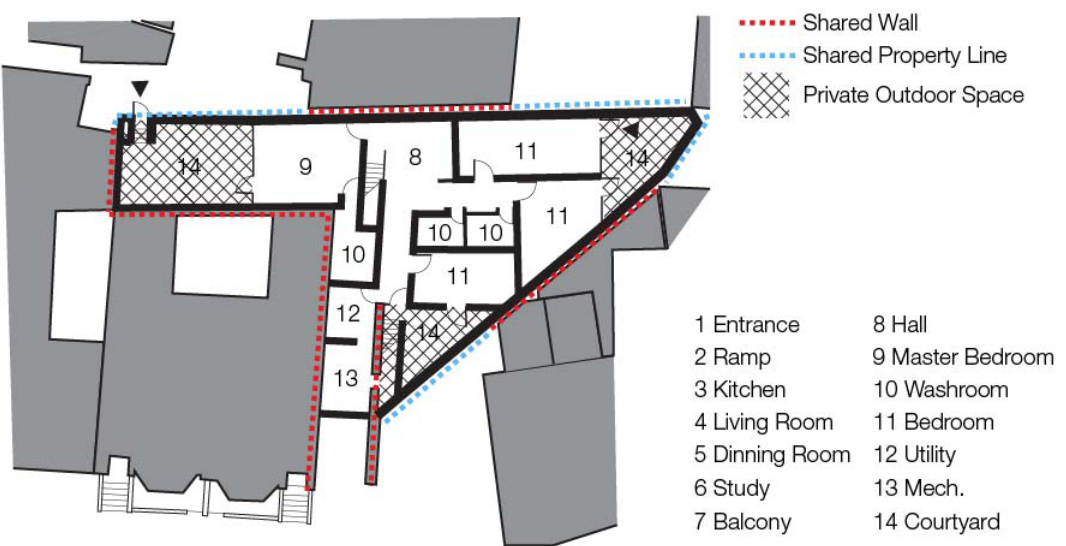

Ground level plan and abutting walls (Sauder, 2014). 


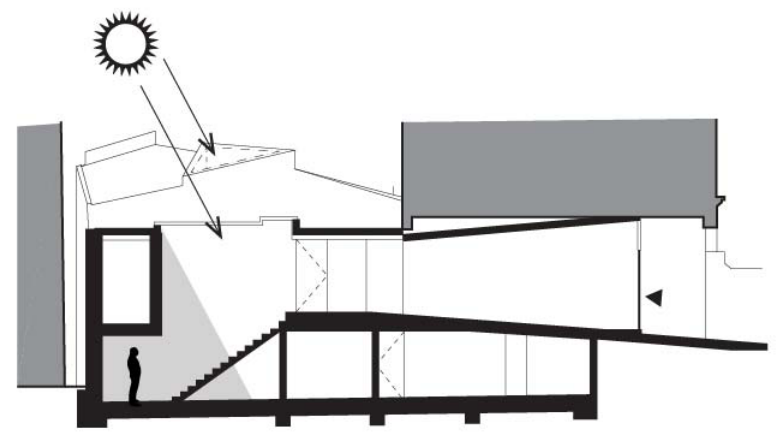

Building section - light entering through ceiling openings (Sauder, 2014).

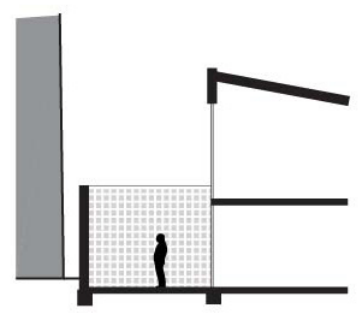

Terrace section - privacy with adjacent building (Sauder, 2014). 
BIBLIOGRAPHY 


\section{BIBLIOGRAPHY}

Acs, Z (ed.). (2006). The Growth of Cities. Cheltenham: Edward Elgar Publishing Limited.

Allen, S. (2002). Mat Urbanism: The Thick 2-D. In: Sakris, Hashim Case: Le Corbusier's Venice Hospital and the Mat building revival. Prestel. Retrieved from: http://modulatingspace.files. wordpress.com/2010/08/the-thick-2d.pdf

Amsterdamming. (2011). Eastern Docklands of Amsterdam. Amsterdamming.

Retrieved from: http://amsterdamming.com/2011/03/18/eastern-docklands-of-amsterdam/

Apostolides, K. (2013). The problem with development in Toronto. Spacing Toronto.

Retrieved from: http://spacing.ca/toronto/2013/11/26/problem-development-toronto/

a+t Research Group. (2013). 10 Stories of Collective Housing: Graphical analysis of inspiring masterpieces. Spain: a+t publishers.

Bascaramurty, D. (October 12, 2012). Density, infrastructure and the high cost of building a vertical Toronto. The Globe and Mail. Retrieved from: http://www.theglobeandmail.com/news/ toronto/density-infrastructure-and-the-high-cost-of-building-a-vertical-toronto/ article4610721/

Bennett, S. (2011). Condominium Homeownership in the United States: A Selected Annotated Bibliography of Legal Sources. Law Library Journal Vol. 103:2.

Berghauser Pont, M, \& Haupt, P. (2010). Spacematrix: Space, Density and Urban Form. Rotterdam: NAi Publishers.

Boddy, T. (2008, Feb 08). The density debate needs to be reinvigorated. The Globe and Mail (Index- Only) Retrieved from: http://ezproxy.lib.ryerson.ca/login?url=http://search.proquest. com/docview/347769211?accountid=13631

Brook Mcllroy Planning + Urban Design/Pace Architects. (2010). Avenues \& Mid-Rise Buildings Study. Toronto: City of Toronto. Retrieved from: http://www1.toronto.ca/City\%200f\%20T oronto/City\%20Planning/Urban\%20Design/Mid-rise/midrise-FinalReport.pdf

Calthoroe, P. \& Lerup, L. (2004). New Urbanism. Michigan: University of Michigan. 
Chakrabarti, V. (2013). Building Hyperdensity and Civic Delight. The Design Observer.

Retrieved from: http://places.designobserver.com/feature/a-country-of-cities-buildinghyperdensity/37899/

Chakrabarti, V. (2013). A Country of Cities: A Manifesto for an Urban America. New York: Metropolis Books.

City of Toronto. (2011). Tower Renewal: Implementation Book. Toronto: City of Toronto.

Retrieved from:http://www1.toronto.ca/city_of_toronto/social_development_finance__ administration/files/pdf/tr_implementation_book.pdf

City of Toronto. (2012). City of Toronto Property Data Maps.

Retrieved from: https://library.cf.ryerson.ca/madar/geospatial/libdata/action2b. cfm?ResourcelD $=56220$

City of Toronto. (2012). 2011 Census: Marital Status, Families, Households and Dwelling Characteristics. Retrieved from: https://www1.toronto.ca/city_of_toronto/social_ development_finance_administration/files/pdf/censusbackgrounder_hhds_2011.pdf

City of Toronto. (2013). City of Toronto Zoning By-Law 569-2013.

Retrieved from: http://Map.toronto.ca/Maps/Map.jsp?app=ZBL_CONSULT

City of Toronto. (2013). Height Overlay Maps. Retrieved from:

www.toronto.ca_legdocs_bylaws_2013_law0569-schedule-a-ht-Maps-g.pdf

City of Toronto. (2013). Next 10 Years of Tower Renewal: Achieving city-wide improvement. Toronto: City of Toronto.

City of Toronto. (March, 2013). Tall Building Design Guidelines. City of Toronto. Retrieved from: http://www.toronto.ca/legdocs/mmis/2013/pg/bgrd/backgroundfile-57177.pdf

City of Toronto. (2014). City of Toronto Zoning By-Law 569-2013, as amended (Office Consolidation). Retrieved from: http://www1.toronto.ca/wps/portal/ contentonly?vgnextoid=2a8a036318061410VgnVCM10000071 d60f89RCRD 
City of Toronto Archives. (2014). \{Toronto Aerial Photo 1947]. Aerial Photographs.

Retrieved from: http://www1.toronto.ca/wps/portal/

contentonly?vgnextoid=9f53226b48c21410VgnVCM10000071d60f89RCRD

City Planning. (2010). Toronto Official Plan. City of Toronto. Retrieved from:

http://www1.toronto.ca/static_files/CityPlanning/PDF/chapters1_5_dec2010.pdf

City Planning. (2013). Strategic Plan 2013-2018. City of Toronto. Retrieved from:

http://www1.toronto.ca/City\%200f\%20Toronto/City\%20Planning/Home/Files/pdf/S/ strategicplan.pdf

Costa Duran, S. (2009). High Density Housing Architecture. Spain: Loft Publications.

Dotan, H. (2009). Futurist: Toronto in 2030 and Beyond. Torontoist. Retrieved from: http://torontoist.com/2009/03/futurist_toronto_in_2030_and_beyond/

Drover, G. (1974). Urban Density: My Space and Your Space. Halifax: Dalhousie.

Duran, S. (2009). High Density Housing Architecture. Spain: Loft Publications.

Garrett, J. T. (2013). Density by Design. Toronto: NRU Publishing Inc.

Retrieved from: http://ezproxy.lib.ryerson.ca/login?url=http://search.proquest.com/ docview/1291074605?accountid=13631

Gandelsonas, M. (1999). X-Urbanism: architecture and the american city.

New York: Princeton Architectural Press.

Gee, M. (December 22, 2013). Toronto's density plan is work, so keep it going. The Globe and Mail. Retrieved from: http://www.theglobeandmail.com/news/toronto/torontos-density-plan-isworking-so-keep-it-going/article16087623/

Gehl, J. (2011). Life Between Buildings: Using Public Space. Island Press.

Hodge, G \& Gordon, D. (2008). Plannign Canadian Communities. Vancouver: Nelson Thomson.

Kirkman, R. (2010). The Ethics of Metropolitan Growth: The Future of Our Built Environment. London: Continuum International Publishing Group. 
Klein, L. M. (2012). It's the architecture that matters. Journal of Commerce, (66), 1-2. Retrieved from http://ezproxy.lib.ryerson.ca/login?url=http://search.proquest.com/ docview/1036583452?accountid=13631

Krier, L. "Critiques and Urban Components." The Urban Design Reader. Ed. Larice, M \& Macdonald, E. New York: Routledge, 2007. (page 231-250)

Leupen, B. \& Mooij, H. (2011). Housing Design: A Manual. Rotterdam: NAi Puclishers.

Melanson. (2013). Toronto falling from grace? Yeah, right. Canada's No. 1 city is soaring. Canadian Business. Retrieved from: http://www.canadianbusiness.com/economy/torontofalling-from-grace-yeah-right-canadas-no-1-city-is-soaring/

Metrolinx. (2014). Stops \& Stations. Toronto: Eglinton: The Cross Town. Retrieved From: http://www.thecrosstown.ca/the-project/stations-and-stops

Michael McGrath, J. (2013). Jen Keesmaat's Big Idea: Led developers build what we want them to build, and help them do it faster. Torontoist. Retrieved from: http://torontoist.com/2013/01/jen-keesmaats-big-idea/

Moore, Aaron A. (2013). Trading Density for Benefits: Toronto and Vancouver Compared. Munk School for Global Affairs: University of Toronto.

National Multi Housing Council. (2008). Getting Density Right: Tools for Creating Vibrant Compact Development. Washington: Urban Land Institute.

Nino Gheciu, A. (December 26, 2012). Can living in laneways fix Toronto's density issues? Retrieved from: http://www.thestar.com/news/gta/2012/12/26/can_living_in_laneways_fix_ torontos_density_issues.html

North, A. (2013). Operative Landscapes: Building Communities Through Public Space. Germany: The German National Library.

Osorio, C. (2014). How do we cross Toronto's great divides? Toronto: The Star. Retrieved from: http://www.thestar.com/news/gta/2014/11/30/how_do_we_cross_ torontos_great_divides.html 
Oswalt, P. (2006). Atlas of Shrinking Cities. Germany: Hatje Cantz.

O'Toole, M. (2013, 01, 22). Downtown Toronto's pace of population growth triples, outpacing suburbs's as Echo Boomers Flock towards urban centre: report. National Post. Retrieved from: http://news.nationalpost.com/2013/01/22/downtown-torontos-pace-ofpopulation-growth-triples-outpacing-suburbs-as-echo-boomers-flock-towards-urbancentre-report/

Poplak, R. (2012, 12, 12). Breaking Point. The Grid. Retrieved from: http://www.thegridto.com/life/real estate/breaking-point/

Portzamparc, Christian de. (1996). Portzamparc. France: arc en reve centre d'architeture.

Press. (2012). Census: Edmonton, Calgary fastest-growing cities. Retrieved from: http://www.canada.com/technology/ Census+Edmonton+Calgary+fastest+growing+cities/6119830/story.html\#_federated=1

Reynolds, J. (2002). Courtyards: Aesthetic, Social, and Thermal Delight. New York: John Wiley \& Sons, Inc.

Rogers, R. (1998). Cities for a small planet. Colorado: Westview Press.

Rowe, P. \& Kan. H. (2014). Urban Intensities: Contemporary Housing Types and Territories. Switzerland: Birkhauser Verlag.

Scallan. N. (2012, 10, 19). Density Toronto: As GTA population rises, so do expectations for denser living. The Star. Retrieved from: http://www.thestar.com/news/gta/2012/10/19/density_toronto_as_gta_population_rises_ so_do_expectations_for_denser_living.html

Schittich, C. (ed.) (2004). In Detail High-Density Housing: Concepts, Planning, Construction. Berlin: Architektur-Dokumentation $\mathrm{GmbH} \& \mathrm{Co}$.

Statistics Canada. (2014, 04, 17). Focus on Goeography Series, 2011 Census: Cencus metropolitan area of Toronto Ontario. Statistics Canada. Retrieved from:

http://www12.statcan.gc.ca/census-recensement/2011/as-sa/fogs-spg/Facts-cma-eng. cfm?LANG=Eng\&GK=CMA\&GC=535 
Statistics Canada. (2012). The Canadian Population in 2011: Population Counts and Growth. Retrieved from:http://www12.statcan.gc.ca/census-recensement/2011/as-sa/98-310-x/98310-x2011001-eng.pdf

Stewart, G., Thrope, J., \& Mcclelland, M. (2013). The slabs vs. the points: Toronto's two tower booms. Satellite. Retrieved from: http://www.satellitemagazine.ca/2013/09/the-slabs-vsthe-points-torontos-two-tower-booms/

The Canadian Magazine of Immigration. (2015). Canada: Permanent Immigration 1989-2013. Canada Immigrants. Retrieved from:http://www.canadaimmigrants.com/immigration/ statistics/canada-permanent-immigration-1989-2013/

The Toronto Blog. (2011). Proposal to add 43-floor apt tower + townhouses to Sherbourne Str. complex goes to TEYCC Tuesday. Retrieved from: http://thetorontoblog.com/2011/10/03/ proposal-to-add-43-floor-apt-tower-townhouses-to-sherbourne-str-complex-goes-to-teycctuesday/

Troper, H. (2000). History of Immigration to Toronto Since the Second World War:

From Toronto "the Good" to Toronto "the World City." Ontario Institute for Studies in Education. Retrieved from:http://ceris.metropolis.net/Virtual\%20Library/Demographics/ troper1/troper1.html

Toronto Centre for Active Transportation. (2012). Complete Streets by Design: Toronto Streets Redesigned for All Ages and Abilities. Retrieved from: http://www.tcat.ca/wpcontent/uploads/2014/10/Complete-Streets-by-Design-Toronto-Streets-Redesigned-for-AllAges-and-Abilities-Side-by-side-spread.pdf

Tschumi, B. (2014). Architecture: Concept \& Notion. Paris: Centre Pompidou.

United Nations. (2014). World Urbanization Prospects [Highlights]: The 2014 Revision. New York: United Nations.

Urban, Florian. (2013). Tower and Slab: Histories of Global Mass Housing. Hobooken: Taylor and Francis. 
Virilio, P. (1991). The Lost Dimension. Paris: Semiotext(e).

Woodman, E. (2010). Central St Giles by Renzo Piano. BDonline.co.uk.

Retrieved from: http://www.bdonline.co.uk/central-st-giles-by-renzo-piano/5000286.article

Your City. (2014). How Does the City Grow. City of Toronto.

Retrieved from: http://www1.toronto.ca/

(2013). Densityarchitecture: A Study on High Density Residential Architectures.

Wordpress. Retrieved from: http://densityarchitecture.wordpress.com/ 
GLOSSARY 


\section{GLOSSARY}

Activate: A design strategy used to bring liveliness to a specific area. Usually selecting a courtyard, or other defined space, the strategy imposes a function or spacial quality to distinguish the area from its surrounding context.

Centres: Areas designated in Toronto's Official Plan (2010) with "excellent transit accessibility where jobs, housing and services will be concentrated in dynamic mixed use settings with different levels of activity and intensity" (City of Toronto, 2010).

Crowding: A sensation associated with large amounts of people concentrated in one area. OLGGA Architects (2013) conducted a study of high density areas finding that an awareness of crowding came from personal experience and comfort levels as well as a lack of controlled privacy.

EchoBoomer: A term created by O'Toole (2013) refers to the children of who are migrating back to urban centers to be closer to transit, work, and amenities.

Experiential Density: Also referred to as perceived density by Haupt \& Pont (2010), this is an incalculable value based on a personal interpretation and reaction to a dense environment. For example, a person living in a small town may observe Toronto's size to be very dense, but another person from Hong Kong would find Toronto to be quite spacious.

Fragment: Used as a strategy for decreasing the scale of a large or overbearing space. Physically creating a separation, such as cutting a property in half with a street, or changing a rhythm are all form the strategy can take.

Infill: The process of creating additional physical density by constructing a development within a gap or hole. Chakrabarti (2013) discusses this a surgical proceeding, taking great care to avoid disturbances to the surrounding context.

Land User Intensity: A calculable value based on the relationship between the area of a building footprint and the total area of land.

Mediate: A design strategy to ease the movement from one space to another. Usually applicable between public and private areas, where an intervention forces a gradual transition between the different conditions. 
Physical Density: The calculable volume of space occupied by a built form over a specific area of land.

Population Density: The number of people, households, or units occupying a defined area of land.

Quality: A measurement of the success or failure of a space based on distinguishing characteristics.

Quantity: is a numerical measurement evaluating the success of a development based on calculable densities. 